\title{
Essays on the dynamics and heterogeneity of capital structure, risk and profit, with special reference to farm businesses
}

Citation for published version (APA):

Tamirat, A. S. (2018). Essays on the dynamics and heterogeneity of capital structure, risk and profit, with special reference to farm businesses. [Doctoral Thesis, Maastricht University]. Drukkerij Haveka. https://doi.org/10.26481/dis.20181130at

Document status and date:

Published: 01/01/2018

DOI:

10.26481/dis.20181130at

Document Version:

Publisher's PDF, also known as Version of record

Please check the document version of this publication:

- A submitted manuscript is the version of the article upon submission and before peer-review. There can be important differences between the submitted version and the official published version of record.

People interested in the research are advised to contact the author for the final version of the publication, or visit the DOI to the publisher's website.

- The final author version and the galley proof are versions of the publication after peer review.

- The final published version features the final layout of the paper including the volume, issue and page numbers.

Link to publication

\footnotetext{
General rights rights.

- You may freely distribute the URL identifying the publication in the public portal. please follow below link for the End User Agreement:

www.umlib.nl/taverne-license

Take down policy

If you believe that this document breaches copyright please contact us at:

repository@maastrichtuniversity.nl

providing details and we will investigate your claim.
}

Copyright and moral rights for the publications made accessible in the public portal are retained by the authors and/or other copyright owners and it is a condition of accessing publications that users recognise and abide by the legal requirements associated with these

- Users may download and print one copy of any publication from the public portal for the purpose of private study or research.

- You may not further distribute the material or use it for any profit-making activity or commercial gain

If the publication is distributed under the terms of Article $25 \mathrm{fa}$ of the Dutch Copyright Act, indicated by the "Taverne" license above, 


\title{
Essays on the Dynamics and Heterogeneity of Capital Structure, Risk and Profit, With Special Reference to Farm Businesses
}

\author{
Aderajew Shumet Tamirat \\ School of Business and Economics, Maastricht University
}

A thesis submitted for the degree of

Doctor of Philosophy at Maastricht University

November 30, 2018 
(C) 2018 Aderajew Shumet Tamirat

All rights reserved. No part of this publication may be reproduced, stored in a retrieval system, or transmitted, in any form, or by any means, electronic, mechanical, photocopying, recording or otherwise, without the prior permission in writing from the author.

\section{ISBN 9789082967500}

Cover design and print by Drukkerij Haveka. 


\section{Essays on the Dynamics and Heterogeneity of Capital Structure, Risk and Profit, With Special Reference to Farm Businesses}

\section{DISSERTATION}

to obtain the degree of Doctor at Maastricht University,

on the authority of Prof. dr. Rianne M. Letschert, Rector Magnificus, in accordance with the decision of the Board of Deans, to be defended in public

On Friday, November $30^{\text {th }}, 2018$, at 16:15 hours

By

Aderajew Shumet Tamirat 


\section{Supervisor}

Prof. dr. ir. Joost M.E. Pennings

\section{Co-supervisor}

Dr. Andres-Trujillo Barrera [University of Idaho]

\section{Members of the Degree Committee}

Prof. dr. Jaap Bos [Chairman]

Prof. Peter Goldsmith [University of Illinois at Urbana-Champaign]

Prof. dr. Constantine Iliopoulos [University of Athens, Greece]

Dr. Thomas Post 
I dedicate this dissertation to:

My father, for earning an honest living for us, and taught and inspired me to dream big and stay humble.

My wife, who almost gave her life to give me one, and had to learn how to walk again. Who also, I believe, should be a synonym for the word courage.

My son, whose smile lightens my day and warms my heart. 
'Can an Ethiopian change his skin, or a leopard its spots? Neither can you do good who are accustomed to doing evil' Jeremiah 13:23 


\section{Acknowledgments}

I believe luck is a plot where opportunity meets preparation. In that sense, I'm the luckiest person on earth. If this is to be called a success in any form, and I look taller than yesterday, it is only because I stand on the shoulder of so many great friends, families, and colleagues. I'm so happy that I got to write this part for I have so many people to thank who have helped me all the way through and wouldn't be here, otherwise.

First and foremost, praises and thanks to the mother of Jesus Christ, Virgin Mary, for giving me the strength and the showers of blessings throughout my life.

My exceptional tribute goes to my Ph.D. supervisors, Professor Joost M.E. Pennings and Andres-Trujillo Barrera. Joost has been supportive and given me the freedom to pursue various projects. He is as passionate and enthusiastic about research and publication as I met him for the first time at Wageningen University in 2011. I hope that I could be as lively, energetic and passionate as you, and to someday be able to command an audience as well as you can. The progress report I must submit every Friday kept me in track [there were times I want to cry so much when I write those reports]. Your 'hello Addy my friend' whenever you pass by my office serves both as a greeting and a reminder of something I have to finish and email it to you; your discontentment with me for not being able to shoot [aim] high and desire to settle for less, reminds me of my father and always motivates me; and your 'does this ring a bell to you, Addy?' reminds me how much more I have to read. I am grateful for the opportunity you gave me. Andres has been a true support, very easy to talk to and gives much attention to the details. Every time I forget to address the comments he made, he has always a very diplomatic way of reminding me not to forget it again [this could happen a dozen times in one project]. I am grateful for your support, sharing your invaluable experiences, coaching me how to be independent, and above all for treating me as a colleague. I would like also to thank Professor Arvid Hoffmann whose encouragement and out of the box thoughts helped me to ease all the doubts I have had in my first year as a Ph.D. student. I am indeed honored to work with you all. Besides my supervisors, I am very grateful to Mr. Ruud van der Meer at Wageningen Economic Research-WUR for providing the data.

My sincere thanks also goes to the members of my $\mathrm{PhD}$ committee, Professor Jaap Bos, Professor Peter Goldsmith, Professor Constantine Iliopoulos, and Dr. Thomas Post for taking the time to evaluate my dissertation and helpful comments in general. Your inputs are greatly appreciated. 
I feel very privileged to be part of the Finance department, and I will forever be thankful to my officemates and colleagues for making my time at Maastricht enjoyable. Mike [Michael Kurz] and Runliang Li [Jack]; you guys are the best officemates anybody could ever wish for. Mike will have the answer to most of my research questions, and when he suggests books, often he will tell the page numbers where I would find the answer. Who does that you freak with an eidetic memory! You were also so helpful during my preparation for the McKinsey \& Company interviews. Jack, I feel very lucky to meet you, my Chinese friend. Very smart, kind, humble, and had the nerve to sense my stupid remarks and jokes [often, they are funny, I swear]. I like to thank you both sincerely for sharing B1.06 with me for three wonderful years, and for the great conversations we have had about research and life, lunches and dinners, PingPong matches, and walks.

I would also like to thank the Ph.D. students at Maastricht University. If someone from Human Resources department heard when we, the usual suspects [Martijn, Matteo, Inka, Tobias, Joyce, Matthijs, Mike Langen, Lidwien, Juan], talk about racism, sexism and all the 'isms, we would have been all fired by now. Well, I will for sure get fired for the obvious reason $)$. I am glad I met Martijn and Matteo (the M\&M's) in my final year. Boy, they are troublemakers and true friends in crime [Yea Yea I see I see $(-)$ ]. I must confess though that I enjoyed every second of your accompany. Juan, I don't think I have someone in my mind but you who keeps asking me about my baby and wife in one of the darkest moments of my life. I am sure you don't notice that but every time you ask those questions, I open my mouse to say they are ok while my heart smiles thinking that there are such good friends to check up on me. muchas gracias, mi amigo! That being said, according to the Dutch/Limburg law, touching and combing someone's hair [because it is different] with your giant Spanish fingers every day qualifies as sexual harassment, but for what it's worth, I will let it slide $\odot$. I am also grateful for sharing the doctoral journey with Irene, Wiebke, Ming Li, Marina Gertsberg, Nagihan Mimiroglu, Mark, Luuk Perik [Why do I always think Luuk means Ping-Pong in Dutch?], Marten, and Colin. I also thank Sanne Jongen, Sjoke Merk, Pomme Theunissen, Carl Vandenboorn, Janek, and many more for nice chats and many laughs in the hallway.

The senior staffs at our department also deserve a special tribute. I know no one but Jaap who can be friendly and charming, and a boss all in once without losing his charisma. Thank you for having my back whenever I feel I don't have one. I couldn't thank enough Piet and Rob for allowing me to benefit from their rich network in my job search. In one bright Monday morning, I told Piet that I want to go back home and work in Africa [Mike Langen, 
for the last time, Africa is not a country], he almost got me a job in Kenya that afternoon! A friend of a friend for Rob and Piet nearly got me in touch with a respective UN diplomat from my country, Ambassador Sahle-Work Zewde, little did we know that she would become the President of Ethiopia in a couple of months. This is a testimony of how profound and strong your networks are. I also would like to thank Paulo and Peter for answering my econometrics questions [the usual disclaimer applies here that if something goes wrong with my estimation, it is my fault only]. I like to thank Thomas and Stefan for the lovely conversations we had over lunch at Mensa. Stefan, your understanding of world history, medieval Europe and the geopolitics of Africa and Ethiopia always amuses me. Glad that I have shared those moments with you. I am also indebted for the how are you? how is your paper going? and the smiles on the hallway from other colleagues in our department such as Paul Smeets, Jerone, Denis, Perian, Rachel, Stefani, and Nils. I also like to thank my students for being nice to me all the time, and your great evaluations [I still think that I should win a trophy for that:-)].

It's time to acknowledge the special ladies in our special office, the secretariats. If it was not for your hellos every time I knock your door [that will happen probably 20 times a day mostly for those coffee coins], a basket of fruits, your perfect sense of organization, and of all your will to help, the Ph.D. journey would not be as such easy. Thank you Francien Schijlen, Carina Wijnands, Els van Aernsbergen, and Cecile Luijten.

A good support system is imperative to surviving and staying sane in this long journey. I was lucky to be a part of the Habesha [Ethiopian and Eritrean] community in the Netherlands. I am indebted to all my friends who opened their homes to me during my time at Maastricht. Those years in Holland will be difficult without the laughter we shared, the weddings we crashed, the drinks we had, and the visits we made. Thank you Wonde, Shimelis, Haylom, Halefom, Jemal, Kaleab, Hassen, Hiwot, Mulu, Zelalem, Tsegaye, Tomas, Bereket, Genet, Eskinder, Daniel, Yonas, and many more. A heartfelt tribute also goes to my friends and families living in Seattle who has been always there for my family in one of the most difficult times. I won't forget the days we spend in hospital beds, at times with your kids, accompanying my wife and the tears we shed when things seem not going so well. I owe you big one Assefa Abay, Kidist Mengesha, Delina, Ruthaye, Raye, Makiki, Agazi, Elias, Lwam, and Eden. I would like also to thank my friends and families back home for being there for my family in my absence, and most importantly for planning my wedding and made it awesome. You guys fill the void and I never have to worry for a single day. Thank you Yoseph Bizuneh, Abrhame Endrias, Gemechu Waktola, Shambachew, Manaye, Alemayehu, Kalid, Jony Girma, Henok 
Balemual, Getasew Fentaye, Elfnesh G/Amlak, Mikyas Tsegaye, Fisheha Taimyalew, Abeba, Mihret Teshome, Eyouel Girma, and all our friends at Top café. $\rho P C 7 \overline{3}::$

I will forever be thankful to my mother (Menbere Kassahun) for going the extra mile to make sure I stayed in school and there is a roof over my head in those difficult days after dad has passed away. If it was not for your hard work and commitment to my education, I won't have the courage to make those risky first steps. I also like to thank my sisters: Elisabet Shumet, Tenagnework Shumet, Yemisrach Shumet, and my brother Yonas for the love and respect you have shown me all the years, and the emotional and moral support you have provided. It won't be fair at all to forget the support I have had from good friends of my late father, Mulugeta Dessie and Gashew Assefa. Thank you for believing in me when I had the idea of quitting school early and about to follow a different path in life.

I would be remiss if I didn't acknowledge my host, the good people of the Netherlands. Thank you for hosting me for almost six years (two years in Wageningen and almost four years in Maastricht). I have learned so many things from you all, be it in the office or in the community. Sitting on a Dutch train in one of the silent rooms, reading a book while having a double espresso is a match made in heaven. I will remain grateful for the opportunity I have had here. I promise you this; your flag will fly high next to mine, and will remain a big fan of Oranje. Dankjewel.

Finally, I like to thank my beautiful wife, Meseret Taimyalew [Papi]. Mare, words won't do justice to describe how much I value the scarifies you are making to raise our handsome boy, Teddy. Watching you practicing how to walk all over again, and Teddy growsup enough to make fun of your efforts makes me want to laugh and cry at the same time. I know at times the going gets tougher, but the darkest hour is just before the dawn. Hang in there! I only wish to have the opportunity to make it up to you for all the quandaries you had to go through in my absence. My son, Teddy (Baba), I envy you for having the best mother in the whole world, but I envy you more as you have got me as a dad $:$. You outgrew my lap, but never my heart, son. I make these promises to both of you; keeping the smile on your faces is my number one priority, and all the sufferings in the world will have to rain on me before it showers you. Love you both!

\section{K.PG.}




\section{Contents}

Acknowledgments ..................................................................................................................... I

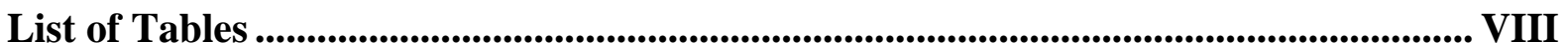

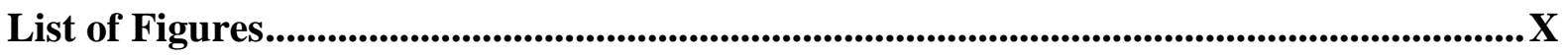

1. Chapter One: General Introduction.....................................................................................................2

1.1. Essays on Capital Structure, Risk Management, and Performance ........................2

1.2. Capital Structure in Farm Businesses.....................................................................4

1.3. Risk Management in Agriculture …................................................................

1.4. The Dynamics of Farm Profitability ................................................................... 11

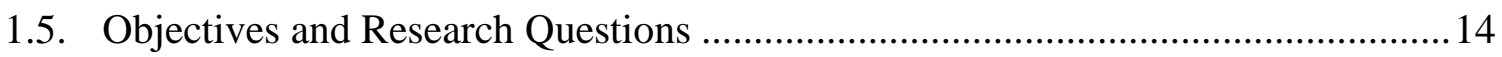

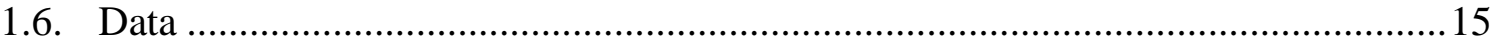

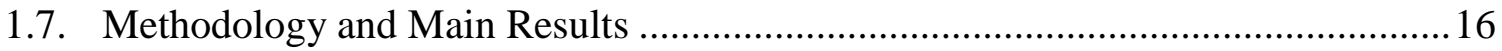

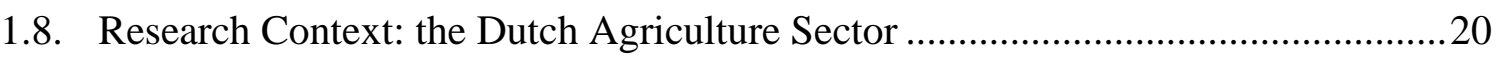

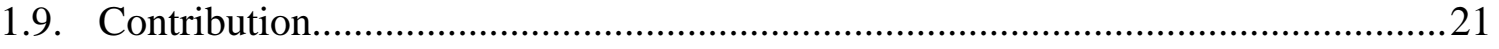

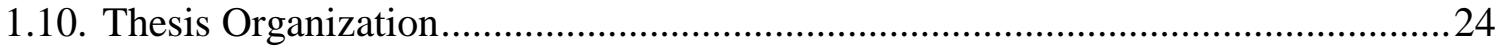

2. Chapter Two: Dynamic Target Capital Structure and Speed of Adjustment in Farm

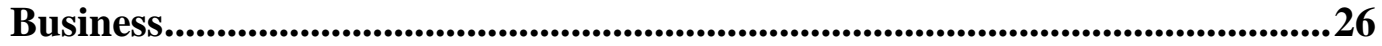

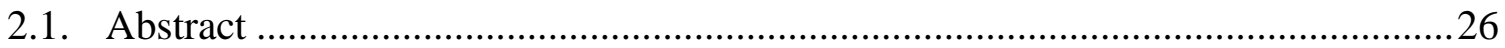

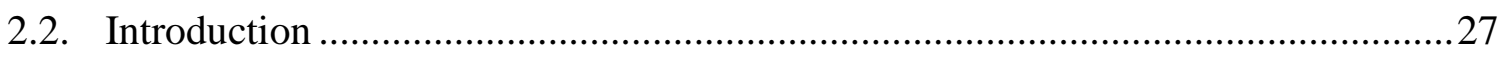

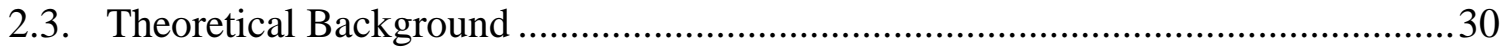

2.3.1. Theories of Capital Structure and the Farm Sector................................... 30

2.3.2. Determinants of Farm Businesses' Capital Structure ............................... 31

2.3.3. Target Capital Structure and Speed of Adjustment ................................ 34

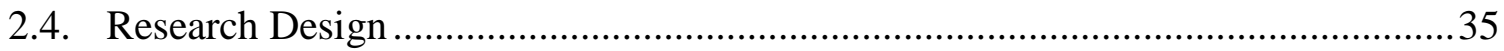

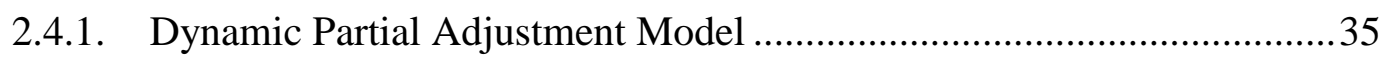

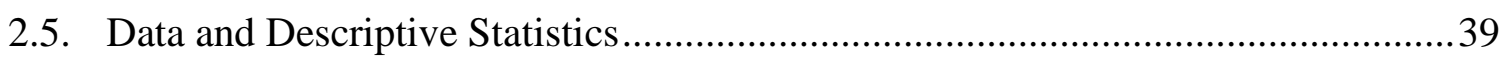

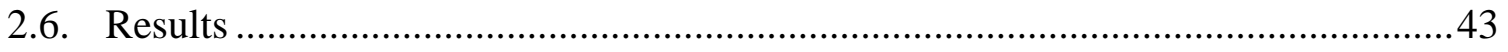

2.6.1. Determinants of Target Capital Structure ............................................... 44

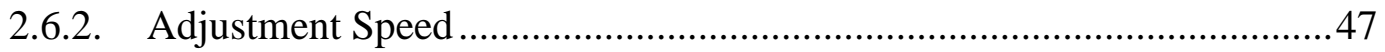

2.7. Farm Size, Growth Opportunity, and Financial Crisis ..........................................49

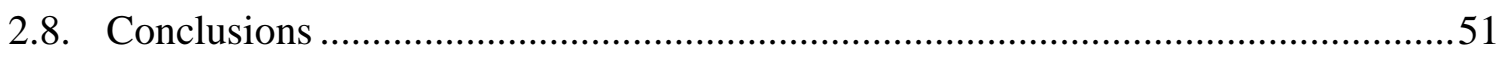

2.8.1. Limitations and Future Research .......................................................53 
2.9. Appendix

3. Chapter Three: Farm-Level Risk-Balancing Behavior and the Role of Latent

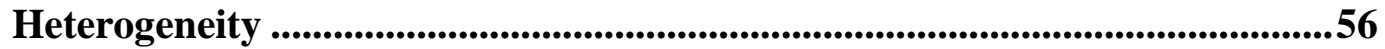

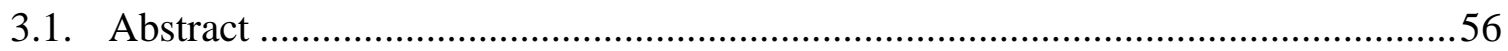

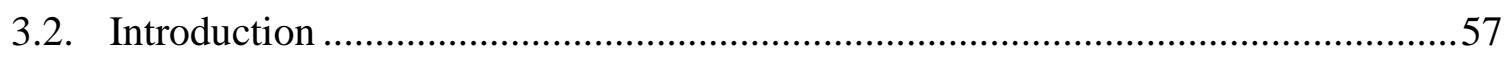

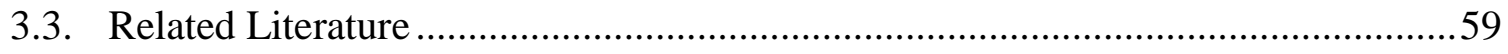

3.3.1. Business and Financial Risks in Agriculture ...........................................6 60

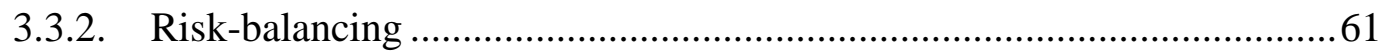

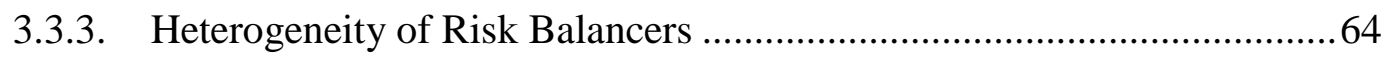

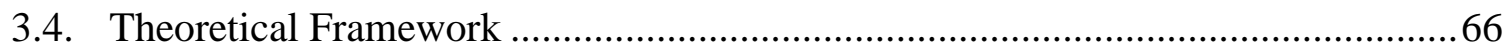

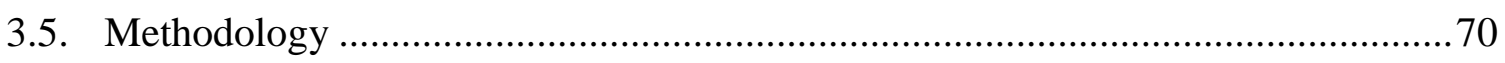

3.5.1. Data and Descriptive Statistics ....................................................... 70

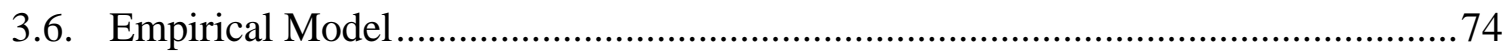

3.6.1. Farm-level Risk-balancing Behavior ..................................................... 74

3.6.2. Drivers of Farm Risk-balancing Behavior .............................................. 75

3.6.3. Farm Risk-balancing Behavior and Latent Heterogeneity ....................... 76

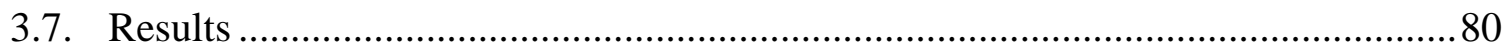

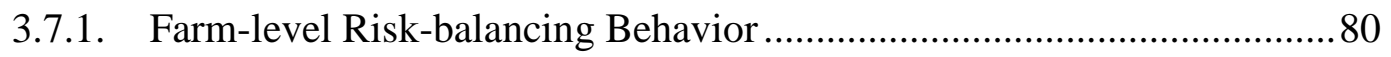

3.7.2. Drivers of Farm-level Risk-balancing Behavior................................... 83

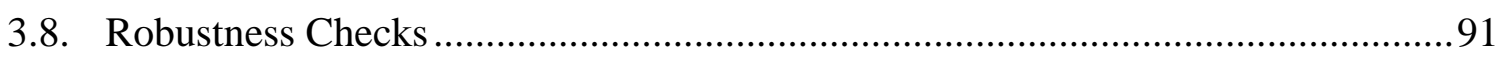

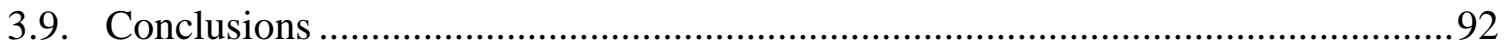

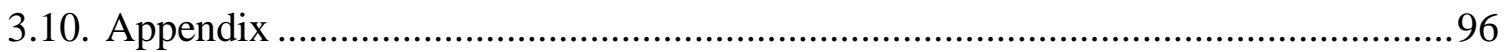

\section{Chapter Four: Do Profit Rates Converge? Evidence on the Persistence of Farm}

Profit .................................................................................................................................................. 109

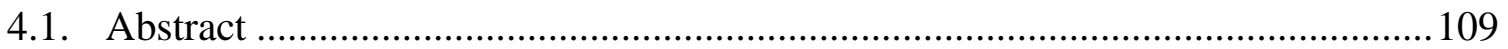

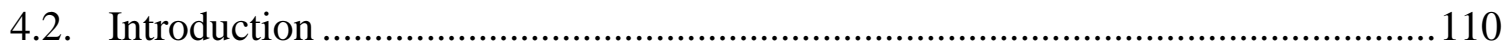

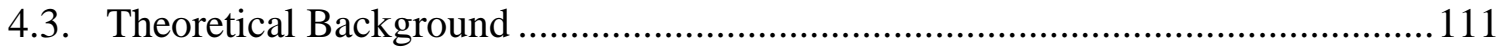

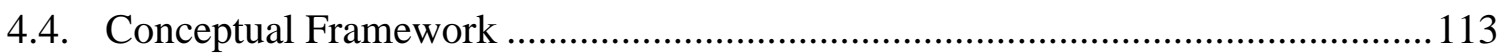

4.4.1. Determinants of Farm Profit and Profit Persistence ............................. 113

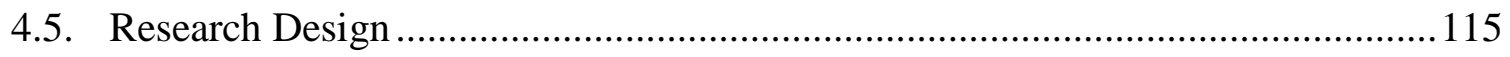

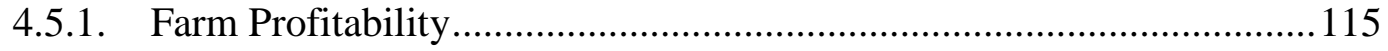

4.5.2. Estimating the Degree and Determinants of Abnormal Farm Profit

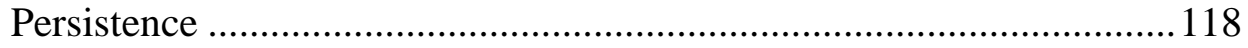

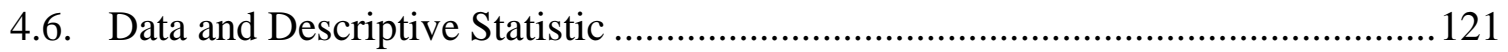


4.7. Empirical Results

4.7.1. Determinants of Farm Profitability .................................................... 123

4.7.2. Dynamic Panel Model Estimation ....................................................... 133

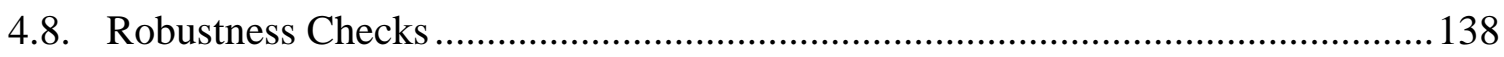

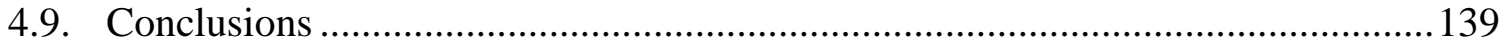

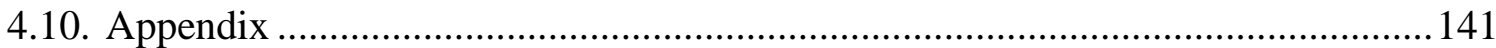

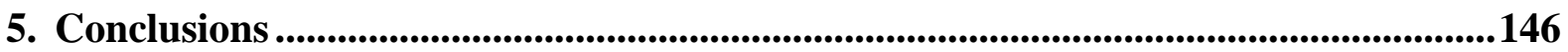

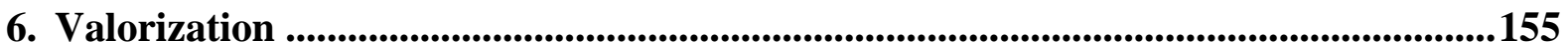

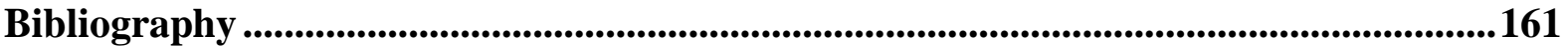

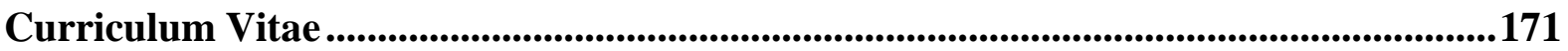




\section{List of Tables}

Table 2.1: Expected relationships between the determinants of target capital structure and leverage .33

Table 2.2: Variables and summary statistics of Dutch farms, 2001-2015 . 41

Table 2.3: Dynamic Panel model estimation results (Dependent Variable; Leverage ${ }_{i t}$ ) .44

Table 2.4: Farm capital structure and the Pecking Order and Signaling theories. 47

Table 2.5: Dynamic panel data estimation results(Dependent Variable: Leverage ${ }_{i t}$ ) 49

Table 2.6: Dynamic panel regression results (Dependent Variable: Leverage ${ }_{i t}$. 54

Table 3.1: Variables and summary statistics. .72

Table 3.2: Fixed-effects panel-regression results over the period 2001-2015 .82

Table 3.3: Logit estimates of drivers of farm risk-balancing behavior..... 84

Table 3.4: Marginal effects of the random effects logit model. .85

Table 3.5: Fit statistics of the mixture models for segments $S=1$ to 6 .........

Table 3.6: Finite Mixture-panel logit regression results for the three-segment solution in which farm risk-balancing behavior is the dependent variable. .88

Table 3.7: Descriptive statistics for identified segments 90

Table 3.8: Profile of the three segments using farm age, business risk, financial risk, and leverage .91

Table 3.9: Proportion of risk balancers .96

Table 3.10: Mean values of selected variables per risk-balancing class. .98

Table 3.11: Fixed-Effects panel-regression results using standard deviation as business risk over the period 2004-2015

Table 3.12: Fixed-effects panel-regression results using downside deviation as business risk over the period 2004-2015 101 
Table 3.13: Fixed-effects panel-regression results using solvency ratio as a financial risk measure over the period 2004-2015.

Table 3.14: Logit-estimates using the standard deviation of net farm income without debt financing as a measure of total risk over the period 2004-2015 103

Table 3.15: System-GMM estimation results 107

Table 4.1: Summary Statistics 122

Table 4.2: Determinants of farm profitability 124

Table 4.3: Determinants of farm profitability, quantile regression results 131

Table 4.4: Dynamic Panel model estimation results 134

Table 4.5: Determinants of farm profitability (PMR), quantile regression 141

Table 4.6: Determinants of farm profitability (PMR), quantile regression by farm type 142

Table 4.7: Dynamic panel regression results (PMR) 144 


\section{List of Figures}

Figure 1.1: Farm capital structure, risk management, and performance

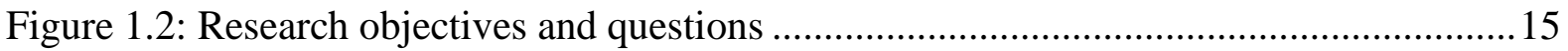

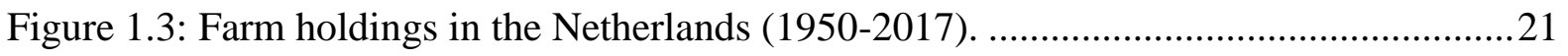

Figure 2.1: Farm leverage by farm type, 2001-2015 .................................................... 42

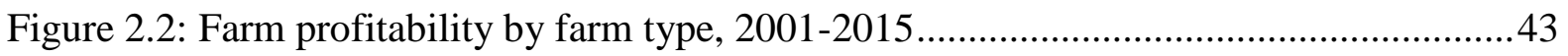

Figure 3.1: Financial and business risks by farm type, 2003-2015 …............................... 73

Figure 3.2: Average marginal effects of total risk, subsidy, leverage, size, profit, and age on

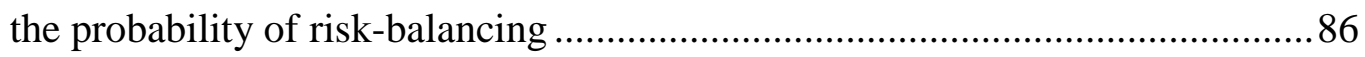

Figure 3.3: Distribution of FR-BR correlations by farm type ......................................... 97

Figure 3.4: Business risk measured as downside deviation by farm type, 2003-2015 ..........100

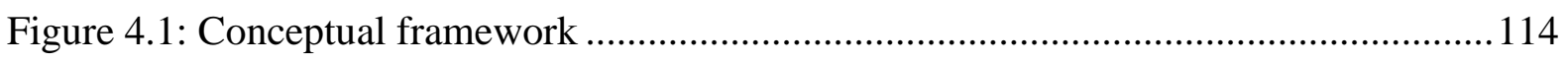

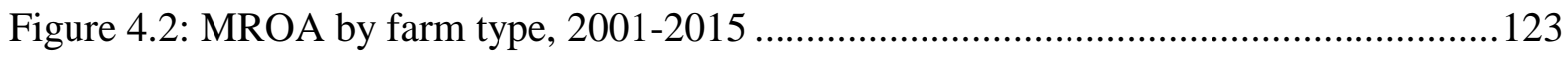

Figure 4.3: OLS and quantile regression estimates for the farm profitability model ........... 127 
Chapter-1

General Introduction 


\section{Chapter One: General Introduction}

\subsection{Essays on Capital Structure, Risk Management, and Performance}

Improving economic, environmental, and social sustainability is a major goal in agriculture (European Commission, 2017). The face of farming has changed dramatically over the last decades, and the key factors influencing farm performance thus require due attention. Changes include: new demand for land use, globalization, competition in the world markets, the rise in volatility in all agricultural commodity markets resulting in a higher volatility in farm income compared to that in other industries, heavy dependency on debt to achieve further growth, continued reforms of agricultural policies, a sharp decline in the number of farms in the developed world, and environmental concerns (Berkhout and van Bruchem, 2015; Burns, Tulman and Harris, 2015). Furthermore, specialization increasingly makes farmers dependent on market prices, as specialization often means less diversification at the farm level; hence the natural hedge at farm level is decreasing (Pennings et al., 2017).

In addition to these trends (and partly caused by above-mentioned changes), a variation in the level of farm competitiveness is observed; some farms consistently perform better (worse) than others. This variation in performance and persistence raises several questions: do the same farms always exhibit high (low) performance? and are these differences in performance systematic or random? It is important to answer these questions to understand future farm competitiveness and the drivers of this heterogeneity in performance. Farm capital structure and risk management lie at the heart this quest.

Capital-structure and risk-management choices are key decisions that a farmer has to make. Their importance stems from the effects that they have on profitability and financial sustainability. For a long time, the capital structure and risk management decisions were thought solely to be affected by farm-internal factors. Recent literature shows, however, that external factors may also have a significant influence on these decisions (Skevas, Wu and Guan, 2018). Hence, there is no doubt that studying the determinants of capital structure and risk management decisions and consequently their impact on the long-run profitability of farms 
is of great importance to farms, lenders, and policy-makers. Interestingly, the report by the Agricultural Market Task Force of the European Union also underlined that the main focus areas after 2020 are improving the market outcomes for farmers, supporting the uptake of integrated risk management tool such as futures market, developing measures to facilitate access to finance, and ensuring the economic viability and competitiveness of farmers (Veerman et al., 2016).

In this thesis ${ }^{1}$, I aim to provide a better understanding of the dynamics of farm business from three different but complementary perspectives. First, I will examine the determinants of farm target capital structure and speed of adjustment, i.e. the speed at which farms adjust their leverage ratio toward the target in a given period of time. In addition, I will examine whether the existing corporate finance capital structure theories, particularly the pecking order and signaling theory, explain leverage dynamics. Second, I will examine the presence of farm riskbalancing behavior as an integrated risk-management tool while accounting for unobserved (latent) heterogeneity. Finally, I will estimate the degree and drivers of farm profitability and abnormal profit persistence, and I will seek to explain why persistence levels differ across farm types using the well-established theory of the Resource-Based View (RBV). Figure 1.1 shows the synthesis of the three essays in the thesis.

${ }^{1}$ Thesis and dissertation are used interchangeably. 


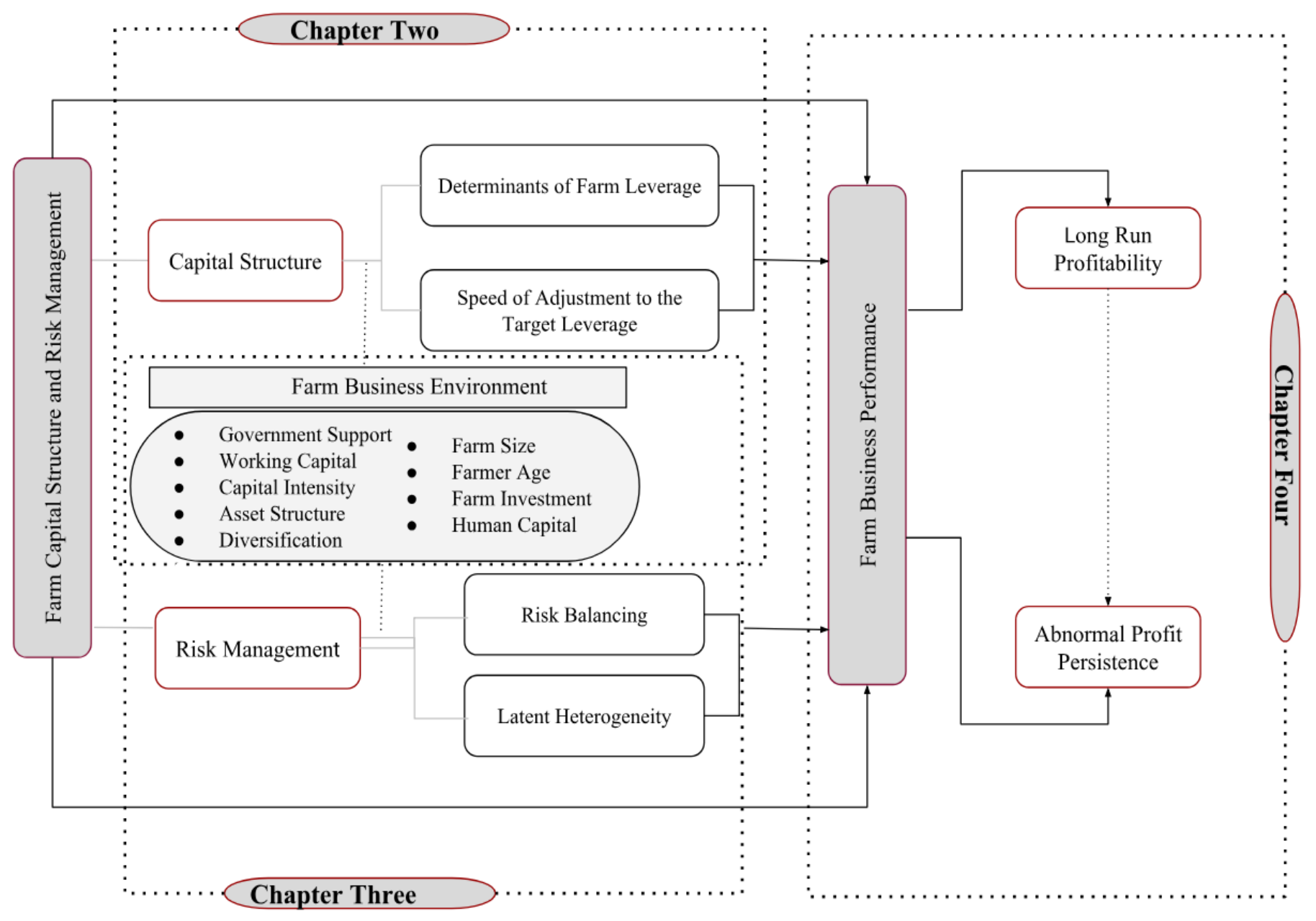

Figure 1.1: Farm capital structure, risk management, and performance

\subsection{Capital Structure in Farm Businesses}

Modigliani and Miller (1958) show that, under the strict assumption of a perfect market, firm value is independent of the way the firm is financed. In reality, however, market frictions do exist, and many theories have been proposed in the literature to explain the choice of corporate financing source in light of the potential costs associated with each source (Graham, Leary and Roberts, 2015; Myers, 1984; Rajan and Zingales, 1995; Titman and Wessels, 1988). They include agency costs, information asymmetry costs, transaction costs and bankruptcy costs (Graham and Leary, 2011). Using these theories, previous studies have identified the determinants of firm capital structure decision making. These factors include, but not limited to, asset structure, earnings volatility, size, growth opportunities and profitability (Frank and Goyal, 2009; Graham, Leary and Roberts, 2015; Rajan and Zingales, 1995; Titman and Wessels, 1988). 
Previous studies, however, almost exclusively focused on the capital structure decision making of corporations. As a consequence, very little is known about the financing behavior of farm businesses, and it is simply assumed that the general theories of the corporate capital structure are applicable across sectors and industries, including farming.

This assumption may not hold for farm businesses, however, given that they are characterized by a number of specific circumstances, including dependency on government support in order to stabilize income; the seasonal nature of production, leading to mismatches in cash inflow and outflow; different legal forms, whereby sole proprietorship is the predominant legal form; and limited access to equity markets. Further, unlike corporate firms that rely on external professional management, farm businesses have small decision-making units that consist of the owners or their family members and perhaps a few external advisors (Pennings et al., 2004; Pennings and Leuthold, 2000). These unique characteristics of the farming sector are expected to lead to different patterns of capital structure decision making. This makes it interesting to answer the question of whether the relationships predicted by existing corporate finance theories still hold true for farm businesses.

In addition, capital structure decisions by agricultural farms became an issue of interest as farms started becoming more market-oriented (Nurmet, 2011) and are influenced by factors such as expected net income, risk level, and lenders' attitudes towards risk. Also, the management of the capital structure influences farm performance in terms of profit, financial risk, and survival. Thus, to make informed decisions about farm viability, farms themselves, as well as lenders and policy analysists, need information about the financial structure of farms, and how farmers balance risk through their choice of capital structure and changes to that structure.

A farm's capital structure is inevitably linked to its performance: absence of sufficient financial resources threatens long-term farm viability while working capital is an important element in making the necessary investments in innovation, processing infrastructure, and production inputs to optimize output, improve quality, reduce costs, and gain efficiencies over time (Zhengfei and Lansink, 2006). Changes in a farm's production structure affect its capital 
structure by either tying up capital as farm production capacity increases or freeing up capital as it decreases. Consequently, investigating the speed of adjustment to the target leverage ratio is important in understanding the agility of farms in adapting to changing production and finance structures.

Farm financing behavior and capital structure decisions also have important implications for the return and stability of lenders and financial institutions (Nenu et al., 2018; Agarwal, 2013). Farms do not typically have access to large equity markets: they rely on debt financing, mostly bank loans, as external funding sources (Katchova, 2005). Consequently, those farms are dependent on banks, whose credit supplies are affected by the state of the economy. Farms that are exposed to business risks, such as weather conditions, market price volatility or other external factors, see their financing resources dwindle. Note that operating farm revenues tend to decline in times of financial downturns as banks grant fewer credits in order to adjust their own liquidity (Cornett et al., 2011). In 2016, for example, Rabobank, a popular bank among Dutch farmers, with nearly 92.3 Billion Euro in outstanding loans to agricultural businesses, announced that one-third of its dairy farm customers were having trouble to pay back the principal and accumulated interests on their loans (CBS, 2017). In such situations, farms are forced to rely on internally generated funds, such as retained earnings, to cover their financial needs.

It is relevant to examine whether corporate finance theories such as the pecking order and signaling theory (Graham, Leary and Roberts, 2015; Myers, 1984; Rajan and Zingales, 1995; Titman and Wessels, 1988) can explain financial decision making in farm businesses. The pecking order theory entails that firms have two sources of funding: internal and external. The cost gap between internal and external funding, attributed to asymmetric information and agency costs, makes firms prefer internal financing (Byoun, 2008; Frank and Goyal, 2003). Whenever external funding is required, firms will issue debt and convertible bonds rather than equity. The signaling theory states that managers have better information about their firms and motives to transfer this information to potential investors and lenders through 'signals'. These signals include, but are not limited to, investment, profitability, leverage, asset accumulation, 
and repurchasing of outstanding stocks (Graham, Leary and Roberts, 2015). The applicability of these theories in a corporate setting is not uncontested, however. Both rely on the assumption that a company has two external financing options: debt and equity. The pecking order theory, for instance, may not hold in more complex corporate capital structure settings, e.g., when a firm chooses between straight and convertible debts, or in the event of an agency problem between a shareholder and a manager. The signaling theory, on the other hand, suffers from the abundance of financial tactics and ways to access capital markets in a corporate finance setting, which complicates the measurement and identification of the signaling effect (Frank and Goyal, 2007).

Farm businesses are less prone to these challenges and provide an interesting background for investigating how these corporate finance theories explain capital structure decision making because: (1) often, there are only two financing options: retained earnings (internal) and debt (external), (2) the facts that sole proprietorship is the predominant legal form $^{2}$ and farms have limited access to the capital market minimize the agency problem, and (3) farms have very few financial tactics, such as leverage and profit, to use as signals, which makes identification of the signaling effects easier.

Studies that use these theories to examine the financing behavior of farm business are scant, however, despite abundant supportive evidence for their applicability in the corporate finance literature. In an attempt to fill this gap, chapter 2 examines the applicability of corporate finance theories to farm businesses, the determinants of farm target capital structure decisions, and the adjustment speed towards the target capital structure.

\subsection{Risk Management in Agriculture}

The unpredictable forces of nature make risk an inherent feature of the agricultural sector. Imperfect information by farmers about the price of inputs and outputs and the weather

\footnotetext{
${ }^{2}$ According to Lowder, Skoet and Raney (2016), family farms constitute about $75 \%$ of global farming.
} 
conditions also make farm competitiveness uncertain in the future. The major risks in agriculture are commonly classified as business and financial risks (Barry et al., 2012).

Business risk can be defined as the variability in the operating net income of a farm (Escalante and Barry, 2003). The most common farm business risks are production (yield), price, institutional, technological, and personal risks. Yield risk occurs due to uncontrollable events such as excessive (lack of) rainfall, extreme temperatures, insect infestations, and diseases (Hardaker et al., 2015). Price risk reflects risks associated with changes in the output or input prices. The prices of the most purchased farm inputs, i.e. seeds, fertilizer, pesticides, and machines, and most sold farm outputs, i.e. milk, tomatoes, and cut flowers, are not known in advance. Thus, farmers are increasingly exposed to price-making forces in unpredictable markets (Pennings et al., 2017). Risks ensuing from changes in agricultural policies and regulations are categorized as institutional risks (Barry et al., 2012). Technology also plays a key role in production risk in farming, in the sense that certain technological practices may become outdated (Harwood et al., 1999). Personal risks, e.g. divorce, illness or the death of the operator or a family member affect the survival chances of the farm (Meuwissen, 2008).

Financial risk, on the other hand, is the risk that arises, often, from debt financing. Farms borrow money from banks and other lending institutions to purchase farming equipment, land and livestock (Hardaker et al., 2015). The use of borrowed funds means that a portion of the returns from the farm business must be reserved for making debt and interest payments. Farms with higher levels of leverage, i.e. more external debt, will earn less money from farming activities, especially when the interest rate on their loans is very high.

Financial risk in farming is thus mostly caused by uncertainty related to interest rates, changes in the value of assets used as collateral, and changes in cash flows allocated to repaying debt (Langemeier, 2016). In addition, financial risks may also be caused by increased input costs, excessive borrowing, higher cash demand for family needs, and lack of adequate cash or credit reserves (Turvey and Kong, 2009). The sources of financial risk and their levels of severity include a size element. Unlike smaller farmers, larger farmers are more likely to possess collateral and have more experience with keeping detailed accounting records, both of 
which are often required by lending institutions for credit risk evaluation. This makes the process of obtaining loans cheaper for larger farms than for smaller farms (Reynolds-Allie, Fields and Rainey, 2013).

The above discussion shows that risks are unavoidable and are at the heart of the major decisions taken by farmers. Dealing with such risks, i.e., risk management, is getting more and more important, not only for individual farmers but also throughout the supply chain. Risk management involves selecting suitable strategies to reduce risk exposure in the farm operation, building a farm's risk-bearing capacities, and transferring risks to a third party that is better equipped to handle this risk exposure (Harwood et al., 1999). Since there are multiple sources of business and financial risk involved, a comprehensive strategy that integrates production, marketing, and financial responses will reduce risk more effectively than a series of separate and individual responses (Barry et al., 2012). It is important to note, however, that good risk management does not necessarily equate the total elimination of risk. Rather, it means containing the risk at a level that the business is willing and able to bear (Ifft, Kuethe and Morehart, 2015).

Currently, farms have different types of risk-management instruments at their disposal. These instruments include insurance, diversification, off-farm employment, mutual funds, saving accounts, futures market, ad-hoc payments, and other fiscal measures (Falco et al., 2014; Organisation for Economic and Development, 2011). However, the low uptake of these various tools by farmers remains one of the major challenges in understanding and designing adequate risk-management tools at a farm level (Cordier, 2015; Finger and El Benni, 2014). Risk-management tools in agriculture are commonly categorized into two approaches: sharing risks with others and taking measures within the farm (Hardaker et al., 2015). While the first approach mostly concerns insurance schemes, the risk-balancing theory may present an interesting alternative, though under-investigated in the risk-management literature, to the already existing integrated risk-management strategies that form part of the second approach of taking measures within the farm. 
Risk-balancing in farming is defined as the adjustments to the financial and business risks in response to changes to the existing optimal total risk level following an exogenous shock (Escalante and Barry, 2003; Gabriel and Baker, 1980). The risk-balancing hypothesis establishes a link between the level of business risk, financial risk and an optimal level of total risk (de Mey et al., 2014). Farms whose levels of business risk have been affected by exogenous shocks will aim for an optimal (constant) level of total risk by adjusting their leverage (financial) positions. Any increase in business risk can be offset by a decrease in leverage.

Contrary to these exogenous shocks, endogenous decisions or actions taken by farmers, such as adopting new production technology or innovation, might decrease the level of business risk, allowing farms to increase their financial risk exposure by taking out more loans in an effort to maintain a constant level of total risk (Ifft, Kuethe and Morehart, 2015). The simple strategy suggested by the risk-balancing hypothesis is that farms with high business risks will abstain from assuming additional financial obligations, so as to reduce their financial risk exposure. Conversely, farms may opt to take out additional loans, i.e. create a higher leverage ratio, as their business risk exposure decreases. The underlying motivation of farms is always risk-balancing, i.e. to restore the total risk to the optimal level, i.e. the level before the disruption by the exogenous shock(s) (Featherstone et al., 1988).

The risk-balancing hypothesis is well established in agricultural economics and finance literature. Its insightfulness has inspired many extensions since its introduction by Gabriel and Baker in 1980. Using the risk-balancing framework, Collins (1985), Featherstone et al. (1988), Escalante and Barry (2003), and, more recently, Uzea et al. (2014), de Mey et al. (2014), de Mey et al. (2016) and Bampasidou, Mishra and Moss (2017) all provided evidence of riskbalancing by farms.

Very few studies, however, have examined the determinants of risk-balancing behavior. This might partly be explained by the lack of comprehensive farm-level longitudinal accounting data to assert the risk-balancing behavior of farms in the long-term. Most importantly, however, the risk-balancing literature does not account, yet, for the (unobserved) heterogeneity of risk balancers. 
Most previous studies in the risk-balancing literature focus on specific farm types (e.g., dairy, cash grains or livestock farms), age or region, rather than explicitly addressing farm type as a mere unit of interest, thus implying that all farms sharing the same observed characteristics follow the same decision-making process. This has led to the assumption that farms within these groups are homogenous. Farm heterogeneity may, however, originate from several sources within these supposedly homogenous farm types, such as: (a) different farming motivations, (b) different external production conditions, (c) other factors such as managerial capacity, risk perception, and risk tolerance (Trujillo-Barrera, Pennings and Hofenk, 2016). To the best of the author's knowledge, no previous study to date explicitly accounts for the heterogeneity of risk-balancing farm behavior. This thesis aims to address this gap.

Chapter three tests the presence of farm risk-balancing behavior while accounting for the unobserved heterogeneity among risk balancers. The effect of unobserved heterogeneity is explicitly modeled by a latent mixture regression model, which classifies farms into segments, whereby their risk-balancing responses to the selected explanatory variables are identical within each segment but different across segments. Note that the term unobserved heterogeneity posits two interrelated ideas (Pennings and Garcia, 2010): the first notion is that not all farm operators respond similarly to a given change in the determinants of risk-balancing, but rather that there may be segments of farm operators who behave in similar ways. The second notion is that prior to the analysis, it is not possible to observe these segments directly.

\subsection{The Dynamics of Farm Profitability}

Farm profitability has been in the spotlight in recent years because income volatility has been higher in farming than in other industries (Sol, Isabel and Alberto, 2016) and because of major socioeconomic changes. In addition to these changes, a variation in the level of farm profitability can be observed; some farms consistently perform better (worse) than others (Mishra, Wilson and Williams, 2009).

Several models have been developed to explain the occurrence of variations in sustained competitive advantage across seemingly similar firms and industries. The Structure Conduct Performance (SCP), the Market-Based View (MBV) and the Resource-Based View (RBV) are 
the predominant models (McGahan and Porter, 2003). The central premise of the SCP is that performance that deviates from the norm is determined by the competitive dynamics and structure of the industry. These can be assessed by analyzing elements such as barriers to entry and exit, product differentiation, the number of competitors, and the number of buyers and sellers, which help determine how firms behave and perform, i.e. gain and sustain competitive advantages (Porter, 2008).

The MBV is an extension of the SCP and argues that superior performance is determined not only by industry structure but also by employing market-positioning strategies, e.g. low cost/product differentiation, in the target market segments help to earn and sustain superior performance (Wiggins and Ruefli, 2002). The MBV stresses that firms devise their strategies based on a market analysis of the industry. Recently, the focus in the literature has shifted from industry structure to a firm's internal resources and capabilities (Furrer et al., 2008). This shift has made the Resource-Based View (RBV) the leading model for analyzing sustained superior performance. A central premise of the RBV is that firms compete and choose strategies based on their material, financial and human resources and their capabilities (Grant, 1991). Competitive advantage can be achieved and sustained by developing and owning resources that are scarce, valuable, non-substitutable and inimitable (Barney, 2001). Resources that sustain competitive advantage will also generate superior economic performance that will persist over time. Long-run profitability and the persistence of this profit have been used as indicators of a sustained competitive advantage (Porter, 2008).

Since the contributions by Mueller (1977), a considerable amount of literature has been published on variations in firm profitability and its persistence in the manufacturing and service sectors (Goddard et al., 2011). Empirical facts from these studies give rise to two main research directions in the so-called 'persistence literature': identifying the level of analysis (whether firm, corporate, industry, and country level) and examining the time dependence of profit rates.

Findings in the first direction show a wide consensus regarding the existence of significant firm and industry effects on performance persistence. Schumacher and Boland (2005) found that profits are generally more persistent within an industry than within any 
specific corporation. Kambhampati (1995) studied the intensity of competition in India from a developing-country perspective and found that above average profitability persisted in a large number of industries. Data from the Turkish banking sector, on the other hand, revealed that the long-run mean profit rate was very close to zero, implying the convergence of profit to the norm. Goddard et al. (2011) also tested for the persistence of profit using bank-level data from 65 developing and developed countries, finding that developed countries show a slightly higher persistence in profit than developing countries. Findings in the second direction suggest that only very few studies on the time dependence of profit rates can confirm the existence of a convergence process toward the mean profit rate (Carhart, 1997).

Even though findings from the manufacturing and service sectors are of great importance in understanding the notion behind the dynamics of long-run profitability, these conclusions cannot directly be applied to the agriculture sector because of its unique characteristics. Zhengfei and Lansink (2006) and Huirne (2003) noted that the agriculture sector is unique in that (a) production processes are seasonal; (b) input-output processes are often sequential (not simultaneous); (c) farms are exposed to uncertainty associated with the nature of production, such as variability of rainfall, the presence of pests and diseases that will determine the risk of partial or total loss of produce; and (d) farm produce is mostly perishable. Given these unique challenges, it would be interesting to gain a better understanding of the characteristics of persistently well-performing farms, the tangible and intangible resources acquired by these farms, the potential for further improvement of well-performing farms, or their ability to maintain their position relative to others, and the challenges that other farm businesses face on their way to performing similarly.

There are studies in the agricultural economics literature that address the determinants of farm profitability and sustained competitive advantage in the long-run (see, e.g., Griffin, Ibendahl and Stabel, 2018; Langemeier and DeLano, 1999). Studies that address the intersection of the two, i.e. the determinants and the persistence of farm profit, are nevertheless lacking. This thesis aims to contribute to filling that gap. Given the vast body of literature on farm profitability and efficiency dynamics, the next logical question to ask is whether farms 
that are performing well (poorly) compared to other farms during one period will continue to outperform (lag behind) the others

Although a useful starting point, previous studies all have their limitations: they pay only nominal attention to documenting persistence determinants and apply mostly nonparametric persistence measures, such as rank correlations and contingency tables. Aimed at filling these gaps, chapter 4 attempts to (a) find evidence of persistent farm performance explained by readily observable data; (b) ascertain whether significant differences in performance can be documented for a large group of farms over time across different farming systems; and (c) identify the main factors that account for variations in long-run profitability and its persistence.

\subsection{Objectives and Research Questions}

The general purpose of this dissertation is to contribute to the ongoing debate on farm competitiveness. This thesis aims to achieve an understanding of the dynamics of farm business from the perspectives of capital structure, risk management, and profitability, specifically where further theoretical reflections are needed and where the empirical evidence is scarce and inconclusive. Figure 3 summarizes the research objectives and questions in each chapter. 


\section{Chapter Two}

Objective: To analyze the applicability of corporate finance theories in farm businesses, the determinants of farm target capital structure decisions, and the adjustment speed towards the target capital structure.

\section{Research Questions:}

- What are the determinants of farm capital structure?

- How quickly or slowly farms adjust their capital structure to the target?

- Can the pecking order and signaling theories of corporate finance explain the farm business financing behavior?

\section{Chapter Three}

Objective: To examine the presence, extent and contributing factor of risk-balancing behaviour at farm level by explicitly accounting for unobserved heterogeneity.

\section{Research Questions:}

- Do farms balance their risk?

- What are the extents of farm risk balancing behavior?

- What drives the risk balancing behavior of farms?

- What is the level of heterogeneity of risk-balancing farms?

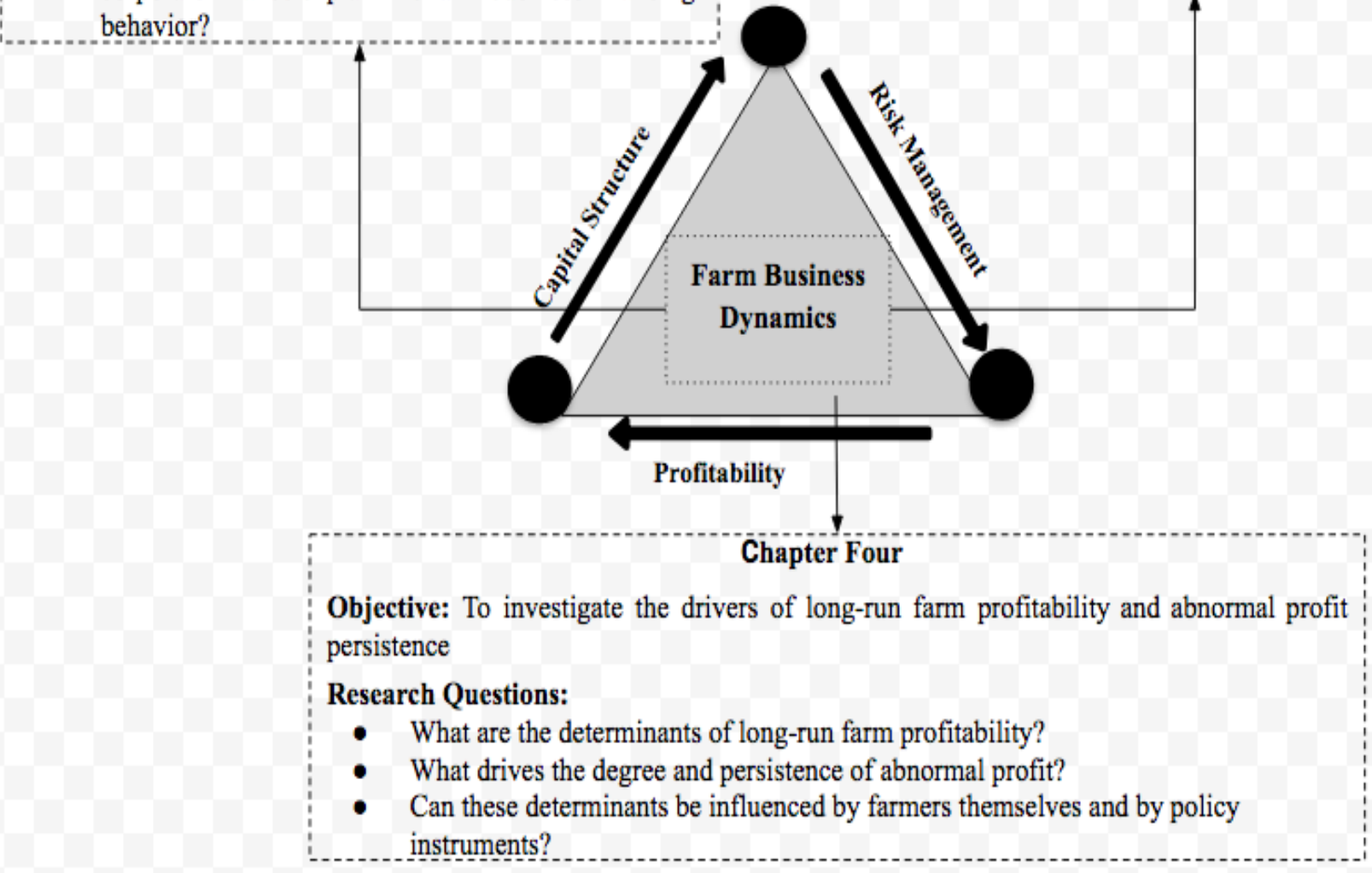

\section{Figure 1.2. Research objectives and questions}

\subsection{Data}

This thesis is based on the accounting data from farms that participated in the Dutch Farm Accountancy Data Network (FADN) between 2001 and 2015. FADN is an annual survey of commercial farms in the European Union (EU) and collects detailed structural and accountancy data on EU farms. The Dutch FADN is compiled and maintained by the Wageningen Economic Research-WUR (formerly known as the Dutch Agricultural Economics Research Institute, $L E I)$. 
The Dutch FADN sample was randomly selected using disproportional stratified sampling from the farm census. Economic size and farm type are the stratification criteria. Stratified random sampling ensures the inclusion of farms from all groups with different characteristics. Disproportional sampling entails that farms have different chances of being included in the sample. Farms from relatively homogenous groups have a smaller chance as a reliable conclusion can be reached based on few observations. This ensures the proper representation of all groups.

The agricultural census provides the sampling frame for selecting farms to be included in the FADN. The type of farming and economic size are used to assign farms to the strata. Only farms with a standard output exceeding EUR 25,000 are included in the sampling frame. The number of farms to be included in the Dutch FADN sample is determined for each stratum and depends on the economic importance of a sector, the number of farms in a stratum, the policy relevance of a group and the heterogeneity of the farms (Meer, Veen and Vrolijk, 2013: p.7).

The dataset used in this thesis is of high quality in that (a) the samples are representative of $80 \%$ of the farms and more than $90 \%$ of production in the Netherlands, and (b) it allows for the separate estimation of farm types for comparison purposes due to the harmonized datacollection procedure, i.e. the bookkeeping principles and sample selection plans are identical for all farm types in the Netherlands, and similar to those in other European countries participating in the FADN.

\subsection{Methodology and Main Results}

This thesis uses multiple research methodologies. Chapter 2 quantifies the determinants of the target capital structure as well as the speed of adjustment to it. Recent literature emphasizes the use of dynamic panel techniques, such as the generalized method of moments (GMM), due to their robust results compared to other approaches (Roodman, 2009). Arellano and Bond (1991) proposed a Difference General Methods Moment (Difference GMM). In this approach, regression equations are expressed in terms of their first difference and endogenous variables are instrumented using lags of their own levels. It allows for the specification of the 
endogenous variables and involves first differencing that removes the time-invariant farmspecific effects. This approach has limitations, however, as the correlation between the first difference and the lagged levels may be weak. To address this limitation, Arellano and Bover (1995) developed an improved estimator known as the 'Level GMM', which expresses regressions in levels and endogenous instruments in terms of their lagged differences. Finally, Blundell and Bond (1998) combined both approaches to construct a system of equations known as the 'System GMM'. It combines the sets of moments from the difference and level equations into instrument-endogenous variables.

The System GMM is particularly suitable for this thesis because (Flannery and Hankins, 2013; Roodman, 2015): (a) it has better asymptotic and finite sample properties; (b) it uses difference equations for instrument-endogenous regressors, so that they are also able to handle time-invariant, farm-specific attributes, e.g. heterogeneity and endogeneity; and (c) it is wellsuited to handling datasets with large numbers of cross-sections, $\mathrm{N}$, and small numbers of available periods, T. Chapter 2 thus specifies an integrated dynamic partial adjustment model based on Blundell and Bond's (1998) System-GMM estimation.

The results from the System-GMM estimation suggest that the signaling behavior in the farm-lender relationship fits the pecking order theory in explaining the leverage ratio of farm businesses. The most robust findings are that farm leverage is negatively related to profit, supporting the pecking order theory. In addition, consistent with the signaling theory, I find that farm leverage is positively related to asset tangibility and growth opportunity. All farm types use their growth opportunities to effectively send signals to facilitate their access to credit. Farm profitability, asset tangibility, risk, growth opportunity, and size significantly determine farm capital structure. The speed of adjustment to the target leverage ratio ranges from $11.4 \%$ to $64 \%$ and varies by farm type. This variation is mainly attributed to the difference in adjustment costs, and the result further confirms the existence of dynamics in the farm capital structure decision.

Chapter three provides farm-level empirical support for the risk-balancing behavior of farmers. In order to examine whether farms exhibit risk-balancing behavior, a fixed-effects 
panel-regression model is used, where the financial risk is regressed on one-year lagged business risk and selected farm characteristics. Estimating the panel fixed-effects regression model is econometrically challenging as some of the explanatory variables are potentially endogenous. Thus, estimating the parameters with the standard OLS estimator may lead to inconsistency and bias (Greene, 2003).

An instrumental variable approach is a common practice when accounting for endogeneity. Consequently, the System-GMM estimation is used as an 'internal' instrument approach. In addition, a logit panel model is estimated to identify the determinants (drivers) of farm risk-balancing behavior. Finally, in chapter three, I explicitly account for latent heterogeneity using a latent-class logit mixture model (Pennings and Garcia, 2010; Wedel and Kamakura, 2012). Using the iterative Expectation-Maximization (EM) algorithm, the model simultaneously identifies segments based on the influence of the selected explanatory variables and estimates the effects of these variables on farm risk-balancing behavior for each identified segment.

The results show that over half of the farms exhibited risk-balancing behavior between 2001 and 2015, implying that farms make strategic adjustments by taking more (less) debt in response to a decrease (increase) in business risk. Results from the fixed-effects regression show evidence of farm risk-balancing behavior: there is a negative relationship between the lagged farm business risk levels and current financial risk. The logit panel regression suggests that the extent of risk-balancing behavior differs across farm types and that farm characteristics such as farm size, profitability, and participation in government support programs determine farm risk-balancing behavior.

The estimates from the latent mixture regression model suggest the presence of multiple segments, and farm profitability, total risk, leverage, age, size, and diversification are the factors related to farm risk-balancing behavior. Interestingly, these factors are found not to be equally important across farms, i.e., segments. Assuming homogeneity in farms' responses and estimating a pooled model or a priori classifying farms based on farm type yields a poor fit and may lead to the false conclusion that only size, profit, subsidy, and investment are the 
determinants of the likelihood of engaging in farm risk-balancing. The existing heterogeneity at segment level appears to have been masked at aggregate farm-type level. These masking effects are prominent for the factors that are part of the risk-balancing hypothesis, such as farm leverage and total risk exposure. The advantage of expressly accounting for unobserved heterogeneity becomes apparent from the presence of different farm types in each segment: each of the three identified segments contains dairy, field-crop, horticulture, and livestock farms in varying proportions.

In chapter four, I use a quantile panel regression to estimate the effects of farm characteristics at different points of the profitability distribution. Quantile regression estimates are considered robust relative to the traditional OLS estimator for a number of reasons: they place less weight on outliers, and are robust to departures from normality (Koenker, 2004). In addition, they avoid the restrictive assumption that the error terms are identically distributed at all points of the conditional distribution. Avoiding this assumption allows these estimates to capture farm heterogeneity, in that the slope parameters can vary at different quantiles of the distributions of farm profitability. Note that a dynamic panel model has been specified to empirically examine the effect of farm characteristics on profit persistence.

Results from the quantile regression show that working capital, labor productivity and investment are associated with profitability, regardless of farm type. These findings suggest that, in an environment where farms don't have regular income from agricultural products, working capital is important for them to have the flexibility and capacity to adapt to changing circumstances. On the other hand, leverage and capital intensity show negative effects on farm profitability, meaning that farms that already exhibit high leverage levels face more cash-flow constraints in their operation due to high financing costs. Estimates using the dynamic panel model provide strong evidence that there is a significant degree of abnormal profit persistence, with variations between farm types. I also find that abnormal profit persistence is responsive to farm characteristics such as risk exposure, investment, capital intensity, leverage, working capital, and diversification. Evidently, farm working capital has a significant, positive effect 
on abnormal profitability. The next section briefly discusses the Dutch agriculture sector as the research context.

\subsection{Research Context: the Dutch Agriculture Sector}

The Dutch agriculture sector accounts for $1.5 \%$ of the country's economy, $20 \%$ of the country's total export value, and $2.5 \%$ of employment. The Netherlands realizes $8 \%$ of total European agricultural production on only $1.6 \%$ of the cultivated land surface in Europe (CBS, 2017).

Following the trend in the developed world, the number of farms has been decreasing since the 1950s (see figure 1.3).

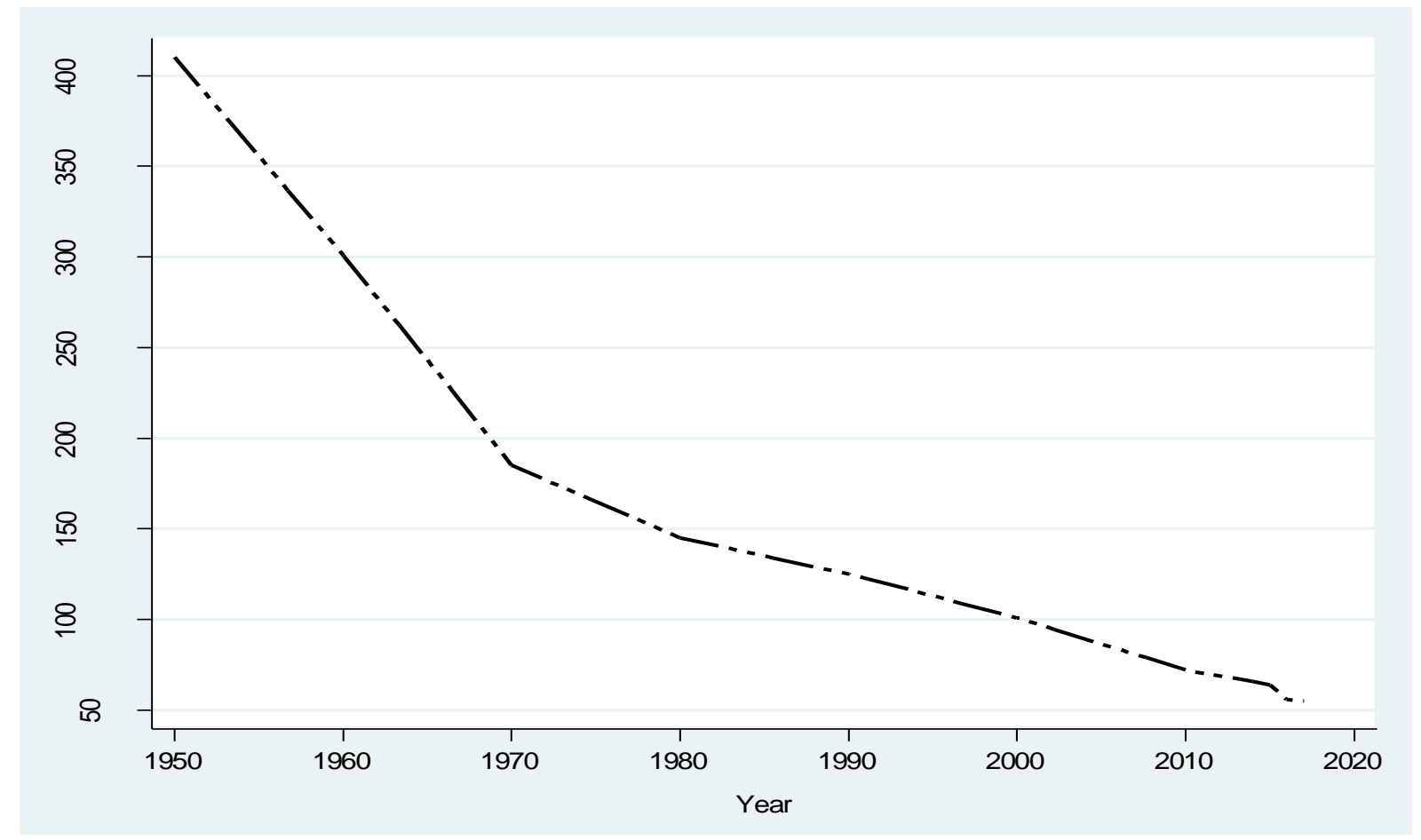

Figure 1.3: Farm holdings (in thousands) in the Netherlands (1950-2017)

Source: $C B S$ (2017)

In 2017, for instance, the Dutch farm sector lost 23 farms every single day (CBS, 2017). Between 2000 and 2014, the number of agricultural holdings significantly decreased from 101,550 to 65,500 farms, representing a $35.5 \%$ decline and exceeding the average EU decline. The combined effects of economic, political and technological factors were the main causes of this decrease (Berkhout and van Bruchem, 2015). Statistics Netherlands (CBS, 2017) reported that the value of agricultural production of the Dutch farming sector increased ten-fold between 
1950 and 2017. Intensification and scaling-up accounted for this strong growth in both agricultural output and productivity.

From a financing perspective, more than two-thirds of the balance sheet total of Dutch farms is financed with equity capital (Berkhout, 2017). Until 2007 the long-term liabilities of agricultural and horticultural holdings rose faster than their total balance sheet value, leading to a decrease in solvency (measured as the ratio of total debt to equity) during that period. After 2007, average solvency remained reasonably stable at around 68\%. From a risk-management perspective, it is important for farms to possess an adequate financial buffer to absorb fluctuations in income.

At a macro level, as an EU Member State, the Dutch agriculture sector is also affected by the European Common Agricultural Policy (CAP), which was introduced in 1957. The European CAP for 2014-2020 was implemented in 2014, with its main goal to achieve a more sustainable development of the agricultural sector (Eurostat, 2015). The starting point is to make farmers less dependent on subsidy payments, induce them to innovate and increase efficiency and competitiveness (European-Commission, 2017). All in all, Dutch agriculture is characterized by highly educated farmers, large-scale capital-intensive farming, export orientation, increasing input and output price volatility resulting in low-profit margins, and strong competition. These characteristics provide an interesting context for studying the capital structure, risk management and profitably of Dutch farm businesses.

\subsection{Contribution}

By empirically examining the dynamics of farm businesses through three independent but complementary studies on farm capital structure, risk management, and profitability, this thesis contributes to the literature in the following ways:

First, it examines the applicability of corporate finance capital structure theories, i.e. the pecking order and signaling theory, to farming. The results in this dissertation show that farm profit and earnings volatility (negative sign), and growth opportunity and asset tangibility (positive sign) significantly explain farm capital structure, suggesting that the pecking and 
signaling theories from corporate finance theory can be applied to farming. The results provide a better understanding of the farm financing decision by inferring that: (a) asset tangibility on the farm balance sheet significantly decreases the costs of financial distress due to easier valuation by lenders, which in turn is beneficial for external financing; (b) internal financing alone is insufficient for farms that are faced with many profitable, i.e. growth-enhancing, investment opportunities, leading to higher leverage ratios for these farms, (c) more profitable farms should prefer internal financing of their investments to achieve a lower leverage ratio and thus avoid the cost of financial distress and the risk of bankruptcy due to higher interest risk, and (d) more volatile farms should lower their leverage ratios since earnings volatility raises the expected costs of financial distress. Increased earnings volatility leads to more investment uncertainty among lenders and outside investors due to an increase in information asymmetry. The affected farms will suffer from adverse selection as external debt financing will force them to allocate a major portion of their retained earnings, if any, to repaying the loan, thus increasing the level of farm financial distress. Following the general idea of the pecking order theory, retained earnings (internal financing) should be the favored form of financing for farms with high earnings volatility. Also note that the results for the determinants of farm capital structure do not seem to follow one single theory, while showing variation across farm types. In addition, I will present findings in the context of the European agricultural policy and market. While extreme price volatility occasionally occurred in world commodity markets, the European market was protected by the prevailing Common Agricultural Policy (CAP). However, since the year 2000, major policy changes in Europe, such as the CAP reforms and trade liberalization, have linked the European agricultural sector to the global market. The results provide a better understanding of capital structure in the farming business in Europe in general and in the Netherlands in particular.

Second, the effects of selected farm characteristics on farm risk-balancing behavior cannot a priori be assumed equal for all farms. Hence, I explicitly model the effects of unobserved heterogeneity using a latent mixture regression model, which classifies farms into segments, in which their risk-balancing response to the selected explanatory variables is identical within each segment but different across segments. This thesis thus offers a greater 
understanding of the interdependence of financial and business risks and the implications for farms and public policy makers while accounting for unobserved heterogeneity in the decisionmaking process.

Third, the thesis extends the application of the sustained competitive advantage framework to the agricultural sector by examining the presence and persistence of long-run farm profitability. Investigating the determinants of long-run farm profitability and presence of profit persistence provides insights for producers and policy-makers by identifying resources to acquire and develop and strategies that producers can use to improve their farm's economic viability. The result should also provide interesting insights into how farm performance has evolved over time.

Fourth, the panel structure of the data and the advancement of the dynamic panel System General Method of Moments (System-GMM) estimator in recent years allow for the disentanglement of the endogeneity issue by explicitly specifying predetermined endogenous variables and using their lag structures as valid instruments. Arellano and Bond (1991) proposed General Methods Moment (GMM) estimation as 'internal' instruments approach. This approach allows for the specification of the endogenous variables and involves first differencing that removes the time-invariant, farm-specific effects. In addition, the use of a dynamic panel model is also crucial as static models fail to capture the dynamics of farm capital structure and performance.

Finally, although the relationships between farm performance, capital structure, and risk management have been the focus of academic research in the field of agricultural economics and finance, most studies have relied on cross-sectional datasets. However, due to the inherently uncertain nature of the agricultural process and the vulnerability of farm business to irregularities caused by uncontrollable factors, longitudinal research is believed to be the proper way to examine the dynamics of farming. This thesis aims to fill the longitudinal information gap by examining a panel of 1500 farms over a 15 year period. In addition, and contrary to previous studies that focus on a single farm type, this thesis considers four farm types: dairy, livestock, field crop, and horticulture farms. As a result, it analyzes a larger 
segment of the farm sector and offers a better understanding of the interdependence between financial and business risks and capital structure and the implications for farm performance.

\subsection{Thesis Organization}

This thesis is organized into five chapters. The first chapter provides a general introduction to the three essays discussed in this dissertation and presented in chapter 2, chapter 3 and chapter 4, respectively. The three essays are related to the general theme of farm business dynamics. These chapters can also stand alone, however, with each topic addressing a different component of the general theme. Chapter two analyses the applicability of corporate finance theories in farm businesses, the determinants of farm target capital structure decisions, and the adjustment speed towards the target capital structure. Chapter three studies the extent and the drivers of risk-balancing behavior at farm level by explicitly accounting for unobserved heterogeneity. Chapter four examines the existence and drivers of long-run farm profitability and abnormal profit persistence (See Figures 1.1 and 1.2). The thesis concludes with final remarks in chapter five. There is a summary of the empirical findings, followed by research implications, and finally, the chapter summarizes the limitations of the thesis and suggests new avenues for future research. 


\section{Chapter-2}

Dynamic Target Capital Structure and Speed of Adjustment in Farm Business 


\section{Chapter Two: Dynamic Target Capital Structure and Speed of Adjustment in Farm Business ${ }^{3}$}

\subsection{Abstract}

This paper quantifies the determinants and speed of adjustment to the target capital structure for a panel of 1500 Dutch farms over the years 2001 to 2015. Using the Blundell and Bond (1998) System-GMM estimator, the results show that farm profitability, earnings volatility, asset tangibility and growth opportunity are important determinants of leverage. Leverage is highly persistent, i.e., the average adjustment speed is relatively slow, with variations among farm types. This variation is mainly attributed to the difference in adjustment costs. Further, we show that the pecking order and signaling theories explain these leverage dynamics.

Keywords: Farm business, System-GMM estimator, speed of adjustment, and target capital structure.

${ }^{3}$ This chapter is published as Aderajew, T. Trujillo-Barrera, A. and Pennings, J.M.E. (2018). Dynamic target capital structure and speed of adjustment in farm business. European Review of Agricultural Economics (https://doi.org/10.1093/erae/jby035) 


\subsection{Introduction}

A question often asked in the literature is whether firms set a target capital structure and adjust to it regularly. Although research in corporate finance has focused on explaining the determinants of target capital structure and speed of adjustment, less attention has been paid to understanding the financing behavior of farm businesses.

The farming business is characterized by a number of specific circumstances, including: (1) dependency on government subsidies to stabilize income (Zhengfei and Oude Lansink, 2006); (2) the seasonal nature of production, leading to mismatches in cash inflow and outflow; (3) different legal forms, whereby sole proprietorship is the predominant form, meaning that debt has a larger disciplinary power when running a farm; and (4) limited access to equity markets. Further, unlike corporate firms that rely on external professional management, farm businesses have a small decision-making unit that consists of the owner or family members. These unique characteristics of the farming sector lead to different patterns of capital structure decision making.

The management of the capital structure influences farm performance in terms of profit, financial risk, and survival. Changes in a farm's production structure affect its capital structure by either tying up capital when farm production capacity increases or freeing up capital when it decreases. Hence, measuring the speed of adjustment is important to understanding the agility of farms in adapting to changing production and finance structures. Farm financing behavior and capital structure decisions also have an important implication for the return and stability of lenders and financial institutions. In 2016, for example, Rabobank, a popular bank among Dutch farmers with nearly 92.3 Billion Euro in outstanding loans to agricultural businesses, announced that one-third of its dairy farm customers were in financial difficulty (CBS, 2017).

It is also relevant to examine whether the existing corporate finance theories (e.g., pecking order and signaling) account for the relationship between target capital structure and the speed of adjustment in the farming business. These theories rely on the assumption that a company has two external financing choices: debt and equity. Note that the pecking 
order theory may not hold in more complex corporate capital structure settings, for example when a firm chooses between straight and convertible debts or, in the event of an agency problem, between a shareholder and a manager (Zhao, Katchova and Barry, 2004). In addition, the presence of many financial tactics and easy access to capital markets make the measurement and identification of the signaling effect difficult in a corporate finance setting. Farm businesses are less prone to these criticisms and provide an interesting background for testing how these corporate finance theories explain capital structure decision making because: (1) often, there are two financing options: retained earnings (internal) and debt (external), (2) the facts that sole proprietorship is the predominant legal form and farms have limited access to the capital market minimize the agency problem, ${ }^{4}$ and (3) farms have very few financial tactics, such as leverage and profit, to use as signals, which makes identification of the signaling effects easier.

In this paper, we analyze the determinants of farm target capital structure decisions, the adjustment speed towards the target capital structure, and examine whether the pecking order and signaling theories help explain farm financing decisions. Few studies have attempted to test the applicability of corporate finance theories to agriculture. Using fiveyear panel data (1990-1994), Barry, Bierlen and Sotomayor (2000) tested whether internal funds are preferred over the use of short and long-term sources of capital (i.e., the applicability of the pecking order theory) and examined whether farms adjust their level of debt, equity, and leasing towards an optimal structure. Zhao, Barry and Katchova (2008) have also shown that farm businesses depend on their size and operation records as financing signals, unlike corporate firms who can choose high leverage as a signaling tool to facilitate investment.

Building on previous literature, particularly extending Barry, Bierlen and Sotomayor (2000), we aim to contribute to the literature in several ways: We present findings in the context of the European policy and market. While extreme price volatility

\footnotetext{
${ }^{4}$ According to Lowder, Skoet and Raney (2016), family farms operate about $75 \%$ of the world's agriculture.
} 
occasionally occurred in world commodity markets, the European market was protected by the prevailing Common Agricultural Policy (CAP). However, since the year 2000, major policy changes in Europe, such as the CAP reforms and trade liberalization, have linked the European agricultural sector to the global market.

We cover the period 2001-2015, which includes the financial crisis of 2007/2008, and we consider four farm types: dairy, field crop, horticulture, and livestock farms, to provide a better understanding of the farming business in Europe in general and the Netherlands in particular. In addition, the period of analysis allows us to examine the capital structure decision-making process during the financial crisis and whether the theories stand the test of time. The panel structure of our data and the advancement of the dynamic panel System General Method of Moments (System-GMM) estimator in recent years enable us to disentangle the endogeneity issue by explicitly specifying predetermined endogenous variables and using their lag structures as valid instruments.

Finally, it is worth noting that most of the empirical studies in the literature ${ }^{5}$ use observed leverage as a proxy for optimal leverage and static capital structure models (Fama and French, 2002; Iliev and Welch, 2010). Using observed leverage instead of optimal leverage is problematic due to the presence of adjustment costs. Static capital structure models cannot capture the dynamic adjustments in leverage ratios (Graham, Leary and Roberts, 2015). Hence, to account for dynamics and adjustment cost in the capital structure, we use a dynamic partial adjustment model.

The remainder of the paper is structured as follows: The next section provides a theoretical review and conceptual framework; Section 3 motivates and explains the empirical strategy, followed by a description of the variables and data used; Section 4 reports our main empirical results, and Section 5 concludes.

\footnotetext{
${ }^{5}$ For a detailed review of the literature, please see Graham and Leary (2011).
} 


\subsection{Theoretical Background}

\subsubsection{Theories of Capital Structure and the Farm Sector}

Different theories ${ }^{6}$ have been used in corporate finance literature to explain firms' capital structure decisions, including the pecking order theory (Myers, 1984; Myers and Majluf, 1984), signaling theory (Ross, 1977), trade-off theory (Miller, 1977), agency theory (Jensen and Meckling, 1976), and market-timing theory (Baker and Wurgler, 2002). Corporate businesses are the focus of the literature; however, farm businesses are fundamentally different from corporations, which results in different decision-making patterns. Hence, few of these theories can be applied directly in an agricultural setting. In this paper, we focus on the pecking order and signaling theories.

The pecking order theory entails that firms have two sources of funding: internal and external. The cost gap between internal and external funds, attributed to asymmetric information and agency costs, makes firms prefer internal to external financing (Frank and Goyal, 2009). Whenever external funding is required, firms will issue debt and convertible bonds before issuing equity. Meanwhile, the signaling theory states that managers have better information about their firm and a motive to transfer this information to potential investors and lenders using signals. These signals include, but are not limited to, investment, profitability, leverage, asset accumulation, and repurchasing of outstanding stocks (Graham, Leary and Roberts, 2015).

Studies on the applicability of these theories in explaining the financing behavior of farm businesses are scant. Barry, Bierlen and Sotomayor (2000) studied the financial structure of farm businesses under imperfect capital markets. They find support for the pecking order theory and report a strong relationship between cash flow and farm debt, whereby a strong cash flow leads crop farms to increase investments, pay off debts, and refrain from additional borrowing. A weak cash flow, on the other hand, is related to lower

\footnotetext{
${ }^{6}$ For a thorough review of theories on capital structure, please see (Graham, Leary and Roberts, 2015).
} 
investments and higher borrowing. Zhao, Katchova and Barry (2004) also examined the applicability of capital structure theories to the farming business. Using cross-sectional time-series data from the Illinois Farm Business Farm Management (FBFM), they have shown that farm businesses rely on their size and operation records as financing signals, unlike corporate firms, which can choose high leverage as a signaling tool to facilitate investment.

Studies in the literature are often cross sectional (Escalante and Barry, 2003; Featherstone et al., 2005; Nurmet, 2011). While cross-section studies are appropriate during periods of stable financial conditions, evidence on the stability of leverage is inconclusive (DeAngelo and Roll, 2015; Lemmon, Roberts and Zender, 2008) and remains largely an empirical question. Further, cross-section studies fail to capture the effects of the business cycle and time-varying farm characteristics on leverage. Farm growth opportunity, for example, is an important leverage determinant, capturing the information asymmetry in the lender-borrower relationship (Zhao, Barry and Katchova, 2008). Growth opportunities are known to vary over the years due to changes in the business cycle and even differences across farm types. In addition, an optimal capital structure decision is a long-term concept with a long-run impact on the survival and success of agricultural firms. As a result, empirical studies using a longitudinal research design are preferred.

\subsubsection{Determinants of Farm Businesses' Capital Structure}

Farm capital structure, defined as the way in which a farm finances its investment through some combination of debt and equity, has been extensively studied over the years. Since farm businesses have limited access to equity markets, leverage is often used as a proxy for farm capital structure. The literature on the determinants of the leverage decisions of farm businesses is wide ranging. Major factors include ownership (Zhengfei and Oude Lansink, 2006), profitability, financing costs (Zhao, Katchova and Barry, 2004), asset tangibility, economies of scale, wealth, risk attitude, adjustment costs (Barry, Bierlen and Sotomayor, 2000), farm risk-management strategies (Katchova, 2005), credit constraints, and government payments (Featherstone et al., 2005). Building on the pecking 
order and signaling theories and on previous literature, we include the following determinants:

Farm profitability: According to the pecking order theory, farms prefer financing new investments out of retained earnings rather than through borrowing; they only issue debt when retained earnings are insufficient (Frank and Goyal, 2009; Graham, Leary and Roberts, 2015). The more profitable the farm, the greater the availability of internal capital should be. Therefore, we expect a negative relationship between profitability and leverage. On the other hand, the signaling theory suggests a positive relationship, since lenders are more willing to lend to profitable farms (Featherstone et al., 2005; Zhao, Barry and Katchova, 2008).

Asset tangibility: Due to the high vulnerability of the agricultural sector to systematic and unsystematic risks, lenders prefer farms with assets as collateral to back up their loans. Tangible fixed assets are pledgeable and easier to liquidate in case of bankruptcy, thereby reducing the cost of financial distress (Chang and Dasgupta, 2009; Halling, Yu and Zechner, 2016). Also, farms with more tangible assets are more recognizable to lenders, leading to less information asymmetry (Getzmann, Lang and Spremann, 2010; Graham and Leary, 2011; Titman and Wessels, 1988). Both the pecking order and signaling theories support a positive relationship between tangibility and leverage.

Farm size: Larger farms are more diversified businesses, which lowers the probability of bankruptcy (Flannery and Rangan, 2006; Heshmati, 2001). Size may also be an indicator of a farm's bargaining power (Graham, Leary and Roberts, 2015) and is considered to be positively correlated to leverage. This relationship lends support to the argument by Frank and Goyal (2009) and Getzmann, Lang and Spremann (2010) that larger farms are easily noticeable, in that lenders have more information about them, and thus have easier access to loans.

Growth opportunities: Farms attempt to signal their positive expectations on investment through high leverage (Zhao, Barry and Katchova, 2008). Lenders provide 
loans based on these signals. This would lead to a positive relationship between growth opportunity and leverage. The pecking order theory, however, suggests that firms rely on retained earnings rather than debt to finance investments (Frank and Goyal, 2007; Graham, Leary and Roberts, 2015). This would imply a negative relationship between farm growth opportunity and leverage.

Risk: A higher variability of earnings increases the risk that farms will be unable to fulfil their interest and principal payment obligations (Barry, Bierlen and Sotomayor, 2000; de Mey et al., 2016). This implies the existence of a negative relationship between leverage and income variability. The signaling theory based on information asymmetry and adverse selection arguments, on the other hand, suggests a positive relationship between leverage and risk, i.e. volatility of earnings, stressing that firms with high income volatility and operational risk tend to be the ones that apply for loans (Flannery and Rangan, 2006; Halling, Yu and Zechner, 2016; Hang et al., 2017). Table 1 summarizes the determinants of target capital structure and the expected relationship based on the pecking order and signaling theories.

Table 2.1: Expected relationships between the determinants of target capital structure and leverage

\begin{tabular}{lll}
\hline Determinant & Pecking order theory & Signaling theory \\
\hline Farm Profit & - & + \\
Asset Tangibility & + & + \\
Farm size & + & + \\
Growth (Investment) Opportunity & - & + \\
Risk (Earnings Volatility) & - & + \\
\hline
\end{tabular}

Macroeconomic factors: there is evidence of the impact of farm-specific factors on capital-structure decisions. Often ignored and less investigated are the possible implications of macroeconomic factors for the target farm's decision making on capital structure (Korajczyk and Levy, 2003). The recent financial crisis of 2008 and the sharp economic recession following the crisis have sparked substantial interest in the link between macroeconomic conditions and financial structure (Halling, Yu and Zechner, 
2016). A literature review reveals that inflation, government debt relative to GDP (Debtto-GDP) and employment level in the industry have a significant impact on capital structure $^{7}$ (Frank and Goyal, 2009). Accordingly, we have included these variables in our model.

\subsubsection{Target Capital Structure and Speed of Adjustment}

In a perfect market, the cost of adjustment would be zero, and adjustment to the target capital structure would be instantaneous (Faulkender et al., 2012; Flannery and Hankins, 2013). The presence of market imperfections, however, such as transaction costs and information asymmetry, causes firms to temporarily deviate from their optimal target leverage (Hüttel, Mußhoff and Odening, 2010).

Frank and Goyal (2007) provided the framework of the target adjustment hypothesis, where the adjustment speed towards the target capital structure depends on two costs: adjustment costs to the target and costs of deviating from the target. When adjustment costs are high, the adjustment speed to the target will be slow. Meanwhile, when the costs of deviating from the target are high, the adjustment speed will be faster (Fischer, Heinkel and Zechner, 1989; Flannery and Rangan, 2006). The incentive to reduce leverage is greater than that to increase leverage, implying an asymmetry in target adjustment, whereby firms would adjust downward faster than upward (Faulkender et al., 2012).

Fama and French (2002) estimated the target leverage adjustment and found that firms tend to adjust to their target slowly. On average, firms close about $15 \%$ of the gap between the actual and target leverage yearly. Conversely, Flannery and Rangan (2006)

\footnotetext{
${ }^{7}$ Note that the policy of the European Commission under the CAP may influence the capital structure of farm businesses in Europe. For example, Jongeneel et al. (2010) analyzed the impact of a 'soft landing' scenario, quota enlargement, free trade agreements and environmental legislation on the overall structural change and financial performance of the Dutch Dairy sector. Their simulation results show that milk production is expected to increase by $11 \%$ after the soft landing and the abolition of the milk quota and that integration into the world market may result in an $8 \%$ decline in the milk price.
} 
reported a much faster speed of adjustment, with an annual reduction of one-third of the difference between the actual and target leverage. They argued that the slower rate reported by previous studies was mainly attributable to the noise in the strategy to estimate the target leverage. Drobetz, Schilling and Schröder (2015) also found a speed of adjustment of about $25 \%$ per year, supporting the economic relevance of dynamics in the capital structure decision. The literature is still inconclusive as to the measurement of annual adjustment speed rates (Graham and Leary, 2011). The measures are usually expressed in terms of the time needed to return to the target capital structure after a shock.

\subsection{Research Design}

\subsubsection{Dynamic Partial Adjustment Model}

Let the leverage ${ }^{8}$ of farm $i$ in period $t$, denoted as Leverage ${ }_{i t}$, be a function of farm-specific $\left(X_{i t}\right)$, macroeconomic $\left(Z_{t}\right)$, and time-specific determinants represented by time dummies $\left(\Gamma_{\mathrm{t}}\right)$ :

Leverage $_{i t}=f\left(X_{i t}, Z_{t}, \Gamma_{t}\right)$

In a frictionless economy, the observed leverage of farm i at time $t$, Leverage $_{i t}$, should be the target leverage, Leverage ${ }_{\text {it }}\left(\right.$ Leverage $_{i t}=$ Leverage $\left._{i t}^{*}\right)$. However, Titman and Wessels (1988) and Fischer, Heinkel and Zechner (1989) show that transaction costs are important determinants of a capital structure decision. Even after an active capital structure adjustment, the presence of convex or proportional transaction costs makes reaching the target leverage impossible or suboptimal (Halling, Yu and Zechner, 2016). Adjustment to the target occurs gradually over time, depending on the trade-off between

\footnotetext{
${ }^{8}$ We calculated leverage as total farm debt divided by total assets. We opt to use the ratio variable because it makes comparing farm leverage between farm types easier. Also, dividing total farm debt by the total assets, allows us to eliminate the differences in farm size. To obtain a more accurate reflection of farm total assets, we take the average total asset as a denominator, i.e. the average of the opening total assets at the beginning of the accounting period and closing total assets at the end of the accounting period.
} 
not operating at target leverage and the costs of adjustment towards the target (Leary and Roberts, 2005). This trade-off suggests that farms adjust their current leverage with a certain speed of adjustment, $\lambda$ to attain the desired target leverage, expressed as:

Leverage $_{i t}-$ Leverage $_{i t-1}=\lambda\left(\right.$ Leverage $_{i t}^{*}-$ Leverag $\left._{i t-1}\right)$

Leverage $_{i t-1}$ is a lagged leverage variable, included to construct a dynamic specification that allows for the potential effect of the autoregressive (AR) process and adjustment costs (Byoun, 2008), $\lambda_{\mathrm{it}}$ represents the rate of convergence of Leverage ${ }_{i t}$ to Leverage $^{*}{ }_{i t}$ or the magnitude of the adjustments between two subsequent periods. Hence, the change in leverage depends on the speed of adjustment and the distance between lagged leverage (Leverage $\left.{ }_{i t-1}\right)$ and target leverage $\left(\right.$ Leverage $\left.{ }_{i t}\right)$.

The existence of adjustment costs is represented by the restriction that $|\lambda|<1$, which is the condition that Leverage ${ }_{i t}$ converges to Leverage ${ }_{i t}$ as $t \rightarrow \infty$. A $|\lambda|=1$, indicates an immediate and full correction of deviations from the target farm leverage in one period. The case of $\lambda<1$ implies that the farm does not fully adjust from period $t-1$ to $t$. If $\lambda>1$, the farm adjusts more than required and is still not at its target leverage level. Finally, a $\lambda=0$ shows the absence of adjustment, i.e. the random leverage hypothesis.

In the absence of adjustment costs, the inferred relationship will suffer from specification error if the observed farm leverage is regressed on the determinants of target capital structure alone (Heshmati, 2001). In order to avoid a misspecification error, equation (2.2) can be rewritten as:

$$
\text { Leverage }_{i t}=(1-\lambda) \text { Leverage }_{i t-1}+\lambda \text { Leverage }_{i t}^{*}+\varepsilon_{i t}
$$

Rewriting equation (2.3) and substituting equation (2.1) results in the following relationship for farm leverage at time $t$ :

$$
\text { Leverage }_{\mathrm{it}}=(1-\lambda) \text { Leverage }_{\mathrm{it}-1}+\lambda\left(\sum_{\mathrm{jmn}} \beta_{\mathrm{j}} \mathrm{X}_{\mathrm{it}}+\gamma_{m} \mathrm{Z}_{\mathrm{it}}+\Delta_{\mathrm{n}} \Gamma_{t}\right)+\varepsilon_{\mathrm{it}}
$$


Farm leverage is modelled as a linear combination of farm-specific, macroeconomic, and year-specific factors. Including this relation, multiplying out, rearranging, and simplifying equation (2.4), we specify equation $(2.5)^{9}$, which is the integrated dynamic partial adjustment mode ${ }^{10}$ and the basis of our empirical investigation:

$$
\begin{aligned}
\text { Leverage }_{i t}= & \alpha+(1-\lambda) \text { Leverage }_{i t-1}+\beta_{1} \text { Tangibility }_{i t}+\beta_{2} \text { Size }_{i t} \\
& +\beta_{3} \text { Profitability }_{i t}+\beta_{4} \text { Growth }_{i t}+\beta_{5} \text { Risk }_{i t}+\gamma_{6} \text { Debt }- \text { to }- \text { GDP }_{t} \\
& +\gamma_{7} \text { Inflation }_{t}+\gamma_{8} \text { Employment }_{t}+\Gamma_{t}+\varepsilon_{i t}
\end{aligned}
$$

Where, the variables in equation (2.5) were defined in section $2.2, \varepsilon_{\mathrm{it}}$ is the error term, which consists of individual effect $\left(\mu_{i}\right)$ and disturbance $\left(v_{i t}\right)$, while $\beta \gamma, \Gamma$, and $\alpha$ are parameters to be estimated.

When estimating equation (2.5) with a short time-series panel, we have a dynamic panel bias or "Nickell bias" (Nickell, 1981) where the coefficient of the lagged dependent variable is biased towards zero ${ }^{11}$. In addition, in equation (2.5), we suspect that some of

\footnotetext{
${ }^{9}$ In this paper, we assume the speed of adjustment to be constant over time. To allow the speed of adjustment to vary over time, one can specify it as a function of farm characteristics. Doing so, however, has two major implications for the dynamics of leverage and statistical inference (Flannery and Rangan, 2006). Firstly, if not restricted to a constant speed, the adjustment parameter may be positive in one period (a farm adjusts its leverage away from the target), negative in the next (a farm adjusts its leverage towards the target), and zero in another (a farm ignores the target). This behavior is inconsistent with the assumptions that farms make financing decisions according to the pecking order and signaling theories outlined in the introduction section. Secondly, allowing the speed of adjustment to vary over time complicates the statistical inference. The parameter is highly sensitive to whether or not the process is stationary, and requires mean reversion tests. Since one has to specify the period in which mean reversion is being tested, and the adjustment parameter is unique for each farm and time period, in that we only observed it only once in one year for each farm, any mean reversion test will have little power. Hence, we assume a constant speed of adjustment.

${ }^{10}$ A similar model is used by Banerjee, Heshmati and Wihlborg (1999) to test the dynamics of capital structure in panels of U.K. and US companies. Getzmann, Lang and Spremann (2010) also used the earlier version of the model to investigate the determinants of the target capital structure and adjustment speed in Asian capital markets. See Chang and Dasgupta (2009) and Iliev and Welch (2010) for a discussion of the partial adjustment model.

${ }^{11}$ Nickell (1981) shows that the demeaning process which subtracts the individual's mean value of $y$ and each $X$ from the respective variable creates a correlation between the regressor and error term. The mean of the lagged dependent variable contains observations 0 through $(T-1)$ on $y$, and the mean error, which is being subtracted from each, $\varepsilon_{i t}$ contains contemporaneous values of $\varepsilon$ for $t=1 \ldots . T$. The resulting correlation creates a bias in the estimate of the coefficient of the lagged dependent variable.
} 
the explanatory variables are potentially endogenous ${ }^{12}$. One solution to this problem involves taking first differences of the original model.

Arellano and Bond (1991) proposed a Difference General Methods Moment (Difference GMM) in which regression equations are expressed in terms of their first difference and endogenous variables are instrumented using lags of their own levels. It allows specifying the endogenous variables and involves first differencing that removes the time-invariant farm-specific effects.

This approach has limitations, however, as the lagged levels may be weakly correlated with first differences. Notably, this bias is not eliminated by using fixed-effects estimators since the regressors and the error term continue to be correlated after such a transformation. This is particularly the case when the lagged levels used as instruments are highly persistent (Bun and Windmeijer, 2010 and Roodman, 2015).

To address this limitation, Arellano and Bover (1995) developed an improved estimator known as the 'Level GMM', in which regressions are expressed in levels and endogenous instruments in terms of their lagged differences. Finally, Blundell and Bond (1998) combined both approaches to construct a system of equations known as the 'System

\footnotetext{
${ }^{12}$ While this paper deals with the effect of profitability on a farm's capital structure, a farm's choice of capital structure may, conversely, also affect its profitability. Both directions of causality are thus possible: increased leverage can positively or negatively affect farm profitability, but leverage can also be affected by profitability. On the one hand, highly leveraged farms may suffer from financial distress, face conflicts of interest between the owners and creditors and incur bankruptcy cost, thus decreasing their profitability. On the other hand, the impact of profitability on leverage is described by the pecking order and signaling theories, each providing a different explanation. The pecking order theory hypothesizes that higher profitability results in higher retained earnings and that farms prefer to use these retained earnings to finance their investments rather than issue debt. As such, this theory suggests a negative relationship between profit and leverage. The signaling theory, however, holds that higher profitability often reduces the bankruptcy cost of a farm. In addition, farms that perform well can usually project higher expected returns. Both these relationships send a positive signal and lenders are more willing to provide loans to more profitable farms. Contrary to the pecking order theory, the signaling theory thus suggests a positive relationship between profit and leverage.
} 
GMM'. It combines the sets of moments from the difference and level equations into instrument-endogenous variables.

The System GMM is particularly suitable for this study because: (a) it has better asymptotic and finite sample properties than the Difference GMM; (b) it uses difference equations for instrument endogenous regressors, so that they are also able to handle timeinvariant farm-specific attributes, e.g. heterogeneity and endogeneity; and (c) it is wellsuited to datasets with large numbers of cross-sections, $\mathrm{N}$, and small numbers of available periods, $\mathrm{T}$.

Nevertheless, the System GMM estimator has limitations too. It requires orthogonality between the lagged levels of the variables used as instruments and the differences of the error terms and, simultaneously, orthogonality between farm-specific effects and the lagged difference of the variables used as instruments. Hence, a specification test on over-identifying restrictions is required to check the validity of the additional instruments (Flannery and Hankins, 2013; Roodman, 2015).

\subsection{Data and Descriptive Statistics}

This paper has benefited from a unique longitudinal data set of Dutch farms that have been participating in the Farm Accountancy Data Network (FADN). After the USA, the Netherlands is the second largest exporter of agricultural products (Berkhout, 2017). The Dutch agriculture sector accounts for $2 \%$ of the country's economy, $20 \%$ of the country's total export value, and $2.5 \%$ of employment. It is further characterized by highly educated farmers, large-scale and capital-intensive farming, export orientation, increasing input and output-price volatility, and an orientation towards sustainability (Berkhout and van Bruchem, 2015; van der Meer, van der Veen and Vrolijk, 2013). 
The Dutch FADN samples are randomly selected using the disproportional stratified random sampling ${ }^{13}$ technique from the farm census. Economic size and farm type are the stratification criteria used to select farms. The data we use in this paper are unique in that: (a) they constitute the sole source of farm-level (microeconomic) data across more than fifteen years; (b) the samples are representative of $80 \%$ of the farms and more than $90 \%$ of production in the Netherlands; and (c) they allow for separate estimation of farm types for comparison purposes thanks to the harmonized data-collection procedure ${ }^{14}$. The World Bank provided us with the macroeconomic data on inflation, government debt-toGDP ratio and employment in the industry.

The panel is unbalanced and covers the period from 2001 - 2015. We use the following filters for including a farm in the analysis: first, a farm must have a non-zero debt, as farm target leverage and adjustment will not occur without liabilities. Second, given the problem with calculating the coefficient of variation, farm observations with a negative ROA are excluded. Third, given the lag structure of our model, farms need to remain in the sample for at least four years. Finally, to address outlier concerns, extreme values in the dataset are dealt with by dropping the top and bottom $0.5 \%$ observations of the variable from the analysis. These criteria reduced the total number of farms included in this study to 1,339 , i.e. 89 percent of the original number. Table 2.2 presents the definitions of the variables used in the empirical analysis and summary statistics of Dutch farms.

\footnotetext{
13 Stratified random sampling implies that the whole farm population is divided into groups (strata). Subsequently, farms are selected from each of the groups. This ensures the inclusion of farms from all groups with different characteristics. Disproportional sampling means that not all farms have the same chance of being included in the sample. Farms in relatively homogenous groups have smaller chances as a limited number of observations would be sufficient to draw a reliable conclusion. The chance of being included is higher for farms in less homogenous groups, which allows for the proper representation of all groups. For details of the Dutch FADN sampling procedure, we refer to van der Meer, van der Veen and Vrolijk (2013).

${ }^{14}$ The bookkeeping principles and sample selection plans are identical for all farm types in the Netherlands and similar to those of other European countries participating in the FADN.
} 
Table 2.2: Variables and summary statistics of Dutch farms, 2001-2015

\begin{tabular}{llcccc}
\hline Variable & \multicolumn{1}{c}{ Explanation } & Obs. & Mean & Median & SD \\
\hline Leverage & The total debt to total assets ratio ${ }^{16}$ & 15,682 & 0.363 & 0.322 & 0.289 \\
\multicolumn{1}{c}{ Dairy Farms } & & 4,101 & 0.274 & 0.267 & 0.163 \\
\multicolumn{1}{c}{ Field Crop } & & 2,695 & 0.253 & 0.221 & 0.204 \\
\multicolumn{1}{c}{ Horticulture } & & 5,136 & 0.457 & 0.413 & 0.375 \\
\multicolumn{1}{c}{ Livestock } & & 3,750 & 0.414 & 0.408 & 0.259 \\
Asset Tangibility & The fixed asset to total assets ratio & 15,682 & 0.709 & 0.740 & 0.172 \\
Farm Size & The natural log of total assets & 15,682 & 14.567 & 14.591 & 0.847 \\
Profit (ROA) & Ratio of net farm income ${ }^{17}$ to total & & & 0.021 & 0.091 \\
Growth Opportunity & The total investment to total assets ratio & 15,682 & 0.043 & 0.017 & 0.078 \\
Earnings Volatility & The standard deviation of ROA & 14,076 & 0.0423 & 0.0197 & 0.0713 \\
Debt-to-GDP & Government debt to GDP percentage & 15,682 & 56.300 & 55.10 & 10.294 \\
Inflation & Inflation percentage & 15,682 & 1.884 & 1.70 & 0.874 \\
Employment ${ }^{18}$ & Employment ratio in the industry & 15,682 & 2.490 & 2.50 & 0.369 \\
\hline
\end{tabular}

We note that the average farm leverage ratio for all farms is $36.3 \%$ over the 2001-15 period. The average leverage for dairy, field crop, horticulture, and livestock farms is $27.4 \%, 25.3 \%, 45.7 \%$, and $41.4 \%$ respectively, with horticulture scoring the highest. Farms earn a $2.53 \%$ profit on average. Figure 2.1 shows the variation in leverage over the years across the four farm types ${ }^{19}$.

General observation reveals that the average leverage ratio for dairy and livestock farms shows a gradual increase over the years. The increased borrowing among Dutch dairy farms may be due to the heavy investments required to comply with

\footnotetext{
${ }^{16}$ Depreciation and changes in market value have been taken into consideration in calculating the value of assets.

${ }^{17}$ We calculate Net Farm Income (NFI) using the FADN principle as Net Farm Income=Operating Receipts -Intermediate Costs- Depreciation+ Balance of Subsidies and Tax-Wages-Rent. Note that in the profit variable, the interest payment is added back to the NFI calculation to account for differences in farm capital structure.

${ }^{18}$ Employment is the ratio of employment in the agricultural sector relative to employment in all other industries in the Netherlands for each year.

${ }^{19}$ We followed the Dutch FADN sampling principle to categorize farms into four types. For a detailed explanation of farm categorization, we refer to van der Meer, van der Veen and Vrolijk (2013).
} 
obligatory manure processing in 2014 and the scale increases prior to the abolition of the milk quotas on 1 April, 2015 (Jongeneel et al., 2010). The farm leverage ratio of horticulture farms reached its peak in 2011 and 2012, when the cold spring weather sparked the need for extra cash to cover the higher energy bills (Berkhout and van Bruchem, 2015).
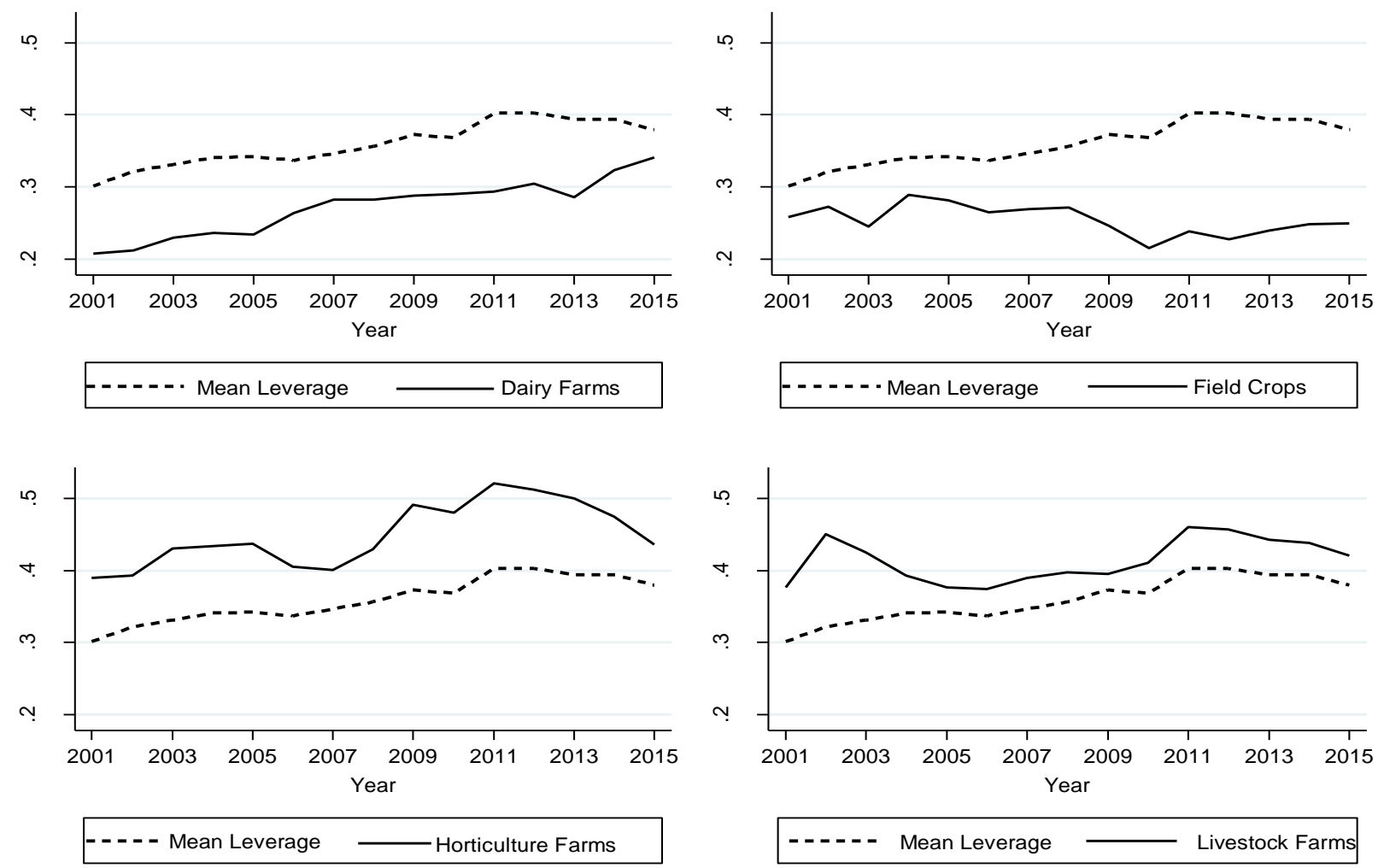

\section{Figure 2.1: Farm leverage by farm type, 2001-2015}

Interestingly, the increasing trend in the leverage ratios of dairy and livestock farms supports the notion that neither the changes in farm-specific characteristics nor the relationship between these characteristics and leverage alone are able to explain the increase. A change in major macroeconomic and financial policies is also relevant in explaining the existing capital structure, as well as the observed shifts in leverage ratio over the years (Graham, Leary and Roberts, 2015). Figure 2.2 shows the variation in profitability over the years across the four farm types.

Note that horticulture farms exhibited a relatively stable growth in profitability compared to other farm types since the year 2011. This is largely attributed to poor 
production figures in Southern Europe during the summer months after the financial crisis (Berkhout and van Bruchem, 2015). The increase in the profit levels of horticulture farms asserts the economic significance of the profit variable on leverage ratio. The next section presents the empirical results.
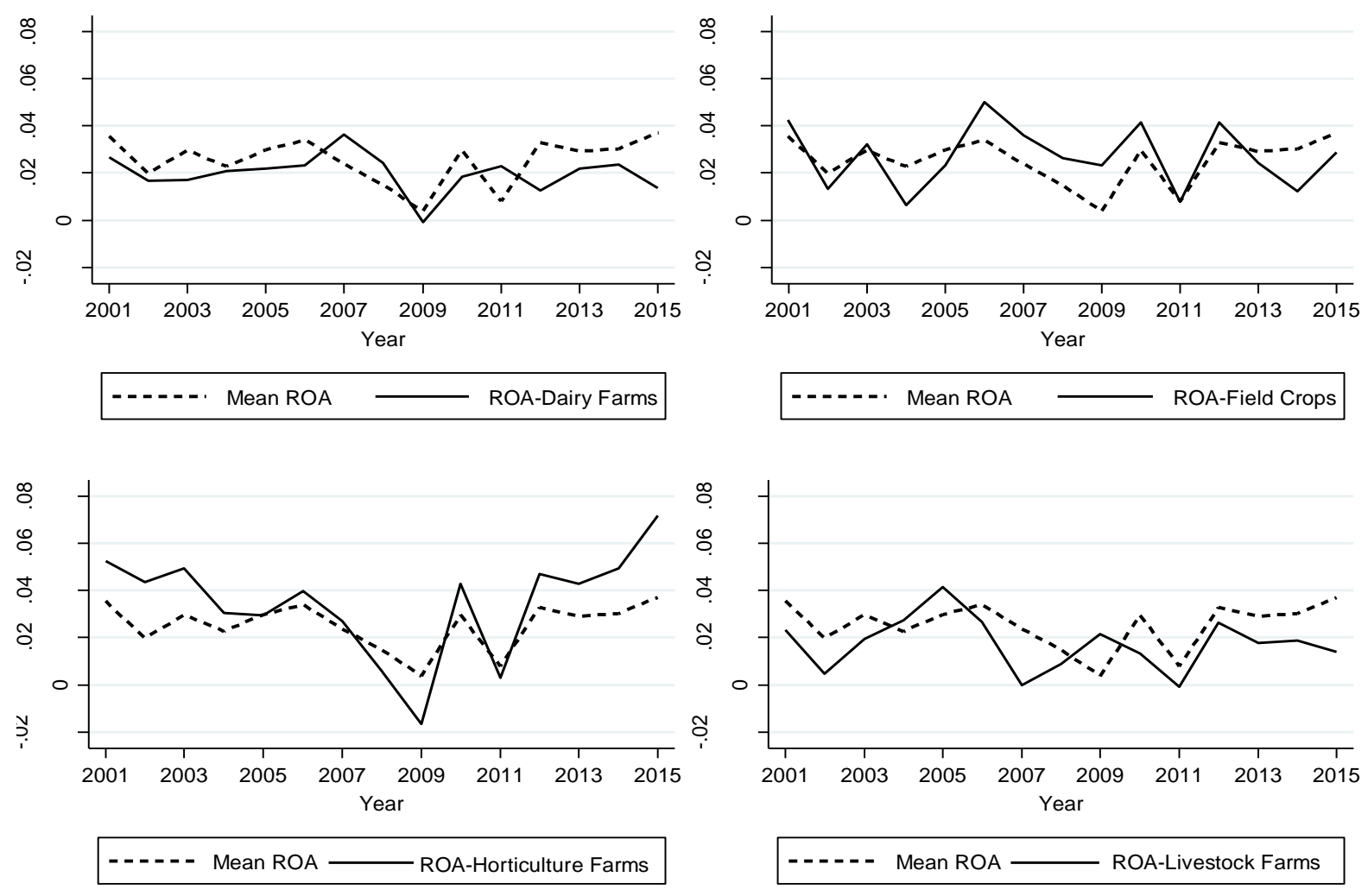

Figure 2.2: Farm profitability by farm type, 2001-2015

\subsection{Results}

We start by establishing stylized facts about the determinants of farm target leverage. Most importantly, however, we address the question whether or not the pecking order and signaling theories of corporate finance can explain the financing behavior of farm businesses. In the next step, we analyze the dynamics of farm leverage and the speed of adjustment to the target. The last section summarizes the results from splitting our sample according to size, growth opportunities, and year. 


\subsubsection{Determinants of Target Capital Structure}

Table 2.3 shows estimates of the System GMM based on the empirical model discussed in Section 2.4.1. The Sargan test of over-identifying restrictions suggests that the instruments used in the System GMM are valid.

Table 2.3: Dynamic Panel model estimation result (Dependent Variable: Leverage $i t)$

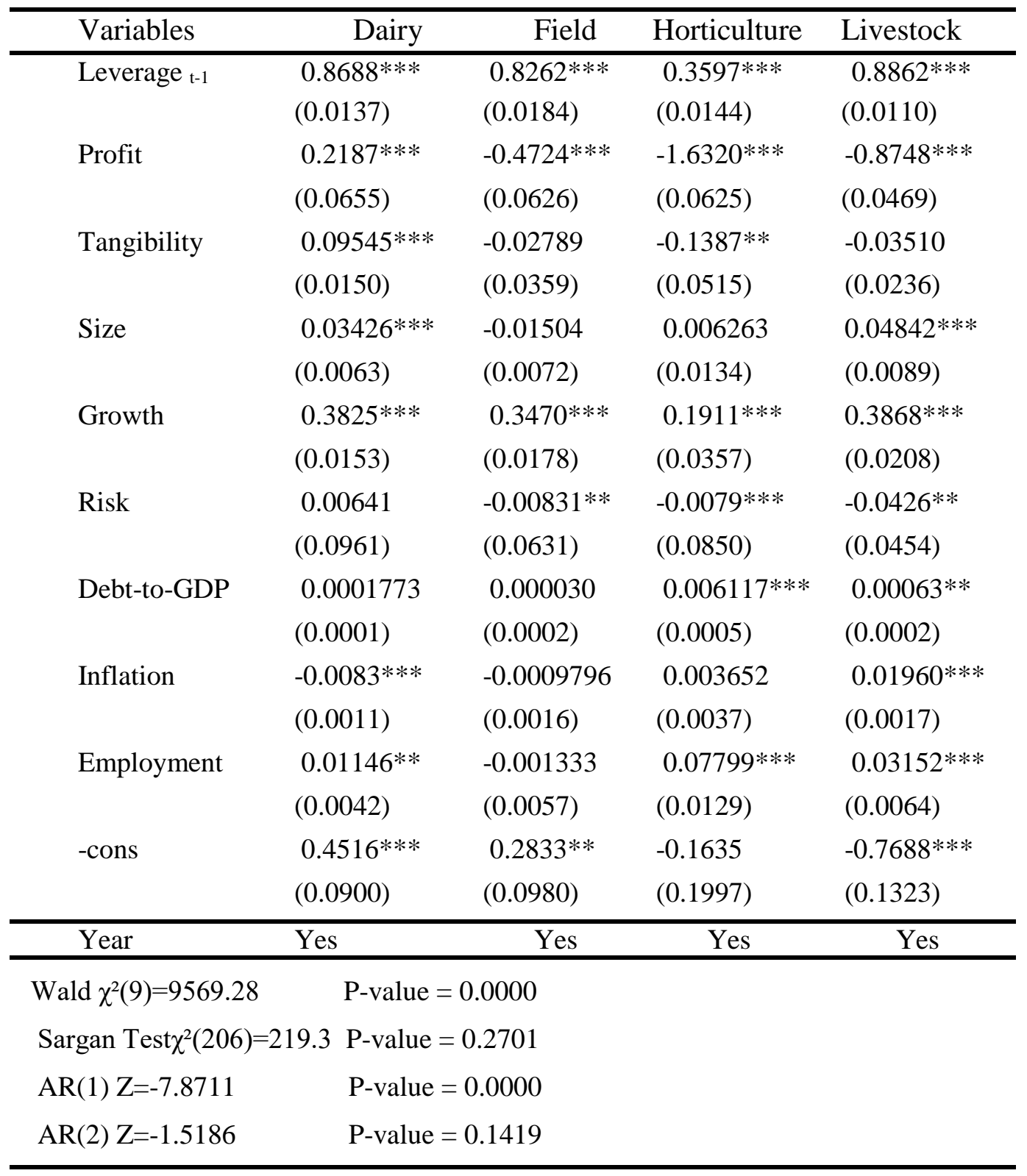

Notes: Numbers in parentheses are robust standard errors, and $* * *$ and $* *$ are significant at the $1 \%$ and $5 \%$ levels respectively. The dummy reference level is the year 2001 . 
The Wald test is significant at the $1 \%$ level for all farm types, ensuring the significance of the right-hand-side variables. The AR (2) test implies that there is no serial correlation. These results indicate that the key identifying assumptions required for the System-GMM estimator are satisfied.

Results in Table 2.3 show a significant and negative relationship between farm profit and leverage for all farm types except dairy farms. These results lend support to the applicability of the pecking order theory, in that other factors remain constant, the high profit earned by farms reduces the need for external funding, and hence more profitable farms should be less leveraged over time. Similar results were reported by Barry, Bierlen and Sotomayor (2000), Zhao, Katchova and Barry (2004) and Frank and Goyal (2003). Nevertheless, the estimates show a positive and significant relationship for dairy farms.

Dutch dairy farms are the most regulated farm type and are subject to frequent policy changes, such as obligatory manure processing and the abolition of the milk quota system (Boere et al., 2015; Jongeneel et al., 2010; Samson, Gardebroek and Jongeneel, 2017). These regulations and policy changes may increase the need for cash, either to comply with the regulations or to expand to meet the expected increase in milk demand after the abolition of the quota. There is a marked difference in the size of the coefficients of profitability, implying different degrees of economic significance of profitability on farm leverage. The negative coefficient, in absolute terms, is the largest for horticulture farms, followed by livestock farms.

The estimated relationship between asset tangibility and leverage is significant and positive for dairy farms. This is consistent with signaling theory, which holds that tangible assets are more valuable to creditors, should farms go into liquidation. The result also supports the importance of tangible assets as collateral for debt financing in the agriculture business. The structure of the Dutch dairy sector has changed significantly in recent years. Compared to the year 2000, the total number of farms had decreased by $29 \%$ to 16,500 in 2016 , while average farm size had increased by $47 \%$ to 
56 ha (CBS, 2017). This structural change, combined with the increase in land value over the years, sends a positive signal to lenders. These findings are also consistent with the existence of a supply effect, whereby lenders might put more emphasis on asset tangibility in loan approval when loan requests are high. Also, larger farms are known to be less exposed to bankruptcy risk and hence are likely to receive more loans from lenders (Frank and Goyal, 2007). Consistent with this argument, farm leverage is positively related to size for horticulture and livestock farms.

The significant and positive relationship between growth (investment) opportunity and leverage for all farm types provides further evidence of the applicability of the signaling theory. The theory suggests that farms with more investment or growth opportunities borrow more over time. Farms with substantial growth rates can afford more financial leverage since they can generate enough earnings to offset the additional interest expenses. Similar findings were reported by Barry, Bierlen and Sotomayor (2000).

The estimated relationship between risk (earnings volatility) and leverage is significant and negative for all farms but dairy farms. This result provides evidence of the applicability of the pecking order theory, which assumes that the probability of financial distress increases and a farm's debt repayment capacity decreases with rising earnings volatility, resulting in a negative relationship between leverage and risk.

Compared to the farm-specific effects, the macroeconomic factors have a less economically significant effect on the capital structure decision. The government debtto- GDP ratio has a significant and positive effect on leverage for horticulture and livestock farms. Mixed results are found regarding the relationship between inflation and farm leverage ratio. The positive and significant coefficient estimates for horticulture and livestock farms are consistent with the fact that inflation makes the real cost of borrowing cheaper, thereby encouraging farms to issue more debt. Lastly, we find a significant coefficient showing a positive relationship between employment in the industry and farm leverage for dairy, horticulture, and livestock farms. Table 2.4 
summarizes the results as to which theory better explains the capital structure decisionmaking pattern of each of the farm types.

Table 2.4: Farm capital structure and the pecking order and Signaling theories

\begin{tabular}{lllll}
\hline Determinants $^{20}$ & Dairy Farms & Field Crop & Horticulture & Livestock \\
\hline Farm Profit & $+\mathrm{ST})$ & $-(\mathrm{PO})$ & $-(\mathrm{PO})$ & $-(\mathrm{PO})$ \\
Asset Tangibility & $+(\mathrm{ST}$ and PO) & $\mathrm{NS}$ & $\mathrm{NS}$ & NS \\
Farm size & $+(\mathrm{PO}$ and ST $)$ & $\mathrm{NS}$ & $\mathrm{NS}$ & $+(\mathrm{PO}$ and ST $)$ \\
Growth Opportunity & $+(\mathrm{ST})$ & $+(\mathrm{ST})$ & $+(\mathrm{ST})$ & $+(\mathrm{ST})$ \\
Risk & $\mathrm{NS}$ & $-(\mathrm{PO})$ & $-(\mathrm{PO})$ & $-(\mathrm{PO})$ \\
\hline
\end{tabular}

Notes: PO, ST, and NS stand for Pecking Order theory, Signaling theory, and Not Supported, respectively

\subsubsection{Adjustment Speed}

The first row of Table 2.3 reports the estimated coefficients of the lagged leverage, which are significant and positive at the $1 \%$ level for all farm types. The results are consistent with the findings reported by Frank and Goyal (2009). The coefficients are between zero and one, implying that farm leverage ratio converges to the target level over time. This also confirms the presence of dynamics in the farm capital structure decision.

We infer from the estimated lagged leverage coefficient values of 0.8688 , 0.8262, 0.3597, and 0.8862, for dairy, field crop, horticulture, and livestock farms, respectively, that farms adjust leverage towards the target. The adjustment speed is

\footnotetext{
${ }^{20}$ Please note that we are not defining the signaling and pecking order theories as the opposite signs for each variable in Table 2.4. These theories may, nevertheless, provide alternative explanations for the impact of the same variable on farm leverage. When considering farm profitability, for instance, the signaling theory holds that farm profit sends a positive signal to lenders to provide more loans. This would lead to a positive relationship between profitability and leverage, which is indeed the case for the dairy farms in our study (see Table 2.3). The pecking order theory, on the other hand, suggests that higher profit is associated with less borrowing because high profits reduce the need for external funding, in that farms rely on retained earnings rather than debt to finance investments. This would imply a negative relationship between farm profitability and leverage, which is indeed the case for field crop, horticulture, and livestock farms. In these cases, the theories offer opposing explanations of the same variable. We only seek to examine which theory better captures the existing capital structures of the four farm types considered.
} 
$13.12 \%(1-\lambda)$ per year for dairy farms, $17.38 \%$ for field crop farms, $64.03 \%$ for horticulture farms, and $11.38 \%$ for livestock farms.

This speed of adjustment corresponds to a half-life ${ }^{21}$ of leverage shocks of about 4.9, 3.6, 0.67, and 5.7 years for dairy, filed crops, horticulture and livestock farms, respectively. Compared to findings in other industries, the adjustment speed of Dutch farms is slow, with the exception of horticulture farms. Frank and Goyal (2003), for instance, report an adjustment speed of around 25\% for US publicly - listed companies.

The slow adjustment to the target leverage is mainly attributed to high adjustment costs. Two factors might explain the high adjustment costs of Dutch farm businesses. First, it is not easy for farm businesses to gain access to loans. There are only a few financial institutions in the Netherlands that specialize in agricultural financing (CBS, 2017). Second, compared to corporations, farm businesses are small and medium in size. Hence there is an adverse selection issue as a result of information asymmetry, which makes adjustments costly. The high adjustment speed of horticulture farms could indicate the ease with which horticulture farms have been able to acquire financing through debt and lower the adjustment cost.

All in all, the less significant impact of macroeconomic factors, both in sign and magnitude, suggests that farm-specific factors are the core determinants of the target capital structure decision. We perform a separate analysis excluding the macroeconomic factors to further substantiate our conclusion. The result is reported in Table 2.6 of the Appendix section. We found that size has a negative and significant relationship with leverage, suggesting that larger farms are able to retain their profit rather than rely on external financing.

\footnotetext{
${ }^{21}$ For example, the $\lambda$ estimate in Table 2.3 for dairy farms is 0.8688 , which means that a typical dairy farm closes about $13.12 \%(1-\lambda)$ of the gap between its current level of leverage and its target in one year. At this rate, it takes approximately 4.9 years for the farm to close half of the gap between the current and target leverage.
} 


\subsection{Farm Size, Growth Opportunity, and Financial Crisis}

We split the sample and re-estimated our model to examine whether our findings were robust to differences in size classes, growth opportunities ${ }^{\mathbf{2 2}}$, and sample year. Table 2.5 shows the results.

Table 2.5: Dynamic panel data estimation results (Dependent Variable: Leverage $i t)$

\begin{tabular}{|c|c|c|c|c|c|c|}
\hline & \multicolumn{2}{|c|}{ Farm Size } & \multicolumn{2}{|c|}{ Growth Opportunity } & \multicolumn{2}{|c|}{ Sample Year } \\
\hline Variables & Large & Small & High & Low & $2001-2007$ & $2008-2015$ \\
\hline \multirow[t]{2}{*}{ Leverage $_{t-1}$} & $0.1740 * * *$ & $0.9339 * * *$ & $0.7277 * * *$ & $0.987 * * *$ & $0.8309 * * *$ & $0.4571 * * *$ \\
\hline & $(0.0193)$ & $(0.0303)$ & $(0.0233)$ & $(0.0136)$ & $(0.0187)$ & $(0.0095)$ \\
\hline \multirow[t]{2}{*}{ Profit } & $-1.1989 * *$ & $-0.8310 * * *$ & $-0.7822 * * *$ & $-1.405 * * *$ & $-0.8614 * * *$ & $-1.4673 * * *$ \\
\hline & $(0.7640)$ & $(0.0492)$ & $(0.0621)$ & $(0.4748)$ & $(0.1080)$ & $(0.0462)$ \\
\hline \multirow[t]{2}{*}{ Tangibility } & 0.0809 & $-0.1487 * *$ & $-0.1905 * * *$ & $-0.5210 * *$ & -0.0425 & -0.0763 \\
\hline & $(0.0583)$ & $(0.0253)$ & $(0.0259)$ & $(0.0323)$ & $(0.0303)$ & $(0.0249)$ \\
\hline \multirow[t]{2}{*}{ Size } & -- & -- & $0.0425 * * *$ & $-0.1397 * *$ & $-0.0575 * * *$ & $0.0476^{* *}$ \\
\hline & --- & --- & $(0.0083)$ & $(0.0109)$ & $(0.0084)$ & $(0.0931)$ \\
\hline \multirow[t]{2}{*}{ Growth } & $0.3022 * * *$ & $0.3506 * * *$ & --- & --- & $0.4006^{* * *}$ & $0.2513 * *$ \\
\hline & $(0.0387)$ & $(0.0184)$ & --- & -- & $(0.0192)$ & $(0.0188)$ \\
\hline \multirow[t]{2}{*}{ Risk } & $-0.3828 * * *$ & $-0.1954 * *$ & 0.04692 & $-0.661 * * *$ & $-0.1061 * *$ & $-0.5694 * * *$ \\
\hline & $(0.01039)$ & $(0.04257)$ & $(0.0553)$ & $(0.0648)$ & $(0.0503)$ & $(0.0589)$ \\
\hline \multirow[t]{2}{*}{ D-Field } & -0.2101 & -0.0100 & $0.0501 * * *$ & $0.0598 * *$ & 0.0133 & $0.0614 * * *$ \\
\hline & $(0.0561)$ & $(0.0189)$ & $(0.0157)$ & $(0.0220)$ & $(0.0171)$ & $(0.0161)$ \\
\hline \multirow[t]{2}{*}{ D-Horticulture } & 0.1625 & $0.06022 * *$ & $0.03831 * *$ & $0.1476^{* *}$ & 0.01657 & $0.2319 * * *$ \\
\hline & $(0.0481)$ & $(0.01622)$ & $(0.01652)$ & $(0.0220)$ & $(0.0191)$ & $(0.0135)$ \\
\hline \multirow[t]{2}{*}{ D-Livestock } & $-0.1765 * *$ & -0.0603 & 0.2193 & $-0.0614 * *$ & 0.01745 & $0.1094 * *$ \\
\hline & $(0.0704)$ & $(0.0136)$ & $(0.0145)$ & $(0.1583)$ & $(0.0137)$ & $(0.0130)$ \\
\hline \multirow[t]{2}{*}{-cons } & 3.4859 & 0.1502 & -0.4073 & $2.357 * * *$ & $0.9093 * * *$ & $0.6495 * * *$ \\
\hline & $(0.2987)$ & $(0.1344)$ & $(0.1246)$ & $(0.1591)$ & $(0.1274)$ & $(0.1339)$ \\
\hline Year & Yes & Yes & Yes & Yes & $\mathrm{NO}$ & $\mathrm{NO}$ \\
\hline Wald (p-value) & $\chi^{2}(9)=1090$ & 0.0000 & $\chi^{2}(9)=3712$ & 0.0000 & $\chi^{2}(9)=448$ & 0.0000 \\
\hline AR-1 (P-value) & $Z=-6.1653$ & 0.0000 & $Z=-4.1325$ & 0.0000 & $Z=-2.3491$ & 0.0186 \\
\hline AR-2 (P-value) & $Z=-1.5142$ & 0.1230 & $Z=-1.5582$ & 0.1192 & $Z=-0.5169$ & 0.6052 \\
\hline
\end{tabular}

Notes: Numbers in parentheses are robust standard errors, and $* * *$ and $* *$ are significant at the $1 \%$ and 5\% levels respectively. The dummy reference levels are dairy farms and the year 2001 .

\footnotetext{
${ }^{22}$ The top and bottom $25 \%$ of farms in terms of total annual output and investment are grouped as large and small and high and low growth-opportunity farms, respectively.
} 
Although the profitability variable has a similar impact on small and large farms, its magnitude is higher for large farms. In addition, the speed of adjustment is much higher for large than for small farms, asserting the applicability of the pecking order and signaling theories in explaining farm businesses' capital structure decisions; it holds that creditors prefer larger, more visible farms. According to the pecking order theory, size provides bargaining power for larger farms, which will reduce the cost of adjustment and thus lead to faster adjustment to the target. Frank and Goyal (2003) also confirm that the pecking order theory is a better descriptor of the behavior of large firms compared to small ones because large firms usually face relatively lower costs of adverse selection than smaller firms when considering the possibility of a risky or mispriced debt.

We also split the sample into sub-samples ${ }^{23}$ based on growth opportunities. The results in Table 2.5 show that farms in the lowest and highest growth-opportunity brackets are similarly affected by farm-specific factors. Only the leverage ratio of highgrowth farms is significantly and negatively affected by the tangibility of their assets. We also find that profitability has a negative impact on target leverage, that size is used as a dominant signal to obtain credit, and that farms with higher growth opportunities exhibit much higher adjustment speeds.

Finally, we split the sample into two periods (2001-2007 and 2008-2015), to examine the farm capital structure decision pre and post the 2008 financial crisis. The analysis shows that the impacts of profit and earnings volatility on leverage are much higher and farms adjust to their target capital much quicker in the post-crisis period. In addition, the coefficients of the farm type dummies are positive and significant in the post-crisis period, suggesting that farm-specific factors played a more prominent role

\footnotetext{
${ }^{23}$ We conduct a T-test to check whether the split sample are significantly different. The results indicate that there is a statistically significant difference between the mean leverage for pre-crisis and post-crisis periods $(t=-10.2205, p=0.0000)$ for larger and smaller farms $(t=7.7971, p=0.0000)$ and for high and low growth-opportunity farms $(t=18.0041, p=0.0000)$.
} 
in determining the target capital structure in the post-crisis period than in the pre-crisis period.

We also show that the speed of adjustment towards the target leverage was significantly lower during the period prior to the financial crisis than after. During the period after the crisis, an average farm would close about $54.29 \%$ of the gap between its target and its actual leverage ratio per year, compared to only around $16.9 \%$ in the pre-crisis period. We note that the impact of size on leverage is negative and significant in pre-crisis periods. This can be attributed to the fact that credit markets do not tighten up equally for farms during pre-crisis periods as loans become disproportionately more expensive and harder to obtain for smaller farms with little collateral.

\subsection{Conclusions}

In this paper, we aim to examine the applicability of the pecking order and signaling theories to farm businesses, the effects of farm-specific and macroeconomic factors in determining the capital structure, and the speed of adjustment to the target. We applied a partial-adjustment model to a unique panel consisting of 1500 farms across fifteen years (2001-2015).

Results from the System GMM estimation support that the signaling behavior in the farm-lender relationship matches the pecking order theory's explanation of the leverage ratios in farm businesses. The most robust findings are the negative association between farm leverage and profit and the support provided to the pecking order theory by earnings volatility (risk). In addition, consistent with the signaling theory, we find that farm leverage is positively related to asset tangibility and growth opportunity, something which has often been rejected for publicly listed firms. Decomposing our analysis into farm types, we show that dairy farms predominantly follow the signaling theory. Horticulture, livestock, and field crop farms, on the other hand, appear to follow the pecking order theory more closely when it comes to their financing opportunities. All farm types use their growth opportunities to effectively send signals that will facilitate their access to credit. As farms do not have much access to external equity, 
signaling their good prospects through profits and investments plays a major role in the borrower-lender relationships. Based on these findings, we were able to provide supporting evidence for both the pecking order and signaling theories being good predictors of the capital structure of firms in the agricultural sector.

Farm profitability, asset tangibility, growth opportunity, and size significantly determine farm capital structure. Although most of the variables identified in the literature affect the leverage of farms, the degree and importance of these factors are farm-type specific. Macroeconomic factors also determine a farm's decision on its capital structure, albeit not strongly. The capital structure decision of a farm is thus not only the product of its own specific characteristics but partially also of the macroeconomic environment in which it operates.

Further, the empirical results indicate that farms appear to adjust their leverage towards the optimal level over time in response to endogenous and exogenous shocks. The speed of adjustment to the target capital is slow and varies according to size and farm type. It is worth noting that farm leverage is highly persistent, i.e. adjustment speed is slow, and that lagged leverage is the best predictor of subsequent leverage ratios. The speed of adjustment is relatively faster for horticulture farms and slower for livestock farms. This variation is mainly attributed to the difference in adjustment costs. The evidence further confirms the existence of dynamics in the farm capital structure decision

The results shed further light on the dynamic nature of the capital structure of farms and the applicability of capital structure theories to farm businesses. The results could also help policy makers and lenders develop effective instruments to control and influence the financial leverage of farms. For example, the estimate of farm size indicates that the speed of adjustment is slow for smaller farms. This suggests that lenders use size as a predominant signal of farm creditworthiness. It also suggests that policy makers should consider size when designing policy instruments to facilitate access to credit. 
The understanding gained from studying the applicability of the pecking order and signaling theories to the farming business benefits both farms and lending institutions. Since historical financial performance is used as a valid signal, farms are encouraged to keep accurate and detailed financial records. It also enables lenders to better understand the dynamics of farm financing decisions and easily identify creditworthy farm businesses through the appropriate signals.

\subsubsection{Limitations and Future Research}

This paper has limitations that motivate further research. Despite our use of unique and high-quality panel data, it is merely an accounting data set. Future research may complement this with behavioral and demographic data on, for example, education, farm risk attitude, and risk perception. Another interesting extension would be to conduct a farm survey on funding preferences or an experimental procedure as an alternative to the econometrics method used in this paper. Future research may also test for the applicability of other theories of capital structure to the farming business and their impact on farm performance in terms of profitability, survival, and viability.

Even though we have used the partial adjustment model to account for leverage dynamics and adjustment cost, this study is limited in that it explores leverage as the only dependent variable. Future research may test some of the richer relationships that come with the pecking order and signaling theories, such as the relationship between cash flow, debt, and equity. Using cash flow, investment, and short and long-term debt as dependent variables might also be an interesting avenue for future research, as is refining the relationship between asset tangibility and the pecking order theory. This study has only found a weak relationship due to limitations in the information available.

Finally, a promising direction for future research would be to improve our understanding of the variations in farm leverage dynamics across countries and economies. This paper documents a number of interesting variations across the four farm types. A better understanding of these variations across economies of, for example, developed vs developing countries and across countries with different legal, 
tax, and farm-support systems, such as European countries and the US, could lead to a valuable understanding of the dynamics and determinants of leverage in farm businesses.

\subsection{Appendix}

Table 2.6: Dynamic panel regression results (Dependent Variable: Leverage $\left.{ }_{i t}\right)$

\begin{tabular}{|c|c|c|c|c|}
\hline Variables & Dairy & Field Crops & Horticulture & Livestock \\
\hline Leverage $_{\mathrm{t}-1}$ & $\begin{array}{l}0.8541 * * * \\
(0.020)\end{array}$ & $\begin{array}{l}0.8379 * * * \\
(0.042)\end{array}$ & $\begin{array}{l}0.3472 * * * \\
(0.135)\end{array}$ & $\begin{array}{l}0.9112 * * * \\
(0.067)\end{array}$ \\
\hline Profit & $\begin{array}{l}0.238 * * \\
(0.119)\end{array}$ & $\begin{array}{l}-0.501 * * * \\
(0.165)\end{array}$ & $\begin{array}{l}-1.972 * * * \\
(0.528)\end{array}$ & $\begin{array}{l}-0.827 * * * \\
(0.1059)\end{array}$ \\
\hline Tangibility & $\begin{array}{l}0.0896 * * * \\
(0.016)\end{array}$ & $\begin{array}{l}-0.053 \\
(0.071)\end{array}$ & $\begin{array}{l}-0.0297 \\
(0.210)\end{array}$ & $\begin{array}{l}-0.0183 \\
(0.0475)\end{array}$ \\
\hline Size & $\begin{array}{l}-0.0234 * * \\
(0.0122)\end{array}$ & $\begin{array}{l}-0.0139 \\
(0.011)\end{array}$ & $\begin{array}{l}0.0875 \\
(0.0586)\end{array}$ & $\begin{array}{l}0.0338 \\
(0.0205)\end{array}$ \\
\hline Growth & $\begin{array}{l}0.372 * * * \\
(0.042)\end{array}$ & $\begin{array}{l}0.3551 * * * \\
(0.061)\end{array}$ & $\begin{array}{l}0.0923 * * \\
(0.0620)\end{array}$ & $\begin{array}{l}0.404 * * * \\
(0.0543)\end{array}$ \\
\hline Risk & $\begin{array}{l}0.0013 \\
(0.0112)\end{array}$ & $\begin{array}{l}-0.08701 * * \\
(0.0359)\end{array}$ & $\begin{array}{l}-0.0501 * * \\
(0.0176)\end{array}$ & $\begin{array}{l}-0.00176^{*} \\
(0.0857)\end{array}$ \\
\hline -cons & $\begin{array}{l}0.3188^{* * *} \\
(0.174)\end{array}$ & $\begin{array}{l}0.2839 \\
(0.1776)\end{array}$ & $\begin{array}{l}-0.8822 \\
(0.9946)\end{array}$ & $\begin{array}{l}-0.4354 \\
(0.3022)\end{array}$ \\
\hline Year & Yes & Yes & Yes & Yes \\
\hline \multicolumn{2}{|c|}{ Wald $\chi^{2}(6)=482.670$} & P-value $=0.990$ & & \\
\hline \multicolumn{2}{|c|}{ Sargan Test $\chi^{2}(151)=945.1$} & P-value $=0.990$ & & \\
\hline \multicolumn{2}{|c|}{ AR (1) $Z=-7.4523$} & $\mathrm{P}$-value $=0.000$ & & \\
\hline \multicolumn{2}{|c|}{$\mathrm{AR}(2) \mathrm{Z}=-1.6229$} & P-value $=0.1050$ & & \\
\hline
\end{tabular}

Notes: Numbers in parentheses are robust standard errors, and $* * *$ and $* *$ are significant at the $1 \%$ and 5\% levels respectively. The dummy reference level is the year 2001 . 


\section{Chapter-3}

Farm-Level Risk-Balancing Behavior and the Role of Latent Heterogeneity 


\section{Chapter Three: Farm-Level Risk-Balancing Behavior and the Role of Latent Heterogeneity}

\subsection{Abstract}

This study provides farm-level empirical support for the risk-balancing hypothesis using a longitudinal dataset from a panel of 1500 Dutch farms. The adjustment in the level of farm financial risk level (exposure) following a change in farm business risk level as a result of exogenous shocks is referred to in the literature as risk-balancing. In empirical studies to date, the heterogeneity of risk-balancing farms has been neglected. In this paper, we explicitly account for latent heterogeneity using a latent mixture regression model. Using the iterative Expectation-Maximization (EM) algorithm, the model simultaneously identifies segments based on the influence of the selected explanatory variables and estimates the effects of these variables on farm riskbalancing behavior for each identified segment. We find that profitability, risk, leverage, age, size, and diversification play an important role in driving farm riskbalancing behavior. Interestingly, the heterogeneity at segment level appears to have been masked at the aggregate farm-type level, notably the effects of leverage and total risk exposure. Assuming homogeneity in farms' responses and estimating a pooled model or a priori classifying farms based on farm type yields a poor fit. The results provide new insights in the interdependence of financial and business risks, spark discussion about the linearity of farm risk reduction policies and total farm risk, and underline the relevance of considering both observed and unobserved factors in devising relevant risk-management strategies.

Keywords: Expectation-Maximization (EM) algorithm, farm business, latent heterogeneity, mixture regression model, risk-balancing behavior. 


\subsection{Introduction}

Risk management in the agricultural sector is important for improved resource allocation, income stabilization, and growth. For public policymakers, an adequate riskmanagement strategy is imperative as risk reduction is the predominant rationale for many farm-support programs, such as the EU-Common Agricultural Policy (CAP) direct payment schemes. Farms have different risk-management strategies at their disposal including but not limited to crop and weather insurance, diversification, hedging, saving accounts, and off-farm employment (Falco et al., 2014; Organisation for Economic and Development, 2011). However, the low uptake of these tools by farmers remains one of the major challenges in understanding and designing adequate risk-management tools at farm level (Cordier, 2015; Finger and El Benni, 2014). The risk-balancing theory presents a practical but often ignored alternative to the existing risk-management strategies.

The risk-balancing theory suggests that the main motivation to balance farm business and financial risks is to maintain an optimal total farm risk. Total farm risk ${ }^{23}$ is defined as the sum (product) of business (or operational) and financial risks. Business risk occurs through production, marketing, institutional, personal, and technological changes, and financial risk arises through the use of farm debt. While business risk is independent of the level of financial risk, the latter, however, is dependent on farm business risk level due to the leverage effect such as credit risk, and interest risks (de Mey et al., 2016). An optimal level of total risk can be achieved (gained back) by making offsetting adjustments through leverage, investment, and production (Gabriel and Baker, 1980) when the level of farm business risk is altered due to exogenous shocks. When these shocks induce a decline in business risk, financial risk will also decrease. This, in turn, results in a slack in the optimal risk constraint since a decrease in both risks will also decrease the total risk. To cope with this slack, farms may opt to adjust their

\footnotetext{
${ }^{23}$ The terms risk and uncertainty can be defined in various ways. One common definition of risk is the variation in possible outcomes of an event based on chance. In the literature, we often see a useful distinction between uncertainties defined as imperfect knowledge and risk as exposure to uncertain unfavorable economic consequences (Hardaker et al., 2015)
} 
financing, e.g. by increasing leverage, investment policies, e.g. by investing in risky projects, or production, e.g. by engaging in riskier farming activities. Alternatively, farms may opt to decrease the leverage level and engage in less risky production when shocks ${ }^{24}$ increase business risk.

The concept of the risk-balancing hypothesis is well established in agricultural finance and economics literature. Its insightfulness has inspired many extensions since its introduction by Gabriel and Baker in 1980. Using the risk-balancing framework, Collins (1985), Featherstone et al. (1988), Escalante and Barry (2003), and, more recently, Uzea et al. (2014), de Mey et al. (2014); (de Mey et al., 2016) and Bampasidou, Mishra and Moss (2017) provide evidence of farm risk-balancing. Very few studies, nevertheless, examine the determinants of risk-balancing behavior. This is partly explained by the lack of comprehensive farm-level longitudinal accounting data to assert the risk-balancing behavior of farms in the long-term.

Most importantly, however, the heterogeneity of risk balancers is unaccounted for in the risk-balancing literature. To the best of our knowledge, no previous study to date explicitly accounts for the heterogeneity of risk-balancing farms. Two reasons may explain why (SaintCyr and Piet, 2017): First, most previous studies focus on specific farm types (e.g., dairy, cash grains or livestock farms), size, age or region, rather than explicitly addressing farm type as a mere unit of interest. Analyzing farms by categorizing using observable characteristics suggests an implicit assumption that the same decision-making process applies to those farms that share the same observable characteristics. This has led to the assumption that farms within these groups are homogenous. Farm heterogeneity may, however, originate from several sources within these homogenous farm types, such as: (a) different farming motivations, (b) different external production conditions, (c) the ability to balance risk may also depend on other factors such as managerial capacity, risk perception, and risk tolerance (Trujillo-Barrera, Pennings and Hofenk, 2016). Second, previous studies often used fixed-effects models to

\footnotetext{
${ }^{24}$ The level of farm financial risk can also be affected by a shock. For instance, the increased risk associated with borrowing due to interest rate shocks is offset by reducing the risk of output price variability by engaging in less risky production or through diversification.
} 
control for any time-invariant unobserved heterogeneity. Explicitly modeling this heterogeneity, however, yields a better understanding of the determinants of risk-balancing behavior as not all sources of farm heterogeneity are observable, nor linkable to farm characteristics. Cases in point would be a farmer's attitudes, perceptions, preferences, and abilities.

Thus, the main objective of this paper is to investigate the presence and determinants farm risk-balancing behavior while accounting for unobserved. We explicitly model the effects of unobserved heterogeneity using a latent mixture regression model, which classifies farms into segments, in which the farms' risk-balancing response to the selected explanatory variables is identical within each segment but different across segments. Hence, we offer a better understanding of the financial structure and characteristics of farms and their relationship with risk-balancing. In addition, we offer a new analysis of risk-balancing behavior using micro-level data. Finally, we take into account four farm types: dairy, livestock, field crop, and horticulture farms. This allows us to analyze a larger segment of the farm sector and gain a better understanding of the interdependence of financial and business risks and the implications for farms and public policymakers.

This chapter is structured as follows: Section 2 provides a review of the risk-balancing literature, followed in section 3 by our theoretical framework. Section 4 offers a description of the empirical model and the data used to examine farm risk-balancing behavior. Section 5 features a discussion of the results of the empirical analyses. The chapter concludes with a discussion of key findings, limitations, and suggestions for further research.

\subsection{Related Literature}

In this section, we provide a brief background of business and financial risks in agriculture, an overview of related studies in the risk-balancing literature, and the theoretical foundations of the heterogeneity of risk balancers. 


\subsubsection{Business and Financial Risks in Agriculture}

Agriculture is inherently a risky business. While risks such as bad weather are unique to agriculture, other types of risks will also create a financial burden on farmers. The sources of total risk in agriculture can be classified in several ways, most commonly by considering the business and financial risks (e.g.,Escalante and Barry, 2003; Gabriel and Baker, 1980; Langemeier, 2016).

Business risk can be defined as the inherent variability in the operating performance of a farm, independent of the way it chooses to finance its operations (Escalante and Barry, 2003). The most common farm business risks are production (yield), price, institutional, technological, and personal risks.

Uncontrollable factors often related to weather such as heavy (lack off) rainfall, insect infections, and diseases result in farm yield (production) risks (Hardaker et al., 2015). Changes in the output and input prices of agricultural products are associated with price risks (Harwood et al., 1999). Changes in government policies and regulation related to agriculture (e.g., the abolition of milk quota in 2015 in Europe) are categorized under institutional risks (Barry et al., 2012).

Technology risk also plays a key role in production risk in farming when certain practices risk becoming obsolete, for example, the use of machinery for which spare parts are no longer available (Harwood et al., 1999). Death, divorce, injury, or poor health of the farm owner (operator) are some of the personal risks.

Financial risk is caused by uncertainties related to inters rates, changes in the cash flow from farm operations, which could be used to repay farm loan, and changes in the market value of farm assets used as loan collaterals (Langemeier, 2016). The use of borrowed funds means that a portion of the returns from the business must be reserved for making debt and interest payments (Harwood et al., 1999). Since the sources of business and financial risks are multiple, a comprehensive strategy that integrates production and finance would reduce total farm risk 
exposure than a separate response. The risk-balancing theory presents an interesting alternative to the already existing risk-management strategies.

\subsubsection{Risk-balancing}

The strategic adjustment (trade-off) between business and financial risks is introduced to the literature as the risk-balancing theory by Gabriel and Baker (1980). According to the theory, total risk is the sum or product of business and financial risks, and when exogenous shocks increase farm business risks and shift the optimal (acceptable) risk level, a farm will opt to reduce their level of debt and refrain from incurring additional financial obligations. Conversely, when exogenous shocks (e.g., export stimulating policies) decrease the level of business risk, a farm may opt to increase their borrowing (increase their financial obligations, hence financial risk), and thus total risk remain optimal (e.g., Collins, 1985; Featherstone et al., 1988).

Gabriel and Baker (1980) make two explicit assumptions about farm behavior: (1) farmers are risk-averse, and (2) profit maximization and survival are the main goals of farmers. Risk aversion ${ }^{25}$ is an important element in understanding a farm's risk-balancing behavior as risk management has always been the major rationale behind decision making at farm level and policy making in general (Pennings and Smidts, 2000). Changes in farming technologies, marketing systems, and environmental policies, for instance, will affect the decision making of farms under risk, such as choosing the optimal level of capital structure (leverage ratio), and asset allocations to investment farming and non-farming activities (de Mey et al., 2016; Skevas, Wu and Guan, 2018).

Including risk aversion in the risk-balancing analysis is not easy due to measurement challenges (Thomas, 2016). Gabriel and Baker (1980) assumed that the ultimate goals of farmers are profit maximization and firm survival and that they will try to maximize net returns

\footnotetext{
${ }^{25}$ Risk aversion is commonly defined in the literature as the risk attitude (perception and preference) and the fundamental descriptor of the feeling guiding the person taking a decision between two alternatives when the outcome of one or both is uncertain (Thomas, 2016).
} 
without exceeding a risk constraint. While they recognized that farmers may respond to shocks out of risk aversion, they did not explicitly include risk aversion in their model.

The role of risk aversion was further explored by Escalante and Barry (2003), who included the risk aversion parameter as a positive determinant, i.e. assumed that the debt-toassets ratio would increase as risk aversion increased. Building on Collin's (1985) expected utility mean-variance (EUMV) approach, Turvey and Kong (2009) modeled profitability as a function of expected returns on assets, financial leverage, and the cost of leverage. In addition, they solved the optimum debt level for a level of risk aversion and hypothesized that more riskaverse individuals would incur less debt than their less risk-averse counterparts. Using microlevel data from US Kansas farms, Jensen and Langemeier (1996) found that farm leverage is associated with risk aversion, alongside farm growth rate, tax and profit, and business risk. Findings by Escalante and Rejesus (2008) suggest that farms only exhibit risk-balancing behavior when decreasing absolute risk aversion and in constant relative risk aversion models. Escalante and Barry (2001) also found that the importance of risk-balancing is low when farmers can use diversified risk-management strategies.

Many studies in the risk-balancing literature revolve around leverage adjustments made by farms following the changes in the level of business risk. Robison and Barry (1987) underlined the importance of adjustments to leverage and financial risk when considering riskmanagement strategies. Applying the expected utility model of optimal hedging, Turkey and Baker (1989) provide empirical evidence of risk-balancing behavior in that hedging is used as a risk management instrument to lower business risk whenever financial risk increases due to a higher leverage ratio. Featherstone et al. (1990) captured the sequential and stochastic nature of capital structure decisions of farms in response to the expected net farm income. Similarly, Moss, Shonkwiler and Ford (1990) used an autoregressive conditional heteroskedastic model and showed that aggregate debt is very elastic( greater than one) with respect to farm earnings (expected farm income).

In line with the leverage adjustment studies, Ramirez, Moss and Boggess (1997) reformulated Collins (1985) risk-balancing hypothesis showing that the ratio of debt to asset is 
elastic for business risk measured as the volatility of expected return on farm asset. Langemeier (2016) showed that farms opt to adjust their exposure to business risk through, for instance, diversification or purchasing crop insurance when financial risk exposure becomes higher following an increase in interest rates on farm loans. Recently, using US data, Bampasidou, Mishra and Moss (2017) modelled farm capital structure choices and showed that earnings volatility is negatively related to the total amount of farm debt.

An interesting phenomenon in the risk-balancing literature is the concept called 'the risk-balancing paradox', where farm policies designed in order to reduce/buffer the level of business risk exposure might actually expose farms even to a higher total risk through riskbalancing. Collins (1985) provided the first evidence in this regard on how policies that aim to increase farm income might induce greater risk-taking behavior. Similarly, Featherstone et al. (1988) showed that farms can go bankrupt by increasing leverage due to income augmentation policies. Ahrendsen, Collender and Dixon (1994) found that policies intended to decrease farm business risk or increase farm profit induce farms to increase financial risk through the acquisition of more debt. They underlined, however, that the adjustment process is slow and time-consuming. Ifft, Kuethe and Morehart (2013) also found evidence supporting the paradox of risk-balancing in which farm financing decisions (debt use), participation in Federal Crop Insurance (FCI) and financial risk are interrelated. They argued that for farms that have been operating at the optimal total risk level, a more financial risk (a higher level of leverage) becomes acceptable when business risk decreases. However, Cheng and Gloy (2008) provide evidence that contradicts the phenomena of the paradox of risk-balancing. Their analysis of risk adjustment by farms shows that policies aiming at reducing farm risks provide discipline in debt use to reduce the volatility of farm income while also increasing the expected income from farm activities.

Only a small number of studies have examined the determinants of risk-balancing behavior. Escalante and Barry (2003) used correlation relationship and regression analysis on US grain farms and found that crop insurance, diversification, and farmland tenure positions significantly affect farm risk-balancing behavior. Turvey and Kong (2009) examined small 
farm household risks in China, finding evidence of risk-balancing. Farm profit, risk, risk aversion, age, and sources of funding were identified as determinants. Using a panel of Canadian farmers, Uzea et al. (2014) found that the likelihood of risk-balancing by farms reduces with the amount received in support payments. Size, operation efficiency, and interest expenses were identified as significant determinants of risk-balancing behavior. In addition, Ifft, Kuethe and Morehart (2015) found that both short-term and long-term farm debts are positively associated with participation in crop insurance programs.

The first empirical evidence of the risk-balancing behavior of European (EU-15) farmers were provided by de Mey et al. (2014) by investigating the adjustment in financial risk levels by farms in response to changes in the business risk as a result of exogenous shocks. A little more than half of the farms investigated are found to be risk balancers in weak form, i.e., while farm balance their risk, there is a form of variation in the total risk constraints contrary to the strong form of risk-balancing where total risk is assumed to be constant all the time.

Recently, de Mey et al. (2016) extended the risk-balancing hypothesis from farm level to household level and provide empirical evidence for household risk-balancing behavior by estimating fixed-effects Seemingly Unrelated Regression (SUR) using the Swiss FADN data. They found that in addition to strategic on farm adjustments, farms at the household level also make off-farm adjustments (e.g., adjusting the level of off-farm income and consumption) in response to the change in farm business risk.

Based on the aforementioned literature review and the original risk-balancing hypothesis, we include structural and financial characteristics of farms (e.g., age, size, total debt, total level of risk exposure, profitability, diversification. investment and participation in government support programs) in our analysis to explore their linkage with the risk-balancing behavior of farms.

\subsubsection{Heterogeneity of Risk Balancers}

The assumption of homogeneity among decision-makers has often been rejected in the analysis of behavior (Pennings and Garcia, 2004). While characterizing all observations by a 
single model is convenient, it may mask critical relationships. In studying farmers' hedging behavior, Pennings and Garcia (2010) showed that unobserved (latent) heterogeneity masks important drivers of hedging. Factors that play an important role in risk-balancing behavior for some farmers may be unimportant for others. Also note that the role of risk attitudes and risk perceptions may vary widely among farmers (Pennings and Garcia, 2001). While economic theory suggests that risk attitude and risk perception are important concepts in understanding risk-balancing behavior (Turvey and Kong, 2009), it is not easy, nevertheless, to include risk preference in the risk-balancing analysis, mostly due to challenges in measuring its variability and lack of data.

To account for the heterogeneity among risk balancers, previous studies have used observable variables like size, location or farm type to segment the total population (de Mey et al., 2014; de Mey et al., 2016; Escalante and Barry, 2003; Escalante and Rejesus, 2008; Uzea et al., 2014). This approach implicitly assumes that farms of the same type will respond similarly to changes in the determinants of risk-balancing behavior. A potential problem is that the assumptions of homogeneity among decision makers and the characterization of all observations by a single model tend to mask critical relationships. This may be misleading if the sample contains latent segments, a situation particularly relevant to the farming sector, where many of the relevant observations concern farmers' highly personal motivations, risk attitudes, and perceptions. In this sector, a priori classification may fail to capture the wide heterogeneity in farm management activities. Further, standard regression neglects the integer properties of the dependent variable, in that it does not allow for creating segments in the population (Morduch and Stern, 1997). Addressing these limitations requires disaggregation of the entire sample into segments.

Following De Soete and DeSarbo (1991); Pennings and Garcia, (2010), and Wedel and Kamakura (2012), we advocate the use of a latent-class logit mixture model to explicitly account for latent heterogeneity. In this model, farms are simultaneously classified into multiple segments based on the relationship between the determinants of risk-balancing behavior and the actual risk-balancing, and finally, the model estimates the influence of the 
determinants of risk-balancing for each segment identified. The classification of the farm is based on whether farms respond to the determinants of risk-balancing in similar ways. For farms within a segment, the influence of these determinants on risk-balancing behavior is the same, and the actual probability/likelihood of risk-balancing by the farm is dependent on the level of the determinants. Ceteris paribus, farms with a similar relationship between their profitability ratio and risk-balancing are classified together, for example, regardless of their size, region or farming systems. In a predictive sense, the exact effect of the farm's profitability ratio on the likelihood of risk-balancing will then be determined by the profitability of the farm.

The procedure emphasizes the role of theory in the empirical analysis, as the determinants of risk-balancing behavior are used both to explain the risk-balancing behavior and to discriminate among groups of farms. This is a fundamentally different approach from previous studies dealing with heterogeneity, where the segments were determined a priori, based on a single observable variable such as size, region or farming types. Note that, from a conceptual perspective, the procedure permits the determinants of risk-balancing to have a different influence on the actual likelihood of risk-balancing behavior in each identified segment.

\subsection{Theoretical Framework}

Two approaches are commonly used to derive the risk-balancing hypothesis: the expected utility mean-variance approach and the equilibrium analysis approach. The former approach derives the risk-balancing hypothesis from an expected utility mean-variance framework and accounts for the effects of the risk magnitude and the risk attitude behavior of decision makes on farm total leverage decisions. The latter approach examines how an optimal asset and liability organization of farms is restored to equilibrium through risk-balancing after the imbalance in the optimal level as a result of exogenous shocks. The additive approach of 
Gabriel and Baker (1980) and the multiplicative approach ${ }^{26}$ of Barry and Robinsons (1987) fall into this category.

We adopt the additive equilibrium approach of Gabriel and Baker (1980), a proven parsimonious model that can help explain risk-balancing behavior. In addition, we have an accounting data that fits this modelling framework well. The approach utilizes income and cash flow statements in developing a conceptual framework to integrate business risk (BR) and financial risk (FR) as:

$\mathrm{TR}=\mathrm{BR}+\mathrm{FR}$

Total Risk (TR) is given by (Gabriel and Baker, 1980):

$\mathrm{TR}=\frac{\sigma_{2}}{\bar{\mu}_{\mathrm{x}}-\mathrm{I}}$

The standard deviation of net farm income is used to measure farm business risk as:

$\mathrm{BR}=\frac{\sigma_{1}}{\bar{\mu}_{\mathrm{x}}}$

Where, $\sigma_{1}$ and $\sigma_{2}$ are, respectively, the standard deviations of net farm income with and without debt financing (Escalante and Barry, 2003), $\bar{\mu}_{\mathrm{x}}$ is the expected net farm income, and I is the interest payments.

Hence, FR can be derived by subtracting equation (3.3) from equation (3.2)

$\mathrm{FR}=\frac{\sigma_{2}}{\bar{\mu}_{\mathrm{x}}-\mathrm{I}}-\frac{\sigma_{1}}{\bar{\mu}_{\mathrm{x}}}$

Baker and Gabriel further simplify equation (3.4) by assuming that leverage has no scale effect $\left(\sigma_{1}=\sigma_{2}\right)$. Hence, rewriting equation (3.4) results in:

\footnotetext{
${ }^{26}$ The multiplicative approach by Robison and Barry (1987) uses concepts from the portfolio theory and proposes an integrated conceptual framework for the optimal organization of the farm assets and liabilities of risk-averse decision makers. The basic concept of the model is that total farm risk (TR) equals the product of farm business risk (BR) and financial risk (FR).
} 
$\mathrm{FR}=\frac{\sigma_{1}}{\bar{\mu}_{\mathrm{x}}} * \frac{\mathrm{I}}{\bar{\mu}_{\mathrm{x}}-\mathrm{I}}$

From equation (3.5), we can see that BR is one of the determinants of FR. Thus, total risk is determined as:

$\mathrm{TR}=\frac{\sigma_{1}}{\bar{\mu}_{\mathrm{x}}}+\frac{\sigma_{1} \mathrm{I}}{\bar{\mu}_{\mathrm{x}}\left(\bar{\mu}_{\mathrm{x}}-\mathrm{I}\right)}$

de Mey et al. (2014) best explained the risk-balancing effect by expressing total risk using the additive relationship between business and financial risks, and by setting the target total risk level with which a farmer can cope (introduce a risk constraint in the framework). The introduced risk constraint depends on farm and farmer characteristics at micro level, and policy and other general economic shocks at the macro level. With the preceding argument, the total risk (TR) constraint can be written as:

$\Phi \leq \mathrm{TR}=\mathrm{BR}+\mathrm{FR}=\frac{\sigma_{1}}{\bar{\mu}_{\mathrm{x}}}+\frac{\sigma_{1} \mathrm{I}}{\bar{\mu}_{\mathrm{x}}\left(\bar{\mu}_{\mathrm{x}}-\mathrm{I}\right)} \leq \beta$

In equation 3.7, a maximum total risk exposure level a given farmer can cope up with is given by $\beta$, whereas, the lower bound to total risk constraint is captured by $\Phi$. If a farm price stabilizing or export inducing policy, for instance, reduces the level of business risk, from equation 3.7, we can infer that the level of financial risk will also decrease. This, in turn, creates a slack in the total risk constraint given by $\beta$. In order to restore the relationship to the optimal level i.e., $\mathrm{TR}=\beta$, farms could opt to increase their exposure to financial risk by taking more debt (de Mey et al., 2014). Alternatively, when exogenous shocks increase the farm business risk level and results in a situation where a farmer is not in a position to cope up with, i.e.,TR > $\beta$, a farmer will adjust its level of financial risk exposure by refinancing the already taken loans or engage in a less risk production activities so that the total risk exposure level remains at the optimum level.

The risk-balancing effect described in the previous paragraph is based on the assumption that the total risk remains constant (optimal) while business and financial risks moves in an opposite direction. If this assumption holds, the risk-balancing behavior is said to 
be of a strong form (de Mey et al., 2014). In practice, however, this assumption is strong and difficult to hold because; (a) according to Robison and Barry (1987), the level of risk aversion varies amongst farms, hence, results in a different level of farm risk-absorbing capacity, (b) according to Ahrendsen, Collender and Dixon (1994), it might take more than a year in order to observe the risk-balancing effect on the total risk constraint. Consequently, this paper considers the weak form of risk-balancing where a change in the total risk constraint can be observed.

Further, the risk-balancing hypothesis assumes an inverse relationship between a lagged business risk and the current level of financial risk. This relationship constitutes the basis of our empirical model. The following paragraphs explain the two rationales behind this hypothesis.

First, if an exogenous shock induced a decline in business risk, financial risk would also be lower. This results in a slack in the total risk constraint. To take advantage of this slack and retain the optimal risk level, a farmer engages in more borrowing, hence, increases the levels of financial risk. Going back the original risk-balancing framework by Gabriel and Baker $(1980)$, we can infer that the standard deviation of the expected farm income $\left(\frac{\sigma_{1}}{\bar{\mu}_{\mathrm{x}}}\right)$ is used to measure the level of business risk whereas the balancing component of equation $3.7,\left(\frac{\mathrm{I}}{\left(\bar{\mu}_{\mathrm{x}}-\mathrm{I}\right)}\right)$ is used to capture the level of farm financial risk. With this relationship in mind, we can introduce time periods in our analysis by stating that past volatility levels are used as a proxy for expected business risk $\mathrm{E}\left(\mathrm{BR}_{\mathrm{t}}\right)=\mathrm{BR}_{\mathrm{t}-1}$, which in turn leads to the argument that $\mathrm{FR}_{\mathrm{t}}$ could be a function of $\mathrm{BR}_{\mathrm{t}-1}$. Thus, considering that the business risk condition of the previous year influences the current year financial structured decision-making, farm risk-balancing behavior is measured by pairing the current financial risk level with a lagged business risk level.

Second, capital structure is one of the critical decisions a farmer will make taking the expected level of farm return and the risk associated with this return into account (Cheng and Gloy, 2008). By increasing their leverage, farm will be able to increase the available investment capital for farming operations such as farm expansion. In addition, if the increase in leverage 
is complemented by a lower cost of debt, it will generate a higher return on equity. These benefits, however, will not come without expenses for highly levered farms must properly manage their cash flows (uncertainty and volatility) in order to meet their financial obligations. The uncertainty and variability of future income from farm business, thus, are one of the determining factors in the farm leverage ratio. Therefore, farm decisions on financial leverage must first consider business risks.

Based on these two arguments, we assume that the financial risk decision in the current period reflects the previous period's level of business risk. Also note that this inverse hypothesis is not a mere theoretical prediction but has been empirically tested in other studies as well, including, for example, Langemeier, (2016), de Mey et al. (2014), Uzea et al. (2014) and Escalante and Barry (2003).

\subsection{Methodology}

\subsubsection{Data and Descriptive Statistics}

The empirical analysis uses an unbalanced rotating panel from the Wageningen Economic Research-WUR database. The Wageningen Economic Research-WUR) is responsible for the Dutch Farm Accountancy Data Network (FADN) ${ }^{27}$, with data available from 2001 to 2015.

The Dutch FADN sample is randomly selected using disproportional stratified sampling ${ }^{28}$ from the farm census. Economic size and farm type are the stratification criteria. The dataset used in this chapter is high quality in that (a) the samples are representative of $80 \%$ of the farms and more than $90 \%$ of production in the Netherlands, and (b) it allows for separate

27 FADN is an annual survey at European Union level, carried out in each member state. (http://ec.europa.eu/agriculture/rica/). Also, we refer the readers to Berkhout and van Bruchem (2015) for a detailed description of the Dutch agriculture sector.

${ }^{28}$ We refer to Meer, Veen and Vrolijk (2013) for details on the Dutch FADN sampling procedure. 
estimation of farm types for comparison purposes due to the harmonized ${ }^{29}$ data-collection procedure, i.e. the bookkeeping principles are identical for all farm types.

We have applied the following inclusion criteria for farms: firstly, continuous wholefarm data had to be available from $2001-2015^{30}$. Secondly, a farm had to have debt, as there can be no farm risk-balancing without debt. Thirdly, farm observations with negative net farm income and return on assets were excluded, given our calculation of the coefficient of variation. Fourthly, farms needed to remain in the sample for at least four years since our model has a lag structure and business risk is calculated based on a three-year rolling window. Finally, to address outlier concerns, extreme values in the dataset were handled by dropping the top and bottom $0.5 \%$ observations of the variable from the analysis. These criteria reduced the total number of farms included in this study to 1,339 (89 percent of the original farms) and reduced the number of observations from 15,982 to 9,040 . Table 3.1 shows the summary statistics and variable definitions for the sample farms.

\footnotetext{
${ }^{29}$ The bookkeeping principles and sample selection plans are identical for all farm types in the Netherlands and similar to those of other European countries participating in the FADN.

${ }^{30} \mathrm{~A}$ farm will be dropped from the analysis if more than half of the variables in each year show missing values.
} 
Table 3.1: Variables and summary statistics

\begin{tabular}{|c|c|c|c|c|c|}
\hline Variable & Definition & Unit & Obs. & Mean & SD \\
\hline Financial Risk & $\begin{array}{l}\text { The Ratio of Interest Paid on Net Farm } \\
\text { Income(NFI) After Interest has been } \\
\text { Paid }\end{array}$ & Ratio & 9,040 & 0.830 & 1.863 \\
\hline Dairy Farms & & & 2,654 & 1.085 & 2.104 \\
\hline Field Crops & & & 1,798 & 0.708 & 1.657 \\
\hline Horticulture & & & 2,888 & 0.618 & 1.629 \\
\hline Livestock & & & 1,700 & 1.700 & 0.921 \\
\hline Business Risk & $\begin{array}{l}\text { Coefficient of Variation of NFI, } \\
\text { Calculated over a Three-Year Window. }\end{array}$ & $\mathrm{CV}$ & 7,717 & 0.330 & 0.271 \\
\hline Dairy Farms & & & 2,329 & 0.252 & 0.218 \\
\hline Field Crops & & & 1,567 & 0.361 & 0.274 \\
\hline Horticulture & & & 2,408 & 0.369 & 0.287 \\
\hline Livestock & & & 1,413 & 0.361 & 0.290 \\
\hline Total Risk & Financial Risk +Business Risk & & 7,717 & 1.128 & 1.128 \\
\hline Cost of Debt & $\begin{array}{l}\text { The Ratio of Interest Paid Over Total } \\
\text { Outstanding Debt }\end{array}$ & $\%$ & 9,040 & 4.261 & 364.61 \\
\hline Leverage & Total Debt/Total Asset & Ratio & 9,040 & 0.276 & 0.219 \\
\hline Farm Area & Total Agricultural Area Utilised & Hectares & 9,040 & 44.527 & 61.376 \\
\hline Farm Size & Ln of Total Farm Output & Euro & 9,040 & 14.568 & 0.833 \\
\hline Profit (ROA) & Net Farm Income/Average Total Asset & Ratio & 9,040 & 0.0517 & 0.0454 \\
\hline Investment $^{31}$ & Total Net Farm Investment & Euro & 9,040 & 148,962 & 38,627 \\
\hline Direct Payment & $\begin{array}{l}\text { Share of Direct Payment Received in } \\
\text { Total Gross Revenue }\end{array}$ & Euro & 9,040 & 0.0297 & 0.050 \\
\hline Diversification $^{32}$ & $\begin{array}{l}\text { Share of Other Farm Output in Total } \\
\text { Farm Output }\end{array}$ & Ratio & 9,040 & 0.163 & 0.201 \\
\hline Age & Age of Farm Operator & Years & 9,040 & 51.15 & 10.096 \\
\hline
\end{tabular}

The average farm's financial risk was $83 \%$ over the $2001-15$ periods, implying that farm indebtedness is at a high level and that more than a substantial part of net farm income is being used to pay-off these debts. The statistics also show variation by farm type. Figure 1

\footnotetext{
${ }^{31}$ According to the FADN guidelines, a farm investment is an investment in fixed assets, which includes costs of current upkeep of equipment (and purchase of minor equipment), car expenses, current upkeep of buildings and land improvements, insurance of buildings, major repairs, new plantations of permanent crops. Net investment is calculated as gross investment on fixed assets minus depreciation.

${ }^{32} \mathrm{We}$ measure farm diversification as the ratio of income (revenue) from other farm outputs to income from the specialized farming activity. For instance, a typical dairy farm average diversification score is 0.75 , meaning that this farm earns $75 \%$ of its net farm income from other farming activities such as sheep, goat or other grazing livestock and earns only $25 \%$ of its income from dairy production. A higher ratio thus represents a more diversified farm.
} 
shows the variation in farm financial and business risk across the four farm types and over the years.
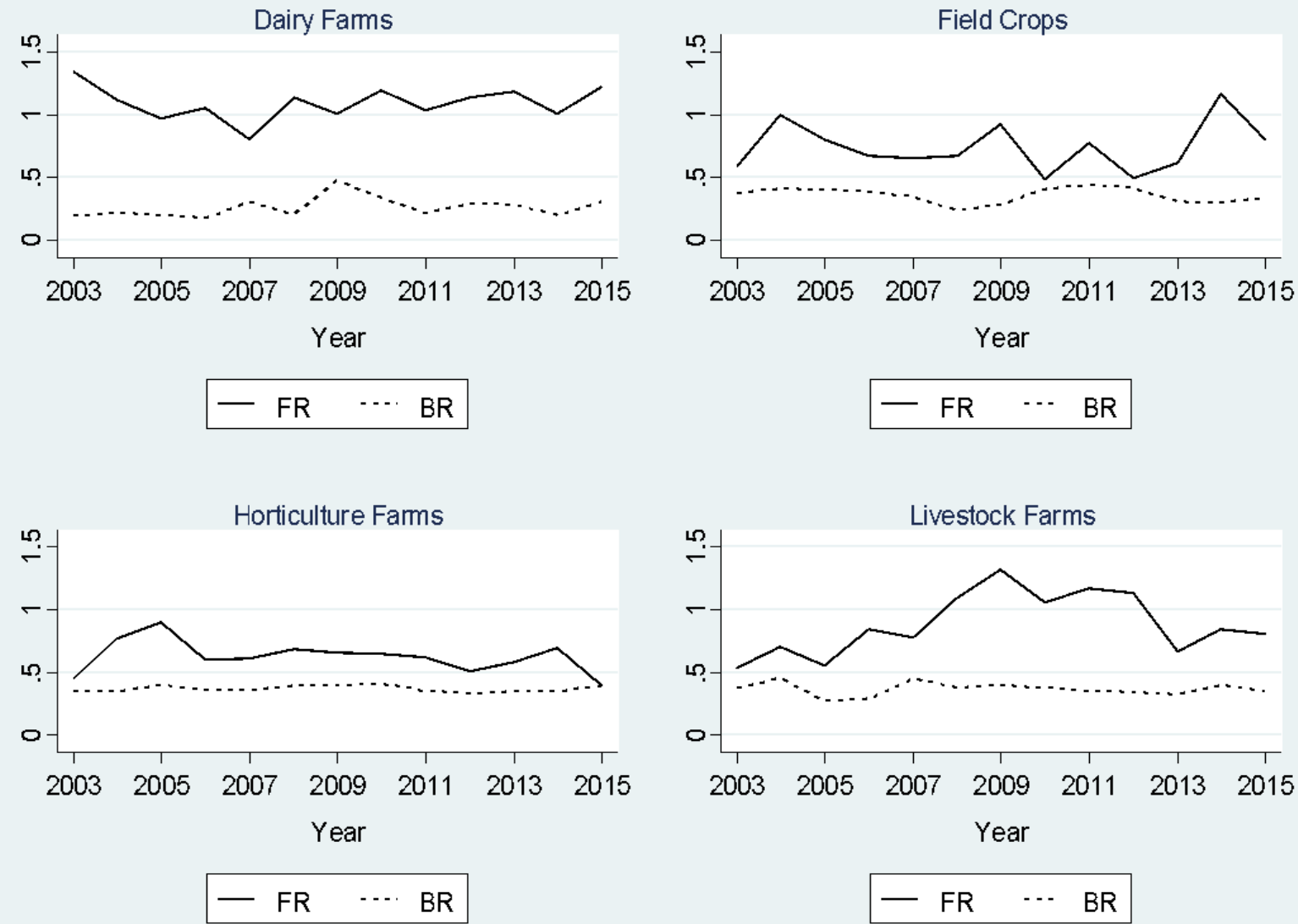

Figure 3.1: Financial and business risks by farm type, 2003-2015

Field-crop and livestock farms exhibit above-average levels of business risk ${ }^{33}$, which can be explained by their increased exposure to production risk due to weather impacts and price volatility in their input and output markets. Interestingly, dairy farms carry below-average business risk, which is attributed to the stable milk price in the Netherlands compared to that of field crops during our sample period (2001-2015) (Rizov, Pokrivcak and Ciaian, 2013). The next section presents the empirical results.

${ }^{33}$ To get a clear picture of the variation in business risk over the years, we plot a new figure using downside deviation as a measure of business risk. We have observed similar patterns and for reference, the figure is presented in the appendix section. 


\subsection{Empirical Model}

\subsubsection{Farm-level Risk-balancing Behavior}

In order to examine whether farms exhibit risk-balancing behavior, we use a fixedeffects panel-regression model ${ }^{34}$, where we regressed the financial risk on one-year lagged business risk and selected farm characteristics. We have used the literature review and the theoretical framework in the previous section to guide the regression and selection of the righthand side variables.

The ratio of interest paid to net farm income after interest is paid (I/(NFI-I)) is used to measure farm financial risk. To measure farm business risk, we use the coefficient of variations of net farm income based on observations from the immediately preceding three years. Equation (3.6) in the theoretical framework section suggests that farm profitability and the cost of debt further motivates risk adjustment by farmers. We expect the cost of debt from the previous year, which is measured as the interest paid on the farm's total outstanding debt $\left(\left(\mathrm{I} / \mathrm{D}_{\mathrm{t}}\right.\right.$ 1), to have a positive effect because a high cost of capital will lead to a higher level of financial risk (de Mey et al., 2014), ceteris paribus. Farm profitability, measured as the ratio of net farm income to total assets, is hypothesized to have a negative effect on farm financial risk as it helps cover the interest expenses while at the same time enabling farms to increase their debt coverage level ( Escalante and Barry, 2003).

We included farm size and operator age as farm-structural factors to explore their linkage with farms' financial risk. Farm size measured in terms of farm total output is expected to be positively related to farm financial risk as large farms tend to incur more debt in order to sustain the benefits of economies of scale and production efficiencies (Escalante and Barry, 2003; Purdy, Langemeier and Featherstone, 1997). Farm operator age, used as a proxy for measuring management expertise, is hypothesized to have a negative relationship with

\footnotetext{
${ }^{34}$ In conformity with previous studies (de Mey et al., 2014; Escalante and Barry, 2003), we have performed a correlation relationship analysis. The results have been included in the Appendix section.
} 
financial risk. Older and more experienced farmers tend to decrease their financial risk. This behavior may be attributed to the increase in risk-averse behavior with age, greater adaptability in devising alternative risk-management strategies (Escalante and Barry, 2003), and the lifecycle hypothesis, which holds that as farmers get older, they tend to pay off their debt obligations (de Mey et al., 2014).

Farm type dummies are included in the regression model to examine the impact of alternative farming systems on financial risk. A time dummy is also included to capture business-cycle impacts, such as inflation, interest rate, unemployment, and GDP growth, on farm financial risk. A logarithmic form of the explanatory variables was used in the regression to normalize the data ${ }^{35}$. Our estimated model can be specified as:

$$
\begin{gathered}
\ln \left(\mathrm{I} /(\mathrm{NFI}-\mathrm{I})_{i, t=} \alpha_{i}+\beta_{1} \ln (B R)_{i, t-1}+\beta_{2} \ln (I / D)_{i, t-1}+\beta_{3} \ln (R O A)_{i, t-1}+\beta_{4} \ln (\text { Size })_{i, t-1}\right. \\
+\Delta_{i, t}+\Gamma_{t}+\varepsilon_{i, t}
\end{gathered}
$$

Where $i$ and $\mathrm{t}$ are indexing farm and year, $\Delta_{i t}$ and $\Gamma_{t}$ are the farm type and year dummies, respectively, $\varepsilon_{i, t}$ is the error term, $\alpha, \beta, \Delta$, and $\Gamma$ are parameters to be estimated.

\subsubsection{Drivers of Farm Risk-balancing Behavior}

Structural and financial characteristics of farms were included in the analyses to explore their possible links with risk-balancing. The characteristics are selected based on the literature and the theoretical framework discussed in section two. These factors include farm profitability, size, total risk, leverage, cost of debt, government-support programs, i.e. subsidies, age, investment, and alternative risk-management strategies (diversification). To identify the drivers of farm risk-balancing behavior, we estimate a the logit panel model as:

$$
\operatorname{Pr}\left(\mathrm{Y}_{\mathrm{it}}=1 \mid \mathrm{X}_{\mathrm{it}}\right)=g\left(\beta \mathrm{X}_{\mathrm{it}}\right)
$$

\footnotetext{
${ }^{35}$ While cleaning the data, we perform a skewedness /kurtosis test for normality, which shows that some of the variables, e.g., cost of debt, are not normally distributed. In addition, a log transformation is performed to increase the interpretability of the coefficients.
} 
With

$\mathrm{Y}_{\mathrm{it}}=\beta \mathrm{X}_{\mathrm{it}}+\Delta_{i t}+\Gamma_{t}+e_{\mathrm{it}}$

Where

- $\mathrm{Y}_{\mathrm{it}}=$ Farm risk-balancing behavior, which only takes the value of 1 when financial risk (FR) moves in the opposite direction of a one-year lagged business risk (BR), and 0 otherwise.

- $\mathrm{X}_{\mathrm{it}}=$ Vectors of right-hand-side variables, such as farm profitability, size, total risk, leverage, cost of debt, subsidies, age, investment, and diversification.

- $g()=$. Logistic cumulative distributions function for the logit model.

\subsubsection{Farm Risk-balancing Behavior and Latent Heterogeneity}

The assumption of homogeneity among decision makers and the characterization of all observations by a single model tend to mask critical relationships and may be misleading if the sample consists of a number of unknown segments. Addressing this limitation requires disaggregation of the entire sample into segments. Following De Soete and DeSarbo (1991) and Wedel and Kamakura (2012), we advocate the use of a latent-class logit mixture model.

The rationale behind this model ${ }^{36}$ is as follows: The sample contains a finite and fixed number of homogeneous segments. Farms belong to these segments with some probabilities, which are assumed a priori and are invariant across farms. Conditional upon membership of a segment, the probability of a farm's choice decision is given by a choice model (logit model). The intercepts and sensitivities to explanatory variables in the choice model are allowed to vary across segments. Then, by maximizing the unconditional likelihood of the entire farm sample, we can obtain the estimates of membership and the associated coefficients for the independent variables simultaneously. Finally, each farm can be assigned to a segment through the updated posterior probability.

\footnotetext{
${ }^{36}$ For a detailed review of latent-class models, see Wedel and Kamakura (2012), Hagenaars and McCutcheon (2002), Kamakura and Russell (1989), and Rabe-Hesketh and Skrondal (2004).
} 
The measures of farm risk-balancing behavior are indexed by $t=1 \ldots, T$ for $i=$ $1 \ldots, N$ farms. Let $y_{i t}$ denote the risk-balancing behavior of farm $i$ in year $t$. If farm $i$ prefers to balance its risk in year $t$, then $y_{i t}=1$; otherwise $y_{i t}=0$. We also assume that farms come from a population that consists of a mixture of unobserved (latent) segments $S$, and each farm $i$ in year $t$ belongs to one, and only one, segment $s$ which is not known in advance. While farms within each segment are assumed to be homogeneous with respect to their sensitivities to the explanatory variables, these sensitivities can vary across segments. The relative size (proportion) of segments $\pi_{S}$ is restricted to:

$0<\pi_{S}<1, \sum_{S=1}^{S} \pi_{S}=1$

Let $\mathbf{X}_{i t}=\left(1, \mathrm{X}_{\mathrm{it}}^{(1)}, \ldots ., \mathrm{X}_{\mathrm{it}}^{(\mathrm{k})}\right)$ denote a row vector of $k$ predictor variables that could help explain farm risk-balancing behavior. Since $y_{i t}$ is binary, then, conditional on farm $i$ in year $t$ belonging to segment $s$, the probability that farm $i$ balances its risk in year $t$ can be represented as follows in a logit regression model:

$P\left(y_{i t}=1 \mid s\right)=\frac{\exp \left(\boldsymbol{\beta}_{s} \mathbf{X}_{i t}^{\prime}\right)}{1+\exp \left(\boldsymbol{\beta}_{s} \mathbf{X}_{i t}^{\prime}\right)}$

where $\boldsymbol{\beta}_{s}=\left(\beta_{s}^{(0)}, \beta_{s}^{(1)}, \ldots \ldots \ldots, \beta_{s}^{(k)}\right)$ is the coefficient vector associated with the vector of the predictor variables $\mathbf{X}_{\boldsymbol{i t}}$.

We model the probability that farm $i$ in year $t$ belongs to segment $s$ in year $t, \mathrm{P}_{i t s}$, depending on a vector of farm-specific variables $\mathbf{Z}_{i t}=\left(1, Z_{i t}^{(1)}, 1, Z_{i t}^{(2)}, \ldots \ldots \ldots, Z_{i t}^{(m)}\right)$. Assuming the values of segment membership follow a multinomial distribution, the probability $\mathrm{P}_{i t s}$ can be written as:

$\mathrm{P}_{i t s}=\frac{\exp \left(\boldsymbol{\eta}_{s} \mathbf{Z}_{i t}^{\prime}\right)}{\left.\sum_{S}^{S} \exp \left(\boldsymbol{\eta}_{s} \mathbf{Z}_{i t}^{\prime}\right)\right)}$

where $\boldsymbol{\eta}_{s}=\left(\eta_{s}^{(0)}, \eta_{s}^{(1)}, \ldots \ldots \ldots, \eta_{s}^{(m)}\right)$ is the vector of segment-specific parameters to be estimated, capturing the difference between the effect that the farm-specific variable has on the 
probability of membership of segment $s$ and its effect on the probability of belonging to segment $S$.

Given Equations (3.12) and (3.13), the unconditional probability that a randomly selected farm $i$ balances its risk in year $t$ is expressed by:

$P\left(y_{i t}=1\right)=\sum_{s}^{S} P_{i s t} . P\left(y_{i t}=1 \mid s\right)$

For each farm, $i$ in year $t$, i.e. the likelihood function conditional on farm $i^{\prime} s$ membership, can be formulated as:

$L_{i t \mid s}=\prod_{i=1}^{N} \prod_{t=1}^{T} P\left(y_{i t}=1 \mid s\right)^{y_{i t}}\left(1-P\left(y_{i t}=1 \mid s\right)\right)^{y_{i t}}$.

Hence, the unconditional likelihood for each farm $i$ is:

$L_{i t}=\sum_{s=1}^{S} P_{i s t} \cdot L_{i t \mid s}$

The complete likelihood over the entire sample of farms is:

$L_{i t \mid s}=\prod_{i=1}^{N} \sum_{s=1}^{S} P_{i s t} \prod_{t=1}^{T} P\left(y_{i t}=1 \mid s\right)^{y_{i t}}\left(1-P\left(y_{i t}=1 \mid s\right)\right)^{y_{i t}}$

The log-likelihood is:

$\ln L=\sum_{i=1}^{N} \ln \left[\sum_{s=1}^{S} P_{i s} \prod_{t=1}^{T} P\left(y_{i t}=1 \mid s\right)^{y_{i t}}\left(1-P\left(y_{i t}=1 \mid s\right)\right)^{y_{i t}}\right]$

By maximizing the log-likelihood function (3.18), the unknown parameters of the problem $\boldsymbol{\beta}_{s}=\left(\beta_{s}^{(0)}, \beta_{s}^{(1)}, \ldots \ldots \ldots, \beta_{s}^{(k)}\right) \boldsymbol{\eta}_{s}=\left(\eta_{s}^{(0)}, \eta_{s}^{(1)}, \ldots \ldots \ldots, \eta_{s}^{(m)}\right)$ can be estimated with the iterative Expectation-Maximization (EM) algorithm ${ }^{37}$.

\footnotetext{
${ }^{37}$ Wedel and Kamakura (2012), Rabe-Hesketh and Skrondal (2004), and Vermunt, Tran and Magidson (2008). provide detailed descriptions of the EM algorithm.
} 
The EM algorithm implies iterative alternation between an expectation step (E-step) and a maximization step (M-step). It is based on the idea that the likelihood function contains missing observations, i.e., the $0 / 1$ memberships of subjects in the s segments. The expectation of the likelihood can be formulated using a multinomial distribution for segment membership. This involves calculating the posterior membership probabilities and the current parameter estimates of independent variables and substituting them into the likelihood function.

In the E-step, the log-likelihood is replaced by its expectation, which is calculated based on provisional estimates of the set of parameters that identify the segment to which the farm belongs. In the M-step, the expectation of $\ln L$ is maximized with respect to the set of parameters to obtain new provisional estimates (Pennings and Garcia, 2010). This iteration of the $\mathrm{E}$ and $\mathrm{M}$ steps continues alternately until convergence is reached.

Once the estimates are obtained from the observed data, the a posteriori probability, $\lambda_{i t \mid s}$ that a farm $i$ belongs to latent class $s$ in year $t$ can be calculated for each observation vector $\mathrm{y}_{i t}$, including an estimate of the vector of the parameters by means of Bayes' theorem:

$\lambda_{i t \mid s}=\frac{\pi_{s} \prod_{t=1}^{T} f\left(y_{i t} \mid x_{i t}, \beta_{s}\right)}{\sum_{s=1}^{S} \pi_{s} \prod_{t=1}^{T} f\left(y_{i t} \mid x_{i t}, \beta_{s}\right)}$

A farm can then be assigned to the segment to which it most likely belongs on the basis of these posteriori probabilities. Once the posteriori probabilities are calculated, a follow-up question is how many classes are required to adequately represent the data, as one cannot know this in advance. The common approach is to test a likelihood ratio statistic on whether a solution with $S+1$ segments gives a significantly better fit than a solution with $s$ segments, expressed as:

$U=-2 \log \left[\frac{L^{(S)}}{L^{(S+1)}}\right]$

where $L^{(S)}$ denotes the maximum obtained for equation (3.18) with $s$ segments. The likelihood ratio in latent class logit models is not asymptotically distributed, however, and its distribution depends on the total number of subjects (De Soete and DeSarbo, 1991). As an alternative, 
several measures have been proposed (McLachlan and Peel, 2004) including the AIC (Akaike Information Criterion) and BIC (Bayesian Information Criterion). These criteria are defined as:

$A I C=-2 \ln L+2(L . S+S-1)$

$B I C=-2 \ln L+(L . S+S-1) \ln (n)$.

The number of segments that best represents the data is reached when either the AIC or BIC hits a minimum. In addition, an entropy statistic $E_{s}$, can be calculated for any segment to ensure that for each segment, the posterior probabilities are separated sufficiently, which determines segment membership:

$E_{S}=1+\sum_{i=1}^{N} \sum_{S=1}^{S} \lambda_{i s} \cdot \ln \left(\lambda_{i s}\right) / N \ln (\mathrm{S})$

The entropy statistic in equation (3.23) is a relative measure, bounded between 0 and 1. $E_{S}$ values close to 1 indicate that the posterior probabilities of farms belonging to a specific segment are close to either 0 or 1 , i.e. the segments are well defined (Pennings and Garcia, 2010). The $E_{s}$ value is trivially 1 if only one segment is used.

\subsection{Results}

\subsubsection{Farm-level Risk-balancing Behavior}

Further evidence of farm level risk-balancing behavior is presented using the log-linear fixed-effects panel-regression model. Table 3.2 shows the parameter estimates from equation (3.8). In general, all factors, except the cost of debt and a few farm type and year dummies, have a significant association with farm financial risk.

After controlling for other financial risk determinants and fixed effects, the coefficient estimate of our variable of interest, lagged business risk $\left(\mathrm{BR}_{\mathrm{t}-1}\right)^{38}$ is negative and significant at

\footnotetext{
38 In the empirical analysis section, we assume that business risk is exogenous. Thus, business risk is defined as the risk inherent in running a farm, independent of the way it is financed. Nevertheless, we recognize that
} 
the 5\% level. The coefficient estimates in Table 3.2 suggests that a one percent increase over last year's business risk is followed by a 0.0276 percent reduction in farm financial risk, suggesting that, consistent with the risk-balancing hypothesis, Dutch farms make strategic financial risk adjustment depending on the level of business risk in the previous year.

This result is consistent with the findings of de Mey et al. (2014) and Escalante and Barry (2003). In addition, the low standard error (0.0150) suggests that farmers have a very slim chance of achieving a positive coefficient. Since a one percent increase in business risk is followed by a less-than $1 \%$ decrease in farm financial risk, we reject the strong form of riskbalancing. The weak form of risk-balancing can be attributed to the fact that it might require more than just three years to make and see the impact of strategic leverage adjustments (Ahrendsen, Collender and Dixon, 1994; de Mey et al., 2014).

In line with our expectation, the estimated relationship between lagged profitability and financial risk is significant and negative at the $1 \%$ level. All things remaining the same, higher farm profitability results in lower farm financial risk. The signs of the significant coefficient estimates for farm size and age are positive and negative, respectively, coinciding with our expectation.

endogeneity is a potential problem in the model that we specified in equation (3.8). In principle, and much like the bulk of the literature, we assume that our main independent variable of interest, lagged business risk is exogenous to current financial risk. Our estimates are biased, however, if this variable is not exogenous due to reverse causality, i.e. feedback effects, or due to the omission of variables that are correlated with it and the dependent variable. Aaccordingly, we run a Durbin-Wu-Hausman test (Cong, 1999). We find that the second and third lag values of the business risk variables are valid instruments (the first stage regression's $\mathrm{R}^{2}$ is high at 0.4055 and the $\mathrm{F}$ test of joint significance result a $\mathrm{p}$ Value of 0.000 ). In the second stage instruments variable regression, a Hausman test for endogeneity results a p-value of 0.623 suggesting that we fail to reject the null hypothesis that the lagged business risk $\left(\mathrm{BR}_{\mathrm{t}-1}\right)$ is exogenous. In other words, there is evidence that the lagged business risk variable is exogenous. 
Table 3.2: Fixed-effects panel-regression results over the period 2001-2015

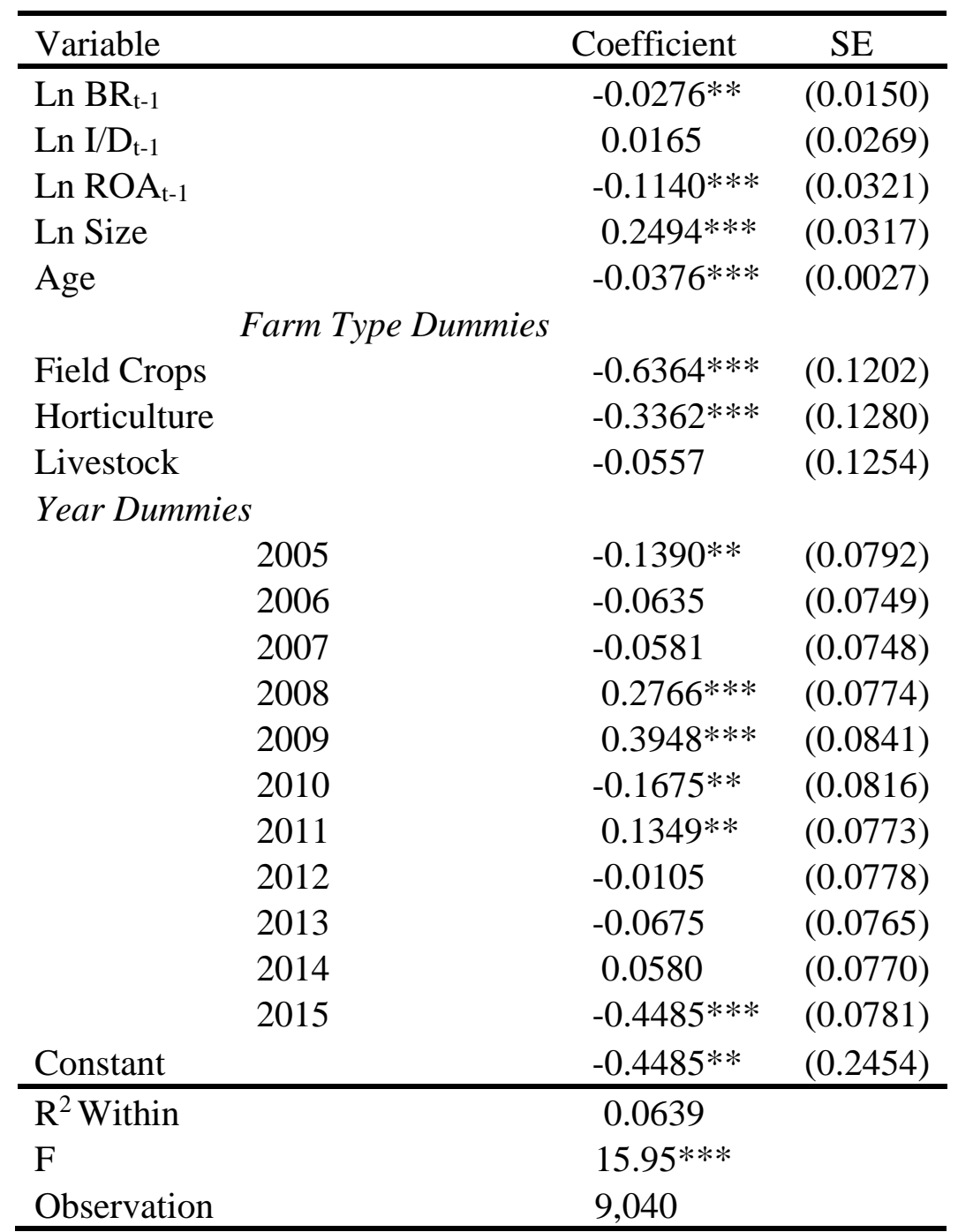

Notes: SE provides the robust standard errors, ***,**, * are significant at the $1 \%, 5 \%$, and $10 \%$ levels, respectively, and the dummy reference levels are dairy farms and the year 2004, respectively.

A joint Wald test of the farm type and year dummies shows overall significant effects at the $1 \%$ level. Field crops have slightly higher levels of financial risk, followed by horticulture. The overall coefficients for farm-type estimates are higher than those for year dummies, implying a more pronounced farm-sectoral difference in financial risk. Interestingly, the magnitude of the year dummies coefficient estimates exhibits an increasing trend in financial risk, especially after 2009, further suggesting the far-reaching impact of the financial crisis. 


\subsubsection{Drivers of Farm-level Risk-balancing Behavior}

Table 3.3 shows the estimation results of logit estimates of drivers of farm riskbalancing behavior. We fail to reject the null hypothesis of the Hausman test that the preferred model is a random-effect model, as opposed to a fixed-effects model. In practice, failure to reject the null hypothesis means that a) the random and fixed-effects estimates are similar and there is no systematic difference between the fixed and random-effects coefficients or (b) the sampling variation in fixed effects is extremely large and the data contains insufficient information to obtain precise estimates (Uzea et al., 2014; Wooldridge, 2015). Hence, both the random and fixed effects were estimated. Since the fixed-effects estimator heavily relies on the farm-internal variation of the dependent variable, farms that consistently balanced or refrained from balancing for the entire observation period were dropped from the estimation. As a result, we lost 752 farms $(1,281$ observations $)$ while estimating the fixed-effects model.

Results show that farm profitability and participation in government support programs, i.e. subsidy schemes, decrease the probability of farm risk-balancing behavior. This lower dependence on government support programs to stabilize income and manage risk is consistent with Escalante and Barry (2003) and may form an interesting policy implication in light of the current debate on the relevance of farm-supporting policy schemes. In addition, contrary to the findings of de Mey et al. (2016), larger farms tend to be significantly less likely to balance their risk. Farm investment, on the other hand, increases the likelihood of farm risk-balancing behavior.

A Wald test of year dummies shows overall significant effects at the $1 \%$ level but does not confirm the statistical significance of the farm type dummies. Interestingly, the magnitudes of the year dummies estimates suggest an increasing trend of farm risk-balancing behavior over the years, particularly in the aftermath of the 2008 financial crisis. 
Table 3.3: Logit estimates of drivers of farm risk-balancing behavior

\begin{tabular}{|c|c|c|c|c|}
\hline & \multicolumn{2}{|c|}{ Random Effects } & \multicolumn{2}{|c|}{ Fixed Effects } \\
\hline Variable & Estimates & $\mathrm{SE}$ & Estimates & SE \\
\hline Age & 0.003 & $(0.004)$ & 0.005 & $\overline{(0.007)}$ \\
\hline Size & $-0.122 * *$ & $(0.057)$ & -0.032 & $(0.265)$ \\
\hline Leverage & 0.113 & (0.199) & $1.441 * * *$ & $(0.554)$ \\
\hline Total Risk & 0.001 & (0.019) & -0.003 & $(0.027)$ \\
\hline Cost of Debt & 0.028 & $(0.053)$ & 0.011 & $(0.032)$ \\
\hline ROA & $-2.936 * *$ & (1.472) & $-7.641 * * *$ & $(2.827)$ \\
\hline Investment & $0.024 * *$ & (0.009) & $0.020 * *$ & $(0.012)$ \\
\hline Subsidy & $-1.472 * *$ & (0.859) & -1.892 & (1.204) \\
\hline Diversification & 0.115 & $(0.224)$ & 0.820 & $(0.723)$ \\
\hline \multicolumn{5}{|l|}{ Farm Dummies } \\
\hline Field Crops & 0.024 & $(0.124)$ & 1.125 & $(0.749)$ \\
\hline Horticulture & -0.102 & $(0.126)$ & 1.060 & $(0.854)$ \\
\hline Livestock & -0.088 & $(0.132)$ & 0.360 & $(0.475)$ \\
\hline \multicolumn{5}{|l|}{ Year Dummies } \\
\hline 2005 & $0.538 * *$ & $(0.301)$ & 1.177 & $(0.804)$ \\
\hline 2006 & 0.456 & $(0.295)$ & 1.072 & $(0.832)$ \\
\hline 2007 & $0.778 * * *$ & $(0.294)$ & $1.414 * *$ & $(0.834)$ \\
\hline 2008 & $0.714 * * *$ & $(0.294)$ & $1.442 * *$ & $(0.835)$ \\
\hline 2009 & $1.001 * * *$ & $(0.302)$ & $1.705 * *$ & $(0.840)$ \\
\hline 2010 & $0.734 * * *$ & $(0.290)$ & $1.451 * *$ & $(0.837)$ \\
\hline 2011 & $0.940 * *$ & $(0.291)$ & $1.574 * *$ & $(0.837)$ \\
\hline 2012 & $0.973 * * *$ & $(0.289)$ & $1.644 * *$ & $(0.838)$ \\
\hline 2013 & $0.886^{* * *}$ & $(0.287)$ & $1.623 * *$ & $(0.837)$ \\
\hline 2014 & $0.801 * * *$ & $(0.285)$ & $1.465 * *$ & $(0.838)$ \\
\hline 2015 & $0.916^{* * * *}$ & $(0.281)$ & $1.632 * *$ & $(0.837)$ \\
\hline Constant & 1.135 & $(0.899)$ & -- & -- \\
\hline $\mathrm{R}^{2}$ Pseudo & 0.025 & & 0.007 & \\
\hline Log-Likelihood & -3085 & & -1405 & \\
\hline$\chi^{2}$ & $38.70 * *$ & & $50.92 * * *$ & \\
\hline Obs. & 9040 & & 7759 & \\
\hline
\end{tabular}

Notes: SE provides the robust standard errors, ***,**,* are significant at the $1 \%, 5 \%$, and $10 \%$ levels, respectively, and the dummy reference levels are dairy farms and the year 2004, respectively.

To increase our understanding and facilitate the interpretation of the coefficients, we estimated the marginal effects of the random-effects logit model, the results of which are included in Table 3.4. The marginal effect is the effect of a one-unit change in the predictor variable on the probability $\mathrm{P}(\mathrm{Y}=1 \mid \mathrm{X}=\mathrm{x})$ with all other variables remaining constant and can be expressed as:

$$
\frac{\partial P\left(y_{i t}=1 \mid x_{i t}\right)}{\partial x_{i t}}=\frac{\partial E\left(y_{i t} \mid x_{i t}\right)}{\partial x_{i t}}=\varphi\left(x_{i t}^{\prime} \beta\right) \beta
$$


Table 3.4: Marginal effects of the random effects logit model

\begin{tabular}{llr}
\hline Variable & Coefficients & SE \\
\hline Age & 0.0007 & $(0.0008)$ \\
Size & $-0.0263 * *$ & $(0.0124)$ \\
Leverage & 0.0243 & $(0.0430)$ \\
Total Risk & 0.0002 & $(0.0041)$ \\
Cost of Debt & 0.0060 & $(0.0114)$ \\
ROA & $-0.6336 * *$ & $(0.2842)$ \\
Investment & $0.0051 * *$ & $(0.0020)$ \\
Subsidy & $-0.3176 * *$ & $(0.1852)$ \\
Diversification & 0.0247 & $(0.0484)$ \\
Farm Dummies & & \\
Field Crops & 0.0051 & $(0.0268)$ \\
Horticulture & -0.0221 & $(0.0273)$ \\
Livestock & -0.0191 & $(0.0286)$ \\
Year Dummies & & \\
2005 & $0.1161 * *$ & $(0.0650)$ \\
2006 & 0.0984 & $(0.0636)$ \\
2007 & $0.1679 * * *$ & $(0.0634)$ \\
2008 & $0.1541 * *$ & $(0.0633)$ \\
2009 & $0.2171 * * *$ & $(0.0650)$ \\
2010 & $0.1584 * * *$ & $(0.0625)$ \\
2011 & $02029 * *$ & $(0.0628)$ \\
2012 & $0.2101 * * *$ & $(0.0629)$ \\
2013 & $0.1913 * * *$ & $(0.0619)$ \\
2014 & $0.1728 * * *$ & $(0.0615)$ \\
2015 & $0.1977 * * *$ & $(0.0606)$ \\
\hline Obs. & 9040 &
\end{tabular}

Notes: SE provides the robust standard errors, ***,**,* are significant at the $1 \%, 5 \%$, and $10 \%$ levels, respectively, and the dummy reference levels are dairy farms and the year 2004, respectively.

The results indicate that, on average, a one-unit change in farm size, profit and subsidy rates results in a $2.63,63.4$, and 31.8 percentage points lower likelihood of making strategic risk adjustments, respectively, with all else held at means.

Due to the nonlinear nature of the logit model, the marginal effect of the predictor variables depends on the location of the covariates. Hence, visualizing the relationship across the range of covariate values enhances the analysis (Trujillo-Barrera, Pennings and Hofenk, 2016). Figure 3.2 depicts the average marginal effects of total risk, subsidy, leverage, size, 
profit, and age on the probability of risk-balancing, leaving all other predicting variable values as observed. Each figure includes the $95 \%$ confidence intervals (CIs) as shaded areas.
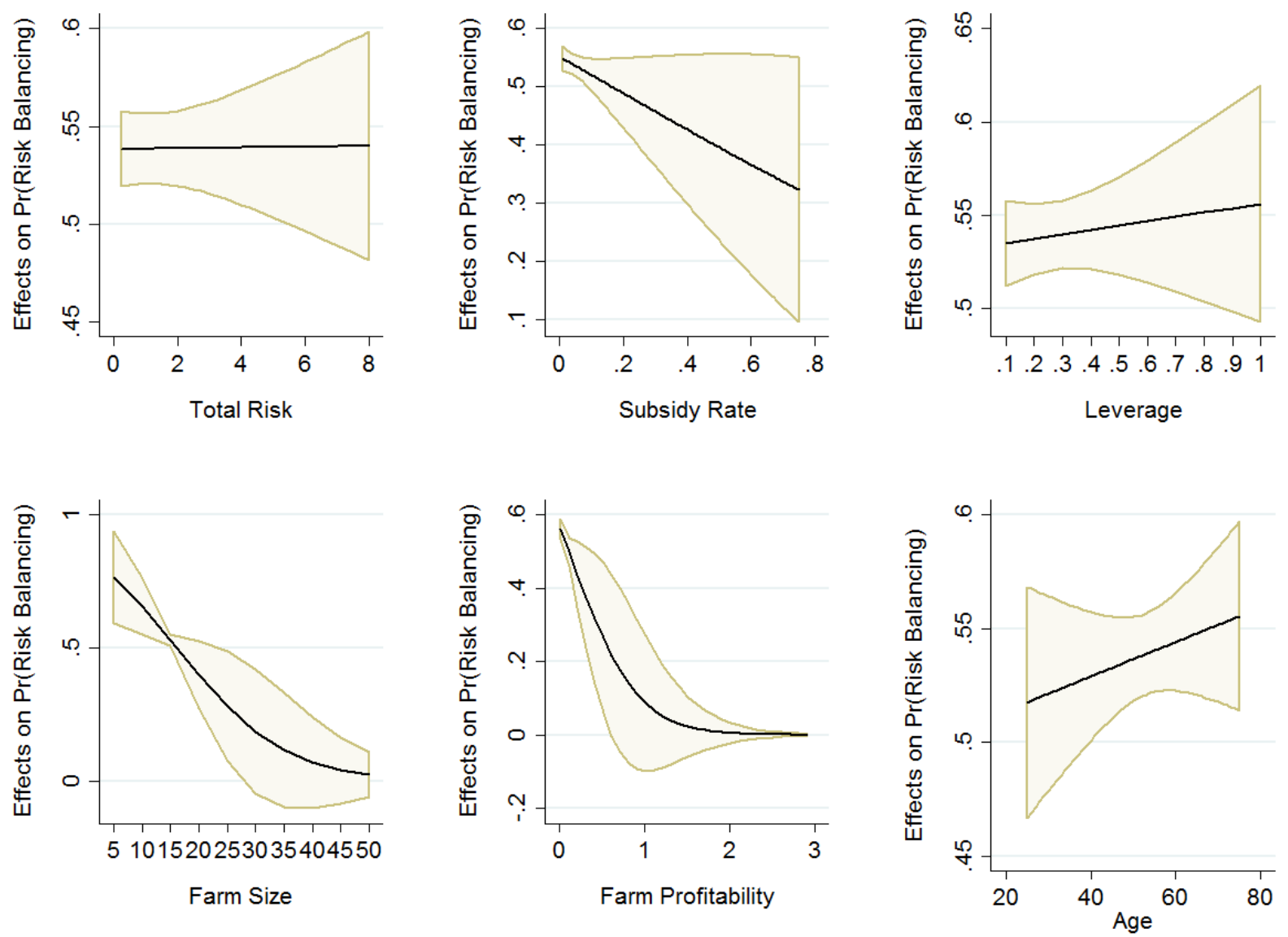

Figure 3.2: Average marginal effects of total risk, subsidy, leverage, size, profit, and age on the probability of risk-balancing

The probability of farms balancing their risk increases steeply as subsidy rates or government support decrease. The likelihood of farms' exhibiting risk-balancing behavior rises as farms age and their leverage ratio increase. In line with our coefficient estimates in Table 3.3, the probability of farm risk-balancing decreases as farms become more profitable and larger in size.

Note that farms from different regions or with different production systems may face dissimilar economic and policy constraints that might lead to different choices in risk-balancing behavior. Similarly, farm managers may have different motivations, risk attitudes and perceptions (Pennings and Garcia, 2010). We may expect this heterogeneity to affect farm riskbalancing behavior. A Wald test did not confirm the statistical significance of farm type 
dummies, however (see Tables 3.3 and 3.4), suggesting that the effects of selected farm characteristics on farm risk-balancing behavior cannot a priori be assumed to be equal for all farm types. Hence, using the latent mixture logit model outlined in section 3.2.3, we examined whether all farms can be treated in a similar way or whether there are segments of farms that exhibit dissimilar risk-balancing behavior. Table 3.5 lists the $\mathrm{AIC}, \mathrm{BIC}$, and $\mathrm{E}_{\mathrm{s}}$ statistics from our mixture regression analysis that correspond to the log-likelihood.

Table 3.5: Fit statistics of the mixture models for segments $S=1$ to 6

\begin{tabular}{lllll}
\hline Segments $S$ & Log Likelihood & AIC & BIC & $E_{S}$ \\
\hline 1 & -3165 & 6354 & 6431 & 1.000 \\
2 & -3096 & 6242 & 6403 & 0.251 \\
$\mathbf{3}$ & $\mathbf{- 3 0 6 3}$ & $\mathbf{6 1 0 3}$ & 6447 & $\mathbf{0 . 4 1 0}$ \\
4 & -3065 & 6206 & 6451 & 0.372 \\
5 & -3027 & 6183 & 6594 & 0.310 \\
6 & -3018 & 6190 & 6686 & 0.314 \\
\hline
\end{tabular}

Based on the minimum AIC statistic (6103) and maximum entropy value ${ }^{39}(0.410)$, we selected $s=3$ as the appropriate number of segments. This solution has a log likelihood of 3063. Table 6 presents the estimated coefficient for the three-segment solution. The results document the presence of multiple farm segments with different relationships between farm characteristics and the likelihood of a risk-balancing behavior.

Segment $1(s=1)$ is the smallest segment, which constitutes $13.3 \%$ of the sample and contains $42 \%$ of the dairy farms, $14 \%$ of the field-crop farms, $31 \%$ of the horticulture farms, and $13 \%$ of the livestock farms. Note that, while constituting $42 \%$ of segment 1 , dairy farms are also an important part of the other segments. In this segment farm profitability, total risk exposure, leverage, and diversification show a significant association with farm risk-balancing. These terms can be clearly interpreted. The probability of farms balancing their risk is higher in this segment, which is exposed to a higher total risk, and these farms would probably use

\footnotetext{
${ }^{39}$ The moderate value of our entropy statistic can be attributed to the fact that we have used panel data and allowed farms to switch segments, which might affect the stability of class membership.
} 
leverage as an instrument. These findings confirm the previous findings of de Mey et al. (2014). This segment also includes the highest percentage of risk balancers compared to the other two segments.

Table 3.6: Finite mixture-panel logit regression results for the three-segment solution in which farm risk-balancing behavior is the dependent variable

\begin{tabular}{llll}
\hline Variables & $s=1$ & $s=2$ & $s=3$ \\
\hline ROA & $2.916^{* *}$ & $-10.552^{* * *}$ & $12.206^{* *}$ \\
Total Risk & $30.604 * * *$ & $0.156^{*}$ & $-0.197 *$ \\
Investment & 9.869 & 0.015 & 0.006 \\
Leverage & $0.169 *$ & $1.147 * * *$ & $-2.161^{* *}$ \\
Size & -4.244 & $-1.332^{* *}$ & $1.270 *$ \\
Age & -0.644 & $0.031 * *$ & $-0.049 * * *$ \\
Subsidy & 1.778 & -1.837 & 3.579 \\
Cost of Debt & 0.072 & 0.013 & 0.016 \\
Diversification & $-3.801 *$ & -0.089 & $1.615 * *$ \\
Constant & 2.916 & $-1.800 * *$ & $3.726 * * *$ \\
Percentage of farm types & & & \\
Dairy Farms & $157(42 \%)$ & $865(30 \%)$ & $481(37 \%)$ \\
Field Crops & $53(14 \%)$ & $660(23 \%)$ & $258(20 \%)$ \\
Horticulture & $119(31 \%)$ & $850(29 \%)$ & $366(28 \%)$ \\
Livestock & $48(13 \%)$ & $542(18 \%)$ & $188(15 \%)$ \\
\hline Segment Size, $\pi_{s}$ & $0.133 \%$ & $0.637 \%$ & $0.286 \%$ \\
\hline Note: $* * * * * *$ are significant at the $1 \%, 5 \%$, and $10 \%$ levels, respectively.
\end{tabular}

Segment $2(s=2)$ is the largest segment, containing $63.7 \%$ of the entire sample. It is composed of $30 \%$ dairy farms, $23 \%$ field-crop farms, $29 \%$ horticulture farms, and $18 \%$ livestock farms. Similar to segment 1 , farm profitability, total risk and leverage show a significant effect on farm risk-balancing behavior. Similar to segment 3, farm size and age also have a significant effect on farm risk-balancing behavior.

The risk-balancing behavior of farms in segment $3(s=3)$ is driven by farm profitability, total risk, leverage, farm size, age, and diversification. This segment represents $28.6 \%$ of the entire sample and consists of $37 \%$ dairy farms, $20 \%$ field-crop farms, $28 \%$ horticulture farms, and $15 \%$ livestock farms. 
Note further that farm leverage, profitability, and total risk are significantly associated with risk-balancing behavior in all three identified segments, with different size effects. The importance of the risk variable and leverage is consistent with the risk-balancing hypothesis that farms will use leverage to balance their risk when exogenous shocks alter their total risk level.

Interestingly, we find that the three segments are not homogeneous with respect to the type of farm (dairy, field-crop, horticulture, and livestock). In addition, contrary to our findings in Table 3.6, variables such as leverage, size, age, and diversification were not significantly related to farm risk-balancing behavior during the traditional logit analysis in section 3.2. The results in Table 3.6 thus substantiate the importance of applying the mixture model. Using the latter, heterogeneity emerges from the impacts of the determinants of farm risk-balancing behavior (as measured in the estimated coefficients for each segment), rather than from a single observation variable, such as farm type. Table 3.7 provides further descriptive statistics for each identified segment.

If we were to ignore this latent heterogeneity and instead adhere to our approach of farm classification based on farm type as outlined in section 3.2, we would explicitly restrict the relationship between the explanatory variables and risk-balancing behavior to being identical for all dairy, field crops, horticulture, and livestock farms, but different across these farm types.

The results in Tables 3.6 and 3.7 provide interesting economic interpretations. Segment 1 is characterized by the highest percentage $(80 \%)$ of farms that balance their risk, and their risk-balancing decisions depend mostly upon their total risk exposure, leverage, diversification, and profitability. Interestingly, compared to the other segments, segment 1 is dominated by farms with the smallest non-farm incomes, direct payments, land size, and, most importantly, risk-bearing capacity. These characteristics contribute to the fact that farms in this segment depend heavily on risk-balancing as a risk-management instrument. In this context, diversification is an alternative, not a complementary strategy in the overall risk-management approach. 
Table 3.7: Descriptive statistics for identified segments

\begin{tabular}{llll}
\hline & \multicolumn{1}{c}{$\boldsymbol{s = 1}$} & \multicolumn{1}{c}{$\boldsymbol{s = 2}$} & \multicolumn{1}{c}{$\boldsymbol{s = 3}$} \\
\hline Segment Size (obs.) & $377(13.3 \%)$ & $2,917(63.7 \%)$ & $1,293(28.6 \%)$ \\
Percentage Risk Balancers & $303(80 \%)$ & $1,427(49 \%)$ & $699(54 \%)$ \\
Average Net Farm Income & 144,933 & 152,558 & 122,418 \\
Total Asset & $3,154,874$ & $3,417,973$ & $3,087,186$ \\
Non-Farm Income & 7766 & 10,237 & 9244 \\
Total Farm output & 768,216 & 745,083 & 597,222 \\
Investment & 154,401 & 170,733 & 146,415 \\
Subsidy-direct payment & 16,328 & 16,444 & 17,381 \\
Average land size & 38.767 & 48.33 & 54.596 \\
Average Risk bearing capacity & 0.170 & 0.455 & 0.427 \\
\hline
\end{tabular}

Segment 2 contains the largest proportion of the sample's farm population (63.7\%), with a relatively low proportion of risk-balancing farms (49\%). In contrast to the other segments, this segment is dominated by larger farms in terms of total assets, with the highest profitability, non-farm incomes, investments, and risk-bearing capacity. These attributes account for the strong risk resilience of the farms in this segment, which leads to lower riskbalancing and a preference for alternative risk-management strategies.

Segment 3 is dominated by farms with the largest utilized land area, but with the smallest non-farm income and total assets. Relative to farms in the other segments, these farms receive the highest subsidies in the form of direct payments from the government. It is also interesting to note that farms in this segment use diversification as a complementary, rather than a substitute strategy for balancing risk. Proportionally, dairy and horticultural farms take the lion share in all three segments. To further investigate what sets these three segments apart,

\footnotetext{
${ }^{40}$ Following Mishra, Wilson and Williams (2009), we use liquidity as a proxy for farm risk-bearing capacity and measure it as the ratio of current liability to current asset. It reflects the utilization of current assets to efficiently meet short-term and long-term financial obligations without disrupting normal operations. Maintaining optimal liquidity is important for farms that do not have continuous sales throughout the year.
} 
i.e. why farms respond differently across segments, we used age, business and financial risk, and leverage as profiling variables. Table 3.8 presents the results.

Table 3.8: Profile of the three segments using farm age, business risk, financial risk, and leverage

\begin{tabular}{lllllll}
\hline & $\boldsymbol{s}=\mathbf{1}$ & & $\boldsymbol{s}=\mathbf{2}$ & & $\boldsymbol{s}=\mathbf{3}$ \\
& Mean & SD & Mean & SD & Mean & SD \\
\hline Age & 53 & 10.130 & 52 & 9.890 & 52 & 10.140 \\
Business Risk & 0.346 & 0.303 & 0.335 & 0.270 & 0.310 & 0.250 \\
Financial Risk & 0.458 & 1.023 & 0.721 & 1.731 & 0.932 & 2.242 \\
Leverage & 0.270 & 0.234 & 0.254 & 0.223 & 0.244 & 0.206 \\
\hline
\end{tabular}

$\mathrm{SD}$ is the standard deviation.

Interestingly, segment $1(s=1)$ is dominated by farms with the highest business risk and leverage ratios and the lowest financial risk. Note that the majority of farms (80\%) in this segment balance their risk, and the descriptive statistics in Table 3.7 further suggests that these farms use leverage to respond to increased business risk due to major shocks in the sector. In contrast, segment $3(s=3)$ is characterized by relatively young farms with the highest financial risk and the lowest business risk and leverage ratios. Recall that the percentage of risk balancers in segment $1>$ segment $3>$ segment 2 , and age is significant in defining segment 2 and 3 , though not segment 1 .

\subsection{Robustness Checks}

One of the challenges in agricultural economics and finance literature is the lack of a commonly accepted measure of farm risks (Hardaker et al., 2015; Thomas, 2016). To obtain a complete picture of farm risk exposure and further examine the measurement invariance robustness of our results, four separate analyses are done using (a) standard deviation as a measure of business risk, (b) downside deviation as a measure of business risk, (c) solvency ratio $^{41}$ as a measure of business risk, and (d) the standard deviation of net farm income without debt financing as a measure of total risk. The results presented in Tables 3.9 through 3.12 of

\footnotetext{
${ }^{41}$ It is measured as the ratio of total debt to equity (total debt/equity).
} 
the Appendix show that a change in risk measure does not significantly alter our main conclusions about the existence and the drivers of risk-balancing behavior among Dutch farms.

In addition, estimating the panel fixed-effects regression model is econometrically challenging. We suspect that some of the explanatory variables in equation (3.8) are potentially endogenous. Hence, estimating the parameters with the standard OLS estimator may lead to inconsistency and bias (Greene, 2003). An instrumental variable approach is a common practice to account for endogeneity. In most socio-economic research, it is very difficult to obtain (external) instruments that are valid from a theoretical and an empirical point of view. We use System-GMM estimation as an 'internal' instrument approach ${ }^{42}$. We ran the analysis using the -xtdpdsys- command on STATA, and the results are included in Table 3.10 of the Appendix. The specification tests, i.e. the Sargan test of over-identifying restrictions and no second-order autocorrelation, indicate that the key identifying assumptions required for the System-GMM estimator are satisfied.

Finally, dropping an observation just because it is an outlier is not always an optimal solution. Hence, we ran all the additional analyses in the robustness section without trimming the data and found that including the outlier does not change the results but only affects the assumptions of the distribution.

\subsection{Conclusions}

The paper provides a farm-level empirical support for the risk-balancing hypothesis based on longitudinal data from a panel of 1500 Dutch farms over a period of fifteen years between 2001 and 2015. We have found that more than half of the farms exhibited riskbalancing behavior over this period, implying that farms make strategic adjustments by taking more (less) debt in response to a decrease (increase) in business risks. Results from the linear fixed-effects model show evidence of farm risk-balancing behavior: a negative relationship between lagged farm business risk levels and the current financial risk, with its extent differing

\footnotetext{
${ }^{42}$ A detailed discussion of the System-GMM estimator is included in the Appendix of this chapter.
} 
across farm types. The logit panel regression results show that the likelihood of risk-balancing by farms decreases with size, profit, and share of government subsidy payments. Conversely, it increases with investment and leverage.

Because we expect our sample to contain latent segments, we have applied a latent mixture regression model. The model, estimated with the iterative EM algorithm, simultaneously identifies segments based on the influence of the selected explanatory variables and estimates the effects of these variables on farm risk-balancing behavior for each identified segment. Our analysis shows that farm profitability, leverage, age, size, and diversification play an important role in driving the probability of farm risk-balancing behavior. The importance of the risk variable and leverage is consistent with the risk-balancing hypothesis that farms will use leverage to adjust to the optimal total risk level when exogenous shocks alter their total risk level.

In addition, the analysis shows the presence of multiple segments that can be interpreted by the risk-balancing hypothesis. Farm profitability, total risk, leverage, age, size, and diversification are the factors related to farm risk-balancing behavior. Interestingly, we find that these factors are not equally important across the farm sector. Assuming homogeneity in farms' responses and estimating a pooled model or a priori classifying farms based on farm type would, therefore, yield a poor fit and would lead to the conclusion that only size, profit, subsidy, and investment were determinants of the likelihood of farm risk-balancing. The existing heterogeneity at segment level appears to have been masked at aggregate farm-type level. These masking effects are prominent for the factors that are part of the risk-balancing hypothesis, such as farm leverage and total risk exposure. The advantage of the segmentation method becomes apparent from the different farm types present in each segment: each of the identified three segments contains dairy, field-crop, horticulture, and livestock farms in varying proportions.

Our work has implications for farms, financial institutions, and policymakers. The importance of leverage and farm profitability in farm risk-balancing behavior has at least two important implications. First, farms rely heavily on the availability of and access to loans. 
Given the fact that farm businesses have minimal access to equity markets or none at all, policies aimed at helping farms manage their risk should make access to credit facilities a priority. Furthermore, the heterogeneity of farm risk balancers suggests that financial institutions can use these characteristics for risk profiling and loan evaluation in each segment. Second, farm profitability and risk-balancing are strongly related, suggesting that farms use their retained earnings as a buffer when exogenous shocks disturb the optimal total risk level. As a result, the effects of farm-support programs, such as subsidies and direct payments aiming at stabilizing profit, cannot be easily identified. Our work should thus spark discussion about the linearity of the relationship between risk-management policy instruments and total farm risk. Furthermore, with the identification of farm segments and the provision of information for profiling within each segment, public policymakers will be able to target these segments more effectively and design risk-management strategies that best suit each segment. In general, our results suggest that more attention should be paid to both observed and unobserved factors in designing and implementing individual risk-management instruments and in assessing their impact on the farm sector.

This paper has limitations that motivate further research. Despite our use of high-quality panel data, this is merely an accounting data set. Future research may complement this study with behavioral and demographic data on, for example, education, farm risk aversion, risk attitude, and risk perception. It is also interesting to examine alternative measurements of farm risk-balancing behavior. Another interesting extension would be to conduct a farm survey on risk preferences or an experimental procedure as an alternative to the econometrics method used in this paper. Future research may also test the synergistic relationship of risk-balancing with other alternative risk-management strategies and its impact on farm performance in terms of profitability, risk resilience ${ }^{43}$, and viability ${ }^{44}$.

\footnotetext{
${ }^{43}$ Risk resilience is commonly defined as the capacity to prepare for, cope with, and adapt to a shock as a result of farm business and financial risks while maintaining the basic farming operations(Gitz and Meybeck, 2012; Hardaker et al., 2015).

${ }^{44}$ Here, the term farm viability is used to conceptualize the ability/capability of a farm to generate revenue (farm income) from its basic farming activities, which is then used to cover all the fixed and variable costs of the farm
} 
Policy-wise, in this chapter, we argue that risk management should be still a public policy and should recognize both the observed and unobserved heterogeneity among farms. Nevertheless, it would be also interesting to see whether risk management in agriculture in Europe could be strictly a public policy matter or left to the discretion of individual farmers with minimal support from the government. A final promising direction for future research would be to improve our understanding of the variations in farm risk-balancing behavior across countries and economies, including, for example, the economies of developed vs developing countries and across countries with different risk-management and farm-support systems, such as European countries and the US. 


\subsection{Appendix}

\section{A1. Correlation Relationship Analysis}

The correlation coefficients are estimated over pairings between one-year lagged business risk (BR) and the current period's financial risk (FR). Since the risk-balancing theory hypothesizes an inverse relationship between one-year lagged business risk and current financial risk, a negative and significant correlation coefficient would constitute simple descriptive evidence of farm risk-balancing behavior.

Table 3.9: Proportion of risk balancers

\begin{tabular}{cccc}
\hline Year & $\begin{array}{c}\text { Risk }^{45} \\
\text { Balancers }\end{array}$ & $\begin{array}{c}\text { Proportion } \\
(\%)\end{array}$ & $\begin{array}{c}\text { Average Coefficients } \\
\text { Risk Balancers }\end{array}$ \\
\hline 2004 & 28 & 46.15 & -0.0769 \\
2005 & 119 & 50.66 & -0.0271 \\
2006 & 143 & 47.83 & -0.0234 \\
2007 & 180 & 53.73 & -0.0117 \\
2008 & 177 & 51.91 & -0.0147 \\
2009 & 157 & 57.93 & -0.0600 \\
2010 & 223 & 51.74 & -0.0034 \\
2011 & 230 & 57.07 & -0.0095 \\
2012 & 268 & 57.26 & -0.0867 \\
2013 & 274 & 55.02 & -0.0402 \\
2014 & 293 & 53.47 & -0.0767 \\
2015 & 382 & 55.93 & -0.0710 \\
Farm Type & & & \\
\hline Dairy Farms & 831 & 55.33 & -0.0601 \\
Field Crops & 524 & 53.96 & -0.0644 \\
Horticulture & 705 & 52.80 & -0.0171 \\
Livestock & 414 & 53.21 & -0.0381 \\
\hline Overall & & $\mathbf{5 3 . 0 3}$ & $\mathbf{- 0 . 0 4 3 2}$ \\
\hline
\end{tabular}

We can infer from Table 3.9 that the overall correlation coefficient between financial risk and one-year lagged business risk is -0.0432. de Mey et al. (2014) also document a slightly lower negative coefficient. Table A-1 further shows that more than half of the observations (53.03\%) exhibit risk-balancing behavior. Comparing across farm types, dairy farms and fieldcrop farms have a slightly higher proportion of risk balancers. The difference between the

\footnotetext{
${ }^{45} \mathrm{~A}$ farm observation is classified as risk balancer when the three-year correlation coefficient between financial risk and one-year lagged business risk is negative.
} 
annual distributions of risk balancers is also documented: the proportion of risk balancers exceeded $50 \%$ in ten out of twelve years. Both the proportion and the coefficients increased in magnitude in the post-financial crisis period (2009-2015).

Figure 3.3 illustrates the distribution of the correlation coefficient measure of riskbalancing by sector. All farm sectors exhibit fairly similar risk-balancing behavior despite their exposure to different business environments, production systems, policy factors, and other macro-economic conditions over the period under investigation.

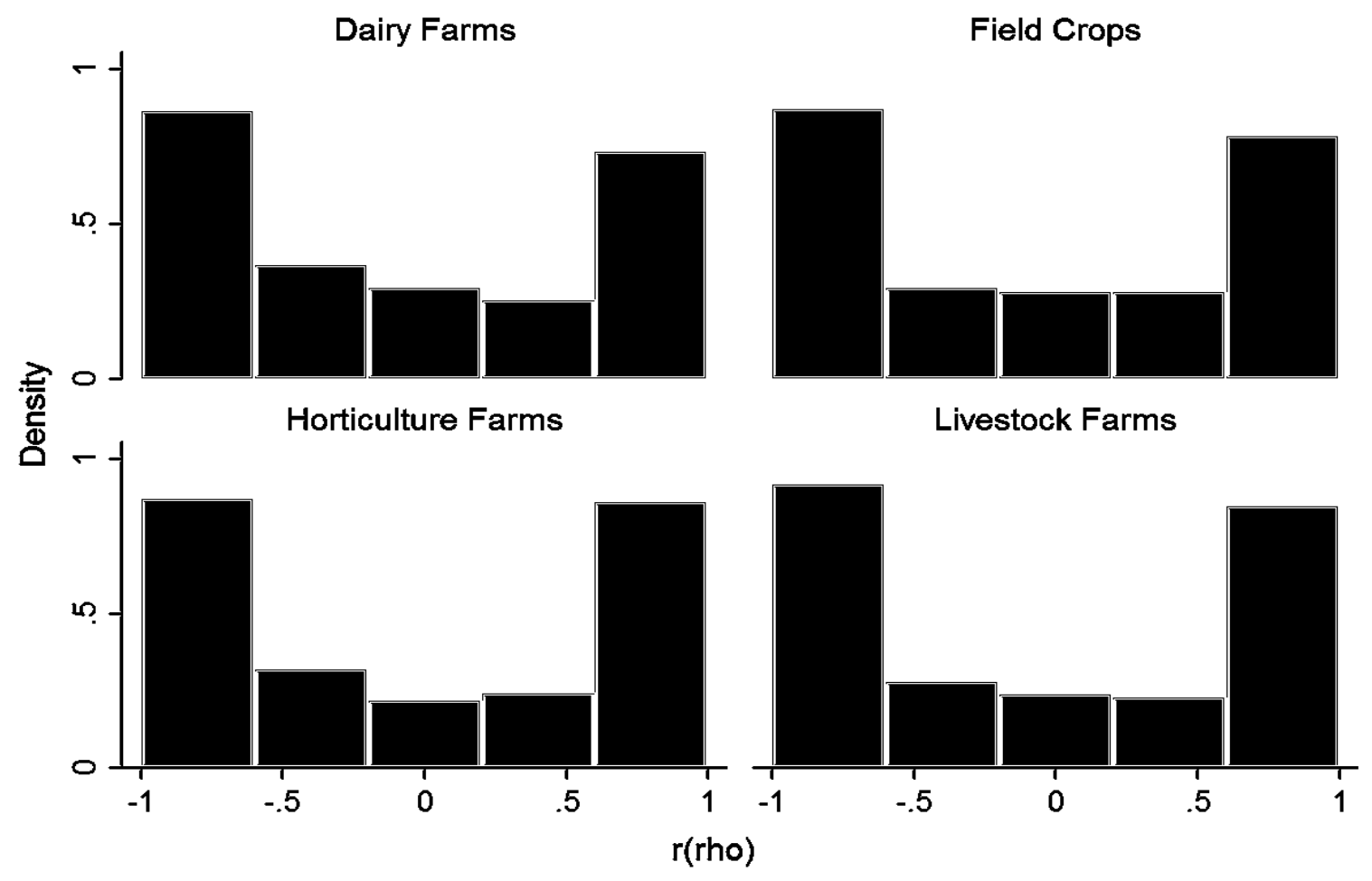

Figure 3.3: Distribution of FR-BR correlations, by farm type

Figure 3.3 further shows a symmetric bimodal, i.e. two-peak distribution with the correlation coefficients between lagged business risk and current financial risk clustered around 1 and -1 , implying a sinusoidality in the response that farms tend to balance (or not) their risk in the strong form. A descriptive summary of the mean values of the variables is presented in Table 3.10. 
Table 3.10: Mean values of selected variables per risk-balancing class

\begin{tabular}{lllll}
\hline & \multicolumn{2}{c}{ Non-Risk Balancers } & \multicolumn{2}{c}{ Risk Balancers } \\
\hline Variables & $(0.75$ to 1.00$)$ & $(0.74$ to 0.01$)$ & $(-0.74$ to 0.00$)$ & $(-1.00$ to -0.75$)$ \\
\hline Obs. & 1,482 & 695 & 845 & 1,629 \\
NFI & 149,115 & 142,432 & 143,883 & 137,301 \\
ROA & 0.050 & 0.040 & 0.045 & 0.049 \\
Age & 52.400 & 52.800 & 52.800 & 52.000 \\
Leverage & 0.268 & 0.244 & 0.250 & 0.266 \\
Size & 14.650 & 14.750 & 14.700 & 14.63 \\
Diversification & 0.174 & 0.178 & 0.190 & 0.180 \\
\hline Farm Type $(\%)$ & & & & \\
Dairy Farms & 0.300 & 0.350 & 0.370 & 0.320 \\
Field Crops & 0.210 & 0.240 & 0.200 & 0.210 \\
Horticulture & 0.310 & 0.270 & 0.270 & 0.290 \\
Livestock & 0.180 & 0.140 & 0.160 & 0.180 \\
\hline
\end{tabular}

The sample farms are classified into four groups based on their correlation coefficients. Farms with negative correlation coefficients are classified as risk balancers while those with positive coefficients are grouped as non-risk balancers. Sixty-five percent of risk-balancing farms exhibit a strong form of risk-balancing. There is no clear trend in the mean values of the selected variables. Smaller farms with lower NFI and managed by younger farm operators tend to strongly balance their risk.

\section{A2. Measurement of Risk Exposure in Agriculture}

Four separate analyses are performed using (a) standard deviation as a measure of business risk, (b) downside deviation as a measure of business risk, (c) solvency ratio as a measure of business risk, and (d) the standard deviation of net farm income without debt financing as a measure of total risk. The results are presented through Tables 3.11 and 3.14. 


\section{A2.1. Standard deviation as a measure of business risk}

Table 3.11: Fixed-Effects panel-regression results using standard deviation as business risk over the period 2004-2015

\begin{tabular}{|c|c|c|}
\hline Variable & Coefficient & SE \\
\hline$\overline{L n}$ BR $_{t-1}$ & $-0.59295 * *$ & $(0.2398)$ \\
\hline $\operatorname{Ln~} / / D_{t-1}$ & 0.04319 & $(0.0276)$ \\
\hline $\operatorname{Ln~ROA}_{t-1}$ & $-4.4372 * * *$ & $(0.4074)$ \\
\hline Ln Size & $0.5313 * * *$ & $(0.0436)$ \\
\hline Age & $-0.2468 * * *$ & $(0.0329)$ \\
\hline \multicolumn{3}{|c|}{ Farm Type Dummies } \\
\hline Field Crops & $-0.5563^{*}$ & $(0.1088)$ \\
\hline Horticulture & -0.4686 & $(0.0984)$ \\
\hline Livestock & -0.0101 & $(0.1017)$ \\
\hline \multicolumn{3}{|l|}{ Year Dummies } \\
\hline 2005 & $-0.3237 * * *$ & $(0.0632)$ \\
\hline 2006 & $-0.2706 * * *$ & $(0.0622)$ \\
\hline 2007 & $-0.3061 * * *$ & $(0.0629)$ \\
\hline 2008 & -0.0162 & $(0.0662)$ \\
\hline 2009 & 0.0620 & $(0.0717)$ \\
\hline 2010 & $-0.4431 * * *$ & $(0.0641)$ \\
\hline 2011 & $-0.2722 * * *$ & $(0.0662)$ \\
\hline 2012 & $-0.4875 * * *$ & $(0.0647)$ \\
\hline 2013 & $-0.5060 * * *$ & $(0.0645)$ \\
\hline 2014 & $-0.4595 * * *$ & $(0.0661)$ \\
\hline 2015 & 0 & (omitted) \\
\hline Constant & $-7.5847 * * *$ & $(0.6311)$ \\
\hline $\mathrm{R}^{2}$ Within & 0.0431 & \\
\hline $\mathrm{F}$ & $14.38 * * *$ & \\
\hline
\end{tabular}

Notes: SE provides the robust standard errors, $* * *, * *, *$ are significant at the $1 \%, 5 \%$, and $10 \%$ levels respectively, the dummy reference levels are dairy farms and the year 2004, respectively, and the year 2015 is omitted due to collinearity

\section{A2.2. Downside deviation as a measure of business risk}

One of the limitations of using the standard deviation is that it is simply a measure of variation that does not differentiate between upside and downside risks. To address this concern, we ran an additional analysis and plotted a new figure using downside deviation as a measure of business risk rather than standard deviation. 
The downside deviation was calculated as follows: Firstly, we defined the minimum acceptable yearly return (ROA). Similar to our calculation of the coefficients of variation, we set the target return to a three-year rolling average of farm return on asset. Secondly, we subtracted the minimum acceptable (ROA) from the ROA for the year in the return stream for all the years that the farm remained in the sample. Thirdly, we reset the value to 0 if the ROA remained positive after subtracting the minimum acceptable (ROA) from each year's ROA. Fourthly, we squared the difference, and finally, we took the square root of the number in step four to get the downside deviation. We use the following formula:

$\sqrt{\frac{1}{n} \sum_{r<t}(r-t)^{2}}$

Where $r$ and $t$ are the farmer's ROA and minimum acceptable yearly return (ROA), respectively.
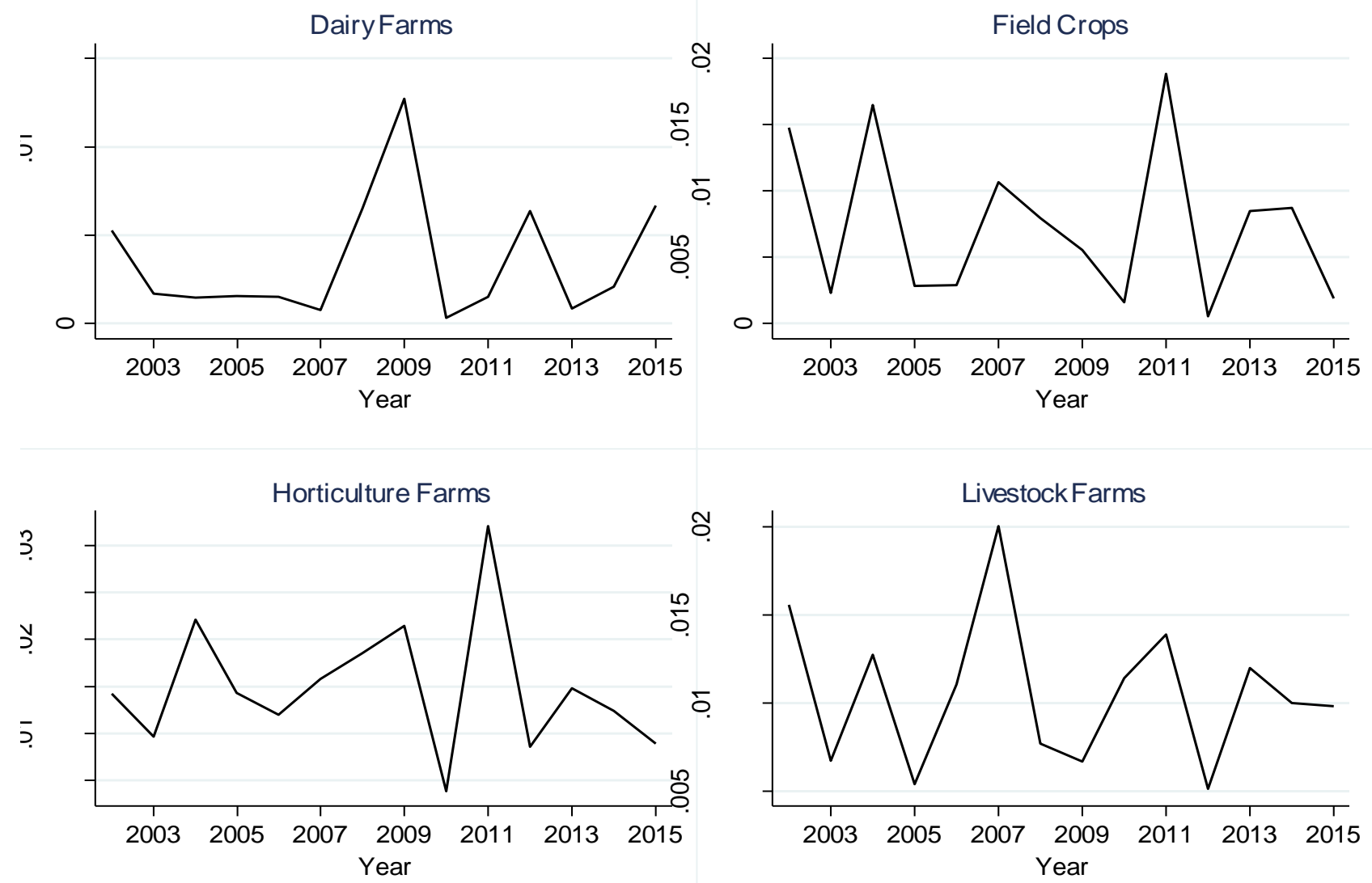

Figure 3.4: Business risk measured as downside deviation by farm type, 2003-2015 
Table 3.12: Fixed-effects panel-regression results using downside deviation as business risk over the period 2004-2015

\begin{tabular}{|c|c|c|}
\hline Variable & Coefficient & $\overline{\mathrm{SE}}$ \\
\hline$\overline{\operatorname{Ln} B R_{t-1}}$ & $-4.9024 * * *$ & $(1.3468)$ \\
\hline $\mathrm{Ln} \mathrm{I/D} \mathrm{D}_{\mathrm{t}-1}$ & 0.0304 & $(0.0299)$ \\
\hline $\operatorname{Ln} \mathrm{ROA}_{\mathrm{t}-1}$ & $-5.0133 * * *$ & $(0.5074)$ \\
\hline Ln Size & $0.5184 * * *$ & $(0.0473)$ \\
\hline Age & $-0.2241 * * *$ & $(0.0358)$ \\
\hline \multicolumn{3}{|c|}{ Farm Type Dummies } \\
\hline Field Crops & $-0.5931 *$ & $(0.1146)$ \\
\hline Horticulture & -0.4663 & $(0.1065)$ \\
\hline Livestock & -0.0376 & $(0.1093)$ \\
\hline \multicolumn{3}{|l|}{ Year Dummies } \\
\hline 2005 & $-0.2516 * * *$ & $(0.0713)$ \\
\hline 2006 & $-0.2181 * *$ & $(0.0691)$ \\
\hline 2007 & $-0.2540 * * *$ & $(0.0698)$ \\
\hline 2008 & 0.0821 & $(0.0732)$ \\
\hline 2009 & $0.1524 * *$ & $(0.0771)$ \\
\hline 2010 & $-0.3714 * * *$ & $(0.0706)$ \\
\hline 2011 & $-0.1981 * *$ & $(0.0730)$ \\
\hline 2012 & $-0.3922 * * *$ & $(0.0715)$ \\
\hline 2013 & $-0.4232 * * *$ & $(0.0708)$ \\
\hline 2014 & $-0.3621 * * *$ & $(0.0726)$ \\
\hline 2015 & 0 & (omitted) \\
\hline Constant & $-7.5368 * * *$ & $(0.6848)$ \\
\hline $\mathrm{R}^{2}$ Within & 0.0421 & \\
\hline $\mathrm{F}$ & $11.78 * * *$ & \\
\hline
\end{tabular}

Notes: SE provides the robust standard errors, ***,**, $*$ are significant at the $1 \%, 5 \%$, and $10 \%$ levels respectively, the dummy reference levels are dairy farms and the year 2004, respectively, and the year 2015 is omitted due to collinearity 
A2.3. Solvency ratio (total debt/equity) as a measure of financial risk.

Table 3.13: Fixed-effects panel-regression results using solvency ratio as a financial risk measure over the period 2004-2015

\begin{tabular}{llc}
\hline Variable & Coefficient & SE \\
\hline Ln BR $\mathrm{BR}_{\mathrm{t}-1}$ & $-0.0086^{* * *}$ & $(0.0018)$ \\
$\mathrm{Ln} \mathrm{I}_{\mathrm{t}-1}$ & $-0.0379 * *$ & $(0.0053)$ \\
Ln ROA $\mathrm{t}-1$ & $0.9215^{* * *}$ & $(0.0714)$ \\
Ln Size & 0.0196 & $(0.0140)$ \\
Age & $0.0426 * * *$ & $(0.0065)$
\end{tabular}

Farm Type Dummies

$\begin{array}{ccc}\text { Field Crops } & 0.0181 & (0.0403) \\ \text { Horticulture } & 0.0377 & (0.0487) \\ \text { Livestock } & -0.0083 & (0.0291)\end{array}$

Year Dummies

\begin{tabular}{clll} 
& 2005 & 0.0035 & $(0.0104)$ \\
2006 & 0.0033 & $(0.0104$ \\
2007 & 0.0015 & $(0.0106)$ \\
2008 & $-0.0221 * *$ & $(0.0110)$ \\
2009 & -0.0179 & $(0.0113)$ \\
2010 & -0.0061 & $(0.0114)$ \\
2011 & $-0.0675 * * *$ & $(0.0112)$ \\
2012 & $-0.0525 * * *$ & $(0.0113)$ \\
2013 & $-0.0592 * * *$ & $(0.0116)$ \\
2014 & $-0.0574 * * *$ & $(0.0117)$ \\
2015 & 0 & $($ omitted) \\
Constant & $3.8702 * * *$ & $(0.2011)$ \\
\hline R ${ }^{2}$ Within & 0.0518 & \\
F & $22.52 * * *$ &
\end{tabular}

Notes: SE provides the robust standard errors, $* * *, * *, *$ are significant at the $1 \%, 5 \%$ and $10 \%$ levels respectively, the dummy reference levels are dairy farms and the year 2004, respectively, and the year 2015 is omitted due to collinearity 
A2.4. Using the standard deviation of net farm income without debt financing as a measure of total risk

Table 3.14: Logit-estimates using the standard deviation of net farm income without debt

financing as a measure of total risk over the period 2004-2015

\begin{tabular}{|c|c|c|c|c|}
\hline & Fixed Effect & & Random Ef & \\
\hline Variables & Estimates & $\mathrm{SE}$ & Estimates & $\mathrm{SE}$ \\
\hline Age & -0.0708 & $(0.0661)$ & 0.0047 & $(0.0349)$ \\
\hline Size & -0.2806 & $(0.1287)$ & $-0.0179 * *$ & $(0.0407)$ \\
\hline Leverage & $0.1060 * * *$ & $(0.2216)$ & -0.0678 & $(0.1104)$ \\
\hline Total Risk & -0.0004 & $(0.0011)$ & 0.0002 & $(0.0011)$ \\
\hline Cost of Debt & 0.2129 & $(0.2345)$ & 0.2159 & $(0.2103)$ \\
\hline ROA & $-1.0910 * *$ & $(0.6098)$ & $-0.0612 * *$ & $(0.4872)$ \\
\hline Investment & $0.3702 *$ & $(0.3206)$ & $0.3645^{* *}$ & $(0.2847)$ \\
\hline Subsidy & 0.0026 & $(0.0013)$ & 0.0008 & $(0.0007)$ \\
\hline Diversification & -0.4952 & $(0.2744)$ & -0.2965 & $(0.1478)$ \\
\hline \multicolumn{5}{|c|}{ Farm Type Dummies } \\
\hline Field Crops & -0.4751 & $(0.3696)$ & $0.2415^{*}$ & $(0.0876)$ \\
\hline Horticulture & -0.3374 & $(0.4629)$ & 0.1000 & $(0.0801)$ \\
\hline Livestock & 0.0245 & $(0.2551)$ & $0.1741 *$ & $(0.0829)$ \\
\hline \multicolumn{5}{|l|}{ Year Dummies } \\
\hline 2005 & $-0.2311 * *$ & $(0.0972)$ & $-0.2404 * *$ & $(0.0936)$ \\
\hline 2006 & $-0.2066^{* *}$ & $(0.0967)$ & $-0.2260 * *$ & $(0.0909)$ \\
\hline 2007 & 0.1500 & $(0.0974)$ & 0.1103 & $(0.0897)$ \\
\hline 2008 & 0.0463 & $(0.0980)$ & 0.0030 & $(0.0880)$ \\
\hline 2009 & 0.1112 & $(0.1026)$ & 0.0872 & $(0.0895)$ \\
\hline 2010 & -0.0262 & $(0.1052)$ & -0.098 & $(0.0885)$ \\
\hline 2011 & $0.1987 * * *$ & $(0.1050)$ & $0.1729 * *$ & $(0.0884)$ \\
\hline 2012 & $0.2929 * * *$ & $(0.1062)$ & $0.2453^{* * *}$ & $(0.0881)$ \\
\hline 2013 & 0.1204 & $(0.1080)$ & 0.0566 & $(0.0872)$ \\
\hline 2014 & 0 & (omitted) & 0 & (omitted) \\
\hline 2015 & 0 & (omitted) & 0 & (omitted) \\
\hline Constant & - & - & 0.2207 & $(0.5805)$ \\
\hline $\mathrm{R}^{2}$ Pseudo & 0.0757 & & 0.0044 & \\
\hline Log-Likelihood & -4053.76 & & -6705.68 & \\
\hline$\chi^{2}$ & $61.18 * * *$ & & $59.31 * * *$ & \\
\hline No of Farms & 1,092 & & 1,569 & \\
\hline
\end{tabular}

Notes: SE provides the robust standard errors, ***,**,* are significant at the $1 \%, 5 \%$, and $10 \%$ levels respectively, the dummy reference levels are dairy farms and the year 2004, respectively, and the years 2014 and 2015 are omitted due to collinearity 


\section{A3. Accounting for Endogeneity Using the Instrumental Variable Approach}

Estimating the panel fixed-effects regression model is econometrically challenging. We suspect that the profitability variable in equation (3.8) is potentially endogenous ${ }^{46}$. Hence, estimating the parameters in equation (3.8) with the standard OLS estimator may lead to inconsistency and bias (Greene, 2003).

The use of an instrumental variable approach is common practice to account for endogeneity. In most socio-economic research, it is very difficult to obtain (external) instruments that are simultaneously valid from a theoretical and empirical point of view. Arellano and Bond (1991) proposed a Difference General Methods Moment (DifferenceGMM) as 'internal' instruments approach, in which regression equations are expressed in terms of their first difference and endogenous variables are instrumented with lags of their own levels. This approach allows for the specification of the endogenous variables and involves first differencing that removes the time-invariant farm-specific effects. It has its limitations, however, as the lagged levels may be weakly correlated with first differences. Notably, this bias is not eliminated by using fixed-effects estimators since the regressors and the error term continue to be correlated after such a transformation. This is particularly relevant when the lagged levels used as instruments are highly persistent (Roodman, 2015).

To address this limitation, Arellano and Bover (1995) developed an improved estimator known as the 'Level GMM', in which regressions are expressed in levels and endogenous instruments in terms of their lagged differences. Finally, Blundell and Bond (1998) combined both approaches to construct a system of equations known as the 'System GMM'. It combines the set of moments in the difference and level equations to form instrument-endogenous

\footnotetext{
${ }^{46}$ While this chapter deals with the effect of profitability on a farm's financial risk, a farm's level of financial risk may, conversely, also affect its profitability. Both directions of causality are thus possible: increased profitability decreases the level of financial risk farms are facing in their operation, whereas a higher level of financial risk limits the available fund for further investment on the farm, hence, lowers farm profit. Accordingly, we run a Durbin-Wu-Hausman test, and in the second stage instruments variable regression, a Hausman test for endogeneity results a p-value of 0.089 suggesting that we reject the null hypothesis at the $10 \%$ critical value that the profitability variable is exogenous. Thus, in conformity to our suspicion, there is evidence that the profitability variable is endogenous.
} 
variables. The difference GMM estimator follows the Arellano and Bond (1991) data transformation, where differences are instrumented by levels. The system GMM estimator adds to this one extra layer of instrumentation, where the original levels are instrumented with differences.

The system GMM procedure consists of first-differencing the data, as opposed to the fixed-effect transformation that demeans them, i.e. subtracts the sample mean. Additional orthogonality conditions for both difference and system GMM arise from suitable lags of the lagged explanatory variables in levels which can be treated as endogenous, predetermined or strictly exogenous. Endogenous variables are then instrumented using their own lagged values. The main advantages of these estimators are that they deal with individual-level fixed effects without incurring the bias to which standard panel estimators are subject. In addition, with System-GMM, instrumentation is not confined to one instrument per parameter to be estimated; rather, it is possible to define more than one moment condition per parameter to be estimated. Furthermore, the system GMM offers 'internal' solutions for dealing with endogenous regressors, and its additional orthogonality conditions improve asymptotic efficiency (Roodman, 2015).

The System GMM is particularly suitable as a robustness test for this study because: (a) it uses difference equations to instrument endogenous regressors, so that they are also able to deal with time-invariant, farm-specific attributes, i.e. heterogeneity and endogeneity can be handled with this estimator; (b) it is well-suited to datasets with large numbers of crosssections, $\mathrm{N}$, and small numbers of available periods, $\mathrm{T}$; (c) any gaps in a panel - our FADN sample is unbalanced - are magnified by the difference GMM (compared to the system GMM), indeed a motivating factor for the creation and development of the system GMM (Roodman, 2009: p.104); and (d), unlike OLS, FE and RE estimation, the GMM estimators do not require distributional assumptions, like normality, and can allow for the heteroscedasticity of an unknown form (Greene, 2003).

We ran the analysis using the -xtdpdsys- command on STATA, and Table 3.15 provides the results. We fit the model using optimal or two-step GMM and report robust 
standard errors. The variables size and age are treated as strictly exogenous and appear as regular regressors. The other variables are treated as endogenous variables and appear with two lags, such that maximally two lags are used as instruments.

The $\operatorname{AR}(2)$ tests the null hypothesis that $\operatorname{Cov}\left(\Delta \varepsilon_{\mathrm{it}}, \Delta \varepsilon_{\mathrm{it}-\mathrm{k}}=0\right)$ for $\left.k=1,2\right)$ is rejected at a level of 0.05 if $p<0.05$. If $\varepsilon_{i t}$ are serially uncorrelated, we expect to reject at order 1 but not at higher orders. From Table 3.15, we can see that we reject the hypothesis at order 1 $(A R(1))$ because of $p=0.0040$. At order $2, \Delta \varepsilon_{i t}$, and $\Delta \varepsilon_{i t-k}$ are serially uncorrelated because $p=0.4258>0.05$. As desired, there is no serial correlation in the original error $\varepsilon_{i t}$.

A second specification test is the Sargan test of over-identifying restrictions. The -estat sargan- command starts the test. The null hypothesis that the population moment conditions are correct, i.e. the instruments as a group are exogenous, is not rejected because $p=0.9918>$ 0.05, which suggests that the instruments used in the System-GMM are valid. These specification test results indicate that the key identifying assumptions required for the SystemGMM estimator are satisfied. 
Table 3.15: System-GMM estimation results

\begin{tabular}{|c|c|c|}
\hline Variables & Coefficient & SE \\
\hline \multicolumn{3}{|l|}{ Financial Risk } \\
\hline L1. & $-0.004856 * * *$ & $(0.0005)$ \\
\hline $\mathrm{L} 2$. & $-0.006538 * * *$ & $(0.0004)$ \\
\hline Business Risk (t-1) & -0.4224 & $(0.2369)$ \\
\hline L1. & $-1.8432 * * *$ & $(0.2929)$ \\
\hline $\mathrm{L} 2$. & $-0.6859 * * *$ & $(0.1999)$ \\
\hline Cost of $\operatorname{Debt}(t-1)$ & 1.3816 & $(1.0295)$ \\
\hline L1. & 1.4821 & $(1.1692)$ \\
\hline $\mathrm{L} 2$. & $-2.7646^{*}$ & $(1.1510)$ \\
\hline Profitability(t-1) & $-11.0746 * *$ & $(5.2927)$ \\
\hline L1. & $-8.2162 * *$ & $(4.3582)$ \\
\hline $\mathrm{L} 2$. & -6.1181 & $(4.0301)$ \\
\hline Size & $-1.0983 *$ & $(0.5480)$ \\
\hline Age & -0.1679 & $(0.4339)$ \\
\hline \multicolumn{3}{|l|}{ Year Dummies } \\
\hline 2005 & -0.3383 & $(0.5058)$ \\
\hline 2006 & -0.3801 & $(0.5933)$ \\
\hline 2007 & 0.3508 & $(0.5588)$ \\
\hline 2008 & -0.4463 & $(0.6324)$ \\
\hline 2009 & 0.1489 & $(0.6716)$ \\
\hline 2010 & 10.222 & $(0.6173)$ \\
\hline 2011 & 0.7375 & $(0.641)$ \\
\hline 2012 & $1.7734 * *$ & $(0.6656)$ \\
\hline 2013 & 0.5593 & $(0.6546)$ \\
\hline 2014 & $1.3796^{*}$ & $(0.6761)$ \\
\hline 2015 & 0 & (omitted) \\
\hline Constant & 13.599 & $(8.55400)$ \\
\hline Wald $\chi^{2}(21)=1028.83$ & \multicolumn{2}{|c|}{$\mathrm{P}$-value $=0.0000$} \\
\hline Sargan Test $\chi^{2}(131)=95.33$ & \multicolumn{2}{|c|}{3 P-value $=0.9918$} \\
\hline $\mathrm{AR}(1) \mathrm{Z}=-2.8741$ & \multicolumn{2}{|c|}{$\mathrm{P}$-value $=0.0040$} \\
\hline $\mathrm{AR}(2) \mathrm{Z}=-0.7964$ & \multicolumn{2}{|c|}{$\mathrm{P}$-value $=0.4258$} \\
\hline
\end{tabular}

Notes: Numbers in parentheses are robust standard errors, and $* * *, * *$ and $*$ are significant at the $1 \%$, $5 \%$, and 10\% levels respectively, and the dummy reference level is the year 2004. Year 2015 is omitted due to collinearity. 


\section{Chapter-4}

Do Profit Rates Converge? Evidence on the Persistence of Farm Profit 


\section{Chapter Four: Do Profit Rates Converge? Evidence on the Persistence of Farm Profit}

\subsection{Abstract}

Ensuring farm survival and competitiveness requires a better understanding of why some farms consistently perform better (worse) than others. This chapter investigates the drivers of farm profitability, the degree of abnormal profit persistence, and its determinants based on a unique longitudinal data set collected from a panel of Dutch farms between 2001 and 2015. We apply a quantile regression approach to examine the drivers of farm profitability, and a dynamic panel System-GMM to estimate the persistence of abnormal farm profit. The results of the quantile regression show that working capital, labor productivity, leverage, capital intensity, and investment are important determinants of profitability. The findings suggest that working capital is important for farms' flexibility and their capacity of adapting to changing circumstances in environments where they don't receive regular income from agricultural products. Estimates using the dynamic panel model provide evidence on abnormal profit persistence. Profit persistence is responsive to farm risk exposure, investment, capital intensity, leverage, working capital, and diversification. We show that long-run farm profit can be achieved and sustained by ensuring adequate working capital to cope with the cash flow mismatch.

Keywords: Dynamic panel model, quantile regression, profit persistence, System-GMM estimation. 


\subsection{Introduction}

Why some firms persistently earn higher profits that deviate from the average earned in the industry? Are these differences random events or driven by resources and capabilities? Most of the literature supports the existence of firms that exhibit abnormal profits that persist in the long-run (Hirsch, 2018). While most studies consider the manufacturing and service sectors, articles focused on the agricultural sector at the farm level are scarce. Exceptions include Schumacher and Boland (2005), Hirsch and Gschwandtner (2013) and Hirsch and Hartmann (2014) that examine profit persistence in the food industry.

Unlike the manufacturing and service sectors, agribusiness is characterized by specific circumstances, including seasonality of production, different legal forms, smaller decisionmaking units, and limited access to equity markets. These unique characteristics increase the likelihood of cash flow mismatches, heterogeneous risk profiles, and create different patterns of decision making, providing a relevant context for extending the study of profit persistence into the agricultural sector.

Farm profitability has been in the spotlight in recent years because farm income has exhibited higher volatility compared to other industries (Burns, Tulman and Harris, 2015; Sol, Isabel and Alberto, 2016) and because of major socioeconomic changes, including new land use demand, globalization, agricultural policy reforms, and a decline in the number of farms ${ }^{47}$ in the developed world.

In addition to these trends, we observe a different level of farm profitability; some farms consistently perform better (worse) than others (European-Commission, 2017). Such variations even after accounting for farm size and types raise several questions: are these differences in profit level and persistence systematic or random? what are the determinants of these

\footnotetext{
${ }^{47}$ In 2005, the European Union (excluding Croatia) had an estimated 14.5 million farmers. By 2013, this number declined to 10.8 million, i.e. a $34.2 \%$ decline, equivalent to an average decline of $3.8 \%$ per year (Berkhout and van Bruchem, 2015). The Dutch farm sector was no exception. Between 2000 and 2014, the number of agricultural holdings significantly decreased from 101,550 to 65,500 farms, representing a $35.5 \%$ decline and exceeding the average EU decline (Eurostat, 2015).
} 
differences? and can these determinants be influenced by farmers themselves and by policy instruments? From a policy perspective, these questions are relevant since most agricultural policy instruments aim to increase farm competitiveness. More importantly, it is critical for farms to benchmark their operations in the same sector and relative to other sectors, so they can address potential weaknesses and capitalize on strengths.

This paper contributes to the literature in four ways: first, we extend the understanding of profit persistence and its drivers to the agriculture sector. Second, examining the determinants of long-run farm profitability provides insights about the distinct farm resources and capabilities that help farms to gain and sustain competitive advantages. Third, contrary to previous studies, which focused on a single farm type, we use panel data to consider four farm types: dairy, livestock, field crop, and horticulture farms. This allows for the analysis of a larger part of the farm sector in the Netherlands, while the panel data enables us to provide insight into the evolution of farm profit over time and its variation across farm types. Finally, this study is based on a dynamic panel model of Blundell and Bond's (1998) System-GMM estimator. This approach is crucial as the dynamics of farm profits can be too complex to be captured by the simple AR (1) model often used in the literature and the dynamic panel model helps to address potential endogeneity problems common to static models.

This chapter is structured as follows. The next section provides a theoretical background and conceptual framework. This is followed by a description of the variables, data used, and methodology applied. Next, the results of the empirical analyses are presented and discussed. The final section sets out the conclusion and limitations and provides suggestions for further research.

\subsection{Theoretical Background}

The classic perfect competition model considers the deviation of firm profit from the industry's average (norm) as a short-run phenomenon as competition will cause profit to converge to the norm in the long-run. However, a substantial number of firms earn profits above the norm for sustained periods of time (Gschwandtner and Hauser, 2016), constituting an abnormal profit persistence that the classic model fails to explain (Hirsch and Hartmann, 
2014). Several models have been developed to explain this phenomenon where the Structure Conduct Performance (SCP), the Market-Based View (MBV), and the Resource-Based View (RBV) are predominant.

The central premise of SCP is that abnormal profit is determined by the competitive dynamics and structure of the industry. That can be assessed by analyzing elements such as barriers to entry and exit, product differentiation, the number of competitors, and the number of buyers and sellers, which help to determine how firms behave and perform, i.e., gain and sustain abnormal profits (Porter, 2008).

The MBV is an extension of the SCP and argues that superior performance is determined not only by industry structure but also by market-positioning strategies, e.g. lowcost/product differentiation, employed in the target market segments that determine superior performance and its sustainability (Wiggins and Ruefli, 2002). The MBV stresses that firms design their strategies based on market analysis of the industry

Recently, the focus in the literature has shifted from industry structure to firm's internal resources and capabilities (Olivier, Howard and Anna, 2008). This shift has made the Resource- Based View (RBV) the leading model for analyzing sustained superior performance. A central premise of the RBV is that firms compete and choose strategies based on their material, financial and human resources and their capabilities (Grant, 1991). Competitive advantage can be achieved and sustained by developing and owning resources that are scarce, valuable, non-substitutable and inimitable (Barney, 2001). Resources that create competitive advantage will also generate superior economic performance that will persist over time.

The SCP, MBV, and RBV are similar in that they all assume that a firm's ultimate goal is to achieve and sustain a competitive advantage and that above-normal profit is possible. They differ as to the sources of competitive advantage and the unit of analysis. Despite the relevance of each of these views in explaining abnormal profit, the RBV provides an established analytical tool for examining the relationship between farm resources, profit, and sustained abnormal profit. Hence, our conceptual framework is based on the RBV. 


\subsection{Conceptual Framework}

Profit persistence is widely studied in the manufacturing and service sectors under the lenses of industrial organization and resource-based views (Gompers et al., 2010; McGahan and Porter, 2003; Villalonga, 2004). Most studies report a moderate degree of persistence by examining the variation of normalized firm-level profit rates over time using first-order autoregressive models ${ }^{48}$. However, the evidence of persistence of profit in the agricultural sector is rather rare.

Griffin, Ibendahl and Stabel (2018) estimate transition probabilities of Kansas arable farms across five profitability categories, and find a moderate persistence of farms in their initial profitability class. Urcola et al. (2004)) measure yield productivity persistence and show that difference in management-skills explains the most and least productive farms. Yeager and Langemeier (2016) find that farm size, farm type, and operator age explain efficiency persistence. Yet, empirical evidence at farm level is still scarce. Most importantly, understanding of the unique resources and capabilities to gain and sustain a competitive advantage in farm business remains a major gap in the literature. This study aims to provide evidence that explains the level and the determinants of profit persistence at a farm level.

\subsubsection{Determinants of Farm Profit and Profit Persistence}

Figure 4.1 shows the proposed conceptual model. Alongside the literature review, the RBV provides an established framework for empirically examining the impact of farm resources on long-term profitability and abnormal profit persistence.

\footnotetext{
${ }^{48}$ See Goddard et al. (2011) for a comprehensive review of profit persistence studies using standard first-order autoregressive models.
} 


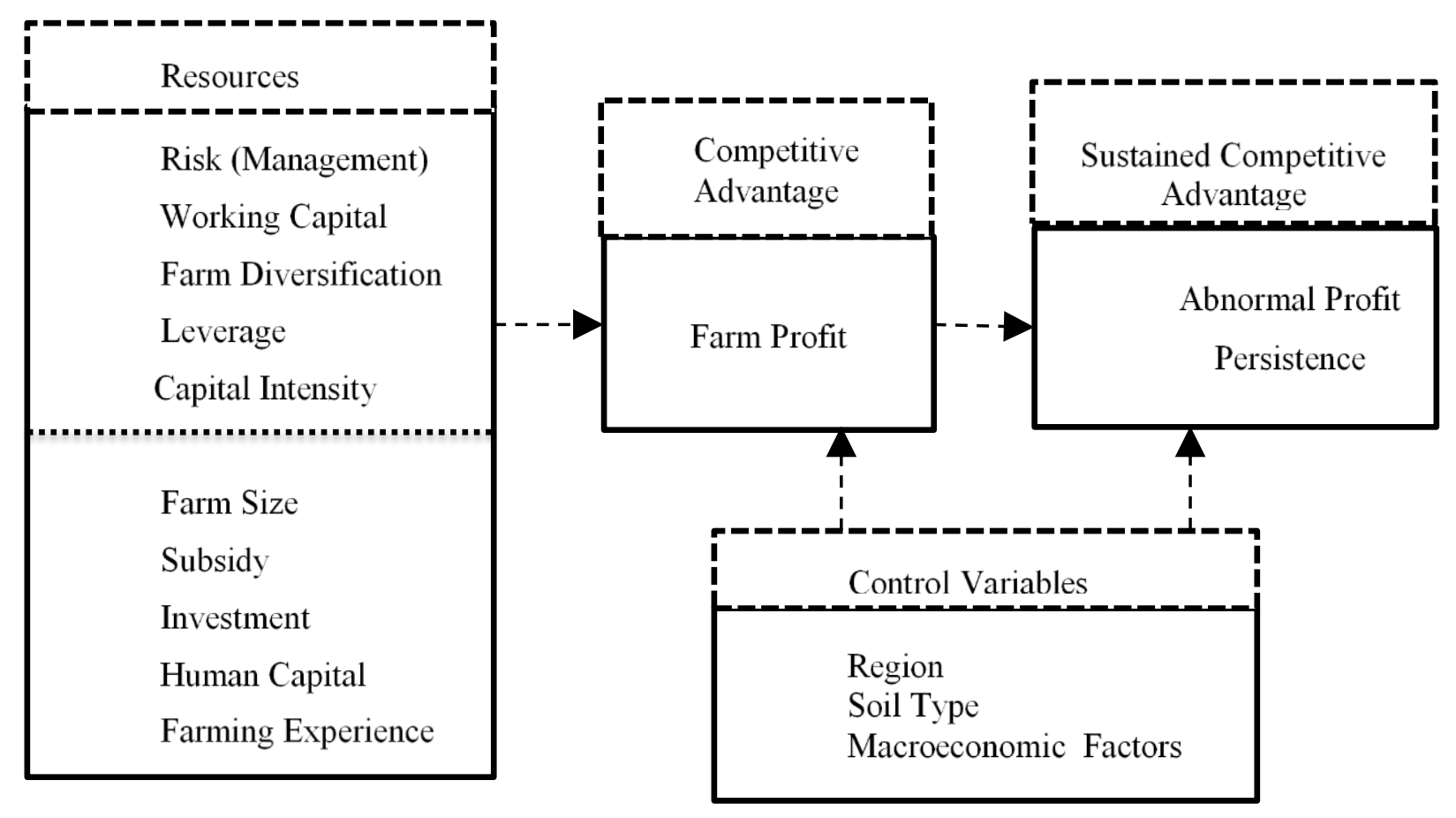

Figure 4.1: Conceptual framework

In addition to developing risk-bearing capacity, farms may employ diversification as one of their risk-management strategies. Diversification can help mitigate different farm risks, lower profit fluctuation and optimize production (Kwansoo et al., 2012; Meraner et al., 2015). It may also lead to economies of scope, which lowers costs and increases profit (Mishra et al., 2009). Leverage also explains sustained competitive advantage. In line with the pecking-order theory of capital structure, we expect farms with less leverage, i.e. use of internal funds over external funds, to gain and sustain profit by reducing financing costs and investing in highly profitable investments (Feng, Zhengfei and Robert, 2014).

The capital spent to produce one unit of farm revenue indicates a farm's level of capital intensity. It includes the assets used in a farm's production functions. Farms that continuously require capital to earn profits are unlikely to earn and sustain abnormal profits in the long-term (Gardebroek, Kedir and Wijnands, 2010). Also, farms that rely on capital for their competitive advantage are more exposed to imitation risk by competitors, which might cause rapid erosion of abnormal returns (Porter, 2008).

We also include farm size, subsidy, investment, labor productivity, and age in the analysis. Farm size is expected to drive profit persistence because large farms have the 
opportunity to achieve economies of scale and have access to more markets and investment opportunities. Alternatively, if a farm scale leads to diseconomies of scale and inefficiencies, the size-sustained competitive advantage relationship could be negative. A government subsidy ${ }^{49}$ is included to address the impact of participation in government support programs on farm profitability and its persistence. The decision of how to allocate farm cash surplus, i.e., investment, is also a crucial factor in the long-term wealth creation of farm businesses. Labor productivity is used as a proxy of human capital and shows how farm labor is managed to accomplish objectives. If laborers are efficient, we expect the farm to sustain abnormal profits in the long-run. Farming experience or age may also influence how farms manage their operations. McBride and Greene (2007), for instance, show that age is positively correlated with farm production costs.

As control variables, we include region, soil type, and year dummies in the analysis. Soil type addresses the productivity differences between sand, clay and peat. Region dummies are included to control for differences in precipitation and farmland value. A set of time dummies is included to capture business-cycle impacts in the farm business. The next section presents the research design.

\subsection{Research Design}

\subsubsection{Farm Profitability}

Annual farm profit as a measure of performance is a well-documented procedure in the literature. However, it is not immune from criticism because profit is an absolute amount and mostly size driven. Thus, it is not easy to make comparisons across different farm types. To

\footnotetext{
${ }^{49}$ In most developed countries, payments received in the form of subsidies and direct payments represent a major portion of farm total income (D'Antoni and Mishra, 2013; El-Osta, Mishra and Morehart, 2007). For instance, the annual European Union Common Agricultural Policy (CAP) budget is about 50 Billion Euros, of which farm subsidization absorbs $72 \%$ on average. In the Netherlands, roughly 50,000 Dutch farm businesses received over 805 million Euros in direct payments in 2014 alone. The total amount that Dutch farmers received through the CAP between 2007 and 2014 approximates 8.35 Billion Euros (European-Commission, 2017).
} 
address such concerns, we use the Modified Return on Asset (MROA). Following Mishra, Wilson and Williams (2009), MROA is defined as:

MROA $=\frac{\text { Modified Net Farm Income }}{\text { Average Total Asset }}$

where Modified Net Farm Income (MNFI) is calculated as Net Farm Income $\left(\mathrm{NFI}^{50}\right)$ plus interest expense. By adding back interest expense to the calculation, it is possible to compare farms with different capital structures. The MROA is useful for determining what the assets invested in the farm operation earned. Average market values are considered to determine the worth of farm assets ${ }^{51}$. Hence, it is possible to use the MROA to compare farm earnings to those of other businesses across the same time period. This measure of profitability eliminates differences in farm size and expenses such as financing, and can be a useful tool for assessing true farm profitability. We assume that the profit function of Dutch farms can be approximated by a linear panel model:

$\mathrm{Y}_{\mathrm{it}}=\beta \mathrm{X}_{\mathrm{it}}+\alpha_{\mathrm{i}}+\mu_{\mathrm{it}}$

where $\mathbf{Y}$ is the vector of farm profit for each farm $i$, and time $t, \mathbf{X}$ is the vector of all the regressors, $\boldsymbol{\beta}$ is the vector of parameters to be estimated, $\alpha$ is the unknown intercept for each farm, and $\mu$ is the vector of residuals.

If OLS is used to estimate equation (4.2) with the presence of unobserved heterogeneity, the estimated coefficients are not representative of the entire conditional profit distribution. To account for some of the heterogeneity in the sample, observed farm-level characteristics, i.e., farm type, region, size, soil quality, can be explicitly included in the regression equation. Nevertheless, there may also be other sources of farm heterogeneity that cannot be observed and accounted for. For example, in our case, farm characteristics such as risk perception, risk

\footnotetext{
${ }^{50}$ We calculate NFI using the FADN principle as Net Farm Income=Operating Receipts -Intermediate CostsDepreciation+ Balance of Subsidies and Tax-Wages-Rent

${ }^{51}$ To obtain a more accurate version of NFI, we take the average total asset as a denominator, i.e. the average of the opening total assets at the beginning of the accounting period and closing total assets at the end of the accounting period.
} 
attitude and managerial ability have not been taken into account in the data although they may cause unobserved heterogeneity. Unobserved heterogeneity may render the dependent variable and the error term in equation (4.2) to be independently, but not identically distributed across farms. When observations are not identically distributed, OLS estimates will be inefficient and extreme observations will have a significant influence on the estimated coefficients (Green, 2003).

Quantile regression estimates ${ }^{52}$ are considered robust relative to the traditional OLS estimator for a number of reasons: they place less weight on outliers and are robust to departures from normality (Koenker, 2004). In addition, it avoids the restrictive assumptions that the error terms are identically distributed at all points of the conditional distribution. Avoiding this assumption allows us to capture farm heterogeneity in that the slope parameters can vary at different quantiles of the distributions of farm profitability. Quantile regression ${ }^{53}$ can be illustrated as follows:

$\mathbf{Y}_{\mathrm{it}}=\mathbf{X}_{i t}^{\prime} \boldsymbol{\beta}_{\theta}+\boldsymbol{\mu}_{\mathrm{it}}$ with $Q_{\theta}\left(\mathbf{Y}_{\mathrm{it}} / \mathbf{X}_{\mathrm{it}}\right)=\mathbf{X}_{i t}^{\prime} \boldsymbol{\beta}_{\theta}$,

where $Q_{\theta}\left(\mathbf{Y}_{\mathrm{it}} / \mathbf{X}_{\mathrm{it}}\right)$ denotes the $\theta^{\text {th }}$ conditional quantile of $\mathbf{Y}_{\mathrm{it}}$ given $\mathbf{X}_{\mathrm{it}}$. The $\theta^{\text {th }}$ regression quantile which is restricted to $0<\theta<1$,. The model in equation (4.2) is specified as:

$$
\begin{aligned}
\mathrm{Y}_{\mathrm{it}}= & \alpha_{i}+\beta_{1} \mathrm{Lev}_{\mathrm{it}}+\beta_{2} \text { Risk }- \text { Short }_{\mathrm{it}}+\beta_{3} \text { Risk }- \text { Long }_{\mathrm{it}}+\beta_{4} \mathrm{WC}_{\mathrm{it}}+\beta_{5} \mathrm{KInt}_{\mathrm{it}}+ \\
& \beta_{6} \text { Hcap }_{\mathrm{it}}+\beta_{7} \text { Divr }_{\mathrm{it}}+\beta_{8} \text { Age }_{\mathrm{it}}+\beta_{9} \text { InTA }_{\mathrm{it}}+\beta_{10} \text { Invest }_{\mathrm{it}}+\beta_{11} \text { Sub }_{\mathrm{it}}+\beta_{12} \text { Dsoil }_{\mathrm{it}}+ \\
& \beta_{13} \text { Dreg }_{\mathrm{it}}+\Gamma_{\mathrm{t}}+\varepsilon_{\mathrm{it}}
\end{aligned}
$$

- $Y_{i t}$ denotes the Modified Return on Asset (MROA);

- Lev denotes leverage and is measured as the ratio of total debt to asset;

- Risk-Short denotes farm short-run financial exposure and is calculated as current liability divided by total asset;

\footnotetext{
52 Since the aim is to understand the effects of farm characteristics at different points of the profitability distribution, the focus is on quantile regression. Nevertheless, results from the traditional OLS estimation are also reported in the results section, for the sake of comparison to previous studies.

${ }^{53}$ See Koenker and Hallock (2001) and Koenker (2004) for a detailed discussion and implementation of quantile regression with longitudinal data.
} 
- Risk-Long denotes farm long-run financial risk exposure (gearing) and is calculated as long-term liability divided by the owner's equity;

- $W C$ represents working capital, i.e., current asset minus current liability, and is used as a proxy for farm risk-bearing capacity;

- KInt represents farm capital intensity, i.e., total assets divided by total output;

- Hcap indicates labor productivity, i.e., total farm output/Agricultural Working Unit (AWU), as a proxy to farm human capital;

- Divr denotes farm diversification, i.e., other farm output/total farm output;

- Age indicates the age of the farmer;

- $\ln T A$ denotes the natural logarithm of total farm assets;

- Sub denotes subsidy rate, i.e., total subsidy payments divided by total output;

- Invest denotes investment ratio i.e., total farm investment divided by total output;

- Dsoil denotes dummy soil type: 0 for sand, 1 for clay, 2 for peat and 3 for mixed soil types;

- Dreg denotes dummy regions; and

- $\quad \Gamma_{t}$ denotes year dummies; $\varepsilon$ is the error term, $\alpha$ and $\beta$ are the parameters to be estimated.

\subsubsection{Estimating the Degree and Determinants of Abnormal Farm Profit Persistence}

Previous studies use average industry profit to gauge the industry norm (McGahan and Porter, 2003; Waring, 1996). Following a similar approach, we define abnormal farm profit ${ }^{54}$ of farm $i$ at time $\mathrm{t}\left(\bar{\Pi}_{i t}\right)$ as the deviation of the profit of farm $i$ at time $t\left(\Pi_{\mathrm{it}}\right)$ from the average profit of all other farms in sector $s$ at time $t\left(\Pi_{\mathrm{st}}\right)$ :

$\bar{\Pi}_{i t}=\Pi_{\mathrm{it}}-\Pi_{\mathrm{st}}$

\footnotetext{
${ }^{54}$ Note that, when estimating the quantile regression, the dependent variable is farm profit ( $\left.\mathrm{Y}_{\mathrm{it}}\right)$, measured as MROA in equation (4.1). When estimating the degree and determinants of abnormal profit persistence, however, the dependent variable is abnormal profit $\left(\bar{\Pi}_{i t}\right)$ as measured in equation (4.5).
} 
This normalization removes the variations in farm profit induced by external influences and business cycle (Gschwandtner, 2012). To test the hypothesis that competition will erode abnormal profit in the long-run, the literature commonly uses a standard first-order autoregressive model, given by:

$\bar{\Pi}_{i t}=\alpha_{i}+\lambda_{j} \bar{\Pi}_{i, t-1}+\varepsilon_{i t}$

Equation (4.6) yields both short-run and long-run persistence measures. Short-run profit persistence is captured by $\lambda_{j}$. It indicates the percentage of total abnormal profit in $t-1$ that remains in $t$. The long-run persistence measure is estimated from the long-run average of the auto regressive process, $\hat{\pi}_{j}$ :

$\hat{\pi}_{j}=\frac{\hat{\alpha}_{i}}{\left(1-\hat{\lambda}_{j}\right)}$

Profit persistence studies based on AR models (See, e.g.,Gschwandtner, 2012; Yurtoglu, 2004) apply a standard two-step approach: first they estimate equation (4.6) to get $\hat{\lambda}_{j}$ and $\widehat{\Pi}_{j}$. Second, selected variables are regressed on the estimated parameters in step one using OLS regression to explain profit persistence. This approach has its limitations nevertheless. The dependent variable in equation (4.6) is correlated with the error term, suggesting that the OLS estimator is inconsistent and biased (Baltagi, 2008). To address these concerns, we specify a dynamic panel model with the General Methods Moment (GMM) estimator as follows:

$$
\bar{\Pi}_{\mathrm{it}}=\alpha_{i}+\lambda \bar{\Pi}_{\mathrm{i}, \mathrm{t}-1}+\sum_{\mathrm{j}} \beta_{\mathrm{j}}\left(\mathrm{X}_{\mathrm{jit}}\right)+\Gamma_{\mathrm{t}}+\varepsilon_{\mathrm{it}}
$$

Within this framework, $\lambda$ indicates the speed of convergence of profits to the long-term level. Since $\lambda$ reflects the fluctuations of profit from period to period, it can also be interpreted as short-term persistence ${ }^{55}$. The GMM estimator does not produce a long-run persistence

\footnotetext{
55 The speed of adjustment parameter, $\lambda$ often takse values between -1 and 1 . It shows how quickly a farm's profit rate converges to its long-run level.
} 
measure. Yet, the $\beta_{j}$ coefficients capture the impacts of the farm characteristics ${ }^{56}\left(X_{j} \mathrm{~s}\right)$ on abnormal profit over the entire period analyzed. Hence, through $\beta_{j}$, it is possible to weigh the direction of change in long-run abnormal profit for a given change in the variable $X_{j}$ (Hirsch and Gschwandtner, 2013).

Arellano and Bond (1991) proposed a Difference General Methods Moment (Difference-GMM) in which regression equations are expressed in terms of their first difference and endogenous variables are instrumented using lags of their own levels. It allows us to specify the endogenous variables and involves first differencing that removes the timeinvariant, farm-specific effects:

$Z_{i}=\left[\begin{array}{ccccc}{\left[\bar{\Pi}_{i}\right]} & 0 & \cdots & \cdots & 0 \\ 0 & {\left[\bar{\Pi}_{i 1}, \bar{\Pi}_{i 2}\right]} & \cdots & \cdots & 0 \\ \vdots & \vdots & \ddots & \cdots & \vdots \\ \vdots & \vdots & \cdots & \ddots & \vdots \\ 0 & 0 & \cdots & \cdots & {\left[\bar{\Pi}_{i 1}, \cdots \cdots \cdots, \bar{\Pi}_{i, T-p}\right]}\end{array}\right]$

Where, $Z$ is the matrix of instruments for individual $i, i=1, \ldots, n, p$ is the number of lags, and $T$ is the number of time periods.

This approach has, however, limitations as the lagged levels may be weakly correlated with first differences. Notably, this bias is not eliminated by using fixed effects estimators since the regeressors and the error term continue to be correlated after such a transformation. To address this limitation, Arellano and Bover (1995) developed an improved estimator known as the 'Level GMM', in which regressions are expressed in levels and endogenous instruments in terms of their lagged differences. Finally, Blundell and Bond (1998) combined both approaches to construct a system of equations known as the 'System GMM'. It combines the set of moments in the difference and level equations into instrument endogenous variables.

The System GMM is particularly suitable for this chapter because: (a) variables such as soil type and region are included in our model. These variables vary only across individuals,

\footnotetext{
${ }^{56}$ Note that the same variables (see equation 4.4) are used to explain both the determinants of farm profitability and abnormal profit persistence.
} 
and identification of the parameters would be inefficient with the Difference GMM (Zhengfei and Oude Lansink, 2006), (b) it has better asymptotic and finite sample properties than the Difference GMM (Blundell and Bond, 1998), (c) it uses difference equations to instrument endogenous regeressors, so that they are also able to deal with time-invariant farm-specific attributes, i.e., heterogeneity and endogeneity can be handled with this estimator, and (d) it is well-suited to datasets with large numbers of cross-sections, $\mathrm{N}$, and a small number of available periods, T.

Nevertheless, the System-GMM estimator has limitations too. It requires orthogonality between lagged levels of the variables used as instruments and the differences of the error terms and simultaneously orthogonality between farm-specific effects and the lagged difference of the variables used as instruments. Hence, a specification test on over-identifying restrictions is required to check the validity of the additional instruments (Roodman, 2009).

\subsection{Data and Descriptive Statistic}

We use a unique longitudinal dataset of farms that participate in the Dutch Farm Accountancy Data Network (FADN), and Table 4.1 provides summary statistics. 
Table 4.1: Summary Statistics

\begin{tabular}{lclll}
\hline Variable & Measurement & Obs. & Mean & SD \\
\hline MROA & Ratio & 15,682 & 0.025 & 0.092 \\
\multicolumn{1}{c}{ Dairy Farms $\quad$ Field Crops } & & 4,101 & 0.019 & 0.022 \\
$\quad$ Horticulture & & 2,695 & 0.027 & 0.042 \\
$\quad$ Livestock & & 5,136 & 0.034 & 0.148 \\
Abnormal MROA & & 3,750 & 0.017 & 0.055 \\
Leverage & & 15,682 & -0.001 & 0.085 \\
Short-run risk exposure & Ratio & 15,682 & 0.364 & 0.289 \\
Long-run risk exposure & Ratio & 15,682 & 0.049 & 0.078 \\
Working Capital & Ratio & 15,682 & 0.667 & 17.85 \\
Age & 1,000 euro & 15,682 & 54.740 & 541.9 \\
Labor Productivity & Year & 15,682 & 50.396 & 10.08 \\
Capital Intensity & Ratio & 15,682 & 95.688 & 88.99 \\
Farm size & Ratio & 15,682 & 7.076 & 6.315 \\
Diversification & $\log$ (Asset) & 15,682 & 14.567 & 0.847 \\
Subsidy Ratio & Ratio & 15,682 & 0.158 & 0.200 \\
Investment & Ratio & 15,682 & 0.053 & 0.078 \\
\hline
\end{tabular}

Average farm return on asset for all farms was $2.5 \%$ over the $2001-2015$ period and showed variation by farm type. The average MROAs for dairy farms, field crops, livestock and horticulture were $1.9 \%, 2.7 \%, 3.4 \%$, and $1.7 \%$ respectively, with horticulture being the largest. Figure 2 shows the variation in MROA over the years across the four farm types. Note that the impact of the financial crisis on farm performance is clearly visible from Figure 4.2. 

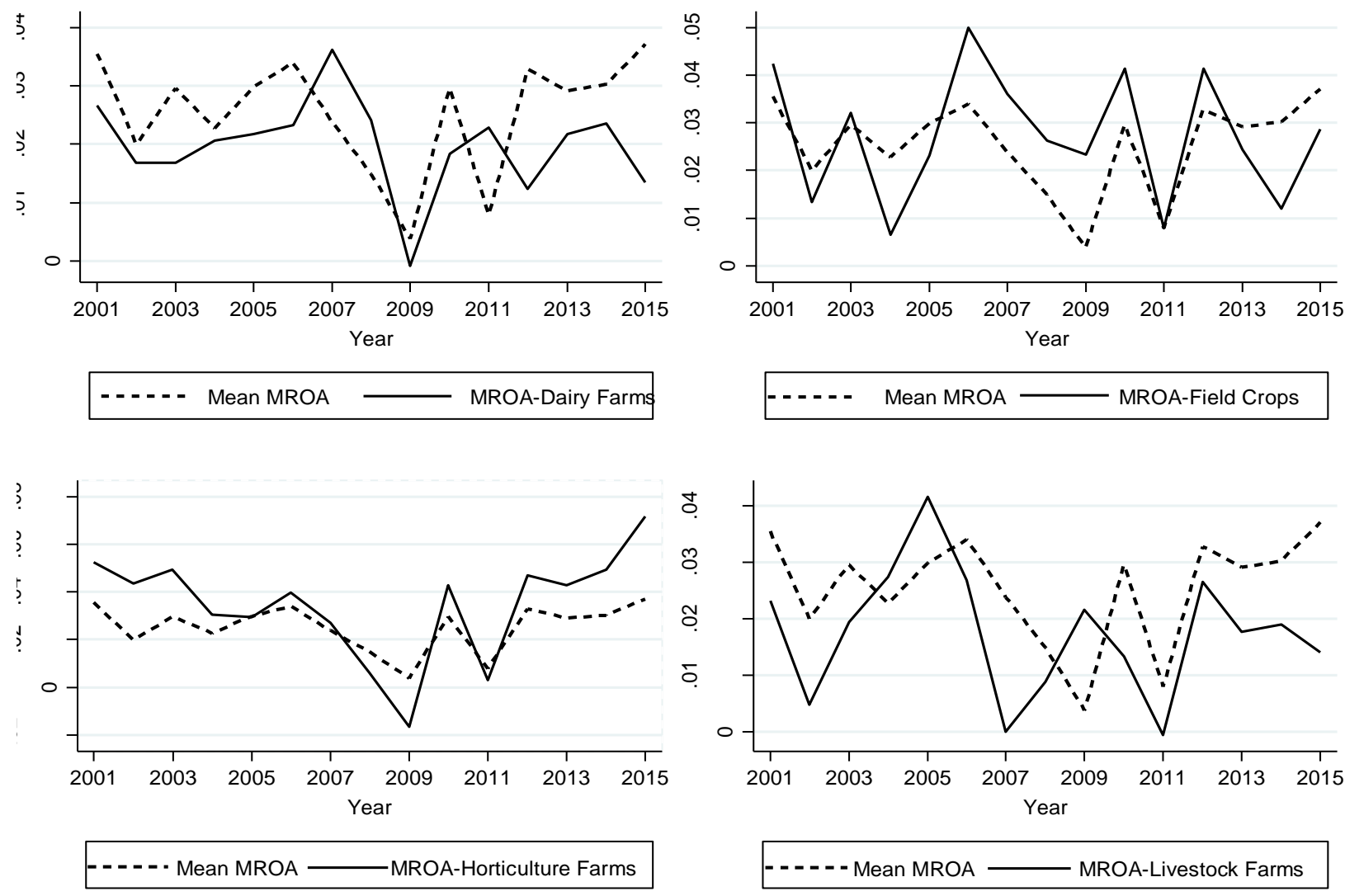

Figure 4.2: MROA by farm type, 2001-2015

Nevertheless, empirical measures of profit persistence may suffer from survivorship bias (Linnainmaa, 2013). In our data set, 323, i.e., 31\% of farms, stayed in the sample for the entire measurement period, and 1403 farms (70\%) remained in the sample for more than five years. For a farm to be included in the analysis, firstly, continuous whole-farm data had to be available from 2001-2015. Secondly, due to the lag structure of our model, a farm had to have remained in the sample for at least three years. Applying these criteria reduced the total number of farms to 1,796 , and the next section presents the results.

\subsection{Empirical Results}

\subsubsection{Determinants of Farm Profitability}

Evaluation of the quantile regressions as shown in Table 4.2 allows examination of the effects of selected variables at multiple distributions of farm profitability. 
Table 4.2: Determinants of farm profitability

\begin{tabular}{|c|c|c|c|c|c|c|}
\hline ROA & OLS & $q(10)$ & $q(25)$ & $q(50)$ & $q(75)$ & $(90)$ \\
\hline everage & $\begin{array}{c}-0.320 * * * \\
(0.0042)\end{array}$ & $\begin{array}{c}-0.1047 * * * \\
(0.0045)\end{array}$ & $\begin{array}{c}-0.0810 * * * \\
(0.0022)\end{array}$ & $\begin{array}{c}-0.0641 * * * \\
(0.0020)\end{array}$ & $\begin{array}{c}-0.0488 * * * \\
(0.0024)\end{array}$ & $\begin{array}{c}-0.0374 * * * \\
(0.0038)\end{array}$ \\
\hline Short-run risk & $\begin{array}{c}-0.232^{*} \\
(0.1287)\end{array}$ & $\begin{array}{l}-0.2116 \\
(0.2642)\end{array}$ & $\begin{array}{l}0.0007 \\
(0.2781)\end{array}$ & $\begin{array}{c}-0.2410 \\
(0.2517)\end{array}$ & $\begin{array}{r}-0.1500 * \\
(0.1471)\end{array}$ & $\begin{array}{c}-0.0929 \\
(0.1484)\end{array}$ \\
\hline Long-run risk & $\begin{array}{l}0.4127 \\
(0.448)\end{array}$ & $\begin{array}{l}0.3841 \\
(0.7002)\end{array}$ & $\begin{array}{c}-0.1731 \\
(0.9900)\end{array}$ & $\begin{array}{l}0.7134 \\
(0.9056)\end{array}$ & $\begin{array}{l}0.4783 \\
(0.6471)\end{array}$ & $\begin{array}{l}0.8028^{*} \\
(0.5587)\end{array}$ \\
\hline Working capital & $\begin{array}{l}0.0045 * * \\
(0.0017)\end{array}$ & $\begin{array}{l}0.0059 \text { *** } \\
(0.0010)\end{array}$ & $\begin{array}{l}0 * * * \\
08)\end{array}$ & $\begin{array}{l}0.0099 * * * \\
(0.0010)\end{array}$ & $\begin{array}{l}0.0146^{* * * *} \\
(0.0013)\end{array}$ & $\begin{array}{l}0.0155^{* * * *} \\
(0.0017)\end{array}$ \\
\hline Capital Inte & $\begin{array}{c}-0.3171 \text { *** } \\
(0.0022)\end{array}$ & $\begin{array}{c}-0.1922 * * * \\
(0.0130)\end{array}$ & $\begin{array}{c}-0.2291 * * * \\
(0.0096)\end{array}$ & $\begin{array}{c}-0.2846 * * * \\
(0.0084)\end{array}$ & $\begin{array}{c}-0.3149 * * * \\
(0.0138)\end{array}$ & $\begin{array}{c}-0.2860 \\
(0.0186)\end{array}$ \\
\hline Age & $\begin{array}{c}-0.0434 * * * \\
(0.0058)\end{array}$ & $\begin{array}{l}-0.0103 * * * \\
(0.0022)\end{array}$ & $\begin{array}{c}-0.0073 * * * \\
(0.0015)\end{array}$ & $\begin{array}{c}-0.0067 * * * \\
(0.0014)\end{array}$ & $\begin{array}{c}-0.0038^{* *} \\
(0.0014)\end{array}$ & $\begin{array}{c}-0.0018 \\
(0.0020)\end{array}$ \\
\hline Investment & $\begin{array}{l}0.0596 * * * \\
(0.0081)\end{array}$ & $\begin{array}{l}0.0 \\
(0.0\end{array}$ & $\begin{array}{l}7 * * * \\
42)\end{array}$ & $\begin{array}{l}0.0244 * * * \\
(0.0055)\end{array}$ & $\begin{array}{l}0.0378 * * * \\
(0.0065)\end{array}$ & $\begin{array}{l}0.0702 * * * \\
(0.0132)\end{array}$ \\
\hline Subsidy rate & $\begin{array}{l}0.0124 \\
(0.0130)\end{array}$ & $\begin{array}{l}0.0183 \text { *** } \\
(0.0064)\end{array}$ & $\begin{array}{l}0.0077 \\
(0.0053)\end{array}$ & $\begin{array}{c}-0.0010 \\
(0.0050)\end{array}$ & $\begin{array}{c}-0.0089 \\
(0.0070)\end{array}$ & $\begin{array}{c}-0.0298 * * \\
(0.0162)\end{array}$ \\
\hline Diversifi & *** & *** & $* *$ & $\begin{array}{l}0.0260 * * * \\
(0.0021)\end{array}$ & $\begin{array}{l}0.0 \\
0.0\end{array}$ & $\begin{array}{l}98 * * * * \\
556)\end{array}$ \\
\hline Size & $\begin{array}{l}0.0021 \\
(0.0030)\end{array}$ & $\begin{array}{l}0.0070 * * * \\
(0.0008)\end{array}$ & $\begin{array}{l}0.0026^{* * * *} \\
(0.0005)\end{array}$ & $\begin{array}{c}-0.0017 * * * \\
(0.0005)\end{array}$ & $\begin{array}{c}-0.0085^{* * * *} \\
(0.0006)\end{array}$ & $\begin{array}{c}-0.0178 * * * * \\
(0.0011)\end{array}$ \\
\hline Labor Productivi & $\begin{array}{l}0.2663 * * * \\
(0.0176)\end{array}$ & $\begin{array}{l}0.0667 \text { *** } \\
(0.0070)\end{array}$ & $\begin{array}{l}0.0601 * * * \\
(0.0055)\end{array}$ & $\begin{array}{l}0.0666^{* * * *} \\
(0.0050)\end{array}$ & $\begin{array}{l}0.0 \\
(0 .\end{array}$ & $\begin{array}{l}0.1713^{* * * *} \\
(0.0230)\end{array}$ \\
\hline Farm-Field crops & $\begin{array}{l}-0.0110 \\
(0.0085)\end{array}$ & $\begin{array}{l}-0.0102 \text { *** } \\
(0.0011)\end{array}$ & $\begin{array}{c}-0.0047 * * * \\
(0.0007)\end{array}$ & $\begin{array}{l}0.0002 \\
(0.0007)\end{array}$ & $\begin{array}{l}0.0056^{* * * *} \\
(0.0008)\end{array}$ & $\begin{array}{l}0.0103 * * * \\
(0.0016)\end{array}$ \\
\hline Farm-Horticulture & $\begin{array}{c}-0.0149 \\
(0.0101)\end{array}$ & $\begin{array}{c}-0.023 * * * \\
(0.0019)\end{array}$ & $\begin{array}{c}-0.0082 * * * \\
(0.0012)\end{array}$ & $\begin{array}{l}0.0075^{* * *} * \\
(0.0011)\end{array}$ & $\begin{array}{l}0.0269 * * * \\
(0.0015)\end{array}$ & $\begin{array}{l}0.0527 * * * \\
(0.0027)\end{array}$ \\
\hline Farm-Livestock & $\begin{array}{c}-0.0151^{* *} \\
(0.0061)\end{array}$ & $\begin{array}{c}-0.0277 * * * \\
(0.0014)\end{array}$ & $\begin{array}{c}-0.0220 * * * \\
(0.0010)\end{array}$ & $\begin{array}{c}-0.0161 * * * \\
(0.0010)\end{array}$ & $\begin{array}{c}-0.0101 * * * \\
(0.0012)\end{array}$ & $\begin{array}{c}-0.0030 \\
(0.0020)\end{array}$ \\
\hline _cons & $\begin{array}{l}0.2538 * * * \\
(0.0548)\end{array}$ & $\begin{array}{c}-0.0194 \\
(0.0131)\end{array}$ & $\begin{array}{l}0.0442 * * * \\
(0.0091)\end{array}$ & $\begin{array}{c}0.1137 * * * \\
(0.0086)\end{array}$ & $\begin{array}{l}0.2074 * * * \\
(0.0098)\end{array}$ & $\begin{array}{l}0.3335^{* * * *} \\
(0.0163)\end{array}$ \\
\hline Year & Yes & Yes & Yes & Yes & Yes & \\
\hline Region & $\mathrm{Ye}$ & $\mathrm{Ye}$ & $\mathrm{Ye}$ & Yes & $\mathrm{Ye}$ & $Y$ \\
\hline Soil & Yes & $\mathrm{Ye}$ & $\mathrm{Ye}$ & Yes & Yes & Yes \\
\hline $\begin{array}{l}R^{2}\left(\text { Pseudo } R^{2}\right) \\
\text { Obs. }\end{array}$ & $\begin{array}{l}0.067 \\
15,659\end{array}$ & 0.219 & 0.149 & 0.136 & 0.197 & 0.250 \\
\hline
\end{tabular}

$* * *, * *, *$ are significant at the $1 \%, 5 \%$, and $10 \%$ levels, respectively. Numbers in parentheses are bootstrap standard errors based on 1000 replications, and the dummy reference levels are dairy farms, the year 2001, Drenthe region, and clay soil.

The second column in Table 4.2 shows the parameter estimates ${ }^{57}$ for the ordinary least squares (OLS) regression. The third, fourth, fifth, sixth and seventh columns present the results

\footnotetext{
${ }^{57}$ Note that, in the interest of space, the coefficients for year, region, and soil type dummies are not reported in all tables. Bootstrap standard errors are presented in brackets. The bootstrap standard errors retain the assumption
} 
of the quantile regression at the following quantiles: $0.10,0.25,0.50,0.75$ and 0.90 . The quantile value estimates indicate that there is a significant difference in the parameter estimates across the five quantile estimates ${ }^{58}$. Evaluated at the median, most of the variables are highly significant (Table 4. 2), and the coefficients vary greatly across the conditional profit distribution. For example, there is more than a $175 \%$ difference, in absolute value, between the leverage coefficient for the $10^{\text {th }}$ and the $90^{\text {th }}$ quantile.

Results suggests that a larger proportion of the profit of high-profit farms is attributable to their high levels of long-term risk, working capital, investment, diversification and labor productivity. Farm size has a negative effect on farms in the highest-profit quantile groups, while a positive effect of size is observed in the lower quantiles, which can be due to the lower marginal profit obtained from economies of scale for higher-profit farms.

The regression coefficients for the subsidy rate are positive and significant in the lowerprofit quantile (10\%) and negative and significant in the high-profit quantile (90\%). The underlying economic reason may be tied to subsidies from the government that constitutes the major portion of net farm income for farms in the lower-profit groups. A one percent increase in farm subsidy increases profitability by 1.83 percent in the $10^{\text {th }}$ quantile while it decreases profitability by 2.98 percent in the $90^{\text {th }}$ quantile. This finding contributes to the current debate on the relevance of farm subsidies to stabilizing farm income.

The effect of short-run financial risk exposure is negative but significant in the upper conditional distribution of farm profit (75\%), suggesting that farms in this range do not benefit from taking more risks in the short-run. Conversely, the long-run risk exposure of farms in the upper end of the distribution (90\%) appears positive and significant.

of independent errors but relax the assumption of identically distributed errors and are hence analogous to the robust standard errors in linear regression (Koenker, 2004).

${ }^{58}$ Detailed results of the hypothesis test that evaluates the statistical significance of the differences in parameter estimates in all quantiles show that the null hypothesis, i.e. that the coefficients are equal across quantiles, is rejected. This indicates that there are statistically significant differences among the estimated quantile regression parameters. Hence, it confirms the presence of unobserved heterogeneity and validates the use of quantile regression. 
Farms tend to spread their risk through diversification. The significant and positive effect of diversification entails that the addition of non-core activities to the farm enterprise is rewarding in terms of revenue (Kwansoo et al., 2012; Mishra, El-Osta and Johnson, 1999). Positive financial returns can be expected when diversification is undertaken in a way that does not decrease overall farm efficiency, lowers input costs or offsets the risk of low return on one product by increasing the profitability of another. Note that these effects become more pronounced as we move from the lower to the upper profit quantiles, indicating that diversification is systematically associated with high farm profits.

When investment per total asset increases, farm profit also increases in all quantiles but the $10^{\text {th }}$. Moreover, this increase is more pronounced for higher levels of farm profitability. The estimated effects of capital intensity on farm profitability found in Table 4.2, suggests that farms that require more capital to earn the same revenue end up making lower profits.

The same conclusion can be reached for the variable of leverage. Farms that depend heavily on external funds over internal funds incur financing costs, which will ultimately reduce profitability levels. It is worth noting that farmers as sole proprietors face additional credit constraints beyond those faced by partnerships and other legal business forms with limited access to capital markets, which may further restrain the expansion of farm enterprises. Note that these effects are more pronounced as we move from the upper profit quantiles to the lower ones, which further suggests that farms with lower profits will signal lower creditworthiness to creditors and end up paying higher interest rates than farms in the upper end of the profit-distribution quantile.

Figure 4.3 illustrates how the effects of leverage, short-run and long-run risk exposures, working capital, investment, capital intensity, subsidy ratio, diversification, farm size, and labor productivity vary over quantiles and how the magnitude of the effects differs considerably from the OLS coefficient. The solid line represents the 5-point estimates of the effects of selected variables for quantiles ranging from 0.1 to 0.90 . The two dashed lines represent the upper and lower confidence bounds. The bold dotted horizontal line indicates the ordinary least squares estimates of the mean effects. 

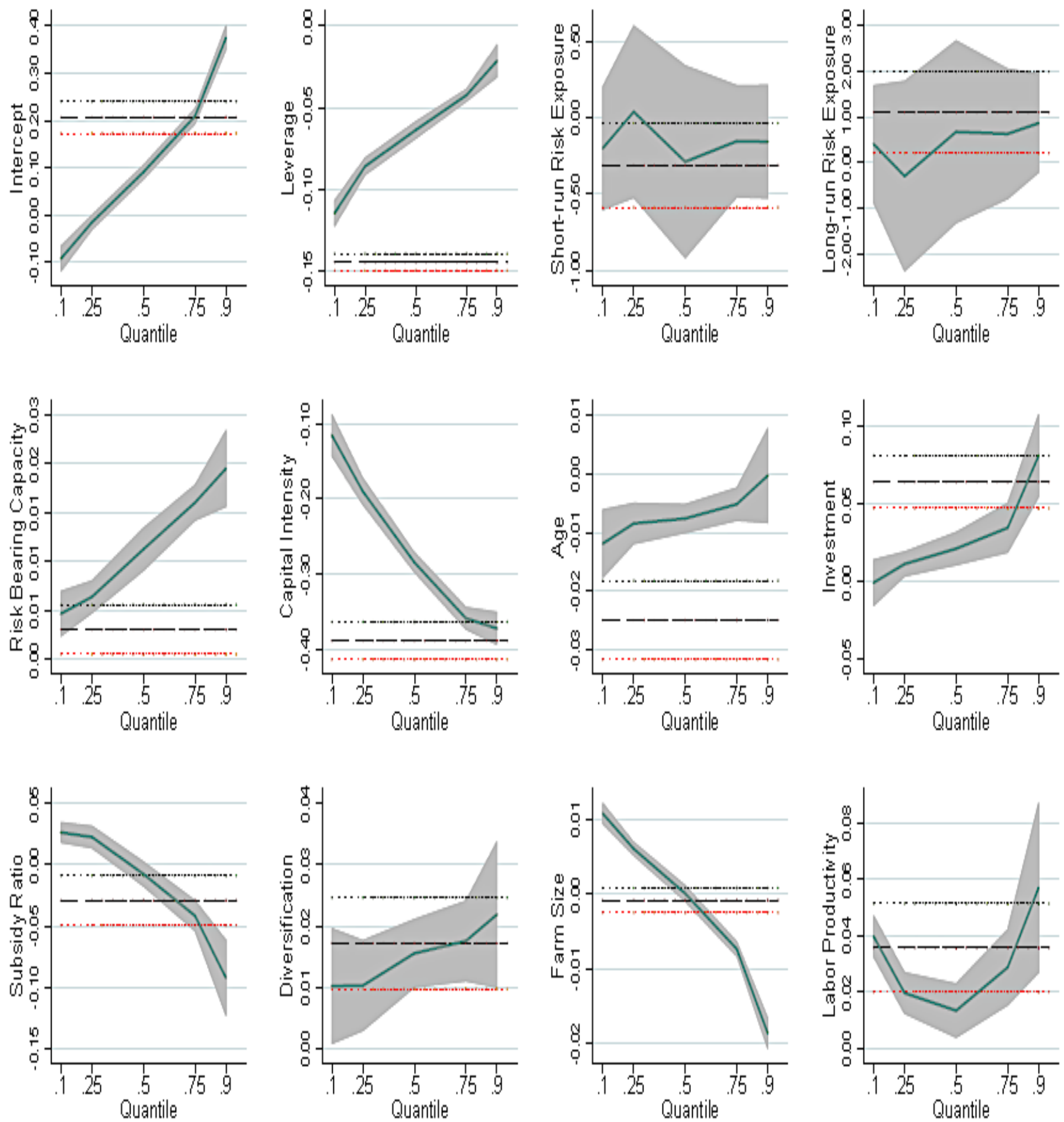

Figure 4.3: OLS and quantile regression estimates for the farm profitability model

The coefficient of farm size on profitability, for example, is 100 times lower at the $90 \%$ quantile than at the median quantile. Finally, the estimated coefficients for the farm type dummies indicate a mixed but statistically significant level of profitability compared to the reference farm type (dairy farms). Hence, we note how the same variables affect profit 
differently for each farm type and at different levels of profitability. Table 4.3 reports the quantile regression estimation results across the four farm types, and the following paragraphs summaries the major findings.

For dairy farms, similar to field-crop, horticulture and livestock farms, the regression estimates of the effects of leverage, capital intensity and age are significantly negative, whereas working capital has a positive effect. Note that the effects of investment, diversification and labor productivity on profitability are only positive and significant at the middle and upper end of the profit distribution. The systematic effects of leverage suggest that the negative role of farm leverage becomes less obvious with an increase in farm profitability. While dairy farm size, short-run and long-run risks have mixed effect, we do not find any effect of government subsidies on profit at any quantile. The relationship of working capital with profitability becomes more pronounced as we move from the lower to the upper profit quantile. This can be explained by the strong regulation and frequent policy changes experienced by Dutch dairy farms, such as the automatic milking system, obligatory manure processing and the abolition of the milk quota system (Klootwijk et al., 2016; Samson, Gardebroek and Jongeneel, 2016). These changes increase the need for cash to comply with the regulations and new market conditions. Hence, having sufficient working capital to fulfill these requirements is expected to impact dairy farm profitability.

For field crop farms, size has mixed effects. While an increase in farm size results in a higher profit at the $25^{\text {th }}$ and $10^{\text {th }}$ quantile, it is linked to lower profitability in the higher $75^{\text {th }}$ and $90^{\text {th }}$ quantiles. As expected, a large farm size contributes to higher farm profit because it generates economies of scale, allows for more cash crops to be produced or for the assets to be used as collateral for other income-generating materials. However, these economies of scale and economies of scope associated with larger size show an adverse effect for farms at the upper end of the profit quantile. Note that, unlike for the other three farm types, the association between the subsidy and profitability is significant and negative for the upper quantiles.

Regarding horticulture farms, the effect of investment systematically increases from the $25^{\text {th }}$ to the $90^{\text {th }}$ quantile, i.e. becomes more pronounced as we move from the bottom to the 
upper profit quantiles. The Dutch horticulture sector is mostly characterized as innovative and technology, capital and energy intensive (Berkhout and van Bruchem, 2015). The result provides confirmation that investment in energy-saving technologies and other innovations is an important determinant of farm profitability for horticulture farms. Diversification is associated with profitability only in the upper quantile. In addition, unlike for dairy and fieldcrop farms, both short and long-run financial risks are not associated with farm profitability in any of the quantiles.

Note that the effects of diversification and age are more pronounced in livestock farms, unlike in the other farm types. The interdependent nature of livestock production enhances onfarm diversification, e.g. the demand for beef, poultry, pork and lamb is highly related, which further motivates farms to diversify. Thus, farms can increase total livestock production through diversifying beyond what could have been produced through specializing on fixed land, fencing, building, labor, and machinery or through minimal increases in resources. The pronounced effect of diversification on profit is particularly true for livestock farms due to the relationship between fixed costs ${ }^{59}$ and profit. By diversifying, livestock farms tend to lower their cash flow risk and increase their profitability. Given that experience accumulates over time, one might expect older farmers to be more likely to better manage a farm and achieve a higher profitability. Contrary to this expectation, however, age is found to be negatively associated with profitability in livestock farms. We could argue that older farmers might be less motivated to increase efficiency or tend to believe operations cannot be improved further, or they may value other aspects of life over financial success. Another explanation could be that age/experience and performance show a linear or exponential relationship and the distribution might be expressed as a bell curve.

In general, the coefficients of working capital, labor productivity, and investment are positive and statistically significant for all farm types. This suggests that, in an environment

\footnotetext{
${ }^{59}$ Fixed costs are a major expense in operating a livestock farm in the Netherlands (Samson, Gardebroek and Jongeneel, 2016). Not surprisingly, as production increases for a fixed level of resources keeping fixed costs per unit lower, the overall farm profitability will also increase.
} 
where farms don't have regular income from agricultural products, working capital is important for them to have the flexibility and capacity to adapt to changing circumstances, which ultimately helps in earning a profit. The findings also lend support to the premise of the RBV that scarce and less imitable resources contribute to superior performance, hence profitability. On the other hand, leverage and capital intensity have negative effects on farm profitability. Farms that already exhibit high leverage levels and use more capital experience more cashflow constraints in their operation due to high financing costs. Farms with a high debt-to-asset ratio often maintain less working capital, and their ability to refinance is limited, which impairs profits and cash flow positions. The next section discusses the impact of the selected characteristics on the persistence of abnormal farm profitability. 
Table 4.3: Determinates of farm profitability, quantile regression results

\begin{tabular}{|c|c|c|c|c|c|c|c|c|c|c|}
\hline \multirow[t]{2}{*}{ MROA } & \multicolumn{5}{|c|}{ Dairy Farms } & \multicolumn{5}{|c|}{ Field Crops } \\
\hline & $q(10)$ & $q(25)$ & $q(50)$ & $q(75)$ & $q(90)$ & $q(10)$ & $q(25)$ & $q(50)$ & $q(75)$ & $q(90)$ \\
\hline Leverage & $\begin{array}{l}-0.0768 * * * \\
(0.0079)\end{array}$ & $\begin{array}{l}-0.0725 * * * \\
(0.0052)\end{array}$ & $\begin{array}{l}-0.0610 * * * \\
(0.0072)\end{array}$ & $\begin{array}{c}-0.0556 * * * \\
(0.0110)\end{array}$ & $\begin{array}{c}-0.0525 * * \\
(0.0160)\end{array}$ & $\begin{array}{l}-0.0880 * * * \\
(0.0114)\end{array}$ & $\begin{array}{l}-0.0639 * * * \\
(0.0089)\end{array}$ & $\begin{array}{l}-0.0519 * * * \\
(0.0058)\end{array}$ & $\begin{array}{l}-0.0409 * * * \\
(0.0080)\end{array}$ & $\begin{array}{c}-0.0310 \\
(0.0163)\end{array}$ \\
\hline Short-run risk & $\begin{array}{c}-0.2889 \\
(0.1767)\end{array}$ & $\begin{array}{r}-0.2298 * \\
(0.1150)\end{array}$ & $\begin{array}{l}-0.1029 \\
(0.7009)\end{array}$ & $\begin{array}{c}-0.2667 \\
(0.4927)\end{array}$ & $\begin{array}{l}0.2422 \\
(0.5795)\end{array}$ & $\begin{array}{c}-0.3956^{*} \\
(0.1664)\end{array}$ & $\begin{array}{l}-0.7768 \\
(0.1661)\end{array}$ & $\begin{array}{l}0.5652 \\
(0.1071)\end{array}$ & $\begin{array}{l}0.8315 \\
(0.1189)\end{array}$ & $\begin{array}{l}0.2320 \\
(0.1724)\end{array}$ \\
\hline Long-run risk & $\begin{array}{l}0.6127 \\
(0.3257)\end{array}$ & $\begin{array}{l}0.4908 * \\
(0.2316)\end{array}$ & $\begin{array}{l}0.2269 \\
(0.2555)\end{array}$ & $\begin{array}{l}0.6494 \\
(0.3910)\end{array}$ & $\begin{array}{c}-0.3510 \\
(0.5361)\end{array}$ & $\begin{array}{l}0.9401 \\
(0.5044)\end{array}$ & $\begin{array}{l}-0.5738 \\
(0.4334)\end{array}$ & $\begin{array}{r}-0.2951 * \\
(0.1379)\end{array}$ & $\begin{array}{c}-0.2111 \\
(0.2545)\end{array}$ & $\begin{array}{l}-0.7946 \\
(0.4691)\end{array}$ \\
\hline Working Capital & $\begin{array}{l}0.0092 * * * \\
(0.0017)\end{array}$ & $\begin{array}{l}0.0098 * * * \\
(0.0015)\end{array}$ & $\begin{array}{l}0.0128 * * * \\
(0.0013)\end{array}$ & $\begin{array}{l}0.0141 * * * \\
(0.0015)\end{array}$ & $\begin{array}{l}0.0144 * * * \\
(0.0023)\end{array}$ & $\begin{array}{l}0.0015 \\
(0.0014)\end{array}$ & $\begin{array}{l}0.0022 \\
(0.0013)\end{array}$ & $\begin{array}{l}0.0064 * * * \\
(0.0014)\end{array}$ & $\begin{array}{l}0.0085 * * * \\
(0.0022)\end{array}$ & $\begin{array}{l}0.0106^{* *} \\
(0.0041)\end{array}$ \\
\hline Capital Intensity & $\begin{array}{l}-0.2681 * * * \\
(0.0216)\end{array}$ & $\begin{array}{c}-0.2585^{* * *} \\
(0.0134)\end{array}$ & $\begin{array}{l}-0.2822^{* * *} \\
(0.0115)\end{array}$ & $\begin{array}{c}-0.2992 * * * \\
(0.0121)\end{array}$ & $\begin{array}{l}-0.3094 * * * \\
(0.0163)\end{array}$ & $\begin{array}{l}-0.1067^{* * *} \\
(0.0198)\end{array}$ & $\begin{array}{l}-0.1553 * * * \\
(0.0102)\end{array}$ & $\begin{array}{l}-0.2013 * * * \\
(0.0092)\end{array}$ & $\begin{array}{l}-0.2197 * * * \\
(0.0158)\end{array}$ & $\begin{array}{l}-0.213 * * * \\
(0.0213)\end{array}$ \\
\hline Age & $\begin{array}{c}-0.0051 * \\
(0.0024)\end{array}$ & $\begin{array}{l}-0.0059 * * * \\
(0.0017)\end{array}$ & $\begin{array}{l}-0.0061 * * * \\
(0.0012)\end{array}$ & $\begin{array}{l}-0.0044 * * * \\
(0.0012)\end{array}$ & $\begin{array}{l}-0.001 \\
(0.0020)\end{array}$ & $\begin{array}{l}-0.0018 \\
(0.0037)\end{array}$ & $\begin{array}{l}0.0002 \\
(0.0026)\end{array}$ & $\begin{array}{l}0.0024 \\
(0.0028)\end{array}$ & $\begin{array}{l}0.0058 \\
(0.0032)\end{array}$ & $\begin{array}{l}0.0056 \\
(0.0049)\end{array}$ \\
\hline Investment & $\begin{array}{l}-0.0020 \\
(0.0090)\end{array}$ & $\begin{array}{l}0.0048 \\
(0.0068)\end{array}$ & $\begin{array}{l}0.0172 * * \\
(0.0061)\end{array}$ & $\begin{array}{l}0.0278 * * * \\
(0.0074)\end{array}$ & $\begin{array}{l}0.0449 * * * \\
(0.0116)\end{array}$ & $\begin{array}{l}0.0005 \\
(0.0187)\end{array}$ & $\begin{array}{l}0.0102 \\
(0.0085)\end{array}$ & $\begin{array}{l}0.0167 * \\
(0.0081)\end{array}$ & $\begin{array}{l}0.0218 * \\
(0.0107)\end{array}$ & $\begin{array}{l}0.03027 \\
(0.0172)\end{array}$ \\
\hline Subsidy rate & $\begin{array}{l}0.0080 \\
(0.0189)\end{array}$ & $\begin{array}{l}0.0080 \\
(0.0106)\end{array}$ & $\begin{array}{l}0.00379 \\
(0.0107)\end{array}$ & $\begin{array}{c}-0.0154 \\
(0.0105)\end{array}$ & $\begin{array}{l}-0.0121 \\
(0.0163)\end{array}$ & $\begin{array}{l}0.0058 \\
(0.0159)\end{array}$ & $\begin{array}{l}0.0030 \\
(0.0110)\end{array}$ & $\begin{array}{l}-0.0073 \\
(0.0099)\end{array}$ & $\begin{array}{c}-0.0273 * * \\
(0.0102)\end{array}$ & $\begin{array}{l}-0.0480^{* *} \\
(0.0151)\end{array}$ \\
\hline Diversification & $\begin{array}{l}0.0072 \\
(0.0070)\end{array}$ & $\begin{array}{l}0.0079 \\
(0.0051)\end{array}$ & $\begin{array}{l}0.0146 * * \\
(0.0046)\end{array}$ & $\begin{array}{l}0.0210 * * * \\
(0.0056)\end{array}$ & $\begin{array}{l}0.0390 * * * \\
(0.0073)\end{array}$ & $\begin{array}{l}0.0024 \\
(0.0063)\end{array}$ & $\begin{array}{l}0.0058 \\
(0.0052)\end{array}$ & $\begin{array}{l}0.0029 \\
(0.0044)\end{array}$ & $\begin{array}{l}0.0075 \\
(0.004)\end{array}$ & $\begin{array}{l}0.0116 \\
(0.0101)\end{array}$ \\
\hline Size & $\begin{array}{l}0.0083 * * * \\
(0.0016)\end{array}$ & $\begin{array}{l}0.0049 * * * \\
(0.0009)\end{array}$ & $\begin{array}{l}0.0015 \\
(0.0008)\end{array}$ & $\begin{array}{l}-0.0022 * \\
(0.0009)\end{array}$ & $\begin{array}{c}-0.0014 * * * \\
(0.0012)\end{array}$ & $\begin{array}{l}0.0104 * * * \\
(0.0016)\end{array}$ & $\begin{array}{l}0.0045^{* * *} \\
(0.0012)\end{array}$ & $\begin{array}{l}-0.0010 \\
(0.0010)\end{array}$ & $\begin{array}{c}-0.0091 * * * \\
(0.0013)\end{array}$ & $\begin{array}{c}-0.014 * * * \\
(0.0018)\end{array}$ \\
\hline Labor productivity & $\begin{array}{c}-0.0378 \\
(0.0240)\end{array}$ & $\begin{array}{c}-0.0102 \\
(0.0128)\end{array}$ & $\begin{array}{l}0.0091 \\
(0.0121)\end{array}$ & $\begin{array}{l}0.0475 * * * \\
(0.0143)\end{array}$ & $\begin{array}{l}0.1013 * * * \\
(0.0198)\end{array}$ & $\begin{array}{l}0.0875 * * * \\
(0.0172)\end{array}$ & $\begin{array}{l}0.0875^{* * * *} \\
(0.0160)\end{array}$ & $\begin{array}{l}0.1215 * * * \\
(0.0155)\end{array}$ & $\begin{array}{l}0.1862 * * * \\
(0.0257)\end{array}$ & $\begin{array}{l}0.2305^{* * *} \\
(0.0293)\end{array}$ \\
\hline _cons & $\begin{array}{r}-0.0444^{*} \\
(0.0218)\end{array}$ & $\begin{array}{l}0.01305 \\
(0.0147)\end{array}$ & $\begin{array}{l}0.0689 * * * \\
(0.0118)\end{array}$ & $\begin{array}{l}0.1237 * * * \\
(0.0138)\end{array}$ & $\begin{array}{l}0.2056 * * * \\
(0.0175)\end{array}$ & $\begin{array}{l}-0.1161 * * * \\
(0.0275)\end{array}$ & $\begin{array}{l}-0.0283 \\
(0.0191)\end{array}$ & $\begin{array}{l}0.0528 * * \\
(0.0185)\end{array}$ & $\begin{array}{l}0.1722 * * * \\
(0.0203)\end{array}$ & $\begin{array}{l}0.3148^{* * *} \\
(0.0312)\end{array}$ \\
\hline Year & Yes & $Y e s$ & Yes & Yes & Yes & Yes & Yes & Yes & Yes & $Y e s$ \\
\hline Region & Yes & Yes & Yes & Yes & Yes & Yes & Yes & Yes & Yes & Yes \\
\hline Soil & Yes & Yes & Yes & Yes & Yes & Yes & Yes & Yes & Yes & Yes \\
\hline $\begin{array}{l}\text { Pseudo R2 } \\
\text { Obs. }\end{array}$ & $\begin{array}{l}0.2489 \\
\mathbf{4 0 9 9}\end{array}$ & 0.2641 & 0.2833 & 0.3158 & 0.3553 & $\begin{array}{c}0.2267 \\
\mathbf{2 6 9 1}\end{array}$ & 0.1965 & 0.2110 & 0.2669 & 0.3425 \\
\hline
\end{tabular}




\begin{tabular}{|c|c|c|c|c|c|c|c|c|c|c|}
\hline & \multicolumn{5}{|c|}{ Horticulture Farms } & \multicolumn{5}{|c|}{ Livestock Farms } \\
\hline & $q(10)$ & $q(25)$ & $q(50)$ & $q(75)$ & $q(90)$ & $q(10)$ & $q(25)$ & $q(50)$ & $q(75)$ & $q(90)$ \\
\hline \multirow{2}{*}{ Leverage } & $-0.1160 * * *$ & $-0.0924 * * *$ & $-0.0746 * * *$ & $-0.0602 * * *$ & $-0.0483 * * *$ & $-0.1070 * * *$ & $-0.0850 * * *$ & $-0.0658 * * *$ & $-0.0483^{* * *}$ & $-0.0228 *$ \\
\hline & $(0.0126)$ & $(0.0056)$ & $(0.0056)$ & $(0.0056)$ & $(0.0059)$ & $(0.0074)$ & $(0.0055)$ & $(0.0048)$ & $(0.0064)$ & $(0.0100)$ \\
\hline \multirow[t]{2}{*}{ Short-run risk } & -0.0569 & 0.2104 & -0.2085 & -0.1107 & -0.1634 & -0.0999 & -0.2992 & 0.1234 & -0.2301 & -0.09775 \\
\hline & $(0.2818)$ & $(0.3116)$ & $(0.3279)$ & $(0.2095)$ & $(0.1820)$ & $(0.0169)$ & $(0.1312)$ & $(0.1056)$ & $(0.0933)$ & $(0.1079)$ \\
\hline \multirow[t]{2}{*}{ Long-run risk } & 0.2234 & -0.6955 & 0.4893 & 0.4306 & 0.9957 & 0.6488 & 0.2228 & -0.04570 & 0.8037 & 0.1483 \\
\hline & -0.1081 & $(0.9435)$ & $(0.1043)$ & $(0.8028)$ & $(0.6215)$ & $(0.6493)$ & $(0.4921)$ & $(0.3352)$ & $(0.2435)$ & $(0.3448)$ \\
\hline \multirow[t]{2}{*}{ Working Capital } & $0.0063 *$ & $0.0084 * * *$ & $0.0093 * * *$ & $0.0105 * * *$ & $0.0137 * * *$ & 0.0028 & $0.0051 *$ & $0.0070 * *$ & $0.0134 *$ & $0.0312 *$ \\
\hline & $(0.0029)$ & $(0.0012)$ & $(0.0013)$ & $(0.0018)$ & $(0.0026)$ & $(0.0015)$ & $(0.0025)$ & $(0.0024)$ & $(0.0060)$ & $(0.0129)$ \\
\hline \multirow[t]{2}{*}{ Capital Intensity } & $-0.2790 * * *$ & $-0.4331 * * *$ & $-0.5361 * * *$ & $-0.5609 * * *$ & $-0.4450 * * *$ & $-0.2758 * * *$ & $-0.3035^{* * *}$ & $-0.3130 * * *$ & $-0.2780 * * *$ & $-0.1922 * *$ \\
\hline & $(0.0615)$ & $(0.0432)$ & $(0.0516)$ & $(0.0673)$ & $(0.1177)$ & $(0.0424)$ & $(0.0326)$ & $(0.0407)$ & $(0.0447)$ & (0.0599) \\
\hline \multirow[t]{2}{*}{ Age } & -0.0140 & -0.0105 & -0.0033 & -0.0103 & -0.0081 & $-0.0129 *$ & $-0.0099 *$ & $-0.012 * *$ & $-0.0171 * * *$ & $-0.0206^{* *}$ \\
\hline & $(0.0077)$ & $(0.0055)$ & $(0.0054)$ & $(0.0060)$ & $(0.0079)$ & $(0.0066)$ & $(0.0039)$ & $(0.0047)$ & $(0.0047)$ & $(0.0073)$ \\
\hline \multirow[t]{2}{*}{ Investment } & 0.0148 & $0.0389 * * *$ & $0.0477 * * *$ & $0.0631 * * *$ & $0.1445^{* * *}$ & 0.0004 & $0.0240 *$ & 0.02170 & $0.0336^{*}$ & $0.1124 * *$ \\
\hline & $(0.0146)$ & $(0.0118)$ & $(0.0105)$ & $(0.0135)$ & $(0.0291)$ & $(0.0199)$ & $(0.0100)$ & $(0.0148)$ & $(0.0149)$ & $(0.0387)$ \\
\hline \multirow[t]{2}{*}{ Subsidy rate } & -0.0339 & -0.0613 & -0.0406 & -0.0346 & -0.0854 & 0.0068 & 0.0006 & 0.0072 & -0.0083 & -0.0043 \\
\hline & $(0.0456)$ & $(0.0481)$ & $(0.0404)$ & $(0.0508)$ & $(0.0844)$ & $(0.0155)$ & $(0.0093)$ & $(0.0086)$ & $(0.0129)$ & $(0.0142)$ \\
\hline \multirow[t]{2}{*}{ Diversification } & -0.0169 & -0.0170 & -0.0030 & -0.0042 & $0.0371 * *$ & $0.0451 * * *$ & $0.0499 * * *$ & $0.0461 * * *$ & $0.0376 * * *$ & $0.0252 * * *$ \\
\hline & $(0.0115)$ & $(0.0102)$ & $(0.0075)$ & $(0.0093)$ & $(0.0141)$ & $(0.0051)$ & $(0.0035)$ & $(0.0027)$ & $(0.0038)$ & $(0.0055)$ \\
\hline \multirow[t]{2}{*}{ Size } & -0.0028 & $-0.0078 * * *$ & $-0.0163 * * *$ & $-0.0230 * * *$ & $-0.0345 * * *$ & $0.0145^{* * *}$ & $0.0114 * * *$ & $0.0061 * * *$ & $-0.0045 * *$ & $-0.014 * * *$ \\
\hline & $(0.0022)$ & $(0.0013)$ & $(0.0013)$ & $(0.0018)$ & $(0.0023)$ & $(0.0019)$ & $(0.0012)$ & $(0.0014)$ & $(0.0014)$ & $(0.0025)$ \\
\hline \multirow[t]{2}{*}{ Labor productivity } & $0.2700 * * *$ & $0.3419 * * *$ & $0.4446 * * *$ & $0.5104 * * *$ & $0.5600 * * *$ & $0.0390 * * *$ & $0.0362 * * *$ & $0.0465 * * *$ & $0.0630 * * *$ & $0.1139 * * *$ \\
\hline & $(0.0428)$ & $(0.0392)$ & $(0.0352)$ & $(0.0556)$ & $(0.0769)$ & $(0.0097)$ & $(0.0088)$ & $(0.0110)$ & $(0.0117)$ & $(0.0211)$ \\
\hline \multirow{2}{*}{ _cons } & 0.0698 & $0.186 * * *$ & $0.3200 * * *$ & $0.4654 * * *$ & $0.6448 * * *$ & $-0.1285^{* *}$ & $-0.0916 * * *$ & 0.0081 & $0.1926 * * *$ & $0.3329 * * *$ \\
\hline & $(0.0364)$ & $(0.0269)$ & $(0.0229)$ & $(0.0284)$ & $(0.0424)$ & $(0.0415)$ & $(0.0211)$ & $(0.0263)$ & $(0.0266)$ & $(0.0463)$ \\
\hline Year & Yes & Yes & Yes & Yes & Yes & Yes & Yes & Yes & Yes & Yes \\
\hline Region & Yes & Yes & Yes & Yes & Yes & Yes & Yes & Yes & Yes & Yes \\
\hline Soil & Yes & Yes & Yes & Yes & Yes & Yes & Yes & Yes & Yes & Yes \\
\hline Pseudo R2 & 0.2157 & 0.1852 & 0.1738 & 0.1792 & 0.1912 & 0.2031 & 0.1744 & 0.1456 & 0.1353 & 0.1253 \\
\hline Obs. & 5133 & & & & & 3736 & & & & \\
\hline
\end{tabular}

$* * *, * *, *$ are significant at the $1 \%, 5 \%$ and $10 \%$ levels respectively. Numbers in parentheses are bootstrap standard errors based on

1000 replications, and the dummy reference levels are the year 2001, the Drenthe region, and clay soil. 


\subsubsection{Dynamic Panel Model Estimation}

Table 4.4 shows the estimation results of the System GMM based on equation (4.8). The Sargan test, and AR (2) second-order serial correlation, and AR (3) tests are presented to gauge the overall model fit. The Sargan test of over-identifying restrictions yields a $p$-value of 0.110, which supports the validity of the instruments used in the system GMM. The hypothesis of no second and third-order autocorrelation of the disturbance term is not rejected at the 5\% significance level ( $p$-values 0.605 and 0.525 , respectively), implying that there is no serial correlation. The model fit tests assure that the key identifying assumption required for the GMM estimator is satisfied.

In Table 4.4, the coefficient on the lagged dependent variable $(\lambda)$, which serves as the measure for short-run profit persistence in this model is positive and significant for all farms. Supporting the notion that the year-to-year persistence of abnormal profit, and the general level of competition in the Dutch farm sector is not sufficiently strong to erode abnormal profit within a year. The coefficient is between zero and one, implying that abnormal profit converges to the mean over time. From the estimated lagged profit coefficient value of 0.075 for all farm types, we infer that farm profitability converges to the mean over time, and the speed of convergence is $92.5 \%(1-\lambda)$ per year. This speed of adjustment corresponds to a half-life ${ }^{60}$ of profit shocks of about 0.3 years respectively.

Decomposing the analysis into farm types, we find that the sign and degree of profit persistence are farm type specific. We find that dairy, field crops and horticulture farms exhibit persistence of abnormal profit. The result is similar to the findings of Hirsch and Gschwandtner (2013) who analyzed the persistence of profit in the European food industry and found values

\footnotetext{
${ }^{60}$ Half-life is the time the process needs to close the gap between the average and abnormal farm profit level by half $(50 \%)$, after a one-unit shock to the error term. Half-life is calculated as $\log (0.5) / \log (\lambda)$. For example, the $\lambda$ estimate for dairy farms in Table 4.4 is 0.304 , which means that a typical dairy farm closes about $69.6 \%(1-\lambda)$ of the gap between its current abnormal profit level and the average long-run profit in one year. At this rate, it takes approximately 0.6 years for the farm to close half of the gap.
} 
between 0.304 for the UK and 0.11 for the Belgian food sector. Dairy farms exhibit the highest degree of short-run persistence, i.e. slower convergence to the average profit.

Table 4.4: Dynamic Panel model estimation results

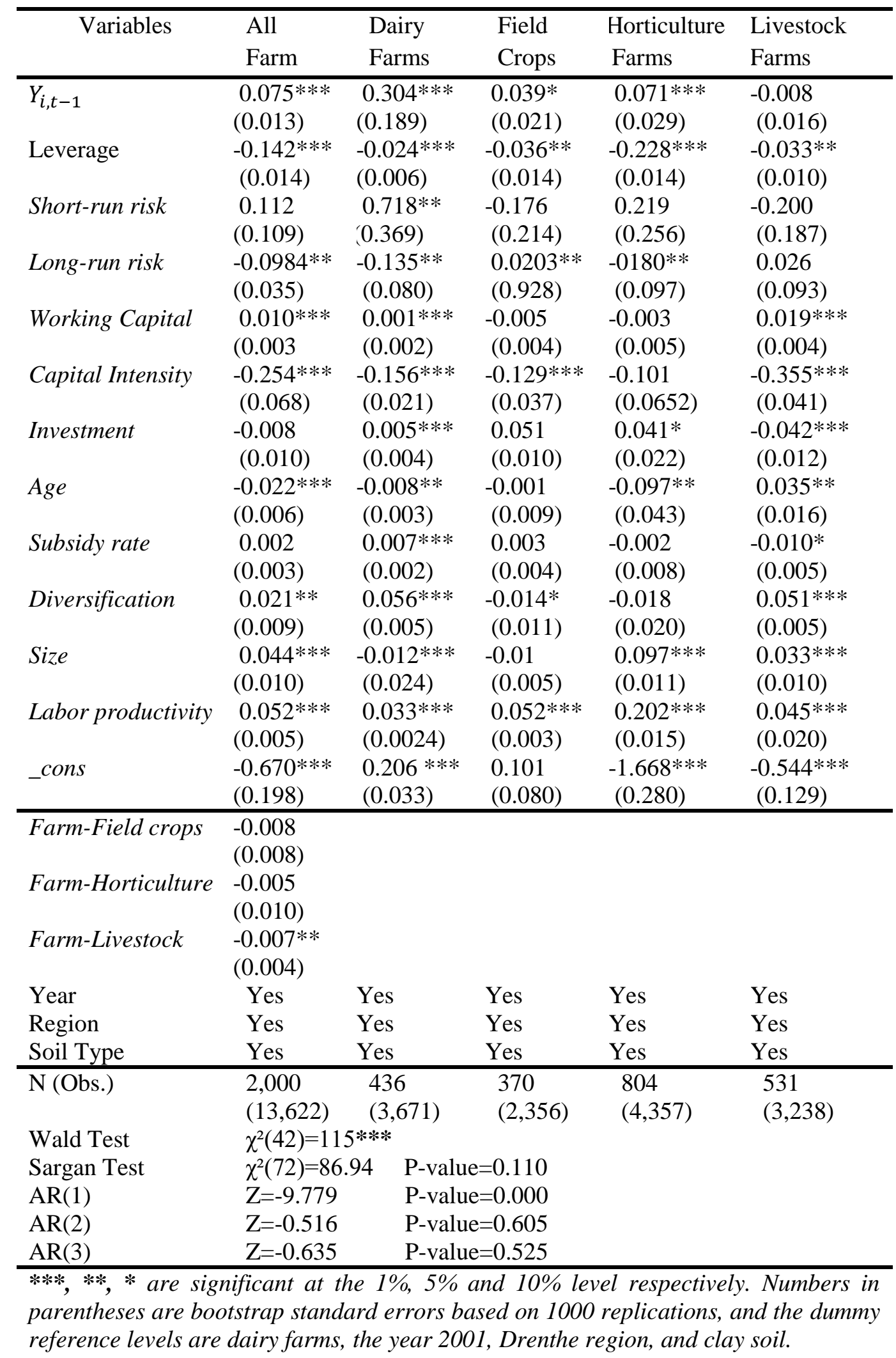


The results further show that, on average, $30.4 \%, 3.9 \%$, and $7.1 \%$ of the abnormal profit earned by dairy, field crops and livestock farms respectively during any prior period is retained in the current period. The higher degree of persistence of dairy farms can be associated to the lower competition in the sector due to the European milk quota system that has been in place for 30 years and was recently abolished on April 1,2015. The high price of quota rights further discourages farm expansion. The intensification of competition in the Dutch field-crop sector explains the low degree of short-run profit persistence, i.e. the high convergence to the average profit. Furthermore, Table 4.4 shows that the value of $\lambda$ for the field crops is 0.039 , indicating a very low level of profit persistence. The persistence level is not only lower than that in previous studies analyzing the entire manufacturing sector, but also lower than that of the food sector reported by Hirsch and Gschwandtner (2013). Note that the lagged dependent variable $(\lambda)$, is negative ${ }^{61}$ but not significant for livestock farms.

The impact of short-run risk exposure, for which the ratio of current liabilities to current assets is used as a proxy, on long-run profitability is positive for dairy farms only. Findings are mixed, however, with regard to the impact of long-run financial risk exposure: it has a significant positive effect for field crops and a negative effect for dairy and horticulture farms. The positive effect supports the risk theory assumption that taking higher risk results in higher returns in the long-run.

The results in Table 4.4 show that the risk-bearing capacity of farms, i.e. working capital, has a significantly positive effect on long-run abnormal profit. Working capital represents the amount of funds available to a farm if all current assets were sold and current liabilities are paid. This liquidity can provide cash to purchase operating inputs or make capital purchases. The results suggest that, in an environment where farms don't have regular income from agricultural products, working capital is important to have the flexibility and capacity to adapt to changing circumstances, which ultimately helps to gain and sustain the abnormal

\footnotetext{
${ }^{61} \mathrm{~A}$ negative lambda could be due to high volatility of profit. If a farm swings between positive and negative abnormal profits, a negative lambda value is possible. A negative lambda is also not unrealistic if the time series is short (Goddard, Tavakoli and Wilson, 2005).
} 
profit. In addition, working capital acts as a first-line buffer in case of economic and financial adversity. The results are consistent with the findings of Barney (2001) that a higher riskbearing capacity of farms helps sustain their competitive advantage. The findings also lend support to the premise of the RBV that resources that are scarce and less imitable contribute to sustained competitive advantage.

The effect of leverage is significantly negative for all farms. A one percent increase in farm leverage results in an average respective decrease by $14.2 \%, 2.4 \%, 3.6 \%$ and $3.3 \%$ in the abnormal returns of dairy, field crops, horticulture, and livestock farms. A possible explanation for our finding is that farms that already exhibit high leverage levels have more cash-flow constraints in their operation due to high financing costs. Also, the impact of leverage can be weakened by other factors beyond the farm's control, such as interest rates and changes in the market value of the collateral.

The relationship between labor productivity and abnormal return is positive at significant for all farm types. This is consistent with findings of Mishra et al. (2009) showing that higher labor productivity helps farms earn a profit in the long-run. The increase in labor productivity contributes to farm profitability only if the resulting value from productivity is greater than the cost of labor. This finding is relevant for Dutch agriculture, where labor costs per hour are among the highest in Europe (Eurostat, 2015).

The negative relationship between capital intensity and long-run abnormal profit is consistent with the a priori expectation that using more capital to earn the same revenue makes farms unlikely to earn and sustain abnormal profits. In addition, the heavy dependency on capital harms farm competitiveness as they are more exposed to the risk of duplication, which would lead to quick erosion of the abnormal returns.

Furthermore, Table 4.4 shows that diversification has a positive effect on abnormal profit for dairy and livestock farms. Our finding is consistent with that of Meraner et al. (2015). Diversification is one of the ways for farms to minimize income and profit variability (McGahan and Porter, 2003). In addition, it may lead to economies of scope, lower costs and increase competitiveness to sustain the long-run abnormal profit. Note that we also find a 
negative relationship between farm diversification and abnormal profit for field-crop farms. Our results are similar to the findings of Katchova (2005) that diversified crop farms face a diversification discount compared to specialized farms. The results suggest that the evidence regarding the impact of diversification on abnormal profit is inconclusive, with some farm sector characteristics being more favorable for diversifiers than specialized farms and vice versa. Thus, the relationship is contingent on the farm types considered.

Likewise, farmer age was found to have a mixed effect. Age is negatively and significantly related to abnormal profit in the dairy and horticulture sector. Argilés and Slof (2003) find a similar relationship. A potential explanation is that, compared to older farmers, younger farmers are more educated and are able to adapt quickly to changes in production, technology, marketing and the legal status of agriculture. This is notably true for farms in dynamic and technology-intensive farm sectors, such as horticulture and dairy. Note, however, that the relationship is positive for livestock farms, implying that aging decreases costs due to learning effects within the farm and learning spillovers from other farms.

Similar to Hirsch and Gschwandtner (2013), we find a positive association of size with profitability. The finding is consistent with consolidation, which is becoming a trend in the Dutch agricultural sectors as farms are getting fewer in number but bigger in size. Another possible reason is that large farms exploit the economies of scale and benefit from economies of scope. Alternatively, it could be argued that large farms have the better bargaining power that they can access capital at a lower cost than small farms and can afford to cope with changes in legislation. The results emphasize that (sufficient) scale is a very important matter in Dutch agriculture. On the other hand, the effect of size is negative and significant for dairy farms. Goddard, Tavakoli and Wilson (2005) also find similar evidence for the inefficiency of larger firms.

Consistent with a priori expectations, the coefficients of subsidy are positive and significant for dairy farms. The subsidy that dairy farms receive from the Dutch government and the European Union under the Common Agriculture Policy (CAP) framework constitutes a significant portion of their profit. The finding also lends strong support to the statement that CAP payments make rich farms richer. Note, however, that the effect is negative for livestock 
farms. Risk-taking farms are more likely to make investments. Therefore, risk exposure and farm investment are expected to be positively related to farm profitability. Our finding in Table 4.4 confirms this expectation for dairy farms. Note also investments might not be always productive or take long time to be fruitful (McBride and Greene, 2007), which may explain the negative association of investment with profitability for livestock farms.

\subsection{Robustness Checks}

We run additional empirical tests to confirm the robustness of our results. MROA is far from being the ideal profitability measurement. To obtain a complete picture of farm profitability, and further examine the measurement invariance robustness of our results, a separate analysis is done using Profit Margin Ratio (PMR) as an alternative measure of farm profitability. PMR is defined as:

PMR $=\frac{\text { Modified Net Farm Income }- \text { Unpaid Labor }}{\text { Total Farm output }}$

Similar to the interest expense logic in equation (4.1), the inclusion of unpaid family labor $^{62}$ in the calculation enables comparison of farms with different labor structures. PMR is a useful measure because: (a) it represents what would generally be accepted as being entrepreneurial profit derived from farming, and (b) it corresponds most closely to the concept of the profit from farming that is available for consumption, investment and saving.

The results presented through Tables 4.5 and 4.7 in the appendix show that a change in profitability measures does not significantly change our major conclusions about the determinants of farm profitability and persistence of abnormal profit. ${ }^{63}$ Furthermore, to account

\footnotetext{
${ }^{62}$ Unpaid labor is computed using the number of working hours by family members and the average hourly wage rate in the Dutch farm sector for each year.

${ }^{63}$ Note that leverage, capital intensity, working capital, diversification and labor productivity still remain the major determinants of farm profitability. Running a separate quantile regression for each farm type entails a minor discrepancy in the magnitudes and signs of the coefficients (see Table 4.5-4.7). Results from the dynamic panel estimation using abnormal PMR suggest similar conclusions, both in terms of signs and magnitudes, to our main findings reported in section 4.2. Decomposing the analysis into farm types, the effect of subsidy rate on the longrun profitability of dairy farms leads to a contradictory conclusion: while the PMR measure shows a negative and significant effect, the coefficient estimates are positive and significant with abnormal MROA as a profit measure. Whether and to what extent this contradiction is due to the inclusion of unpaid labor in our PMR calculation requires further inquiry.
} 
for survivorship bias, we ran both the quantile and dynamic panel models only on those farms that had remained in the sample for the full 15 years.

\subsection{Conclusions}

In this paper, we aim to estimate the drivers of farm profitability, the degree of abnormal profit persistence and its determinants for the Dutch farm sector. We also seek to explain why persistence levels differ across farm sectors by drawing on the well-established theory of the Resource-Based View (RBV). Hence we contribute to better understanding of the distinctive qualities or characteristics that will help farmers gain and sustain their competitive advantage, and the areas where policy interventions might give due emphasis. We apply a quantile regression approach to examine the drivers of farm profitability, and we use dynamic panel System GMM estimation to estimate the persistence of abnormal farm profit.

Results from the quantile regression show that working capital, labor productivity and investment are associated with profitability, regardless of farm type. The findings suggest that, in an environment where farms don't have regular income from agricultural products, working capital is important for them to have the flexibility and capacity to adapt to changing circumstances. On the other hand, leverage and capital intensity show negative effects on farm profitability, meaning that farms that already exhibit high leverage levels face more cash-flow constraints in their operation due to high financing costs. Decomposing the analysis into farm types, we find that risk and profit is only associated for dairy and field crops and the effect of diversification is more pronounced for livestock farms. These results further confirm the importance of controlling for farm heterogeneity when analyzing the determinants of farm profit.

After controlling for farm size, soil, region, and macro-economic factors, estimates using the dynamic panel model provide evidence that there is a significant degree of abnormal profit persistence, with variations between farm types. Dairy farms show the highest and livestock farms show the least persistence. We also find that abnormal profit persistence is responsive to farm characteristics such as risk exposure, investment, capital intensity, leverage, working capital, and diversification. Evidently, farm working capital has a significant, positive effect on abnormal profitability. The negative impact of long-run risk exposure on long-run 
abnormal profit contradicts risk theory, which suggests that risky businesses earn higher profits in the long-run. Interestingly, we show that the farms with a sustained competitive advantage, i.e. persistently high, abnormal profits, are generally young, highly diversified and large farms in particular, which are also characterized by low risk, low leverage level, lower capital intensity, as well as farms with higher working capital and labor productivity. In general, our results show that the variation in farm profit and the persistence of abnormal profit is systematic and, hence, not a product of fortune. In addition, these variations in profitability and persistence levels can be attributed to the farm's resources and capabilities, such as working capital, capital intensity, labor productivity, diversification strategy. These findings lend support to the central premise of the RBV that resource-based competitive advantages last longer.

These results have important implications. The positive and significant association of risk-bearing capacity, i.e. working capital, and farm diversification with sustained abnormal profit underlines the vital role of risk management in farm businesses. The significant negative association of farm leverage with long-run abnormal profit requires careful interpretation, as it might lead to the wrong conclusion that leverage impedes farm profitability. Rather, adjustments towards optimal farm leverage should be encouraged. From a policy viewpoint, the result implies that measures to reduce the capital intensity (i.e., improve asset efficiency) and short-run financial risk exposure of farms might be beneficial. With farming becoming highly competitive, it is crucial that farmers are aware of the factors that could affect their overall profitability and persistence. Financial management training might be helpful, along with measures to improve farm risk-bearing capacity, human capital management, riskmanagement strategies and capital structure.

This chapter has limitations that motivate further research. More direct measures of farm risk and risk-bearing capacity, such as the use of forward contracting and commodity futures, would help further understand the impact of risk-management strategies on farm profit persistence. Despite using a high-quality, unique panel data, we rely merely on farm accounting data. Future research may complement this with behavioral data on, for example, farm risk attitude, risk perception and market orientation (Pennings and Leuthold, 2000; TrujilloBarrera, Pennings and Hofenk, 2016). 


\subsection{Appendix}

Table 4.5: Determinants of farm profitability (PMR), quantile regression

\begin{tabular}{|c|c|c|c|c|c|c|}
\hline PMR & OLS & $q(10)$ & $q(25)$ & $q(50)$ & $q(75)$ & $q(90)$ \\
\hline Leverage & $\begin{array}{l}-0.2559 * * * \\
(0.0102)\end{array}$ & $\begin{array}{l}-0.4013 * * * \\
(0.0169)\end{array}$ & $\begin{array}{l}-0.3301 * * * \\
(0.0108)\end{array}$ & $\begin{array}{l}-0.2843 * * * \\
(0.0096)\end{array}$ & $\begin{array}{l}-0.2685 * * * \\
(0.0086)\end{array}$ & $\begin{array}{l}-0.2607 * * * \\
(0.0129)\end{array}$ \\
\hline Short-run risk & $\begin{array}{l}0.0141 \\
(0.3068)\end{array}$ & $\begin{array}{l}-0.3121 \\
(0.8992)\end{array}$ & $\begin{array}{l}-0.2318 \\
(0.8725)\end{array}$ & $\begin{array}{l}-0.1543 \\
(0.6782)\end{array}$ & $\begin{array}{l}-0.4343 \\
(0.6716)\end{array}$ & $\begin{array}{l}-0.6124 \\
(0.5784)\end{array}$ \\
\hline Long-run risk & $\begin{array}{l}0.1901 \\
(0.0683)\end{array}$ & $\begin{array}{l}0.61681 \\
(0.3432)\end{array}$ & $\begin{array}{l}0.03927 \\
(0.2097)\end{array}$ & $\begin{array}{l}0.7271 \\
(0.2079)\end{array}$ & $\begin{array}{l}0.2081 \\
(0.2016)\end{array}$ & $\begin{array}{l}0.1655 \\
(0.1697)\end{array}$ \\
\hline Working Capital & $\begin{array}{l}0.0477 * * * \\
(0.0041)\end{array}$ & $\begin{array}{l}0.0166 \text { *** } \\
(0.0045)\end{array}$ & $\begin{array}{l}0.03077 * * * \\
(0.0054)\end{array}$ & $\begin{array}{l}0.0379 * * * \\
(0.0052)\end{array}$ & $\begin{array}{l}0.0433 * * * \\
(0.0039)\end{array}$ & $\begin{array}{l}0.0395 \text { *** } \\
(0.0052)\end{array}$ \\
\hline Capital Intensity & $\begin{array}{l}-0.3149 * * * \\
(0.0527)\end{array}$ & $\begin{array}{l}-0.6507 * * * \\
(0.1832)\end{array}$ & $\begin{array}{l}-0.1653 * * * \\
(0.0867)\end{array}$ & $\begin{array}{l}-0.9636^{* * *} \\
(0.0734)\end{array}$ & $\begin{array}{l}-0.4547 * * * \\
(0.0553)\end{array}$ & $\begin{array}{l}-0.08776 \\
(0.0958)\end{array}$ \\
\hline Age & $\begin{array}{l}0.0596 \text { *** } \\
(0.0140)\end{array}$ & $\begin{array}{l}-0.01789 \\
(0.0129)\end{array}$ & $\begin{array}{l}-0.00057 \\
(0.0094)\end{array}$ & $\begin{array}{l}0.0060 \\
(0.0083)\end{array}$ & $\begin{array}{l}-0.0095 \\
(0.0086)\end{array}$ & $\begin{array}{l}-0.0061 \\
(0.0109)\end{array}$ \\
\hline Investment & $\begin{array}{l}0.0876^{* * *} * \\
(0.0192)\end{array}$ & $\begin{array}{l}0.1661 * \\
(0.0521)\end{array}$ & $\begin{array}{l}-0.04290 \\
(0.0322)\end{array}$ & $\begin{array}{l}-0.0016 \\
(0.0269)\end{array}$ & $\begin{array}{l}0.0778 * * \\
(0.0253)\end{array}$ & $\begin{array}{l}0.1204 * * \\
(0.0369)\end{array}$ \\
\hline Subsidy rate & $\begin{array}{l}-0.2097 * * * \\
(0.0311)\end{array}$ & $\begin{array}{l}0.03523 \\
(0.0817)\end{array}$ & $\begin{array}{l}0.08099 \\
(0.0596)\end{array}$ & $\begin{array}{c}0.05097 \\
(0.0331)\end{array}$ & $\begin{array}{l}0.01518 \\
(0.0394)\end{array}$ & $\begin{array}{l}-0.03802 \\
(0.0469)\end{array}$ \\
\hline Diversification & $\begin{array}{l}0.2341 \text { *** } \\
(0.0156)\end{array}$ & $\begin{array}{l}0.0909 * * * \\
(0.0250)\end{array}$ & $\begin{array}{l}0.0967 \text { *** } \\
(0.0178)\end{array}$ & $\begin{array}{l}0.1548^{* * *} \\
(0.0126)\end{array}$ & $\begin{array}{l}0.1812 * * * \\
(0.0134)\end{array}$ & $\begin{array}{l}0.2061 \text { *** } \\
(0.0165)\end{array}$ \\
\hline Size & $\begin{array}{l}0.0655 * * * \\
(0.0072)\end{array}$ & $\begin{array}{l}0.0550 * * * \\
(0.0038)\end{array}$ & $\begin{array}{l}0.0298 * * * \\
(0.0028)\end{array}$ & $\begin{array}{l}-0.0138^{* *} \\
(0.0024)\end{array}$ & $\begin{array}{l}-0.0022 * \\
(0.0027)\end{array}$ & $\begin{array}{l}-0.0181 \text { *** } \\
(0.0035)\end{array}$ \\
\hline Labor prod & $\begin{array}{l}0.6074 * * * \\
(0.0421)\end{array}$ & $\begin{array}{l}0.1915^{* * * *} \\
(0.0356)\end{array}$ & $\begin{array}{l}0.1611 * * * \\
(0.0244)\end{array}$ & $\begin{array}{l}0.1165^{* * *} \\
(0.0260)\end{array}$ & $\begin{array}{l}0.0929 * * * \\
(0.0232)\end{array}$ & $\begin{array}{l}0.1166^{*} \\
(0.0526)\end{array}$ \\
\hline _cons & $\begin{array}{l}-0.6410 * * * \\
(0.1306)\end{array}$ & $\begin{array}{l}-0.3219 * * * \\
(0.0625)\end{array}$ & $\begin{array}{l}-0.08168 \\
(0.0508)\end{array}$ & $\begin{array}{l}0.1272 * * \\
(0.0413)\end{array}$ & $\begin{array}{l}0.4405 * * * \\
(0.0502)\end{array}$ & $\begin{array}{l}0.6894 * * * \\
(0.0592)\end{array}$ \\
\hline Farm-Field crops & $\begin{array}{l}0.0249 \\
(0.0203)\end{array}$ & $\begin{array}{l}-0.0705 * * * \\
(0.0099)\end{array}$ & $\begin{array}{l}-0.0343 * * * \\
(0.0075)\end{array}$ & $\begin{array}{l}-0.0067 \\
(0.0058)\end{array}$ & $\begin{array}{l}0.0203 * * * \\
(0.0052)\end{array}$ & $\begin{array}{l}0.0342 * * * \\
(0.0070)\end{array}$ \\
\hline Farm-Livestock & $\begin{array}{l}0.1788 \\
(0.0241)\end{array}$ & $\begin{array}{l}-0.1789 * * * \\
(0.0126)\end{array}$ & $\begin{array}{l}-0.1113 * * * \\
(0.0080)\end{array}$ & $\begin{array}{l}-0.0776^{* * *} \\
(0.0071)\end{array}$ & $\begin{array}{l}-0.0384 * * * \\
(0.0066)\end{array}$ & $\begin{array}{l}-0.0155 \\
(0.0082)\end{array}$ \\
\hline Farm-Horticulture & $\begin{array}{l}-0.0981 * * * \\
(0.0147)\end{array}$ & $\begin{array}{l}-0.2072 * * * \\
(0.0109)\end{array}$ & $\begin{array}{l}-0.1586^{* * * *} \\
(0.0073)\end{array}$ & $\begin{array}{l}-0.1315^{* * *} \\
(0.0054)\end{array}$ & $\begin{array}{l}-0.1129 * * * \\
(0.0055)\end{array}$ & $\begin{array}{l}-0.0925^{* * *} \\
(0.0090)\end{array}$ \\
\hline Year & Yes & Yes & Yes & Yes & $\overline{Y e s}$ & Yes \\
\hline Region & Yes & Yes & Yes & Yes & Yes & Yes \\
\hline Soil & Yes & Yes & Yes & Yes & Yes & Yes \\
\hline $\mathrm{R}^{2}$ (Pseudo $\mathrm{R}^{2}$ ) & 0.1029 & 0.2144 & 0.1618 & 0.1586 & 0.1749 & 0.1780 \\
\hline Obs. & 15659 & & & & & \\
\hline
\end{tabular}

$* * *, * *, *$ are significant at the $1 \%, 5 \%$ and $10 \%$ levels respectively. Numbers in parentheses are bootstrap standard errors based on 1000 replications, and the dummy reference levels are dairy farms, the year 2001, the Drenthe region, and clay soil. 
Table 4.6: Determinants of farm profitability (PMR), quantile regression by farm type

\begin{tabular}{|c|c|c|c|c|c|c|c|c|c|c|}
\hline \multirow[b]{2}{*}{ PMR } & \multirow[b]{2}{*}{$q(10)$} & \multicolumn{3}{|c|}{ Dairy } & \multicolumn{3}{|c|}{ Field Crops } & \multirow[b]{2}{*}{$q(50)$} & \multirow[b]{2}{*}{$q(75)$} & \multirow[b]{2}{*}{$q(90)$} \\
\hline & & $q(25)$ & $q(50)$ & $q(75)$ & $\mathbf{q}(90)$ & $q(10)$ & $q(25)$ & & & \\
\hline Leverage & $\begin{array}{l}-0.6479 * * * \\
(0.0748)\end{array}$ & $\begin{array}{c}-0.6421 * * * \\
(0.0630)\end{array}$ & $\begin{array}{l}-0.5623 * * * \\
(0.0741)\end{array}$ & $\begin{array}{l}-0.5383 * * * \\
(0.080)\end{array}$ & $\begin{array}{l}-0.4638 * * * \\
(0.0762)\end{array}$ & $\begin{array}{l}-0.5517 * * * \\
(0.0918)\end{array}$ & $\begin{array}{l}-0.5044 * * * \\
(0.0579)\end{array}$ & $\begin{array}{l}-0.3861 * * * \\
(0.0434)\end{array}$ & $\begin{array}{l}-0.3357 * * * \\
(0.0372)\end{array}$ & $\begin{array}{l}-0.260 * * * \\
(0.0436)\end{array}$ \\
\hline Short-run risk & $\begin{array}{l}-0.2134 \\
(0.175)\end{array}$ & $\begin{array}{l}-0.2083 \\
(0.1229)\end{array}$ & $\begin{array}{l}-0.1297^{*} \\
(0.5731)\end{array}$ & $\begin{array}{l}-0.1063^{*} \\
(0.4268)\end{array}$ & $\begin{array}{l}-0.4030 \\
(0.3878)\end{array}$ & $\begin{array}{l}-0.6317 \\
(0.9845)\end{array}$ & $\begin{array}{l}-0.3323 \\
(0.7089)\end{array}$ & $\begin{array}{l}0.4490 \\
(0.4098)\end{array}$ & $\begin{array}{l}0.1674 \\
(0.2272)\end{array}$ & $\begin{array}{l}0.2665 \\
(0.3169)\end{array}$ \\
\hline Long-run risk & $\begin{array}{c}0.4448 \\
(0.3023)\end{array}$ & $\begin{array}{l}0.4379 \\
(0.2482)\end{array}$ & $\begin{array}{l}0.2705 \\
(0.2414)\end{array}$ & $\begin{array}{l}0.2256 \\
(0.2571)\end{array}$ & $\begin{array}{l}0.8785 \\
(0.2195)\end{array}$ & $\begin{array}{l}-0.1617 \\
(0.3859)\end{array}$ & $\begin{array}{l}-0.5139 \\
(0.2427)\end{array}$ & $\begin{array}{l}-0.1928 \\
(0.1298)\end{array}$ & $\begin{array}{l}-0.1009 \\
(0.6806)\end{array}$ & $\begin{array}{l}-0.9843 \\
(0.1127)\end{array}$ \\
\hline Working Capital & $\begin{array}{l}0.1164 * * * \\
(0.0208)\end{array}$ & $\begin{array}{l}0.1099 * * * \\
(0.0147)\end{array}$ & $\begin{array}{l}0.09576 * * * \\
(0.0111)\end{array}$ & $\begin{array}{l}0.1104 * * * \\
(0.0170)\end{array}$ & $\begin{array}{l}0.1119 * * * \\
(0.0250)\end{array}$ & $\begin{array}{l}0.07202 * * * \\
(0.0162)\end{array}$ & $\begin{array}{l}0.06610 * * * \\
(0.0114)\end{array}$ & $\begin{array}{l}0.07556 * * * \\
(0.0144)\end{array}$ & $\begin{array}{l}0.07693 * * * \\
(0.0148)\end{array}$ & $\begin{array}{l}0.1015 * * * \\
(0.0194)\end{array}$ \\
\hline Capital Intensity & $\begin{array}{l}-2.3314 * * * \\
(0.1931)\end{array}$ & $\begin{array}{l}-1.7734 * * * \\
(0.1243)\end{array}$ & $\begin{array}{l}-1.1262 * * * \\
(0.0820)\end{array}$ & $\begin{array}{l}-0.9177 * * * \\
(0.1151)\end{array}$ & $\begin{array}{l}-0.5964 * * * \\
(0.1164)\end{array}$ & $\begin{array}{l}-1.6867 * * * \\
(0.1963)\end{array}$ & $\begin{array}{l}-1.1591 * * * \\
(0.0975)\end{array}$ & $\begin{array}{l}-0.6886 * * * \\
(0.0881)\end{array}$ & $\begin{array}{l}-0.3438 * * * \\
(0.0930)\end{array}$ & $\begin{array}{l}-0.08121 \\
(0.1383)\end{array}$ \\
\hline Age & $\begin{array}{l}-0.02974 \\
(0.0233)\end{array}$ & $\begin{array}{l}-0.04758 * \\
(0.0188)\end{array}$ & $\begin{array}{l}-0.0495^{* * * *} \\
(0.0128)\end{array}$ & $\begin{array}{l}-0.0583 * * * \\
(0.0121)\end{array}$ & $\begin{array}{l}-0.04694 * * \\
(0.0169)\end{array}$ & $\begin{array}{l}-0.02353 \\
(0.0433)\end{array}$ & $\begin{array}{l}0.01969 \\
(0.0230)\end{array}$ & $\begin{array}{l}0.04280 * \\
(0.0182)\end{array}$ & $\begin{array}{l}0.03969 \\
(0.0212)\end{array}$ & $\begin{array}{l}0.02695 \\
(0.0227)\end{array}$ \\
\hline Investment & $\begin{array}{l}-0.09820 \\
(0.1028)\end{array}$ & $\begin{array}{l}0.02197 \\
(0.0548)\end{array}$ & $\begin{array}{l}0.1266^{*} \\
(0.0602)\end{array}$ & $\begin{array}{l}0.2094 * * \\
(0.0694)\end{array}$ & $\begin{array}{l}0.1765^{* *} * \\
(0.0668)\end{array}$ & $\begin{array}{l}-0.1920 \\
(0.1539)\end{array}$ & $\begin{array}{l}0.04208 \\
(0.0847)\end{array}$ & $\begin{array}{l}0.06949 \\
(0.0698)\end{array}$ & $\begin{array}{l}0.07391 \\
(0.0466)\end{array}$ & $\begin{array}{l}0.05553 \\
(0.0694)\end{array}$ \\
\hline Subsidy rate & $\begin{array}{l}0.05622 \\
(0.1496)\end{array}$ & $\begin{array}{l}0.02931 \\
(0.1206)\end{array}$ & $\begin{array}{l}-0.03164 \\
(0.0914)\end{array}$ & $\begin{array}{l}-0.1045 \\
(0.1004)\end{array}$ & $\begin{array}{l}0.0007893 \\
(0.1212)\end{array}$ & $\begin{array}{l}0.2567 \\
(0.1756)\end{array}$ & $\begin{array}{l}0.1262 \\
(0.0869)\end{array}$ & $\begin{array}{l}0.1152 \\
(0.0681)\end{array}$ & $\begin{array}{l}-0.02223 \\
(0.0607)\end{array}$ & $\begin{array}{l}-0.1882 * * \\
(0.0711)\end{array}$ \\
\hline Diversification & $\begin{array}{l}0.01912 \\
(0.0595)\end{array}$ & $\begin{array}{l}0.04760 \\
(0.0451)\end{array}$ & $\begin{array}{l}0.1218 * * \\
(0.0413)\end{array}$ & $\begin{array}{l}0.1939 * * * \\
(0.0389)\end{array}$ & $\begin{array}{l}0.2940 * * * \\
(0.0506)\end{array}$ & $\begin{array}{l}0.02408 \\
(0.0626)\end{array}$ & $\begin{array}{l}0.06850 \\
(0.0405)\end{array}$ & $\begin{array}{l}0.04918 \\
(0.0391)\end{array}$ & $\begin{array}{l}0.1406^{* * *} \\
(0.0427)\end{array}$ & $\begin{array}{l}0.2148 * * * \\
(0.0343)\end{array}$ \\
\hline Size & $\begin{array}{l}0.09894 * * * \\
(0.0122)\end{array}$ & $\begin{array}{l}0.07892 * * * \\
(0.0078)\end{array}$ & $\begin{array}{l}0.05860 * * * \\
(0.0058)\end{array}$ & $\begin{array}{l}0.04200 * * * \\
(0.0071)\end{array}$ & $\begin{array}{l}0.03444 * * * \\
(0.0070)\end{array}$ & $\begin{array}{l}0.09311 * * * \\
(0.0116)\end{array}$ & $\begin{array}{l}0.07929 * * * \\
(0.0081)\end{array}$ & $\begin{array}{l}0.05977 * * * \\
(0.0060)\end{array}$ & $\begin{array}{l}0.03118 * * * \\
(0.0063)\end{array}$ & $\begin{array}{l}0.01498 * \\
(0.0074)\end{array}$ \\
\hline Labor productivity & $\begin{array}{l}-0.4854 * \\
(0.2138)\end{array}$ & $\begin{array}{l}-0.3500 * * \\
(0.1341)\end{array}$ & $\begin{array}{l}-0.2261 * \\
(0.0967)\end{array}$ & $\begin{array}{l}-0.1447 \\
(0.1081)\end{array}$ & $\begin{array}{l}-0.1123 \\
(0.1131)\end{array}$ & $\begin{array}{l}0.7441 * * * \\
(0.1340)\end{array}$ & $\begin{array}{l}0.5077 * * * \\
(0.0790)\end{array}$ & $\begin{array}{l}0.4711 * * * \\
(0.0671)\end{array}$ & $\begin{array}{l}0.3778 * * * \\
(0.0859)\end{array}$ & $\begin{array}{l}0.3751 * * * \\
(0.1104)\end{array}$ \\
\hline _cons & $\begin{array}{l}-0.8047 * * * \\
(0.1628)\end{array}$ & $\begin{array}{l}-0.4387 * * * \\
(0.1259)\end{array}$ & $\begin{array}{l}-0.1610 * \\
(0.0802) \\
\end{array}$ & $\begin{array}{l}0.1447 \\
(0.0961) \\
\end{array}$ & $\begin{array}{l}0.2167 * \\
(0.0943) \\
\end{array}$ & $\begin{array}{l}-1.0171 * * * \\
(0.2022)\end{array}$ & $\begin{array}{l}-0.8965^{* * * *} \\
(0.1492)\end{array}$ & $\begin{array}{l}-0.6924 * * * \\
(0.1127)\end{array}$ & $\begin{array}{l}-0.2339 \\
(0.1205) \\
\end{array}$ & $\begin{array}{l}0.1123 \\
(0.1277)\end{array}$ \\
\hline Year & Yes & Yes & Yes & Yes & Yes & Yes & Yes & Yes & Yes & Yes \\
\hline Region & Yes & Yes & Yes & Yes & Yes & Yes & Yes & Yes & Yes & Yes \\
\hline Soil & Yes & Yes & Yes & Yes & Yes & Yes & Yes & Yes & Yes & Yes \\
\hline $\begin{array}{l}\text { Pseudo R2 } \\
\text { Obs. }\end{array}$ & $\begin{array}{l}0.2693 \\
4099\end{array}$ & 0.2630 & 0.2644 & 0.2648 & 0.2705 & $\begin{array}{c}0.2638 \\
2691\end{array}$ & 0.2330 & 0.2140 & 0.2130 & 0.2098 \\
\hline
\end{tabular}




\begin{tabular}{|c|c|c|c|c|c|c|c|c|c|c|}
\hline & \multicolumn{5}{|c|}{ Horticulture Farms } & \multicolumn{5}{|c|}{ Livestock Farms } \\
\hline & $q(10)$ & $q(25)$ & $q(50)$ & $q(75)$ & $q(90)$ & $q(10)$ & $q(25)$ & $q(50)$ & $q(75)$ & $\mathrm{q}(90)$ \\
\hline Leverage & $\begin{array}{l}-0.2840 * * * \\
(0.0257)\end{array}$ & $\begin{array}{l}-0.2462 * * * \\
(0.0140)\end{array}$ & $\begin{array}{l}-0.2223 \text { *** } \\
(0.0135)\end{array}$ & $\begin{array}{l}-0.2297 * * * \\
(0.0120)\end{array}$ & $\begin{array}{l}-0.2138 * * * \\
(0.0186)\end{array}$ & $\begin{array}{l}-0.3820 * * * \\
(0.0281)\end{array}$ & $\begin{array}{l}-0.3027 * * * \\
(0.0241)\end{array}$ & $\begin{array}{l}-0.2666 \text { *** } \\
(0.0142)\end{array}$ & $\begin{array}{l}-0.2455^{* * * *} \\
(0.0170)\end{array}$ & $\begin{array}{l}-0.1984 * * * \\
(0.0231)\end{array}$ \\
\hline Short-run risk & $\begin{array}{l}-0.1053 \\
(0.6966)\end{array}$ & $\begin{array}{l}-0.1365 \\
(0.5974)\end{array}$ & $\begin{array}{l}-0.1893 \\
(0.6667)\end{array}$ & $\begin{array}{l}-0.5157 \\
(0.5050)\end{array}$ & $\begin{array}{l}-0.1492 \\
(0.3677)\end{array}$ & $\begin{array}{l}0.8928 \\
(0.4087)\end{array}$ & $\begin{array}{l}11.204 \\
(0.2253)\end{array}$ & $\begin{array}{l}14.147 \\
(0.1578)\end{array}$ & $\begin{array}{l}-0.4875 \\
(0.2189)\end{array}$ & $\begin{array}{l}0.03571 \\
(0.2413)\end{array}$ \\
\hline Long-run risk & $\begin{array}{l}0.7839 \\
(0.2047)\end{array}$ & $\begin{array}{l}-0.3888 \\
(0.1538)\end{array}$ & $\begin{array}{l}0.1666 \\
(0.1934)\end{array}$ & $\begin{array}{l}0.2146 \\
(0.1738)\end{array}$ & $\begin{array}{l}0.1829 \\
(0.1616)\end{array}$ & $\begin{array}{l}-0.5980 \\
(0.1715)\end{array}$ & $\begin{array}{l}-0.1608 \\
(0.7527)\end{array}$ & $\begin{array}{l}0.4752 \\
(0.3607)\end{array}$ & $\begin{array}{l}0.3859 \\
(0.5687)\end{array}$ & $\begin{array}{l}0.5162 \\
(0.7275)\end{array}$ \\
\hline Working Capital & $\begin{array}{l}0.0150 * * \\
(0.0052)\end{array}$ & $\begin{array}{l}0.0219 * * * \\
(0.0045)\end{array}$ & $\begin{array}{l}0.0250 * * * \\
(0.0044)\end{array}$ & $\begin{array}{l}0.0201 * * * \\
(0.0031)\end{array}$ & $\begin{array}{l}0.0197 * * * \\
(0.0047)\end{array}$ & $\begin{array}{l}0.0376^{*} \\
(0.0186)\end{array}$ & $\begin{array}{l}0.0573 * * * \\
(0.0085)\end{array}$ & $\begin{array}{l}0.0490 * * * \\
(0.0105)\end{array}$ & $\begin{array}{l}0.0585 * * * \\
(0.0136)\end{array}$ & $\begin{array}{l}0.0676 \text { *** } \\
(0.0204)\end{array}$ \\
\hline Capital Intensity & $\begin{array}{l}-4.722 * * * \\
(0.6308)\end{array}$ & $\begin{array}{l}-2.6114 * * * \\
(0.3493)\end{array}$ & $\begin{array}{l}-0.8340 * * * \\
(0.2139)\end{array}$ & $\begin{array}{l}0.1924 \\
(0.1417)\end{array}$ & $\begin{array}{l}0.8460 * * * \\
(0.2152)\end{array}$ & $\begin{array}{l}-4.7014 * * * \\
(0.2037)\end{array}$ & $\begin{array}{l}-3.1825 * * * \\
(0.2832)\end{array}$ & $\begin{array}{l}-2.0764 * * * \\
(0.0793)\end{array}$ & $\begin{array}{l}-1.6185^{* * *} \\
(0.1810)\end{array}$ & $\begin{array}{l}-0.9487 \text { *** } \\
(0.1433)\end{array}$ \\
\hline Age & $\begin{array}{l}-0.0038 \\
(0.0250)\end{array}$ & $\begin{array}{l}0.0252 \\
(0.0176)\end{array}$ & $\begin{array}{l}0.0080 \\
(0.0139)\end{array}$ & $\begin{array}{l}0.0155 \\
(0.0126)\end{array}$ & $\begin{array}{l}0.0311 \\
(0.0189)\end{array}$ & $\begin{array}{l}-0.0299 \\
(0.0246)\end{array}$ & $\begin{array}{l}-0.0079 \\
(0.0175)\end{array}$ & $\begin{array}{l}-0.0152 \\
(0.0160)\end{array}$ & $\begin{array}{l}-0.0053 \\
(0.0165)\end{array}$ & $\begin{array}{l}0.00188 \\
(0.0209)\end{array}$ \\
\hline Investment & $\begin{array}{l}-0.0570 \\
(0.0484)\end{array}$ & $\begin{array}{l}-0.0239 \\
(0.0541)\end{array}$ & $\begin{array}{l}0.03059 \\
(0.0297)\end{array}$ & $\begin{array}{l}0.0857 * \\
(0.0381)\end{array}$ & $\begin{array}{l}0.1520 * \\
(0.0623)\end{array}$ & $\begin{array}{l}0.01766 \\
(0.0854)\end{array}$ & $\begin{array}{l}0.03332 \\
(0.0427)\end{array}$ & $\begin{array}{l}0.04542 \\
(0.0434)\end{array}$ & $\begin{array}{l}0.1484 * * \\
(0.0470)\end{array}$ & $\begin{array}{l}0.2748 * * * \\
(0.0750)\end{array}$ \\
\hline Subsidy rate & $\begin{array}{l}0.1932 \\
(0.1972)\end{array}$ & $\begin{array}{l}0.1173 \\
(0.1815)\end{array}$ & $\begin{array}{l}-0.06187 \\
(0.1107)\end{array}$ & $\begin{array}{l}-0.1754 \\
(0.1190)\end{array}$ & $\begin{array}{l}-0.2171 \\
(0.1662)\end{array}$ & $\begin{array}{l}-0.1001 \\
(0.1394)\end{array}$ & $\begin{array}{l}0.0227 \\
(0.0837)\end{array}$ & $\begin{array}{l}0.0698 \\
(0.0588)\end{array}$ & $\begin{array}{l}0.1195^{*} \\
(0.0565)\end{array}$ & $\begin{array}{l}0.0802 \\
(0.0636)\end{array}$ \\
\hline Diversification & $\begin{array}{l}0.0218 \\
(0.0390)\end{array}$ & $\begin{array}{l}0.0022 \\
(0.0286)\end{array}$ & $\begin{array}{l}0.01883 \\
(0.0212)\end{array}$ & $\begin{array}{l}0.0283 \\
(0.0233)\end{array}$ & $\begin{array}{l}0.05759 \\
(0.0310)\end{array}$ & $\begin{array}{l}0.2918 * * * \\
(0.0280)\end{array}$ & $\begin{array}{l}0.2951 * * * \\
(0.0204)\end{array}$ & $\begin{array}{l}0.2870 * * * \\
(0.0151)\end{array}$ & $\begin{array}{l}0.2738 * * * \\
(0.0142)\end{array}$ & $\begin{array}{l}0.2468 * * * \\
(0.0213)\end{array}$ \\
\hline Size & $\begin{array}{l}-0.0081 \\
(0.0057)\end{array}$ & $\begin{array}{l}-0.0275^{* * *} \\
(0.0047)\end{array}$ & $\begin{array}{l}-0.0431 * * * \\
(0.0038)\end{array}$ & $\begin{array}{l}-0.0548 * * * \\
(0.0033)\end{array}$ & $\begin{array}{l}-0.0639 * * * \\
(0.0050)\end{array}$ & $\begin{array}{l}0.0833 * * * \\
(0.0072)\end{array}$ & $\begin{array}{l}0.0646 * * * \\
(0.0053)\end{array}$ & $\begin{array}{l}0.0497 * * * \\
(0.0040)\end{array}$ & $\begin{array}{l}0.0268 * * * \\
(0.0047)\end{array}$ & $\begin{array}{l}0.0179 * * \\
(0.0065)\end{array}$ \\
\hline Labor productivity & $\begin{array}{l}0.8231 * * * \\
(0.1423)\end{array}$ & $\begin{array}{l}0.7992 * * * \\
(0.1317)\end{array}$ & $\begin{array}{l}0.8838 * * * \\
(0.1066)\end{array}$ & $\begin{array}{l}0.7566 * * * \\
(0.0881)\end{array}$ & $\begin{array}{l}0.5678 * * * \\
(0.1501)\end{array}$ & $\begin{array}{l}-0.007221 \\
(0.0226)\end{array}$ & $\begin{array}{l}-0.0006986 \\
(0.0203)\end{array}$ & $\begin{array}{l}-0.01753 \\
(0.0144)\end{array}$ & $\begin{array}{l}-0.05980 * * * \\
(0.0156)\end{array}$ & $\begin{array}{l}-0.0850 \text { *** } \\
(0.0251)\end{array}$ \\
\hline _cons & $\begin{array}{l}0.2486^{*} \\
(0.1129)\end{array}$ & $\begin{array}{l}0.4247 * * * \\
(0.0772)\end{array}$ & $\begin{array}{l}0.7475 * * * \\
(0.0739)\end{array}$ & $\begin{array}{l}0.9445^{* * *} \\
(0.0616)\end{array}$ & $\begin{array}{l}1.0553 * * * \\
(0.0950)\end{array}$ & $\begin{array}{l}-0.9103 * * * \\
(0.1924)\end{array}$ & $\begin{array}{l}-0.6736 \text { *** } \\
(0.0900)\end{array}$ & $\begin{array}{l}-0.4150 * * * \\
(0.0773)\end{array}$ & $\begin{array}{l}-0.07068 \\
(0.1019)\end{array}$ & $\begin{array}{l}0.07307 \\
(0.1404)\end{array}$ \\
\hline Year & Yes & Yes & Yes & Yes & Yes & Yes & Yes & Yes & Yes & Yes \\
\hline Region & Yes & Yes & Yes & Yes & Yes & Yes & Yes & Yes & Yes & Yes \\
\hline Soil & Yes & Yes & Yes & Yes & Yes & Yes & Yes & Yes & Yes & Yes \\
\hline Pseudo R2 & 0.2734 & 0.1950 & 0.1602 & 0.1730 & 0.1925 & 0.3637 & 0.2513 & 0.2157 & 0.2333 & 0.2528 \\
\hline Obs. & 5,133 & & & & & 3,736 & & & & \\
\hline
\end{tabular}

***, **, * are significant at the $1 \%, 5 \%$ and $10 \%$ levels respectively. Numbers in parentheses are bootstrap standard errors based on 1000 replications, and the dummy reference levels are the year 2001, the Drenthe region, and clay soil. 
Table 4.7: Dynamic panel regression results (PMR)

\begin{tabular}{|c|c|c|c|c|c|}
\hline Variables & All Sample & $\begin{array}{l}\text { Dairy } \\
\text { Farms }\end{array}$ & $\begin{array}{l}\text { Field } \\
\text { Crops }\end{array}$ & Horticulture & Livestock \\
\hline$Y_{i, t-1}$ & $\begin{array}{l}0.080 * * * \\
(0.014)\end{array}$ & $\begin{array}{l}0.192 * * * \\
(0.021)\end{array}$ & $\begin{array}{l}0.059 * * * \\
(0.017)\end{array}$ & $\begin{array}{l}0.043 * * \\
(0.014)\end{array}$ & $\begin{array}{c}0.013 \\
(0.016)\end{array}$ \\
\hline Leverage & $\begin{array}{l}-0.279 * * * \\
(0.044)\end{array}$ & $\begin{array}{l}-0.583^{* * * *} \\
(0.056)\end{array}$ & $\begin{array}{c}0.272 \\
(0.074)\end{array}$ & $\begin{array}{l}-0.303 * * * \\
(0.028)\end{array}$ & $\begin{array}{l}-0.124 * * * \\
(0.036)\end{array}$ \\
\hline Short-run risk & $\begin{array}{c}0.215 \\
(0.182)\end{array}$ & $\begin{array}{c}0.372 \\
(0.029)\end{array}$ & $\begin{array}{l}-0.093 \\
(0.937)\end{array}$ & $\begin{array}{c}0.018 \\
(0.043)\end{array}$ & $\begin{array}{c}0.021 \\
(0.061)\end{array}$ \\
\hline Long-run risk & $\begin{array}{l}-0.0156^{* * *} \\
(0.066)\end{array}$ & $\begin{array}{l}-0.0069 \\
(0.063)\end{array}$ & $\begin{array}{l}0.041 \\
(0.093)\end{array}$ & $\begin{array}{l}-0.103 \\
(0.015)\end{array}$ & $\begin{array}{l}-0.0240 \\
(0.036)\end{array}$ \\
\hline Working Capital & $\begin{array}{l}0.044 * * * \\
(0.009)\end{array}$ & $\begin{array}{l}0.094 * * * \\
(0.015)\end{array}$ & $\begin{array}{l}0.064 * * * \\
(0.018)\end{array}$ & $\begin{array}{c}0.004 \\
(0.009)\end{array}$ & $\begin{array}{l}0.063 \text { *** } \\
(0.013)\end{array}$ \\
\hline Capital Intensity & $\begin{array}{l}-0.035^{* * * *} \\
(0.015)\end{array}$ & $\begin{array}{l}-0.038^{* * * *} \\
(0.016)\end{array}$ & $\begin{array}{l}-0.026^{* * * *} \\
(0.016)\end{array}$ & $\begin{array}{l}-0.036^{* * * *} \\
(0.010)\end{array}$ & $\begin{array}{l}-0.038 * * * \\
(0.012)\end{array}$ \\
\hline Investment & $\begin{array}{c}0.025 \\
(0.030)\end{array}$ & $\begin{array}{l}0.244^{* * *} \\
(0.034)\end{array}$ & $\begin{array}{c}0.036 \\
(0.040)\end{array}$ & $\begin{array}{l}-0.031 * \\
(0.022)\end{array}$ & $\begin{array}{l}-0.007 * \\
(0.042)\end{array}$ \\
\hline Age & $\begin{array}{l}-0.035^{*} \\
(0.021)^{*}\end{array}$ & $\begin{array}{l}-0.051^{* *} \\
(0.023)\end{array}$ & $\begin{array}{l}0.070^{*} \\
(0.042)\end{array}$ & $\begin{array}{l}-0.014 \\
(0.072)\end{array}$ & $\begin{array}{l}0.056^{*} \\
(0.050)\end{array}$ \\
\hline Subsidy rate & $\begin{array}{l}-0.007 \\
(0.008)\end{array}$ & $\begin{array}{l}-0.001 * * * \\
(0.076)\end{array}$ & $\begin{array}{l}0.019 \\
(0.016)\end{array}$ & $\begin{array}{l}-0.015 \\
(0.015)\end{array}$ & $\begin{array}{l}-0.023^{*} \\
(0.017)\end{array}$ \\
\hline Diversification & $\begin{array}{l}0.183^{* * * *} \\
(0.035)\end{array}$ & $\begin{array}{l}0.385^{* * *} \\
(0.041)\end{array}$ & $\begin{array}{l}-0.039^{*} \\
(0.049)\end{array}$ & $\begin{array}{c}0.019 \\
(0.038)\end{array}$ & $\begin{array}{l}0.337 * * * \\
(0.032)\end{array}$ \\
\hline Size & $\begin{array}{l}0.157 * * * \\
(0.017)\end{array}$ & $\begin{array}{l}0.188^{* * *} \\
(0.021)\end{array}$ & $\begin{array}{l}0.156^{* * *} \\
(0.022)\end{array}$ & $\begin{array}{l}-0.035^{* *} \\
(0.018)\end{array}$ & $\begin{array}{l}0.226 * * * \\
(0.022)\end{array}$ \\
\hline Labor productivity & $\begin{array}{l}0.107 * * * \\
(0.013)\end{array}$ & $\begin{array}{l}0.078 * * \\
(0.019)\end{array}$ & $\begin{array}{l}0.213^{* * *} \\
(0.016)\end{array}$ & $\begin{array}{l}0.478 * * * \\
(0.025)\end{array}$ & $\begin{array}{l}0.103 * * * \\
(0.006)\end{array}$ \\
\hline _cons & $\begin{array}{l}-0.670 * * * \\
(0.198)\end{array}$ & $\begin{array}{l}-2.366 * * \\
(0.053)\end{array}$ & $\begin{array}{l}-2.197 * * * \\
(0.374)\end{array}$ & $\begin{array}{l}0.999 * * \\
(0.481)\end{array}$ & $\begin{array}{l}-4.475 * * * \\
(0.462)\end{array}$ \\
\hline Farm-Field crops & $\begin{array}{l}-0.039 \\
(0.037)\end{array}$ & & & & \\
\hline Farm-Horticulture & $\begin{array}{l}0.100 * * * \\
(0.038)\end{array}$ & & & & \\
\hline Farm-Livestock & $\begin{array}{c}0.059 * * \\
(0.034) \\
\end{array}$ & & & & \\
\hline $\begin{array}{l}\text { Year } \\
\text { Region } \\
\text { Soil Type } \\
\end{array}$ & $\begin{array}{l}\text { Yes } \\
\text { Yes } \\
\text { Yes } \\
\end{array}$ & $\begin{array}{l}\text { Yes } \\
\text { Yes } \\
\text { Yes } \\
\end{array}$ & $\begin{array}{l}\text { Yes } \\
\text { Yes } \\
\text { Yes } \\
\end{array}$ & $\begin{array}{l}\text { Yes } \\
\text { Yes } \\
\text { Yes } \\
\end{array}$ & $\begin{array}{l}\text { Yes } \\
\text { Yes } \\
\text { Yes } \\
\end{array}$ \\
\hline $\begin{array}{l}\mathrm{N} \\
\text { (Obs.) } \\
\text { Wald }\end{array}$ & $\begin{array}{l}2,000 \\
(13,622) \\
\chi^{2}(42)=139\end{array}$ & $\begin{array}{l}436 \\
(3,671)\end{array}$ & $\begin{array}{l}370 \\
(2,356)\end{array}$ & $\begin{array}{l}804 \\
(4,357)\end{array}$ & $\begin{array}{l}531 \\
(3,238)\end{array}$ \\
\hline $\begin{array}{l}\text { Sargan Test } \\
\operatorname{AR}(1) \\
\operatorname{AR}(2) \\
\operatorname{AR}(3)\end{array}$ & $\begin{array}{l}\chi^{2}(72)=90 \\
Z=-8.274 \\
Z=-0.921 \\
Z=1.945\end{array}$ & $\begin{array}{r}P \text {-value }=0 . \\
\text {-value }=0.000 \\
\text {-value }=0.357 \\
\text {-value }=0.052\end{array}$ & & & \\
\hline
\end{tabular}




\section{Chapter-5}

Conclusions 


\section{Conclusions}

A report by the FAO (Food and Agriculture Organization) about the future of agriculture underlines that the demand for food will continue to increase amid the scarcity of natural resources. In addition, natural disasters are increasing in number and intensity, along with climate change-related extreme weather events (Bruinsma, 2017). These rapid changes and transitions in the agricultural sector increasingly call for evidence-based and well-targeted policy responses. The overarching challenge facing agriculture will be to ensure that the sector persistently remains productive and innovative so that it will be sustainable. Risk management and financing decisions lie at the heart of many proposed solutions to tackle these challenges. Aimed at providing a better understanding and evidence-based input to make informed decisions, this dissertation examines the dynamics of farm business in the contexts of capital structure, risk, and profitability.

The frequent policy changes in the European agricultural sector, such as the milk and sugar quota abolition, changes in grain intervention policies, mandatory manure processing, labeling, and others, have made farm financing decisions very important. For instance, the increase in borrowing among Dutch dairy farms can be attributed to the heavy investments required to enlarge the scale of production prior to the abolition of the milk quotas on April 1, 2015 in an attempt to increase the demand for dairy (Samson, Gardebroek and Jongeneel, 2017). The farm leverage ratio of horticulture farms reached its peak in 2011 and 2012 when the cold spring weather sparked the need for extra cash to cover the higher energy bills (Berkhout and van Bruchem, 2015). Thus, farm target leverage deserves due emphasis. In addition to target leverage, understanding how fast (slow) farms adjust their leverage to the target level is also important in order to understand the ability and flexibility of farms in adapting to changing legislation, production and finance structures. Chapter 2 of this dissertation examines the applicability of the pecking-order and signaling theories in explaining the financing decisions in farming, the effects of farm-specific and macroeconomic factors in determining the capital structure, and the speed of adjustment to the target. 
The findings suggest that farms prefer internal to external sources of funding, that leverage is negatively related to profit, supporting the pecking-order theory, and, consistent with the signaling theory, that farm leverage is positively related to asset tangibility and growth opportunity, a relationship that has often been rejected for publicly-listed firms. Thus, signaling behavior in the farm-lender relationship nicely fits the pecking-order theory in explaining the leverage ratio of farm businesses.

Farm profitability, asset tangibility, earnings volatility, growth opportunity, and size are strongly associated with farm capital structure. When decomposing the analysis into farm types, interestingly, I find that all farm types use their growth opportunities to effectively send signals to facilitate their access to credit. Farms with substantial growth rates can afford more financial leverage since they can generate sufficient earnings to offset the additional interest expenses. Growth opportunities, combined with the increase in land value over the years, send a positive signal to lenders. They also suggest the presence of a 'supply effect', whereby lenders might put more emphasis on asset tangibility and growth potential in loan approvals when the number of loan requests is high. Not surprisingly, I find that the probability of financial distress increases and debt repayment capacity decreases as farm earnings become more volatile, resulting in a negative relationship between leverage and risk.

Yet, there are variations across farm types in these findings: the results suggest that dairy farms predominantly follow the signaling theory. Horticulture, livestock and field crop farms, on the other hand, appear to follow the pecking-order theory more closely in their financing decisions. Though not strongly, macroeconomic factors, such as government debt to GDP, inflation and employment in the agricultural sector, also determine farm capital structure decisions, suggesting that the capital structure decisions made by farms are not only the product of their own specific characteristics but partially also of the macroeconomic environment in which farms operate.

The results show that farms appear to adjust their leverage towards the optimal level over time in response to shocks and that lagged leverage is the best predictor of subsequent leverage ratios. The speed of adjustment to the target capital, however, is slow and varies 
according to size and farm type. The speed of adjustment is relatively faster for horticulture farms and slower for livestock farms. Horticulture farms need approximately 0.67 years to close half of the gap between their current and their target leverage, whereas livestock farms take nearly 6 years to do so. This relatively slow adjustment to the target leverage is mainly attributed to high adjustment costs. Two factors might explain the high adjustment costs of farm businesses in general and the Dutch farm businesses in particular. First, it is not easy for farm businesses to gain access to loans. There are only a few financial institutions in the Netherlands that specialize in agricultural financing (CBS, 2017). Second, compared to corporations, farm businesses are small and medium in size. Hence there is an adverse selection issue as a result of information asymmetry, which makes adjustments costly.

The high adjustment speed of horticulture farms, on the other hand, could indicate the ease with which horticulture farms have been able to acquire financing through debt and lower the adjustment cost. I also show that the speed of adjustment has a size element in it as the speed of adjustment is slow for smaller farms. This suggests that lenders use size as a predominant signal of farm creditworthiness. The aforementioned findings in chapter two provide a better understanding of the dynamic nature of capital structure and the applicability of capital structure theories to farm businesses. Two interesting findings in chapter 2 that merit further discussion are the negative relationships of leverage with both earnings volatility (risk) and profitability.

First, a review of the risk management literature suggests that effective risk management is expected to stabilize earnings, thereby minimizing the probability of bankruptcy and reducing the cost of acquiring capital. Stable earnings ensure that farms can promptly repay claims, an indication of lower farm risk. Lower volatility in earnings also encourages lenders to grant farms favorable credit terms. The negative relation between leverage and earnings volatility may also be consistent with the argument that the default risk by farms is priced, i.e. taken into account by lenders when issuing loans, given that an increase in leverage ratio may increase the likelihood of default. If this default risk is indeed priced, lenders will respond to higher risk with increased interest rates, thus lowering a farm's access 
to leverage as well as the amount available in leverage. The take-home lesson from this finding is that effective risk management leads to stability in earnings and lower average cost of capital, which is ultimately associated with enhanced farm performance.

Second, while chapter two deals with the effect of profitability on a farm's capital structure, a farm's choice of capital structure may, conversely, also affect its profitability. Both directions of causality are thus possible: increased leverage can positively or negatively affect farm profitability, but leverage can also be affected by profitability. On the one hand, highly leveraged farms may suffer from financial distress, face conflicts of interest between the owners and creditors and incur bankruptcy cost, thus decreasing their profitability. On the other hand, the impact of profitability on leverage as described by the pecking order theory is that higher profitability results in higher retained earnings and those farms prefer to use these retained earnings to finance their investments rather than issue debt. As a result, the relevance of farm risk management in agriculture and the existence and persistence of long-run farm profitability is further investigated in-depth in chapters 3 and 4 of this dissertation, respectively.

Chapter 3 of this dissertation deals with risk management in agriculture and provides farm-level empirical support to the risk-balancing hypothesis. The results suggest that more than half of the farms exhibited risk-balancing behavior over a fifteen-year period: farms make strategic adjustments by assuming more (less) debt in response to a decrease (increase) in business risk induced by exogenous shocks. The logit panel regression results further show that the likelihood of risk-balancing by farms decreases with size, profit, and share of government subsidy payments and increases with farm investment.

The conclusions from the panel fixed effects and logistic regression nevertheless come with caveats. Note that farms from different regions or with different production systems may face dissimilar economic and policy constraints that might lead to different choices in riskbalancing behavior. Similarly, farm managers may have different motivations, risk attitudes and perceptions. It is, therefore, legitimate to expect this heterogeneity to affect farm riskbalancing behavior. Also, a Wald test was unable to confirm the statistical significance of the farm type dummies, suggesting that the effects of selected farm characteristics on farm risk- 
balancing behavior cannot a priori be assumed equal for all farms. Consequently, using the latent mixture logit model, I examined whether all farms could be treated in a similar way or whether there were segments of farms that exhibited dissimilar risk-balancing behavior. The model, which uses the iterative EM (Expectation-Maximization) algorithm, simultaneously identifies segments based on the influence of the selected explanatory variables and estimates the effects of these variables on farm risk-balancing behavior for each identified segment.

The results from the latent mixture model suggest the presence of multiple segments that can be interpreted by the risk-balancing hypothesis. Farm profitability, total risk, leverage, age, size, and diversification are the factors related to farm risk-balancing behavior. Interestingly, these factors are not equally important across the farm sector. To assume homogeneity in farms' responses and to estimate a pooled model or a priori to classify farms based on farm type would yield a poor fit and would lead to the misguided conclusion that only size, profit, subsidy, and investment are determinants of the likelihood of farm risk-balancing.

The heterogeneity in the determinants of farm risk-balancing behavior appears to have been masked at the farm-type level, i.e. the effect of selected farm characteristics on riskbalancing behavior is different when using farm type as the basis of the segments than when using the latent mixture model to simultaneously classify segments. This is most notable for the effects of the most important factors in the risk-balancing hypothesis: farm leverage and total risk exposure. The advantage of the segmentation method becomes further apparent from the different farm types present in each segment: each of the three identified segments contains dairy, field-crop, horticulture, and livestock farms in different proportions. These findings provide insights in the interdependence of financial and business risks, spark discussion about the linearity of farm risk reduction policies and total farm risk, and underline the relevance of considering both observed and unobserved factors in devising relevant risk-management strategies.

Finally, Chapter 4 quantifies the drivers of farm profitability, the degree of abnormal profit persistence and its determinants for the Dutch farm sector. In this chapter, I seek to explain why long-run profitability and its persistence levels differ across farm types by drawing 
on the well-established theory of the Resource-Based View (RBV). In doing so, this chapter identifies the distinctive qualities or characteristics that help farmers gain and sustain their competitive advantages and the areas where policy interventions might give due emphasis. I have used a quantile regression approach to examine the drivers of farm profitability, and a dynamic panel System GMM estimation to estimate the persistence of abnormal farm profit.

The results from the quantile regression show that working capital, labor productivity and investment are associated with profitability, regardless of farm type. The findings suggest the importance of farm working capital for farms to be flexible and responsive to changes in the economic and political environment. The findings also lend support to the premise of the RBV that scarce and less imitable resources contribute to superior performance and hence profitability. Leverage and capital intensity, on the other hand, have negative relationship with farm profitability. Farms that already exhibit high leverage levels and use more capital per output, experience more cash-flow constraints in their operation due to high financing costs. They maintain less working capital, and their ability to refinance is limited, which impairs profits and cash flow positions.

Decomposing the analysis into farm types, I find that risk and profit are only associated with dairy and field crops while the effects of diversification and size are more pronounced for livestock farms. The more pronounced effect of diversification on livestock farms can be explained by the fact that the interdependent nature of livestock production enhances on-farm diversification. The pronounced effect of diversification on profit can partly be attributed to the relationship between fixed costs and profit. By diversifying, livestock farms tend to lower their cash flow risk and increase their profitability. Given that experience accumulates over time, one might expect older farmers to be more likely to successfully manage a farm and achieve a higher profitability. Contrary to this expectation, however, age is found to be negatively associated with profitability. One explanation for this might be that older farmers are less motivated to increase efficiency, tend to believe operations cannot be improved any further or may value other aspects of life over financial success. These results further confirm 
the importance of controlling for farm heterogeneity when analyzing the determinants of farm profit.

Estimates using the dynamic panel model suggest that there is a significant degree of abnormal profit persistence, with variations between farm types. Dairy farms exhibit the highest levels of persistence and livestock farms the lowest. The results show that abnormal profit persistence is responsive to farm characteristics such as risk exposure, investment, capital intensity, leverage, working capital, and diversification. Evidently, farm working capital has a significant, positive effect on abnormal profitability. Working capital represents the amount of funds available to a farm if all current assets were sold and current liabilities are paid. This liquidity can provide cash to purchase operating inputs or make capital purchases. The results are consistent with the notion that a higher risk-bearing capacity of farms helps sustain their competitive advantage.

The negative association of long-run risk exposure with long-run abnormal profit contradicts risk theory, which postulates that risky businesses earn higher profits in the longrun. An alternative explanation could be that capital costs are nonlinear and that more risk is thus not compensated by higher expected returns. These returns are disproportionally punished, after all, in that the risk premium on risks and returns is not linear in farming. In conformity to the literature, we find a positive impact of size on long-run profitability. This finding is consistent with consolidation, which is becoming a trend in the Dutch agricultural sector as farms are getting fewer in number but larger in size. Another possible reason is that large farms exploit the economies of scale and benefit from economies of scope. Alternatively, it could be argued that large farms have a better bargaining power in the supply chain and can access capital at a lower cost than small farms and can afford to cope with changes in legislation. The results emphasize that (sufficient) scale is a very important matter in Dutch agriculture.

In general, chapter four shows the variation in farm profit and the persistence of abnormal profit is systematic and, hence, not a product of fortune. In addition, these variations can be attributed to the farm's resources and capabilities, such as working capital, capital intensity, labor productivity, and diversification strategy. Note that the positive and significant 
impact of risk-bearing capacity, i.e. working capital, and farm diversification on gaining and sustaining long-run farm profit underlines the vital role of risk management in farm businesses.

Finally, this dissertation has limitations that motivate further research. Despite our use of high-quality panel data, it is merely an accounting data set. Future research may complement this with behavioral and demographic data on, for example, education, farm risk attitude, risk perception, and farming motivation. More direct measures of farm risk and risk-bearing capacity, such as the use of forward contracting and commodity futures, would help further our understanding of the impact of risk-management strategies on farm performance. Another interesting extension would be to conduct a farm survey to support the accounting data. In addition, a (quasi) experimental procedure might constitute an interesting alternative to the econometrics methods used in this dissertation to account for endogeneity problems and the System GMM used as an internal instrument variable approach. Future research may also test for the applicability of other theories of capital structure, such as the market-timing and tradeoff theories, to the farming business and their impact on farm performance in terms of profitability, and viability.

A final promising direction for future research would be to improve our understanding of the variations in farm leverage, risk management, and profitability dynamics across countries and economies. This dissertation documents a number of interesting variations across the four farm types. A better understanding of these variations across economies of, for example, developed vs developing countries and across countries with different legal, tax, and farm-support systems, such as European countries and the US, could lead to a valuable understanding of the dynamics of farm businesses. 


\title{
Chapter-6
}

\author{
Valorization
}




\section{Valorization}

The world has been witnessing major shifts in the agricultural sector in recent years. Price volatility has increased, with sharp swings in product and input prices. Global markets are highly integrated and hence affected by macro-economic disturbances, disease outbreaks and adverse weather events such as floods and droughts. With agricultural policies abandoning production and price-supporting schemes, farmers are now more exposed to market forces than in the past. Aimed at gaining a better understanding of the dynamics of the farm business in the midst of such trends, this dissertation explores capital structure, risk management and profitability in farm business. The findings of this dissertation have implications for farmers, policy-makers, researchers and the society at large.

In chapter two, I examine the applicability of the pecking-order and signaling theories to farming, the effects of farm-specific and macroeconomic factors in determining the target capital structure, and the speed of adjustment to the target. The implications of the findings for farms (farm operators) mostly start from their preferences for debt financing. As a higher probability of financial distress increases bankruptcy costs, farms should aim to reduce these costs by giving higher priority to internal financing. Farms are also encouraged to maintain extra capital as a buffer.

The positive association between farm size, profitability, and the speed of adjustment to the target leverage suggests that a stable lending system could help to minimize financial distress among farms. As a more stable lending system injects more confidence into the agriculture sector, farms can adjust their capital structure much cheaper and faster. Since the speed of adjustment to the target capital is a positive function of farm size, a recent trend in the Dutch farm sector, i.e. a decline in the number farms but an increase in farm size (scale), fits nicely with this phenomenon. The results suggest that farms should adjust their capital structure less frequently because the cost of adjustment to the target is higher for smaller farms.

The results of chapter two could also help policy-makers and lenders to develop effective instruments to control and influence the financial leverage of farms. For example, the estimate of farm size indicates that the speed of adjustment is slower for smaller farms. This 
suggests that size is considered a predominant signal of farm creditworthiness. It also suggests that policy-makers should consider size when designing policy instruments to facilitate access to credit. Governments should put in place prudent regulations that monitor credit allocation by lending institutions in the farming business. In economic sectors where banks are major capital providers, as is mostly the case in farming, a shift away from lending conditional on assets as collateral towards lending based on a farm's key performance indicators is recommended, as this will encourage farms to engage in investments and innovations that will enhance their competitiveness in the long-run. Public-policy makers can also encourage a cooperative banking model as an alternative to the predominant commercial bank-based lending system in the agricultural sector.

The understanding gained from studying the applicability of the pecking order and signaling theories to the farming business benefits both farms and lending institutions. Since historical financial performance is used as a valid signal, farms are encouraged to keep accurate and detailed financial records. These records also enable lenders to better understand the dynamics of farm financing decisions and easily identify creditworthy farm businesses through the appropriate signals. The fact that the pecking order and signaling theories of capital structure explain the leverage dynamic of farm business suggests that farms rely heavily on retained earnings. Specifically, those farms that have higher levels of retained earnings after a profitable season are better equipped to reduce their debt obligations during periods of operational risk. They may well minimize the risk of bankruptcy costs and financial distress. In addition, it is important that universities (research institutions) and banks (alone or in cooperation) should engage in discourse to develop tools, e.g. platforms, that offer farmers insight in the vulnerability of income in various markets and in capital choice strategies, so that they may make timely and informed decisions. An example of such an initiative is the Commodity Risk Management Expertise Center (CORMEC), a joint initiative by Wageningen University and the University of Illinois at Urbana-Champaign on topics of market-risk management in the agribusiness sector, among other things. 
From a development-economics point of view, the findings suggest that farms use internally generated funds when they go through periods of credit constraint. In periods of macroeconomic instability, however, they appear to reduce not only external financing but also the use of internal funds in their capital structure. Specifically, this implies that if farms lowered their reliance on external financing and reduced their use of internal funds, perhaps they would end up also cutting back farm investments and household expenditures. This, in turn, would adversely affect the production capacity of farms, negatively influencing economic growth. By providing easy access to and availability of further funds, however, banks and other credit providers, such as private-equity and crowd-funding initiatives, might cancel or mitigate the impact of limited access to finance on farm investments and competitiveness.

Chapter three presents empirical evidence of the risk-balancing behavior of Dutch farms as one of the integrated risk-management tools while accounting for unobserved heterogeneity. The findings have implications for farms, financial institutions, and public policymakers. The importance of leverage and farm profitability in farm risk-balancing behavior has at least two important implications. First, farms rely heavily on the availability of and access to loans. Given the fact that farm businesses have minimal access to equity markets or none at all, policies aimed at helping farms manage their risk should make access to credit facilities a priority. In addition, the heterogeneity of farm risk balancers suggests that financial institutions can use these characteristics, i.e. segment-based heterogeneity, for risk profiling and loan evaluation in each segment. Second, farm profitability and risk-balancing are strongly related, suggesting that farms use their retained earnings as a buffer when exogenous shocks disturb the optimal total risk level. As a result, the effects of farm-support programs, such as subsidies and direct payments aiming at stabilizing profit, cannot be easily identified. This, in turn, should spark a discussion about the linearity of the relationship between risk-management policy instruments and total farm risk.

Furthermore, with the identification of farm segments and the provision of information for profiling each segment, public policymakers will be able to target these segments more effectively and design risk-management strategies that best suit each segment. The results also 
suggest that more attention should be paid to both observed and unobserved factors in designing and implementing individual risk-management instruments and in assessing their impact on the farm sector.

At a societal level, the findings also contribute to the on-going debate on the impact of farm risk management policies on farm viability. If some of the farm risk exposures are covered by government policy, it may reduce the incentive to use other alternative strategies such as diversification, price hedging and insurance. The findings thus point to externalities, i.e. undesired consequences, of farm risk-balancing, known as 'the risk-balancing paradox' in the risk management literature: farm policies intended to support farms unintentionally end up introducing more risk to farms. From a farm perspective, the level of risk mostly remains higher or the same, regardless of government intervention. This suggests that promoting the uptake of additional risk-management instruments, such as hedging and commodity futures, is both relevant and timely. From a development economics perspective, farms that tend to use their level of debt (leverage) to balance their risk will ultimately suffer credit constraints caused by their levels of risk, which will hamper their exploitation of investment opportunities. This makes it very difficult for these farms to gain and sustain competitive advantages.

To cope with these negative externalities of farm risk-balancing behavior, I propose that farms and policy-makers focus on the introduction and development of alternative risk management responses (strategies). These responses could include, but are by no means limited to, a production response, i.e. low-risk production, diversifying enterprises and crops, and geographically dispersing production, a marketing response, i.e. obtaining market information, spreading sales by making several sales during a year, forward contracting, hedging, and futures trading, and a financial response, i.e. insuring against losses, maintaining reserves, managing the pace of investments, acquiring assets, limiting leverage, and working off-farm.

It should be highlighted that even though managing agricultural risks is mainly a responsibility of farmers themselves, the government irrefutably also has roles to play, ranging from designing effective risk-management strategies to support their implementation in agriculture. Policy makers, for instance, can devise rural development policies aimed at 
offering greater off-farm employment possibilities, which may have a far better influence on the stability of farm household incomes than policies directed at stabilizing agricultural markets. In addition, training activities might be also necessary to sensitize farmers to the need for more systematic risk management. Finally, politicians should be aware that their decisions are perceived as one of the most important risks in agriculture. Chapter 3 underlines the fact that minimum intervention prices or payments triggered when prices or returns are low as a result of catastrophic losses may even be counterproductive as they tend to induce more risky farming practices. In recent years, the Dutch government has made consistent efforts to shift away from ad hoc responses to catastrophes, promoting public-private partnerships and supporting the development of plans to deal with catastrophic risks. This includes the operation of a livestock veterinary fund and the introduction of several insurance schemes, including a recently subsidized multi-peril crop insurance (OECD, 2011). This has to be part of a longterm strategy as it may take several years for these instruments to prove efficient.

Finally, chapter four aims to answer what drives long-run farm profitability. The question of why differences in profit persistence occur is found to be equally fundamental as profit existence and profit persistence could be driven by different factors. Answering these questions is important from a managerial, theoretical and public-policy perspective. With farming becoming highly competitive, it is crucial that farmers are aware of the factors that could affect their overall profitability and persistence. From a farm management perspective, much of the available literature on sustained competitive advantage implies that farm managers need to invest resources in the search for an advantage, which, if successful, will allow their farms to realize consistent rewards over longer periods of time.

Interestingly, working capital is found to be one of the robust findings that determine long-run farm profitability and its persistence. Working capital becomes even more crucial as a buffer during periods of financial crisis and credit constraints, when access to external funding, mostly bank loans, will typically be difficult. Some of the reasons may include: (a) financial crises may cause a credit crunch for agricultural borrowers, which, in turn, disrupts the functioning of the loan/credit markets for farms, (b) following an economic crisis, the 
demand for income-elastic food products may lead to a reduction in income from farming, and (c) constraints on public budgets due to the crisis may lead to spending cuts in agriculture. Thus, ensuring adequate working capital is most important for farms to survive, gain and sustain their competitive advantages.

The implications of these findings for farm management are that financial and nonfinancial resources are important for value creation and generate sustained competitive advantages. Financial resources provide farms with assets that are needed to create and leverage value. Non-financial resources provide complementary resources, in terms of information, control, skill, risk management, etc., that are needed to leverage financial resources. Another management implication is that farmers can use the framework of the resource-based view to configure how to use their resources (both financial and non-financial) to make their farm business model, i.e. their strategies, valuable, rare, inimitable, and nonsubstitutable. Resource-based thinking gives a good footing when developing new directions for an individual farm. It could, for example, be used as a guiding tool when considering how to deploy a farm's current resources and which other resources to create and make available in order to make profitable changes.

Finally, with the aim of communicating the major findings to the general public, all chapters of this dissertation were presented at international conferences in different parts of the world, such as the NC-1177 meeting on Agricultural and Rural Finance Markets in Transition in 2016 (Denver, USA), the American Agricultural and Applied Economics Association (AAEA) conference in 2017 (Chicago, USA) and 2018 (Washington D.C, USA), and the European Association of Agricultural Economists (EAAE) congress in 2017 (Parma, Italy). In addition, the main findings of this thesis have been used by the Commodity Risk Management Expertise Center (CORMEC) ${ }^{64}$ to educate/train farmers in the areas of risk management, farm competitiveness and capital structure.

\footnotetext{
${ }^{64}$ CORMEC is a joint initiative of Maastricht University, Wageningen University and the University of Illinois at Urbana-Champaign, among others parties, addressing topics of market risk management in the agribusiness sector (https://www.wur.nl/en/CORMEC Wageningen/Commodity-Risk-Management-Expertise-Centre-CORMEC.htm)
} 


\section{Bibliography}

Agarwal, Y. (2013). Capital structure decisions: Evaluatng risk and uncertainity. John Wiley and Sons.

Ahrendsen, B. L. Collender, R. N. and Dixon, B. L. (1994). An empirical analysis of optimal farm capital structure decisions. Agricultural Finance Review 54: 108-119.

Arellano, M. and Bond, S. (1991). Some tests of specification for panel data: Monte Carlo evidence and an application to employment equations. The Review of Economic Studies 58: 277-297.

Arellano, M. and Bover, O. (1995). Another look at the instrumental variable estimation of error-components models. Journal of Econometrics 68: 29-51.

Argilés, J. M. and Slof, E. J. (2003). The use of financial accounting information and firm performance: An empirical quantification for farms. Accounting and Business Research 33: 251-273.

Baker, M. and Wurgler, J. (2002). Market timing and capital structure. Journal of Finance 57: $1-32$.

Bampasidou, M. Mishra, A. K. and Moss, C. B. (2017). Modeling debt choice in agriculture: The effect of endogenous asset values. Agricultural Finance Review 77: 95-110.

Banerjee, S. Heshmati, A. and Wihlborg, C. (1999). The dynamics of capital structure. New York University-Salomon Center-Leonard N. Stern School of Business.

Barney, J. B. (2001). Resource-based theories of competitive advantage: A ten-year retrospective on the resource-based view. Journal of Management 27: 643-650.

Barry, P. J. Bierlen, R. W. and Sotomayor, N. L. (2000). Financial structure of farm businesses under imperfect capital markets. American Journal of Agricultural Economics 82: 920-933.

Barry, P. J. Ellinger, P. N. Hopkin, J. A. and Baker, C. B. (2012). Financial Management in Agriculture. Interstate Printers and Publishers, Danville, Illinois.

Berkhout, P. (2017). Food economic report 2016 of the Netherlands: summary. Wageningen Economic Research-WUR.

Berkhout, P. and van Bruchem, C. (2015). Agricultural Economic Report 2015 of the Netherlands: summary. Wageningen Economic Research.

Blundell, R. and Bond, S. (1998). Initial conditions and moment restrictions in dynamic panel data models. Journal of Econometrics 87: 115-143.

Boere, E. Peerlings, J. Reinhard, S. and Heijman, W. (2015). The dynamics of dairy land use change with respect to the milk quota regime. European Review of Agricultural Economics 42: 651-674.

Bruinsma, J. (2017). World agriculture: Towards 2015/2030: an FAO study. Routledge. 
Bun, M.J.G. and Windmeijer, F. (2010). The weak instrument problem of the system GMM estimator in dynamic panel data models. The Econometrics Journal 13: 95-126.

Burns, C. Tulman, S. and Harris, J. M. (2015). Farm Financial Stress in a Changing Economic Environment: Simulating Credit Risk with New Imputed ARMS Data on Farm Debt. AAEA and WAEA Joint Annual Meeting, July 26-28.

Byoun, S. (2008). How and when do firms adjust their capital structures toward targets? Journal of Finance 63: 3069-3096.

Carhart, M. (1997). On persistence in mutual fund performance. Journal of Finance 52: 57-82.

CBS (2017). Statline, Statistics Netherlands, The Hague

Chang, X. and Dasgupta, S. (2009). Target behavior and financing: How conclusive is the evidence? The Journal of Finance 64: 1767-1796.

Cheng, M. L. and Gloy, B. A. (2008). The paradox of risk-balancing: Do risk reducing policies lead to more risk for farmers. The AAAE Annual Meeting. Orlando.

Collins, R. A. (1985). Expected utility, debt-equity structure, and risk-balancing. American Journal of Agricultural Economics 67: 627-629.

Cong, R. (1999). Durbin-Wu-Hausman Test for Endogeneity.

Cordier, J. (2015). Comparative analysis of risk-management tools supported by the 2014 US Farm Bill and the CAP 2014-2020. European Parliament, workshop of Committee on Agriculture and Rural Development (plenary session). Bruxelles, Belgium, 14.

Cornett, M. M. McNutt, J. J. Strahan, P. E. and Tehranian, H. (2011). Liquidity risk management and credit supply in the financial crisis. Journal of Financial Economics 101: 297-312.

D'Antoni, J. M. and Mishra, A. K. (2013). Welfare implications of reduced government subsidies to farm families: Accounting for fringe benefits. Agricultural Economics 44: 191-202.

de Mey, Y. Van Winsen, F. Wauters, E. Vancauteren, M. Lauwers, L. and Van Passel, S. (2014). Farm-level evidence on risk-balancing behavior in the EU-15. Agricultural Finance Review 74: 17-37.

de Mey, Y. Wauters, E. Schmid, D. Lips, M. Vancauteren, M. and Van Passel, S. (2016). Farm household risk-balancing: Empirical evidence from Switzerland. European Review of Agricultural Economics 43: 637-662.

De Soete, G. and De Sarbo, W. S. (1991). A latent class probit model for analyzing pick any/N data. Journal of Classification 8: 45-63.

DeAngelo, H. and Roll, R. (2015). How stable are corporate capital structures? Journal of Finance 70: 373-418. 
Drobetz, W. Schilling, D. C. and Schröder, H. (2015). Heterogeneity in the speed of capital structure adjustment across countries and over the business cycle. European Financial Management 21: 936-973.

El-Osta, H. S. Mishra, A. K. and Morehart, M. J. (2007). Determinants of economic well-being among U.S. farm operator households. Agricultural Economics 36: 291-304.

Escalante, C. L. and Barry, P. J. (2003). Determinants of the strength of strategic adjustments in farm capital structure. Journal of Agricultural and Applied Economics 35: 6778.

Escalante, C. L. and Rejesus, R. M. (2008). Risk-balancing under constant absolute and relative risk aversion. Review of Business Research 8: 1-8.

European-Commission (2017). 7th Financial report from the commission to the European parliament and the council. Office for Official Publication of the European Communities

Eurostat (2015). Eurostat regional yearbook (2015). European Comission.

Falco, S. D. Adinolfi, F. Bozzola, M. and Capitanio, F. (2014). Crop insurance as a strategy for adapting to climate change. Journal of Agricultural Economics 65: 485-504.

Fama, E. F. and French, K. R. (2002). Testing trade-off and pecking order predictions about dividends and debt. Review of Financial Studies 15: 1-33.

Faulkender, M. Flannery, M. J. Hankins, K. W. and Smith, J. M. (2012). Cash flows and leverage adjustments. Journal of Financial Economics 103: 632-646.

Featherstone, A. M. Ibendahl, G. A. Randy Winter, J. and Spaulding, A. (2005). Farm financial structure. Agricultural Finance Review 65: 97-117.

Featherstone, A. M. Moss, C. B. Baker, T. G. and Preckel, P. V. (1988). The theoretical effects of farm policies on optimal leverage and the probability of equity losses. American Journal of Agricultural Economics 70: 572-579.

Feng, W. Zhengfei, G. and Robert, M. (2014). Farm capital structure choice: Theory and an empirical test. Agricultural Finance Review 74: 115-132.

Finger, R. and El Benni, N. (2014). A note on the effects of the income stabilisation tool on income inequality in agriculture. Journal of Agricultural Economics 65: 739745 .

Fischer, E. O. Heinkel, R. and Zechner, J. (1989). Dynamic capital structure choice: Theory and tests. Journal of Finance 44: 19-40.

Flannery, M. J. and Hankins, K. W. (2013). Estimating dynamic panel models in corporate finance. Journal of Corporate Finance 19: 1-19.

Flannery, M. J. and Rangan, K. P. (2006). Partial adjustment toward target capital structures. Journal of Financial Economics 79: 469-506.

Frank, M. Z. and Goyal, V. K. (2003). Testing the pecking order theory of capital structure. Journal of Financial Economics 67: 217-248. 
Frank, M. Z. and Goyal, V. K. (2007). Trade-off and pecking order theories of debt. Handbook of Empirical Corporate Finance 2: 135-202.

Frank, M. Z. and Goyal, V. K. (2009). Capital structure decisions: Which factors are reliably important? Financial Management 38: 1-37.

Gabriel, S. C. and Baker, C. B. (1980). Concepts of business and financial risk. American Journal of Agricultural Economics 62: 560-564.

Gardebroek, C. Kedir, N. T. and Wijnands, J. H. M. (2010). Growth dynamics of dairy processing firms in the European Union. Agricultural Economics 41: 285-291.

Getzmann, A. Lang, S. and Spremann, K. (2010). Determinants of the target capital structure and adjustment speed-evidence from Asian capital markets. European Financial Management Symposium.

Gitz, V. and Meybeck, A. (2012). Risks, vulnerabilities and resilience in a context of climate change. Building resilience for adaptation to climate change in the agriculture sector 23: 19-37.

Goddard, J. Liu, H. Molyneux, P. and Wilson, J. O. S. (2011). The persistence of bank profit. Journal of Banking and Finance 35: 2881-2890.

Goddard, J. Tavakoli, M. and Wilson, J. O. S. (2005). Determinants of profitability in European manufacturing and services: Evidence from a dynamic panel model. Applied Financial Economics 15: 1269-1282.

Gompers, P. Kovner, A. Lerner, J. and Scharfstein, D. (2010). Performance persistence in entrepreneurship. Journal of Financial Economics 96: 18-32.

Graham, J. R. and Leary, M. T. (2011). A review of empirical capital structure research and directions for the future. Annual Review of Financial Economics 3: 309-345.

Graham, J. R. Leary, M. T. and Roberts, M. R. (2015). A century of capital structure: The leveraging of corporate America. Journal of Financial Economics 118: 658-683.

Grant, R. M. (1991). The resource-based theory of competitive advantage: Implications for strategy formulation. California Management Review 33: 114-135.

Greene, W. H. (2003). Econometric analysis. Pearson Education India.

Griffin, T. Ibendahl, G. A. and Stabel, J. (2018). Do profitable farms remain profitable? Markov switching models applied to transition probabilities. Journal of Applied Farm Economics 2:23-31.

Gschwandtner, A. (2012). Evolution of profit persistence in the USA: Evidence from three periods. The Manchester School 80: 172-209.

Gschwandtner, A. and Hauser, M. (2016). Profit persistence and stock returns. Applied Economics 48: 3538-3549.

Hagenaars, J. A. and McCutcheon, A. L. (2002). Applied latent class analysis. Cambridge University Press. 
Halling, M. Yu, J. and Zechner, J. (2016). Leverage dynamics over the business cycle. Journal of Financial Economics 122: 21-41.

Hang, M. Geyer-Klingeberg, J. Rathgeber, A. W. and Stöckl, S. (2017). Measurement matters - A meta-study of the determinants of corporate capital structure. The Quarterly Review of Economics and Finance 68:211-25.

Hardaker, J. B. Lien, G. Anderson, J. R. and Huirne, R. B. M. (2015). Coping with risk in agriculture: Applied decision analysis. CABI.

Harwood, J. L. Heifner, R. Coble, K. Perry, J. and Somwaru, A. (1999). Managing risk in farming: concepts, research, and analysis. US Department of Agriculture, Economic Research Service.

Heshmati, A. (2001). The dynamics of capital structure: Evidence from Swedish micro and small firms. No. 0440 Stockholm School of Economics.

Hirsch, S. (2018). Successful in the long-run: A meta-regression analysis of persistent firm profits. Journal of Economic Surveys 32: 23-49.

Hirsch, S. and Gschwandtner, A. (2013). Profit persistence in the food industry: Evidence from five European countries. European Review of Agricultural Economics 40: 741759.

Hirsch, S. and Hartmann, M. (2014). Persistence of firm-level profitability in the European dairy processing industry. Agricultural Economics 45: 53-63.

Huirne, R. B. M. (2003). Strategy and risk in farming. NJAS - Wageningen Journal of Life Sciences 50: 249-259.

Hüttel, S. Mußhoff, O. and Odening, M. (2010). Investment reluctance: Irreversibility or imperfect capital markets? European Review of Agricultural Economics 37: 5176.

Ifft, J. Kuethe, T. and Morehart, M. (2013). Farm debt use by farms with crop insurance. Choices 28: 1-5.

Ifft, J. E. Kuethe, T. and Morehart, M. (2015). Does federal crop insurance lead to higher farm debt use? Evidence from the Agricultural Resource Management Survey (ARMS). Agricultural Finance Review 75: 349-367.

Iliev, P. and Welch, I. (2010). Reconciling estimates of the speed of adjustment of leverage ratios. Working Paper. Brown University.

Jensen, F. E. and Langemeier, L. N. (1996). Optimal leverage with risk aversion: Empirical evidence. Agricultural Finance Review 56: 85-97.

Jensen, M. C. and Meckling, W. H. (1976). Theory of the firm: Managerial behavior, agency costs and ownership structure. Journal of Financial Economics 3: 305-360.

Jongeneel, R. A. Van Berkum, S. de Bont, C. Van Bruchem, C. Helming, J. F. M. and Jager, J. H. (2010). European dairy policy in the years to come; Quota abolition and competitiveness. Wageningen Economic Research-WUR. 
Kamakura, W. A. and Russell, G. J. (1989). A probabilistic choice model for market segmentation and elasticity structure. Journal of Marketing Research 26: 379390.

Kambhampati (1995). The persistence of profit differentials in Indian industry. Applied Economics 27: 353-361.

Katchova, A. L. (2005). Factors affecting farm credit use. Agricultural Finance Review 65: 1729.

Klootwijk, C. W. Van Middelaar, C. E. Berentsen, P. B. M. and de Boer, I. J. M. (2016). Dutch dairy farms after milk quota abolition: Economic and environmental consequences of a new manure policy. Journal of Dairy Science 99: 8384-8396.

Koenker, R. (2004). Quantile regression for longitudinal data. Journal of Multivariate Analysis 91: 74-89.

Koenker, R. and Hallock, K. F. (2001). Quantile regression. Journal of Economic Perspectives 15: $143-156$.

Korajczyk, R. A. and Levy, A. (2003). Capital structure choice: Macroeconomic conditions and financial constraints. Journal of Financial Economics 68: 75-109.

Kwansoo, K. Jean-Paul, C. Bradford, B. and Jeremy, F. (2012). Specialization, diversification, and productivity: A panel data analysis of rice farms in Korea. Agricultural Economics 43: 687-700.

Langemeier, M. R. (2016). Balancing Business and Financial Risk. farmdoc daily.

Langemeier, M. R. and DeLano, F. D. (1999). Characteristics of highly efficient farms. Western Agricultural Economics Association. Fargo, ND

Leary, M. T. and Roberts, M. R. (2005). Do firms rebalance their capital structures? Journal of Finance 60: 2575-2619.

Lemmon, M. L. Roberts, M. R. and Zender, J. F. (2008). Back to the beginning: Persistence and the cross-section of corporate capital structure. Journal of Finance 63: 15751608 .

Lowder, S. K. Skoet, J. and Raney, T. (2016). The number, size, and distribution of farms, smallholder farms, and family farms worldwide. World Development 87: 16-29.

McBride, W. and Greene, C. (2007). A comparison of conventional and organic milk production systems in the U.S. American Agricultural Economics Association (New Name 2008: Agricultural and Applied Economics Association).

McGahan, A. M. and Porter, M. E. (2003). The emergence and sustainability of abnormal profits. Strategic Organization 1: 79-108.

McLachlan, G. and Peel, D. (2004). Finite mixture models. John Wiley and Sons.

Meer, R. W. v. d. Veen, H. B. v. d. and Vrolijk, H. C. J. (2013). Sample of Dutch FADN 2011 : design principles and quality of the sample of agricultural and horticultural holdings. No. 2013-064.Wageningen Economic Research-WUR. 
Meraner, M. Heijman, W. Kuhlman, T. and Finger, R. (2015). Determinants of farm diversification in the Netherlands. Land Use Policy 42: 767-780.

Meuwissen, M. P. M. (2008). Income stabilisation in European agriculture design and economic impact of risk-management tools. Wageningen, The Netherlands : Wageningen Academic Publishers, 2008.

Miller, M. H. (1977). Debt and taxes. Journal of Finance 32: 261-275.

Mishra, A. El-Osta, H. S. and Johnson, J. D. (1999). Factors contributing to earnings success of cash grain farms. Journal of Agricultural and Applied Economics 31: 623637.

Mishra, A. Wilson, C. and Williams, R. (2009). Factors affecting financial performance of new and beginning farmers. Agricultural Finance Review 69: 160-179.

Modigliani, F. and Miller, M. H. (1958). The cost of capital, corporation finance and the theory of investment. The American Economic Review 48: 261-297.

Morduch, J. J. and Stern, H. S. (1997). Using mixture models to detect sex bias in health outcomes in Bangladesh. Journal of Econometrics 77: 259-276.

Moss, C. B. Shonkwiler, J. S. and Ford, S. A. (1990). A risk endogenous model of aggregate agricultural debt. Agricultural Finance Review 50: 73-79.

Mueller, D. (1977). The persistence of profits above the norm. Economica 44: 369-380.

Myers, S. C. (1984). The capital structure puzzle. Journal of Finance 39: 574-592.

Myers, S. C. and Majluf, N. S. (1984). Corporate financing and investment decisions when firms have information that investors do not have. Journal of Financial Economics 13: 187-221.

Nenu, E. A. Vintila, G. and Gherghina, S. C. (2018). The impact of capital structure on risk and firm performance: Empirical evidence for the Bucharest stock exchange listed companies. International Journal of Financial Studies 6: 41-62.

Nickell, S. (1981). Biases in dynamic models with fixed effects. Econometrica 49: 1417-1426.

Nurmet, M. (2011). Financial structure of agricultural firms. Management Theories and Studies for Rural Business and Infrastructure Development 25: 187-193.

O'Donoghue, C. Devisme, S. Ryan, M. Conneely, R. and Gillespie, P. (2016). Farm economic sustainability in the European Union: A pilot study. Studies in Agricultural Economics 118: 163-171.

Olivier, F. Howard, T. and Anna, G. (2008). The structure and evolution of the strategic management field: A content analysis of 26 years of strategic management research. International Journal of Management Reviews 10: 1-23.

Organisation for Economic, Coopeartion and Development (2011). Managing risk in agriculture: Policy assessment and design. OECD Publishing. 
Pennings, J.M.E. Tamirat, A. Trujillo-Barrera, A. and Garcia, P. (2017). Perspective on the Agricultural Markets Task Force Report by the European Commission: Special session. XV EAAE Congress 2017: Towards Sustainable Agri-Food Systems: Balancing between Markets and Society.

Pennings, J.M.E. Isengildina, O. Irwin, S. H. and Good, D. L. (2004). The impact of market advisory service recommendations on producers' marketing decisions. Journal of Agricultural and Resource Economics 29: 308-327.

Pennings, J.M.E. and Garcia, P. (2004). Hedging behavior in small and medium-sized enterprises: The role of unobserved heterogeneity. Journal of Banking and Finance 28: 951-978.

Pennings, J.M.E. and Garcia, P (2001). Measuring producers' risk preferences: A global risk attitude construct. American Journal of Agricultural Economics, 83: 993-1009.

Pennings, J.M.E. and Garcia, P. (2010). Risk and hedging behavior: The role and determinants of latent heterogeneity. Journal of Financial Research 33: 373-401.

Pennings, J.M.E. and Leuthold, R. M. (2000). The role of farmers' behavioral attitudes and heterogeneity in futures contracts usage. American Journal of Agricultural Economics 82: 908-919.

Pennings, J.M.E. and Smidts, A. (2000). Assessing the construct validity of risk attitude. Management Science 46: 1337-1348.

Porter, M. E. (2008). Competitive advantage: Creating and sustaining superior performance. Simon and Schuster.

Purdy, B. M. Langemeier, M. R. and Featherstone, A. M. (1997). Financial performance, risk, and specialization. Journal of Agricultural and Applied Economics 29: 149-161.

Rabe-Hesketh, S. and Skrondal, A. (2004). Generalized latent variable modeling: Multilevel, longitudinal, and structural equation models. Chapman and Hall/CRC.

Rajan, R. and Zingales, L. (1995). What do we know about capital structure? Some evidence from international data. Journal of Finance 50: 1421-1460.

Ramirez, O. Moss, C. B. and Boggess, W. G. (1997). A stochastic optimal control formulation of the consumption/debt decision, International Food Policy Research Institute (IFPRI). Washington DC: IFPRI.

Reynolds-Allie, K. Fields, D. and Rainey, R. (2013). Risk management issues for small farms within local food systems. Choices 28: 1-4.

Rizov, M. Pokrivcak, J. and Ciaian, P. (2013). CAP subsidies and productivity of the EU farms. Journal of Agricultural Economics 64: 537-557.

Robison, L. and Barry, P. (1987). The Competitive Firm's Response to Risk. New York: MacMillan.

Roodman, D. (2009). A note on the theme of too many instruments. Oxford Bulletin of Economics and Statistics 71: 135-158. 
Roodman, D. (2015). xtabond2: Stata module to extend xtabond dynamic panel data estimator.

Ross, S. A. (1977). The determination of financial structure: The incentive-signaling approach. The Bell Journal of Economics: 23-40.

Saint-Cyr, L. D. F. and Piet, L. (2017). Movers and stayers in the farming sector: Accounting for unobserved heterogeneity in structural change. Journal of the Royal Statistical Society: Series C (Applied Statistics) 66: 777-795.

Samson, G. S. Gardebroek, C. and Jongeneel, R. A. (2016). Explaining production expansion decisions of Dutch dairy farmers. NJAS - Wageningen Journal of Life Sciences 76: 87-98.

Samson, G. S. Gardebroek, C. and Jongeneel, R. A. (2017). Analysing trade-offs between milk, feed and manure production on Dutch dairy farms. European Review of Agricultural Economics 44: 475-498.

Schumacher, S. K. and Boland, M. A. (2005). The persistence of profitability among firms in the food economy. American Journal of Agricultural Economics 87: 103-115.

Skevas, T. Wu, F. and Guan, Z. (2018). Farm capital investment and deviations from the optimal path. Journal of Agricultural Economics 69: 561-577.

Sol, G. G. Isabel, B. and Alberto, G. (2016). Evaluating price transmission between global agricultural markets and consumer food price indices in the European Union. Agricultural Economics 47: 59-70.

Thomas, P. J. (2016). Measuring risk-aversion: The challenge. Measurement 79: 285-301.

Titman, S. and Wessels, R. (1988). The determinants of capital structure choice. Journal of Finance 43: 1-19.

Trujillo-Barrera, A. Pennings, J. M. E. and Hofenk, D. (2016). Understanding producers' motives for adopting sustainable practices: The role of expected rewards, risk perception and risk tolerance. European Review of Agricultural Economics 43: 359-382.

Turvey, C. and Kong, R. (2009). Business and financial risks of small farm households in China. China Agricultural Economic Review 1: 155-172.

Urcola, H. A. Schnitkey, G. Irwin, S. and Sherrick, B. J. (2004). Testing for yield persistency: is it skill or is it luck?. (No. 19991) Agriculture and Applied Economics Assocaition.

Uzea, N. Kenneth, P. David, S. and Alfons, W. (2014). Farm support payments and riskbalancing: Implications for financial riskiness of Canadian farms. Canadian Journal of Agricultural Economics/Revue canadienne d'agroeconomie 62: 595618.

van der Meer, R. W. van der Veen, H. B. and Vrolijk, H. C. J. (2013). Sample of Dutch FADN 2011: design principles and quality of the sample of agricultural and horticultural holdings. Wageningen Economic Research-WUR. 
Veerman, C. P., Cabrero, E. V., Babuchowski, A., Fresco, L. O., Giesen, H., Iwarson, T., and Juhász, A. (2016). Improving market outcomes: enhancing the position of farmers in the supply chain. European Commission.

Vermunt, J. K. Tran, B. and Magidson, J. (2008). Latent class models in longitudinal research. Handbook of longitudinal research: Design, measurement, and analysis: 373385 .

Villalonga, B. (2004). Intangible resources, Tobin's q, and sustainability of performance differences. Journal of Economic Behavior and Organization 54: 205-230.

Vrolijk, H. C. J. Bont, C. J. A. M. d. Blokland, P. W. and Soboh, R. A. M. E. (2010). Farm viability in the European Union : assessment of the impact of changes in farm payment. Wageningen Economic Research-WUR.

Waring, G. F. (1996). Industry differences in the persistence of firm-specific returns. American Economic Review 86: 1253-1265.

Wedel, M. and Kamakura, W. A. (2012). Market segmentation: Conceptual and methodological foundations. Springer Science and Business Media.

Wiggins, R. R. and Ruefli, T. W. (2002). Sustained competitive advantage: Temporal dynamics and the incidence and persistence of superior economic performance. Organization Science 13: 81-105.

Wooldridge, J. M. (2015). Introductory econometrics: A modern approach. Nelson Education.

World Bank, G. (2017). World Development Indicators 2017. World Bank.

Yeager, E. A. and Langemeier, M. R. (2016). Productivity divergence across Kansas farms. Agricultural and Resource Economics Review 40: 282-292.

Yurtoglu, B. B. (2004). Persistence of firm-level profitability in Turkey. Applied Economics 36: 615-625.

Zhao, J. Barry, P. J. and Katchova, A. L. (2008). Signaling credit risk in agriculture: Implications for capital structure analysis. Journal of Agricultural and Applied Economics 40: 805-820.

Zhao, J. Katchova, A. L. and Barry, P. J. (2004). Testing the Pecking Order Theory and the Signaling Theory for Farm Businesses. (No. 20215). American Agricultural Economics Association (New Name 2008: Agricultural and Applied Economics Association) 51: 61801.

Zhengfei, G. and Oude Lansink, A. (2006). The source of productivity growth in Dutch agriculture: A perspective from finance. American Journal of Agricultural Economics 88: 644-656. 


\section{Curriculum Vitae}

Aderajew Shumet Tamirat was born on August 26, 1986, in Gondor, Ethiopia. He received his Bachelor's degree in Banking and Insurance (2006) and Master's degree in Business Administration, MBA (2010) from Adama Science and Technology University, both with great distinction (summa cum laude). After his bachelor program, he started teaching at the same university, and later appointed as chairman of the Department of Banking and Insurance. In September 2011, he went to Wageningen University and Research and obtained his Research Master's degree in Management, Economics and Consumer Studies in 2013 with distinction (cum laude).

In September 2015, he started his Ph.D. in Finance in the School of Business and Economics at Maastricht University. Aderajew's fields of research are risk management and capital structure with special reference to farm businesses. His academic papers have been published in peer-reviewed journals such as the European Review of Agricultural Economics. He has also presented his papers in various international conferences such as the Agricultural and Applied Economics Association Annual Meetings (Washington D.C. 2018, Chicago 2017, and Minneapolis 2014), XV European Association of Agricultural Economists (EAAE) Congress in 2017, Parma, Italy, and the annual NC-1177 meeting on Agricultural and Rural Finance Markets in Transition in 2016 in Denver, United States.

Beside his PhD study, he is also affiliated with CORMEC (Commodity Risk Management Expertise Center) as a junior research fellow. Finally, as of January 2019, Aderajew will join McKinsey \& Company as an Associate consultant. 